\title{
SPACE-TIME CLUSTERING AND PROSPECTIVE HOT-SPOTTING OF CANADIAN CRIME
}

\author{
by \\ Karla Emeno \\ A thesis submitted to \\ the Faculty of Graduate and Postdoctoral Affairs \\ in partial fulfillment of the requirements for the degree of \\ Doctor of Philosophy \\ in \\ Psychology \\ Carleton University \\ Ottawa, Canada \\ (C) 2014 \\ Karla Emeno
}




\begin{abstract}
Previous research has consistently shown that repeat crime victimization is common. More recently, research has shown that near repeat victimization is also common, whereby targets located in close proximity to previously victimized dwellings/people/vehicles (depending on the crime) are at an increased risk of also being victimized. However, this elevated risk is only temporary and subsides over time. This near repeat space-time clustering has been found across various crime types (e.g., burglary, theft from motor vehicle (TFMV), gun crime, etc.) as well as across jurisdictions. However, the precise space-time patterning of crimes is location-specific. To date, no published research exists that has examined near repeat victimization using Canadian data; the current study fills this gap. This dissertation consisted of 4 phases of analyses. Phase 1 determined the exact space-time clustering of three crime types (burglary, TFMV, common assault) across three Canadian cities (Edmonton, AB, Moose Jaw, MB, Saint John, NB). Phase 1 results found significant near repeat space-time clustering for Edmonton burglary, Edmonton TFMV, and Saint John TFMV, with the exact near repeat space-time pattern varying from one data file to the next. Phase 2 analyses used the time and distance over which crime clusters (as found in Phase 1) to generate prospective risk surfaces. Risk surfaces were also generated using two traditional hot-spotting methods. Overall, the various hotspot mapping techniques examined were found to be comparable in their accuracy at predicting future crime. Phase 3 examined whether it was possible to improve the accuracy of prospective hot-spotting by considering three different strategies. Although Phase 3 results suggested that the three strategies examined were not effective at improving predictive accuracy of the
\end{abstract}


maps, some interesting trends did emerge, which may have practical implications. Finally, Phase 4 investigated whether near repeat burglaries in one Canadian city (Edmonton, $\mathrm{AB}$ ) were more likely to be committed by the same offender than more distant burglaries. Phase 4 results suggested that serial offending by the same offender offers a viable explanation for near repeat crime. The theoretical and practical implications of these results, as well as some limitations and directions for future research, are also discussed. 


\section{Acknowledgements}

First and foremost, I would like to thank my Ph.D. thesis supervisor, Dr. Craig Bennell, for his unwavering guidance and support over the years. It goes without saying that this thesis would not have been possible without him. It has truly been a privilege to learn from him. Many thanks also go out to my examination committee members - Drs. Adelle Forth, Ralph Serin, Samantha Lundrigan, and Roberta Sinclair - for all the time, effort, and valuable insight that they contributed. I would like to express my gratitude to the Edmonton Police Service, Moose Jaw Police Service, and Saint John Police Force as well for providing the Canadian crime data necessary to carry out this research.

I would also like to extend my thanks to all of the other graduate students, both past and present, of the Police Research Lab at Carleton University, particularly Tamara, Rebecca, Shevaun, and Holly. You will never know how essential your continued support has been to my successful completion of this thesis. I knew I could always count on all of you to truly understand what I was going through and to provide the perfect advice and encouragement just when I needed it most.

Finally, I would like to thank my parents, my sister, Jill, and my closest friends back home, Shannon and Sara, who have all helped shape the person I am today. Your unconditional love and support have proven to be immeasurable. I know you will always be there for me whenever I need you and for that I am forever grateful. Mom and Dad, thank you for not only providing me with the opportunity to pursue higher education, but for instilling in me an invaluable passion for knowledge as well. This is for you. 


\section{Table of Contents}

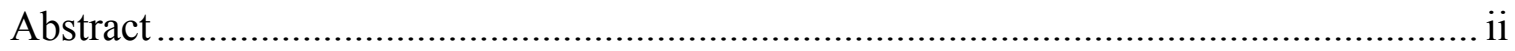

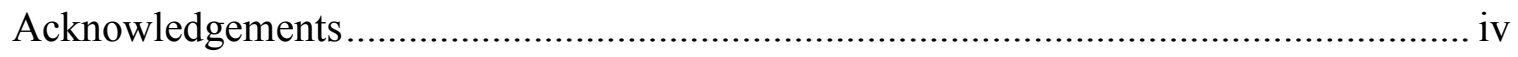

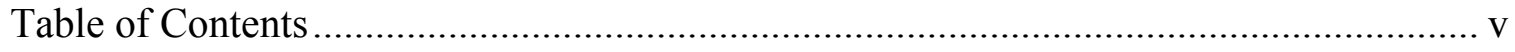

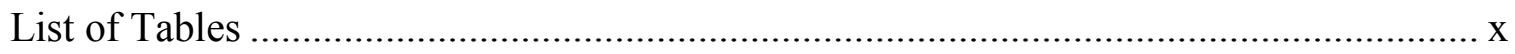

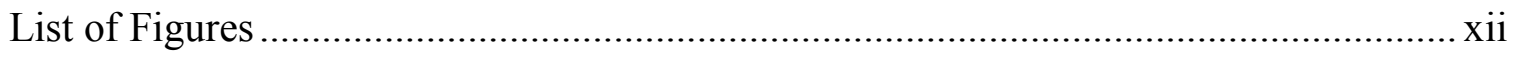

List of Appendices ..........................................................................................

Space-Time Clustering and Prospective Hot-Spotting of Canadian Crime ...................... 1

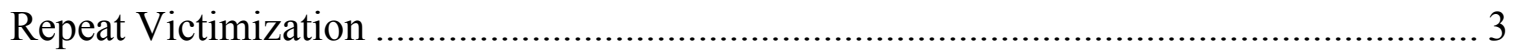

Theoretical Explanations for Repeat Burglary Victimization ................................... 4

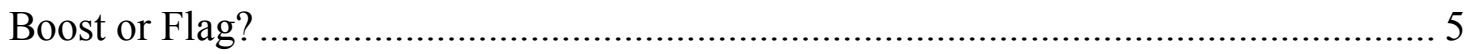

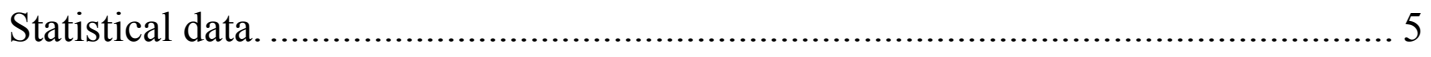

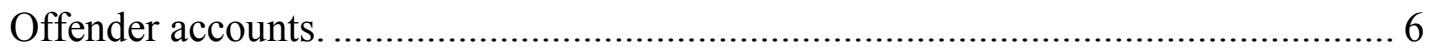

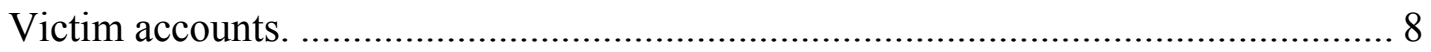

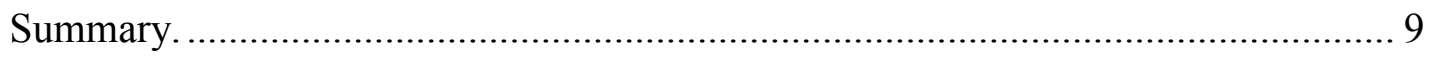

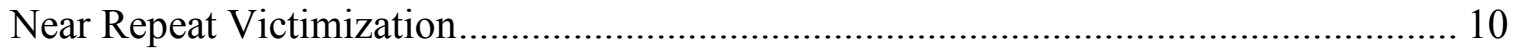

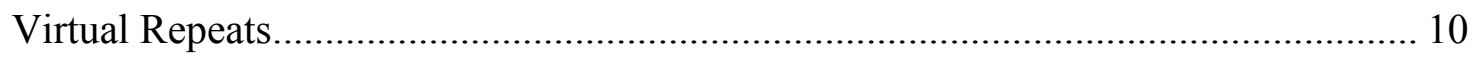

Near Repeat Victimization Research ............................................................. 11

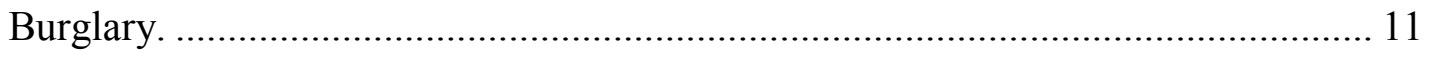

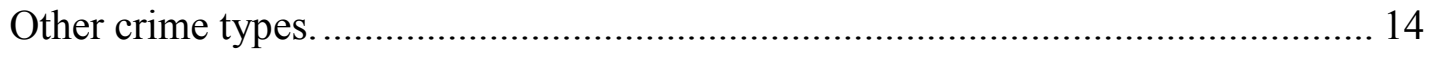

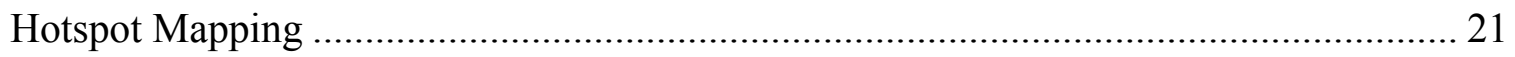

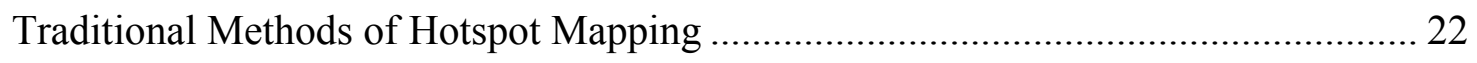

Kernel density estimation (moving window technique) .................................. 22 


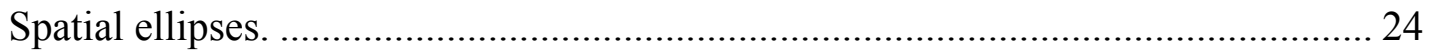

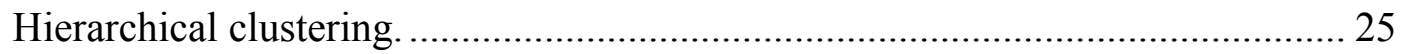

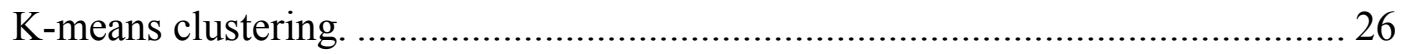

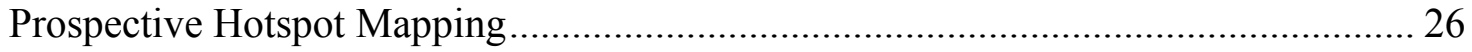

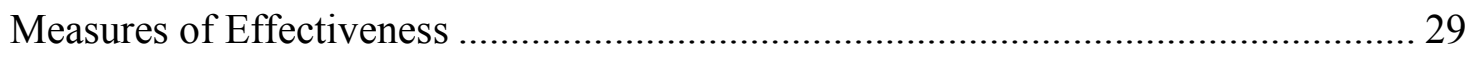

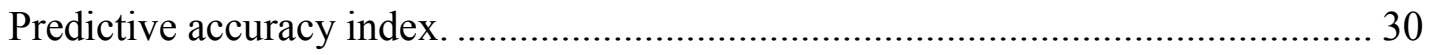

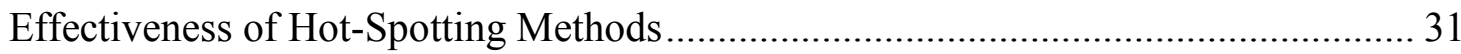

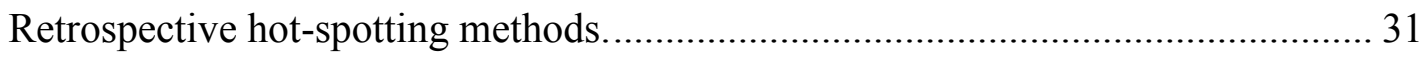

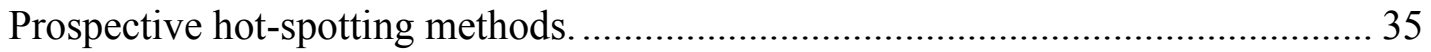

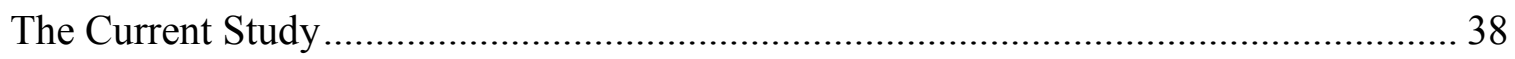

Phase 1 - Space-Time Patterns in Canadian Crime ............................................................ 39

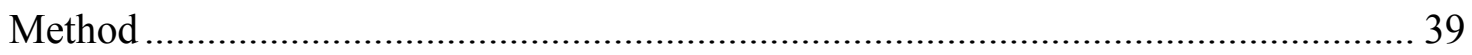

Data.

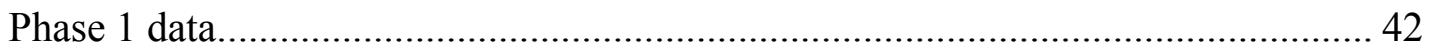

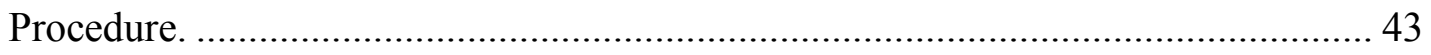

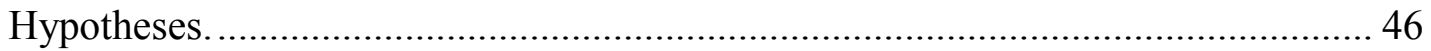

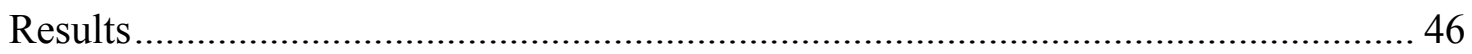

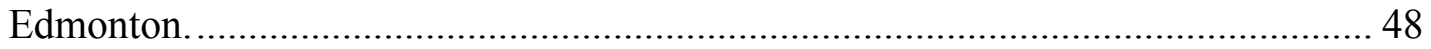

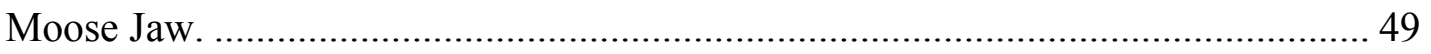

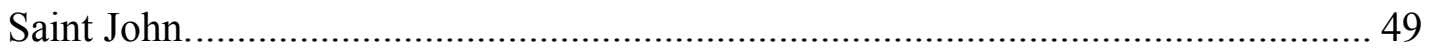

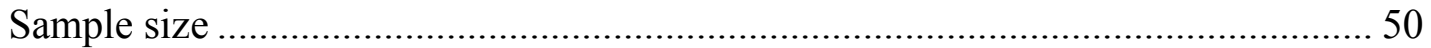

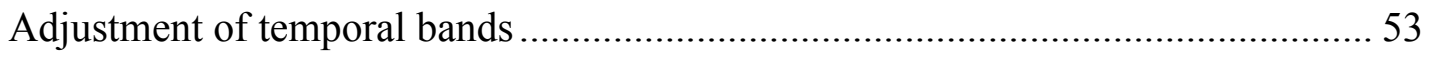

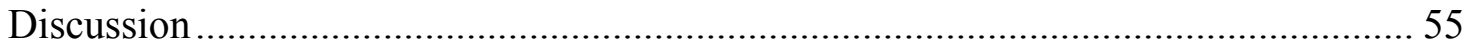




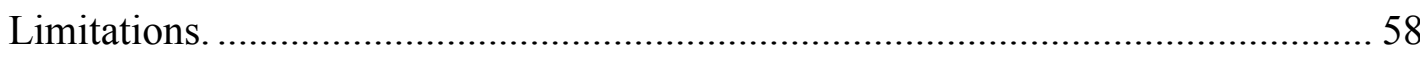

Phase 2 - Generating and Assessing Prospective Risk Surfaces ...................................... 60

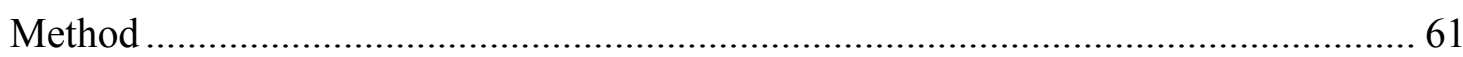

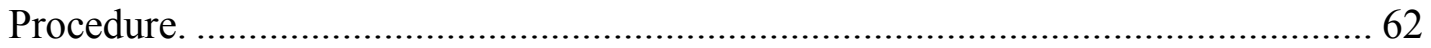

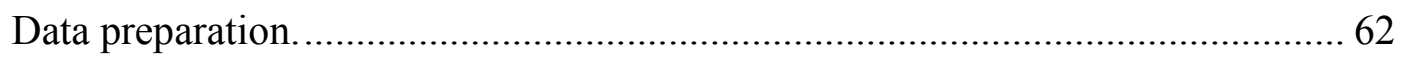

Kernel density estimation (moving window) maps. ............................................... 64

Prospective hotspot mapping (modified moving window) maps. ........................... 67

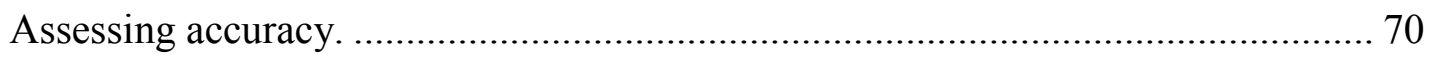

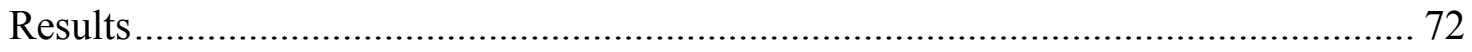

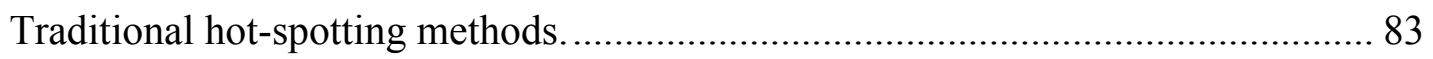

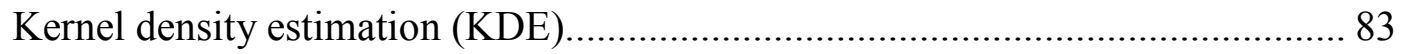

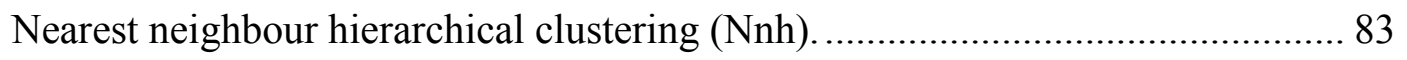

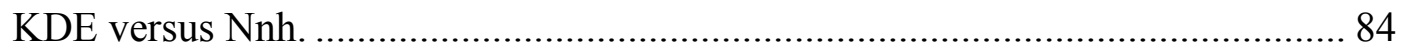

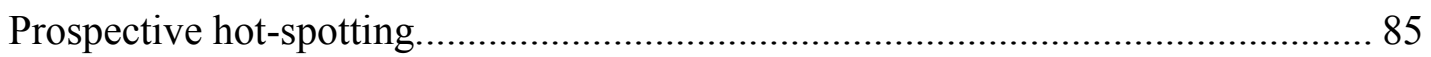

Prospective hot-spotting - 7-day temporal bandwidth. .......................................... 85

Prospective hot-spotting - 2-month temporal bandwidth...................................... 86

Prospective hot-spotting - 7-day versus 2-month temporal bandwidth.................. 87

Prospective hot-spotting versus traditional hot-spotting techniques. ........................ 88

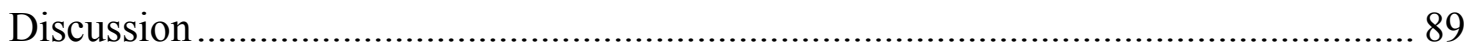

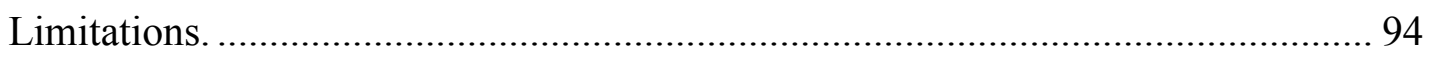

Phase 3 - Improving the Accuracy of Prospective Risk Surfaces ...................................... 96

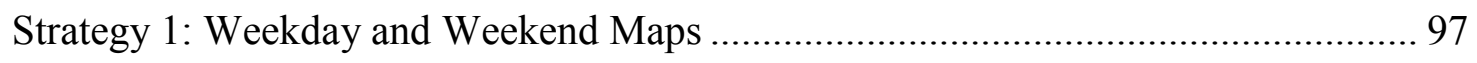

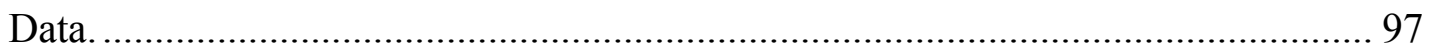




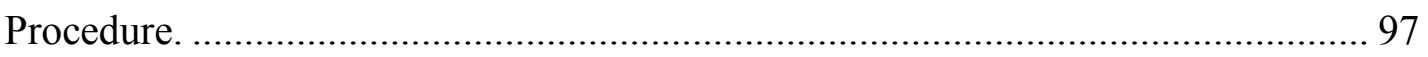

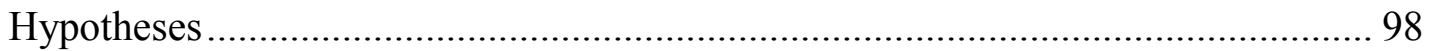

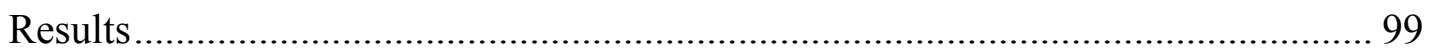

Comparison of hotspot mapping approaches............................................ 105

Weekday/weekend hotspot maps vs. general hotspot maps. ........................... 105

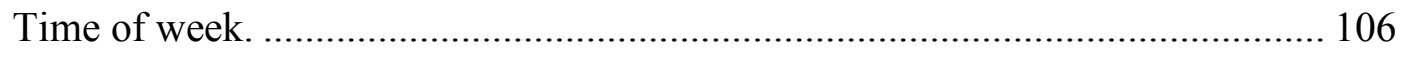

Strategy 2: Time Period Used to Generate the Maps............................................. 107

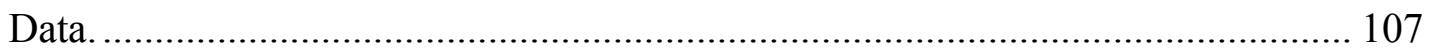

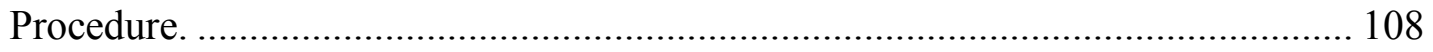

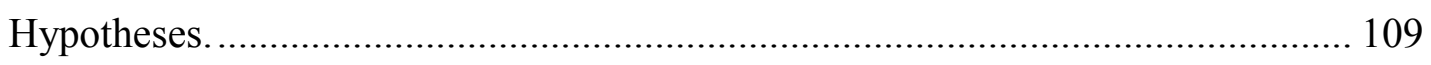

Comparison of hotspot mapping approaches.............................................. 114

Temporal bandwidth manipulation.......................................................... 114

Strategy 3: Time Period Used to Assess Predictive Accuracy …........................... 115

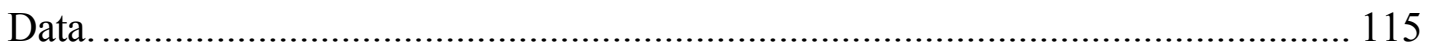

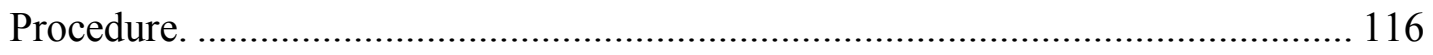

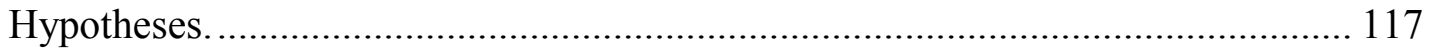

Comparison of hotspot mapping approaches............................................ 122

Time period used to assess predictive accuracy. ......................................... 122

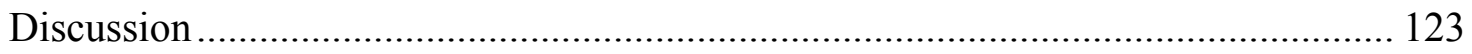

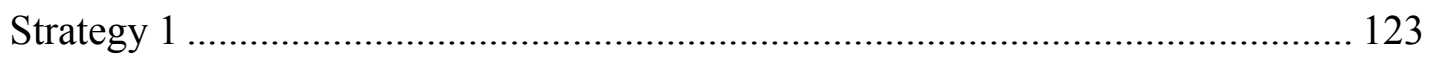

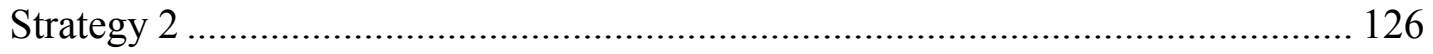

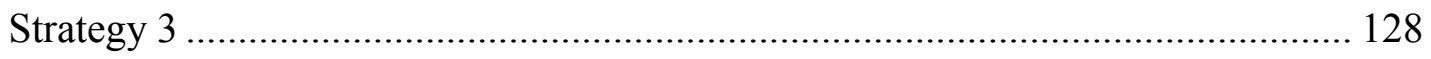

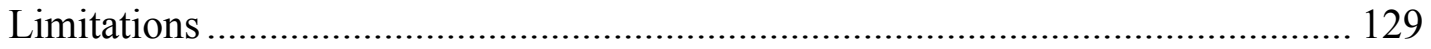


Phase 4 - Testing the Boost Account .................................................................. 131

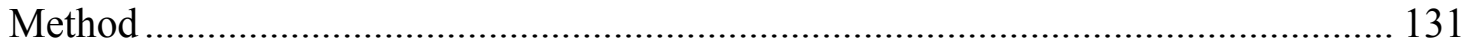

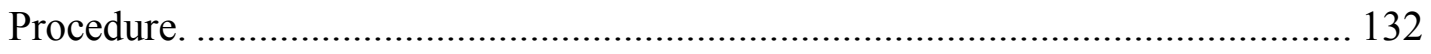

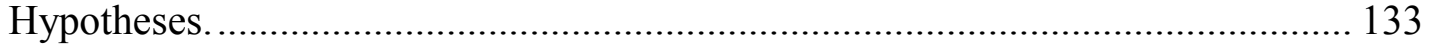

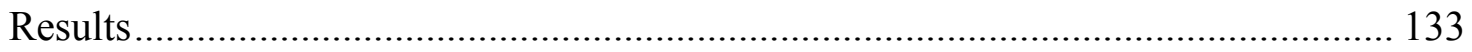

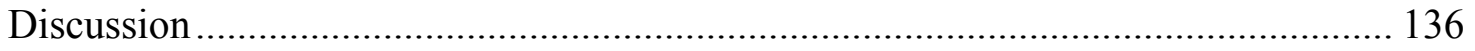

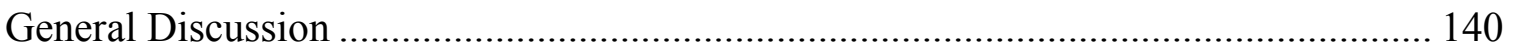

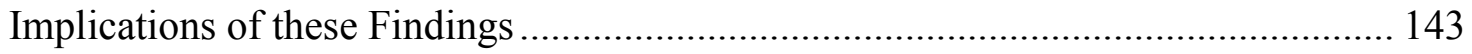

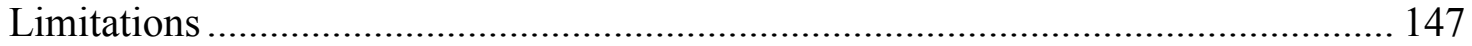

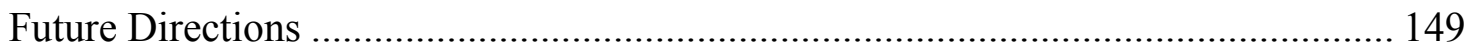

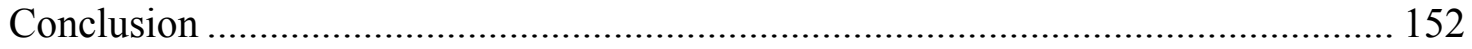

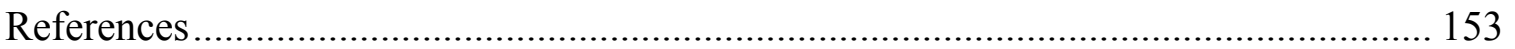




\section{List of Tables}

Table 1. Summary of risk communication findings and target density in each city examined by Johnson et al. (2007).

Table 2. Relative prediction effectiveness of the different hot-spotting techniques

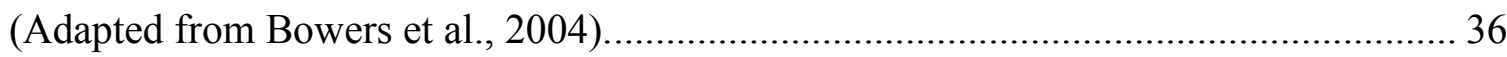

Table 3. Demographics for Edmonton, Moose Jaw, and Saint John from 2006 census

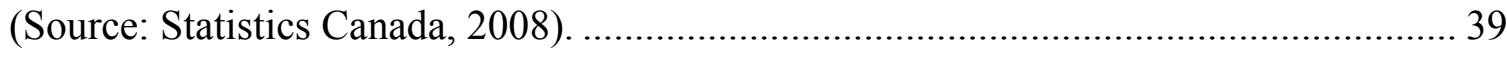

Table 4. Number of incidents for each data file....................................................... 42

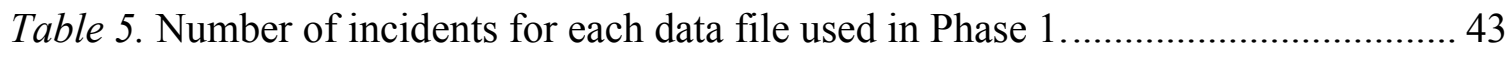

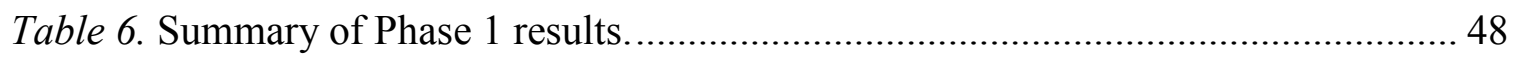

Table 7. Number of incidents by year for each data file........................................... 51

Table 8. Summary of near repeat space-time pattern results across each year................ 53

Table 9. Near repeat space-time patterns using 1-day, 4-day, and 7-day temporal

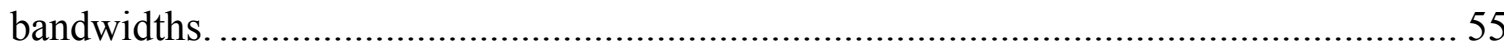

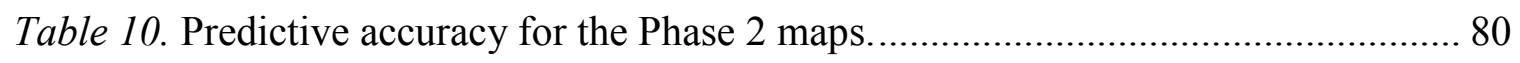

Table 11. Predictive accuracy results for Phase 3: Strategy 1 maps............................ 100

Table 12. Breakdown of crimes used to generate and test the risk surfaces in Phase 3:

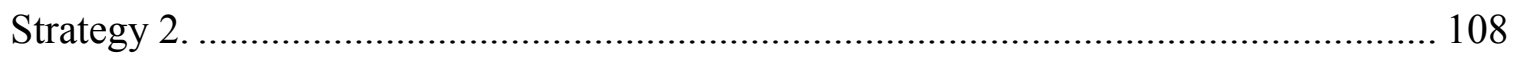

Table 13. Predictive accuracy of Phase 3: Strategy 2 maps. .................................... 110

Table 14. Breakdown of crimes used to generate and test the risk surfaces in Phase 3:

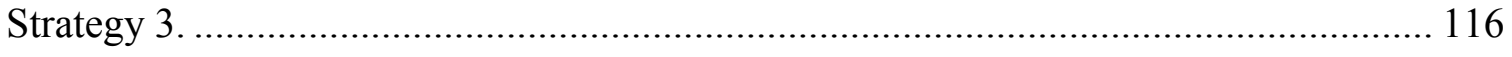

Table 15. Predictive accuracy of Phase 3: Strategy 3 maps. ...................................... 118 
Table 16. Percentage of burglary pairs for each space-time interval where one or more

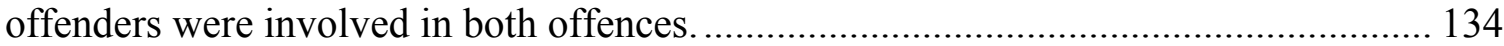




\section{List of Figures}

Figure 1. Example of a hotspot map generated using quartic kernel density estimation (Source: Eck, Chainey, Cameron, Leitner, \& Wilson, 2005)........................................ 22

Figure 2. Example of K-means elliptical clusters (Source: Eck et al., 2005).................. 24

Figure 3. Example of a hotspot map generated using the prospective hotspot mapping

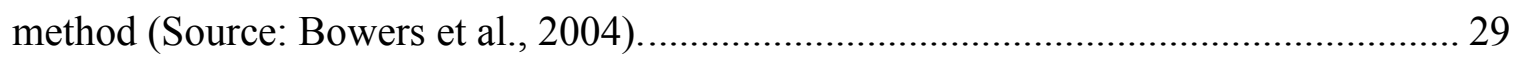

Figure 4. Manhattan versus Euclidean distance. ..................................................... 44

Figure 5. Example of an observed over mean expected frequencies table (Source:

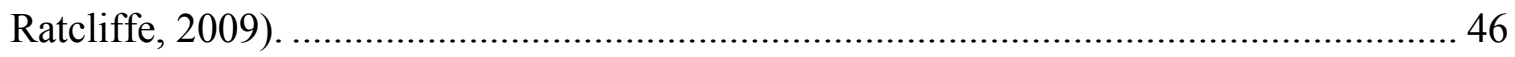

Figure 6. Phase 2: KDE map for Edmonton burglary January-February....................... 74

Figure 7. Phase 2: Nnh map for Edmonton burglary January-February. ........................ 75

Figure 8. Phase 2: Prospective hot-spotting map (7-day temporal bandwidth) for

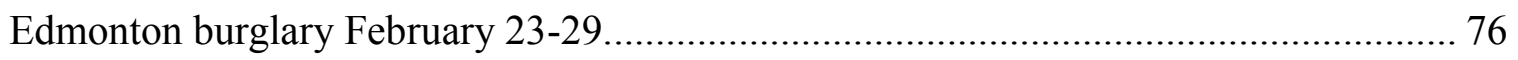

Figure 9. Phase 2: Prospective hot-spotting map (2-month temporal bandwidth) for

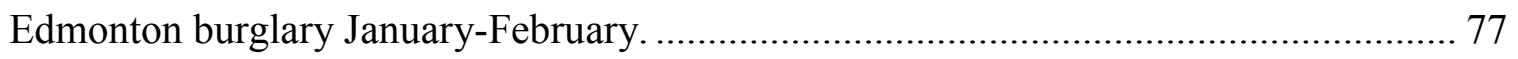




\section{List of Appendices}

Appendix A. Observed over mean expected frequencies and statistical significance

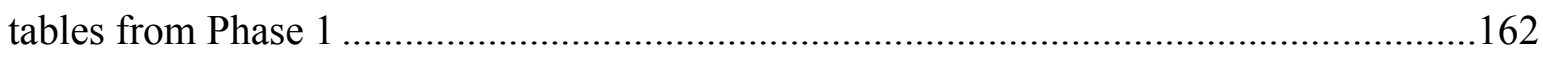

Appendix B. Examples of maps generated for the Phase 2 analyses ...............................180

Appendix C. Number of burglary pairs for each space-time interval where one or more offenders were involved in both offences (number of crime pairs where same offender committed both crimes/total number of crime pairs) .............................................. 188

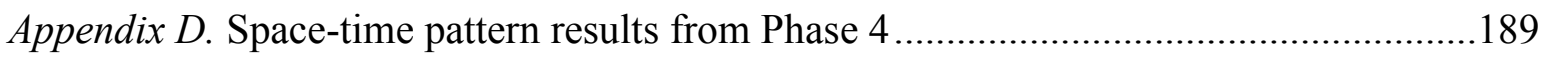


Space-Time Clustering and Prospective Hot-Spotting of Canadian Crime

Previous research has shown that prior burglary victimization is a significant predictor of future victimization (i.e., repeat victimization is common; e.g., Budd, 1999; Townsley, Homel, \& Chaseling, 2000). While this research clearly has value in terms of the development of crime prevention strategies (i.e., installing security devices on previously victimized residences) there is also value in determining how burglary victimization impacts the risk of attack for other dwellings that are in close proximity to the targeted site (i.e., near repeats). In the UK, Johnson and Bowers (2004a) have conducted research on the topic of near repeat victimization and found that residential burglaries do in fact cluster together in time and space.

Interestingly, Johnson and Bowers' (2004a) study demonstrates how burglary, much like a disease, can be thought of as being communicable. In fact, this communicability of burglary appears to be a fairly robust finding with Johnson et al. (2007) obtaining similar results for ten cities in five different countries. However, the precise pattern of burglary risk varies across samples, which highlights the importance of examining the near repeat phenomenon in different countries and cities. In addition to burglary, further research has examined the space-time patterns of other types of crimes, such as gun crime (Ratcliffe \& Rengert, 2008) and theft from motor vehicles (Summers, Johnson, \& Pease, 2007). These studies found that these crime types also cluster together in time and space, but again, the precise patterns that were observed varied across crime types.

This communicability of crime led Bowers, Johnson, and Pease (2004) to develop a new crime mapping technique referred to as prospective hot-spotting. Briefly, 
prospective hot-spotting involves applying a mathematical formula to the locations of past crime in order to generate a prospective risk surface, which indicates high risk areas for future crime. Although traditional hot-spotting methods can be used for prospective hot-spotting, Bowers et al.'s technique differs from these other approaches in that it considers the space-time patterns of the specific crime type and geographic region under examination, which should result in risk surfaces that are more effective at predicting future crime. ${ }^{1}$

To date, no study of the near repeat phenomenon has been published in Canada, nor has there been any published examination of the potential for prospective hotspotting. This dissertation helps fill these important gaps. Specifically, the first phase of this dissertation examined how criminal events cluster together in space and time across several Canadian cities (of various sizes) and across various crime types. The second phase used the time and distance over which different crime types (committed in different cities) cluster (as found in Phase 1) to generate prospective risk surfaces. The effectiveness of these risk surfaces was then assessed using a variety of measures. The third phase explored whether the effectiveness of prospective hot-spotting could be improved through various adjustments to the generation/test samples. More specifically, the time period of crime data used to generate and test the maps was varied to determine its impact on map accuracy. In addition, maps specific to weekday and weekend crime were produced in an attempt to generate more accurate maps. The final phase attempted to understand why space-time clusters of crimes exist in Canada. Specifically, Phase 4

\footnotetext{
${ }^{1}$ Traditional methods of hotspot mapping are retrospective in nature as they rely on existing crime data to determine the hotspots of previously committed crimes. As well, traditional hot-spotting relies on default space-time parameters, whereas prospective hot-spotting relies on space-time parameters that are empirically derived using crime data from the geographic region of interest.
} 
examined whether one particular theoretical explanation (i.e., the "boost" account, which attributes near repeats to serial offending by the same offender) applies to the occurrence of Canadian near repeat crime. A more thorough discussion of the literature pertinent to this dissertation will now be provided.

\section{Repeat Victimization}

Although the current dissertation focuses on near repeat crime, repeat victimization is also an important concept to discuss given that the discovery of the near repeat phenomenon was the direct result of repeat victimization research. Repeat victimization refers to "the recurrence of crime in the same places and/or against the same people" (Pease, 1998, p. 1). Several studies have shown that repeat victimization is not a rare occurrence, with people and places that have been victimized in the past being at an elevated risk for future victimization (e.g., Kleemans 2001; Sherman, 1992; Tseloni $\&$ Pease, 1998). In other words, repeat victimization occurs much more frequently than would be expected by chance. The 1992 British Crime Survey, for example, found that $4 \%$ of people in the UK experienced $44 \%$ of the crime in that year (Farrell \& Pease, 1993). Similarly, the Australian Bureau of Statistics found that $50.6 \%$ of all property crimes were committed against only $28.7 \%$ of households (Mukherjee \& Carcach, 1998). In fact, prior burglary victimization is one of the most significant predictors of future victimization (e.g., Budd, 1999; Pease, 1998; Townsley et al., 2000). ${ }^{2}$ It is important to note, however, that the risk of repeat burglary victimization is highest during the time period immediately following the initial burglary and that this risk declines over time (e.g., Kleemans, 2001; Sagovsky \& Johnson, 2007).

\footnotetext{
${ }^{2}$ Although repeat victimization can and does occur for many types of crime, most research has focused on repeat burglaries.
} 


\section{Theoretical Explanations for Repeat Burglary Victimization}

Two key theories have been put forth to explain the occurrence of repeat burglary victimization: (1) risk heterogeneity (the "flag" account) and (2) event dependency (the "boost" account). Each of these theories will now be discussed in more detail.

According to the risk heterogeneity theory, or the "flag" account, repeat burglary victimization occurs as a result of a dwelling's enduring attributes that flag it as a suitable target. For example, a house may be easily accessible, lack an alarm system, and have no nearby neighbours, all of which signal to burglars that the house is an attractive target. Thus, according to the flag account, repeat victimization is the result of different offenders choosing to burglarize the same dwelling as a result of its particular attributes (i.e., houses have an enduring level of risk for burglarization; Pease, 1998).

In contrast to the flag account, the event dependency theory, or the "boost" account, proposes that repeat burglary victimization is the result of the initial burglary "boosting" the likelihood of future victimization. More specifically, repeat victimization in this account is the result of the same offender returning to burglarize a dwelling that they have successfully burglarized in the past (it could also be the burglar's acquaintances who return to burglarize the same house in the future if the original offender discussed the initial burglary with them). The offender may return to burglarize the same house for various reasons, such as returning to steal items replaced through insurance or returning to steal valuables that they were unable to carry the first time. In addition, the offender may choose to burglarize the same house multiple times because the initial burglary has educated them about what they will encounter in the future (e.g., 
house layout, ease of access, known escape routes, etc.), thus lowering the risks associated with burglarizing that particular dwelling (Pease, 1998).

\section{Boost or Flag?}

A number of studies have examined whether repeat burglary can most often be attributed to the same offender (boost account) or different offenders (flag account). In general, these studies have examined this issue by focusing on: (1) statistical data, (2) offender accounts, or (3) victim accounts.

Statistical data. Several studies have used solved crime data in order to test the boost account of repeat burglary victimization. For example, Bernasco (2008) used solved crime data from The Hague to determine whether repeat burglary victimization was more likely to be the work of the same offender or different offenders. The results indicated that $95 \%$ of repeat burglaries committed within 15 days of the initial offence were committed by the same offender. Similarly, Johnson, Summers, and Pease (2009) used solved crime data from Dorset, UK, to test the boost account and found that $99 \%$ of repeat burglaries occurring within 14 days of the initial offence were committed by the same offender. The results from these two studies offer some initial support for the boost explanation of repeat victimization.

In another study, Johnson (2008) used a simulation experiment to determine whether the boost or flag account could best explain repeat burglary. More specifically, Johnson used boost, flag, and mixed models to generate computer-simulated burglary data. The simulated data for each model was then compared to actual burglary data to determine which model generated the most realistic data. A mixed model based on both the boost and flag account was found to produce computer-simulated data most similar to 
real burglary data, which led Johnson to conclude that both accounts need to be considered in order to fully explain the occurrence of repeat burglary victimization.

Pitcher and Johnson (2011) reported similar findings when they also used boost, flag, and mixed models to generate computer-simulated burglary data. In another study, Short, D’Orsogna, Brantingham, and Tita (2009) used data from Long Beach, CA, and found that risk heterogeneity alone could not explain repeat burglary and also found support for a form of event dependence.

Offender accounts. Through the use of offender interviews, researchers have been able to investigate whether or not burglars engage in repeat victimization and the reasons why offenders decide to burglarize the same dwelling multiple times. Based on an overview of this research, Winkel (1991) determined that around one third of residential burglars have indeed burglarized the exact same dwelling on more than one occasion, which is consistent with the boost account.

In another study, Bennett (1995) interviewed apprehended burglars from Cambridge, UK, and found that the majority of offenders had burglarized the same house more than once within a 12-month period. Their reasons for doing so included perceived low risks, high rewards, and ease of access. In addition, about half of the offenders had burglarized a household based on information provided to them by another offender who had previously burglarized that particular dwelling. However, in this scenario their reasons were more likely to focus on the perceived rewards of burglarizing that particular household rather than on perceived risks or ease of entry.

In a study comparable to Bennett's (1995), Ericsson (1995) interviewed 21 convicted burglars from East Anglia, UK, and found that $76 \%$ had burglarized the same 
house on multiple occasions. Similar to the burglars interviewed in Bennett's study, the offenders' reasons for returning to the same house included perceived low risks, familiarity with features of the house, ease of access, and returning for goods that they had left behind the first time.

The results of these studies, and others (e.g., Ashton, Brown, Senior, \& Pease, 1998; Gill \& Pease, 1998), clearly indicate that the boost account is able to explain the occurrence of at least some repeat burglaries. However, the results do not necessarily indicate that the boost account is able to explain the occurrence of all repeat burglaries. Thus, the flag account cannot be conclusively ruled out as an explanation for the occurrence of some repeat burglaries. Indeed, numerous studies have found evidence based on offender accounts to suggest that different offenders will target the same residence on separate occasions.

For example, several researchers (e.g., Bennett \& Wright, 1984; Maguire \& Bennett, 1982; Nee \& Taylor, 1988, 2000) have interviewed burglars in order to determine the environmental cues responsible for target selection (i.e., why does an offender select a particular house to burglarize?). The results from these studies suggest that different burglars consistently focus on similar environmental cues when selecting a residence to burglarize, thus highlighting the potential for these cues to flag the residence as a suitable target. Nee and Taylor (1988), for instance, had 50 incarcerated burglars from Ireland rate various situational cues based on their importance for target selection. They found that residential area played a very important role in target selection with $88 \%$ of the burglars only selecting targets located in middle-class or wealthy residential areas. 
In addition, about $75 \%$ of burglars rated the presence of two escape routes (one front and one rear) as quite or very important.

In another study, MacDonald and Gifford (1989) utilized Likert-scale ratings to investigate target selection choices of 23 incarcerated male burglars. Fifty photographs of houses were presented to the burglars, which had been rated as having varying degrees of actual barriers (e.g., fences), symbolic barriers (e.g., flower gardens), traces of occupancy (e.g., car in driveway), road surveillability (e.g., distance of house from road), and occupant surveillability (e.g., placement of windows). The burglars then rated each house on a 7-point scale in terms of how likely the house was to be burglarized. They found that $63 \%$ of the burglars rated secluded properties as highly likely to be burglarized, whereas $44 \%$ rated houses with a 'Beware of dog' sign as not likely to be burglarized. In addition, concealment opportunity (39\% of burglars) and appearance of value (35\% of burglars) also led to houses being rated as highly likely to be burglarized. In contrast, too open ( $24 \%$ of burglars) and lack of value ( $22 \%$ of burglars) resulted in houses being rated as not likely to be burglarized. Thus, the results from these studies indicate that many burglars do look for similar environmental cues when selecting an appropriate target, which further supports the flag account as a viable explanation for the occurrence of some repeat burglaries.

Victim accounts. In another study, Pease (1998) utilized victim accounts obtained via the British Crime Survey to examine repeat victimization. The British Crime Survey samples people in England and Wales to collect details of crimes against individuals and their homes for a particular year. When interviewed, respondents are asked whether their home has been burglarized more than once during the previous year 
and if the answer is yes, they are also asked to classify the burglaries according to their similarity. If similar, the burglaries are considered to be a series likely committed by the same offender (i.e., boost account). If dissimilar, then the burglaries are classified as being committed by different offenders (i.e., flag account). Notwithstanding the obvious problems associated with this approach (e.g., assuming that similar crimes could not have been committed by different offenders), Pease found that approximately $75 \%$ of repeat burglaries committed in 1992 were likely the result of the same offender. These results are consistent with the boost account of repeat burglary victimization.

Summary. The evidence provided by the various studies discussed above suggests that the event dependency (or boost) theory provides a viable explanation for repeat burglary victimization. However, as previously mentioned, the boost account cannot necessarily explain the occurrence of all repeat burglaries and the research does not entirely rule out the flag account. Thus, it seems likely that the boost and flag account both play a role in explaining repeat burglary victimization. As explained by Johnson (2008),

Observable variation in target attractiveness is likely to contribute to offender targeting decisions for homes they are yet to victimize, but repeat victimisation, where it occurs swiftly, is likely to be caused by something else, the most parsimonious explanation being a boost process. (p. 235)

In other words, the boost account appears to be the most probable explanation for repeat burglary that occurs soon after the initial offence, whereas the flag account offers a likely explanation for why multiple burglars would all initially select the same dwelling as a suitable target. The conclusion that both the boost and flag accounts must be considered 
in order to fully explain repeat victimization falls in line with the consensus reached by other researchers (e.g., Lauritsen \& Davis Quinet, 1995; Pease, 1998).

\section{Near Repeat Victimization}

\section{Virtual Repeats}

In a review of the repeat victimization literature, Pease (1998) discussed the existence of virtual repeat burglaries. A virtual repeat occurs when an offender burglarizes a house that is identical in some important way (e.g., same layout) to another dwelling that they have burglarized in the past. Essentially, burglarizing the first house provides the offender with important information about other houses that are virtually identical to the first house (e.g., security features, layout, escape routes, etc.), which reduces the risks associated with burglarizing those similar dwellings.

The occurrence of virtual repeats was supported anecdotally by one of the offenders in Ashton et al.'s (1998) study. This offender explained that he decided to rob a particular gas station because he had already successfully robbed another gas station owned by the same major chain and knew the floor plan would be identical, thus making it an attractive target. In a later study, Morgan (2001) was examining repeat burglary in Perth, Australia, when he observed that dwellings near a previously burglarized home would often be victimized soon after the first offence. Morgan referred to these occurrences as near repeats, which can be viewed as a special case of virtual repeat victimization. Morgan's observation resulted in other researchers examining near repeat crime more directly. 


\section{Near Repeat Victimization Research}

Burglary. Among the first to examine the near repeat phenomenon were Townsley, Homel, and Chaseling (2003), who analyzed residential burglary data from Brisbane, Australia, using an epidemiological approach. More specifically, the data were analyzed using the Knox test, which was developed by Knox (1964) to assess whether childhood leukemia is a contagious disease. The Knox test is used to determine whether there are more observed pairs of events that occur close together in space and time than would be expected by chance (i.e., if the pairs of events are independent from one another). The Knox test compares each data point to all other data points and a contingency table is generated. Using this table, observed cell counts for crime pairs that occurred close together in space and time are compared to expected cell counts and contagion is deemed to be present if the observed counts are significantly greater than expected. The results from the Knox test indicated that near repeats were present in Townsley et al.'s data, especially in areas with low housing diversity (i.e., houses that are more homogeneous in appearance). ${ }^{3}$ Thus, the results from this study demonstrate how burglary, much like a disease, can be thought of as being communicable.

According to Townsley et al. (2003), the contagion process of near repeat crime can be explained by routine activity theory (Cohen \& Felson, 1979). This theory argues that, within an environment considered appropriate for criminal activity, crime occurs when a motivated offender's routine activity space intersects, in time and space, with a desirable target's routine activity space in the absence of appropriate guardians (e.g., watchful neighbours, police patrols, security devices, etc.; Cohen \& Felson, 1979). An

\footnotetext{
${ }^{3}$ Note that Townsley et al. (2003) defined near repeats as crime pairs that occurred within 100-200 metres of one another and within 1-2 months apart.
} 
offender's/target's activity space consists of the area where the offender/target performs their routine daily activities (e.g., live, work, shop, etc.). As explained by Townsley et al., routine activity theory predicts that "the greater amount of exposure a potential offender is given to a suitable target the greater the probability of a crime occurring" (p. 618). Thus, according to the routine activity theory, burglary is communicable because houses in close proximity to one another are all located within an offender's activity space, which results in those houses receiving greater exposure to the offender than suitable targets not located in their activity space.

In another study, Johnson and Bowers (2004a) also utilized the Knox test to investigate near repeat burglaries in Merseyside, UK. Johnson and Bowers, however, examined the space-time pattern of near repeat burglary more extensively than Townsley et al. (2003) in order to empirically derive a more precise space-time pattern. Their results indicated that residential burglaries do cluster together in space. More specifically, they found that houses within 300-400 metres of an original burglary exhibit an elevated risk of also being burglarized. Importantly, this elevated risk was only temporary and appeared to subside approximately 1-2 months post-event. Similar results have also been reported by Johnson, Summers, and Pease (2009) for burglaries committed in Bournemouth, UK. In this case, houses within 400 metres of the initial event were found to be at an elevated risk with this risk subsiding after 42 days.

In contrast to Townsley et al. (2003), Johnson and Bowers (2004a), and Johnson, Summers, and Pease (2009), suggest that the communicability of burglary can best be explained by the behavioural ecology perspective known as optimal foraging theory. Optimal foraging theory "asserts that animals optimize foraging strategies to increase the 
rate of reward while minimizing both the amount of time searching for food and the risk of being attacked or being eaten by other animals" (Johnson \& Bowers, 2004a, p. 242). Similar to animal foraging, burglars want to minimize the time spent selecting and travelling to an appropriate target while increasing the potential for rewards and reducing the risk of being apprehended. According to Johnson and Bowers, one method for achieving these goals is to target houses located in close proximity to a house the burglar has previously burglarized. Burglarizing neighbouring houses cuts down on the time spent looking for appropriate targets and familiarity with the area reduces the risk of apprehension. Over the short term, targeting nearby houses instead of the same house also reduces risk since the police, and homeowners, may be vigilant to a repeat burglary (Johnson \& Bowers, 2004a). However, to avoid police attention over the long term, Johnson and Bowers argue that offenders would eventually have to offend in different areas, which may explain why the risk of being burglarized in a particular area (following a previous burglary) decreases over time.

In one of the most comprehensive studies to date, Johnson et al. (2007) observed similar space-time patterns of near repeat burglary for ten cities in five different countries (Australia, Netherlands, New Zealand, United Kingdom, and the United States), thus demonstrating the robustness of the communicability of burglary. Across all their samples, houses within at least 200 metres of a previously burglarized home were at an elevated risk of burglary for a minimum of two weeks. However, the precise pattern of burglary risk varied across the samples (see Table 1), highlighting the importance of examining space-time clustering across different countries and even cities. Similarly, Kikuchi, Amemiya, Shimada, Saito, and Harada (2010), Chen, Yuan, and Li (2013), and 
Moreto, Piza, and Caplan (2013) more recently found significant space-time clustering for residential burglaries in Japan, China, and Newark, NJ, respectively.

Table 1. Summary of risk communication findings and target density in each city examined by Johnson et al. (2007).

\begin{tabular}{|c|c|c|}
\hline Area & Risk (space, time) & $\begin{array}{c}\text { Target density } \\
\text { (households per } \mathrm{km}^{2} \text { ) }\end{array}$ \\
\hline Wirral (UK) & 500 m, 2 weeks & 523.0 \\
\hline Bournemouth (UK) & 300 m, 2 weeks & 1536.0 \\
\hline Palmerston North (NZ) & 400 m, 2 weeks & 24.4 \\
\hline Auckland (NZ) & 200 m, 2 weeks & 494.0 \\
\hline Canberra (Australia) & 1200 m, 4 weeks & 181.5 \\
\hline Beenleigh (Australia) & 600 m, 2 weeks & 256.7 \\
\hline Zoetermeer (Netherlands) & 600 m, 2 weeks & 1285.7 \\
\hline The Hague (Netherlands) & 600 m, 4 weeks & 3316.2 \\
\hline Pompano Beach (USA) & 200 m, 2 weeks & 836.0 \\
\hline Philadelphia (USA) & $200 \mathrm{~m}, 8$ weeks & 1779.5 \\
\hline
\end{tabular}

Other crime types. The ubiquity of the finding that residential burglary is communicable led researchers to examine space-time patterns for other types of crime. Summers et al. (2007), for example, analyzed one year's worth of police data for theft from and theft of a motor vehicle in Derbyside and Dorset, UK. While theft from a motor vehicle was found to be communicable, theft of a motor vehicle was not. Similar to Summers et al., Johnson, Summers, and Pease (2009) also found evidence of space-time clustering for thefts from a motor vehicle occurring in Bournemouth, UK. Specifically, thefts from a motor vehicle were more likely to occur within 800 metres of an initial theft and this elevated risk was found to persist for 14 days. More recently, Block and Fujita (2013) examined the near repeat phenomenon in overall, temporary (recovered), and permanent (unrecovered) motor vehicle thefts that occurred in Newark, NJ, from 2007 to 
2009. Significant space-time clustering was found for both overall and temporary vehicle thefts, but not for permanent thefts. Thus, if Summers et al.'s theft of a motor vehicle data contained a high proportion of permanent vehicle theft then that could offer a potential explanation for why they did not find a near repeat pattern for that particular crime type. ${ }^{4}$ In another study, Kikuchi et al. (2010) analyzed Japanese crime data and found the near repeat phenomenon to be present in purse snatching, theft from motor vehicles, and business burglary. Violent offences were the only crime type examined where significant space-time clustering was not present. As a potential explanation for the differences found between violent offences and property crimes, Kikuchi et al. drew attention to the differences in clearance rates for these different crime types. For example, the clearance rate for homicides occurring in Japan during 2006 was $96.9 \%$, whereas only $27.1 \%$ of thefts during that same year were cleared. If the boost account provides an explanation for near repeat crimes in Japan (i.e., near repeats are committed by the same offender), then it logically follows that crimes with higher clearance rates (like Japanese homicides) would have less significant space-time clustering than crimes with lower clearance rates (like Japanese thefts) since offenders are incapable of committing further offences while incarcerated. Similarly, Youstin, Nobles, Ward, and Cook (2011) examined the near repeat phenomenon using 2006-2008 crime data from Jacksonville, FL, for multiple crime types - auto theft, robberies, and shootings. Youstin et al. found significant space-time clustering for all three crime types examined, but as expected, the exact space-time pattern was found to vary from one crime type to the next.

\footnotetext{
${ }^{4}$ In Block and Fujita's (2013) overall motor vehicle theft sample about $80 \%$ were temporary thefts, whereas only $20 \%$ were permanent thefts.
} 
In other research, Ratcliffe and Rengert (2008) examined whether near repeat patterns exist for shooting incidents in Philadelphia, PA, during a period of 13 months. Contrary to the non-significant results obtained by Kikuchi et al. (2010) for violent offences, but consistent with the results reported by Youstin et al. (2011), Ratcliffe and Rengert did find significant space-time clustering in their data. Specifically, a shooting incident resulted in an elevated risk (33\% greater than expected) of another shooting incident occurring within one city block $(122 \mathrm{~m})$ of the initial incident. This elevated risk was found to subside after two weeks following the initial shooting. Similarly, Wells, $\mathrm{Wu}$, and Ye (2012) examined gun assaults in Houston, TX, over a two year period and also found significant space-time clustering. Indeed, their results were almost identical to those obtained by Ratcliffe and Rengert with a shooting incident resulting in an elevated risk (35\% greater than expected) of another gun assault occurring within 400 feet (122 m) of the initial incident for a period of two weeks following the initial shooting. Haberman and Ratcliffe (2012) also found significant space-time clustering when examining a violent offense. Specifically, they examined the near repeat phenomenon using 2009 armed street robbery data from Philadelphia, PA, and found that a significant space-time pattern of 1200 feet and 7 days.

It is unclear why Kikuchi et al. (2010) is the only study that did not find significant space-time clustering when examining violent offences. The difference may lie in the nature of the violent acts being studied. For example, the shootings in Ratcliffe and Rengert's (2008) study occurred in areas where other illegal activities were occurring, such as drug trade, and many of the shootings may have been retaliatory in nature. This does not appear to be the case for the violent offences examined by Kikuchi 
et al. Indeed, Wells et al. (2012) found gang-related shootings to be slightly more likely to result in follow-up gun assaults than those not related to gang activity. In addition, the violent offences examined in Kikuchi et al.'s study were much more heterogeneous in nature than those examined in the other four studies, which could potentially explain the lack of significant space-time clustering. Specifically, the other studies focused exclusively on either shootings or armed street robbery, whereas Kikuchi et al. included various types of assault in their sample of violent offences rather than just focusing on one particular type. Finally, following the logic of Kikuchi et al.'s argument regarding clearance rates, it might be that the clearance rates for violent offences (specifically shootings and armed street robberies) in the cities examined by Youstin et al. (2011), Ratcliffe and Rengert, Wells et al., and Haberman and Ratcliffe (2012) are relatively low (compared to those reported by Kikuchi et al.). This would presumably allow the near repeat phenomenon to emerge.

In another study, Townsley, Johnson, and Ratcliffe (2008) examined insurgent activity in Iraq in order to identify space-time patterns that would be operationally useful from a security standpoint. Townsley et al. were provided with data that consisted of 3 months of insurgent incidents that had occurred in Iraq between February 4 and April 30, 2004. Forty percent of the data dealt with improvised explosive devices (IEDs) and as a result, the researchers decided to restrict their analyses to this type of insurgent activity. Using the Knox test, in conjunction with Monte Carlo simulation, ${ }^{5}$ Townsley et al. determined that there was evidence of space-time clustering for IED incidents in Iraq

\footnotetext{
${ }^{5}$ As previously mentioned, the Knox test compares observed pairs of events to what would be expected based on chance. Traditionally, the observed pairs would be compared to a Poisson distribution. However, an alternative approach is to generate the expected distribution using permutations of the observed data. A Monte Carlo simulation is a method for generating the expected distribution by selecting a random sample from all permutations (Johnson et al., 2007).
} 
with the highest risk of future IED attacks being at distances up to one kilometre for a period of 2 days following the initial IED attack. ${ }^{6}$ Similarly, Braithwaite and Johnson (2012) examined insurgent activity in Iraq that occurred between January 1 and June 30, 2005, and found that the IED attacks during this particular timeframe also clustered together in space and time. Finally, Behlendorf, LaFree, and Legault (2012) also found significant space-time clustering when examining terrorist attacks by two terrorist organizations - the Farabundo Marti National Liberation Front (FMLN) in El Savador (from 1980 to 1992) and the Euskadi Ta Askatasuna (ETA) in Spain (from 1970 to 2007). Specifically, for both the FMLN and ETA, the risk of future terrorist attacks was found to be highest at distances up to 5 miles ( 8 kilometres) for up to 2 weeks following the initial attack.

More recently, some researchers have even begun exploring the space-time patterns of maritime piracy. In one study, Townsley and Oliveira (2012) used the Knox test to examine the space-time clustering of pirate attacks that occurred on the high seas around the Horn of Africa from 2006 to 2011. Their results indicate that maritime piracy does indeed cluster together in time and space. Specifically, the risk of future pirate attacks was found to be highest within 10 nautical miles $(18.5 \mathrm{~km})$ of the prior pirate activity for a period of one week following the initial attack. Similarly, Marchione and Johnson (2013) examined all incidents of maritime piracy from May 1978 to January 2012 and consistently found significant space-time clustering from 1997 onward.

In conclusion, the aforementioned studies demonstrate how space-time clustering is consistently found across a variety of crime types (with permanent theft of a motor

\footnotetext{
${ }^{6}$ Townsley et al. (2008) were able to refine these results to provide a more specific space-time pattern for IED attacks in Iraq, but these results were not reported for security reasons.
} 
vehicle and violent offences in Japan being the only exceptions thus far) and in a variety of different geographic regions. However, the precise space-time patterns were found to vary across crime types and regions, thus emphasizing the importance for additional research that examines this issue (i.e., specific space-time patterns cannot necessarily be generalized across all crime types and regions).

\section{Explaining near repeat crime - Boost vs. flag accounts. Similar to repeat} victimization, the boost and flag accounts mentioned earlier have also been put forth as potential explanations for near repeat victimization; however, research has focused primarily on testing the boost account. Bowers and Johnson (2004), for example, compared the modus operandi for near repeat and unrelated burglaries occurring in Merseyside, UK, between April 1997 and March 1998. In line with a previous study that determined the space-time clustering of burglary in the UK (Johnson \& Bowers, 2004a), Bowers and Johnson defined near repeats as those burglaries that occurred within 400 metres and one month of an initial burglary (all other burglaries were classified as unrelated). Modus operandi (MO) was assessed by examining two variables: (1) point of entry (e.g., front door, rear window on upper floor, etc.) and (2) means of entry (e.g., bodily pressure was used, offender sneaked into the house, etc.). Bowers and Johnson found that near repeats were significantly more likely to share the same MOs than unrelated burglaries. Assuming that burglars do in fact exhibit these behaviours in a consistent fashion across their crimes, this suggests that near repeats are more likely to be the work of the same offender (consistent with the boost account). ${ }^{7}$

\footnotetext{
${ }^{7}$ While this is the logic used by Bowers and Johnson (2004) to conclude that the boost explanation was a viable explanation for the results in this study, there is research that examines the consistency of burglary behaviour that may lead one to question these results. For example, Bennell and Canter (2002) found that entry variables were not exhibited in a particularly consistent fashion by commercial burglars in the UK.
} 
Johnson, Summers, and Pease (2009) provided a further test of the boost account of near repeats by examining solved burglaries and thefts from a motor vehicle that occurred in Bournemouth, UK, from 2001 through 2005. They found that burglaries occurring within 100 metres and 14 days of each other were more likely to have been committed by the same offender than more distant burglaries. Similarly, thefts from a motor vehicle that occurred within 100 metres and 14 days of each other were more likely to have been committed by the same offender than more distant thefts. These results provide additional support for the boost account.

In another study, Bernasco (2008) examined solved residential burglaries that occurred in The Hague from 1996 to 2004. In line with the research conducted by Bowers and Johnson (2004), and Johnson, Summers, and Pease (2009), he found that near repeat burglaries were much more likely to involve the same offender(s) than unrelated burglaries, thus supporting the boost explanation of near repeat burglaries. More recently, Johnson (2013) used solved serial residential burglary data from two UK cities, Poole and Bournemouth, and found that serial offenders do indeed commit crimes that are clustered together in space and time, which offers further, albeit somewhat indirect, support for the boost account of near repeat burglaries.

Thus, all of the studies to date that have examined the boost account for near repeat crime have found support for this theory. However, as previously mentioned, finding support for the boost account does not necessarily mean that the flag account does not have a role to play in explaining the occurrence of some near repeat crime, especially given that the flag account has rarely been studied directly in the context of near repeats. 


\section{Hotspot Mapping}

The aforementioned space-time clustering of near repeat crime can result in the occurrence of hotspots. A hotspot is defined as "a specific location or small area where an unusual amount of criminal activity occurs that is committed by one or more offenders" (Lersch, 2004, p. 230). Over the past decade, geographic information systems (GISs) have become more readily available and police forces have begun using geo-coded $x-y$ coordinates to record crime site locations. As a result of these two developments, crime hotspots have become increasingly easier to map in recent years.

Hotspot maps are essentially coloured temperature maps indicating areas that have experienced high levels of past crime (i.e., hotspots; see Figure 1 for an example of a hotspot map). Traditional methods of hotspot mapping can be considered retrospective in nature as they identify hotspots (and cold spots) of crimes that have occurred in the past (Johnson, Bowers, \& Pease, 2005). In contrast, prospective methods of hotspot mapping, which will be discussed in more detail below, are considered prospective in nature because they predict future hotspots. 


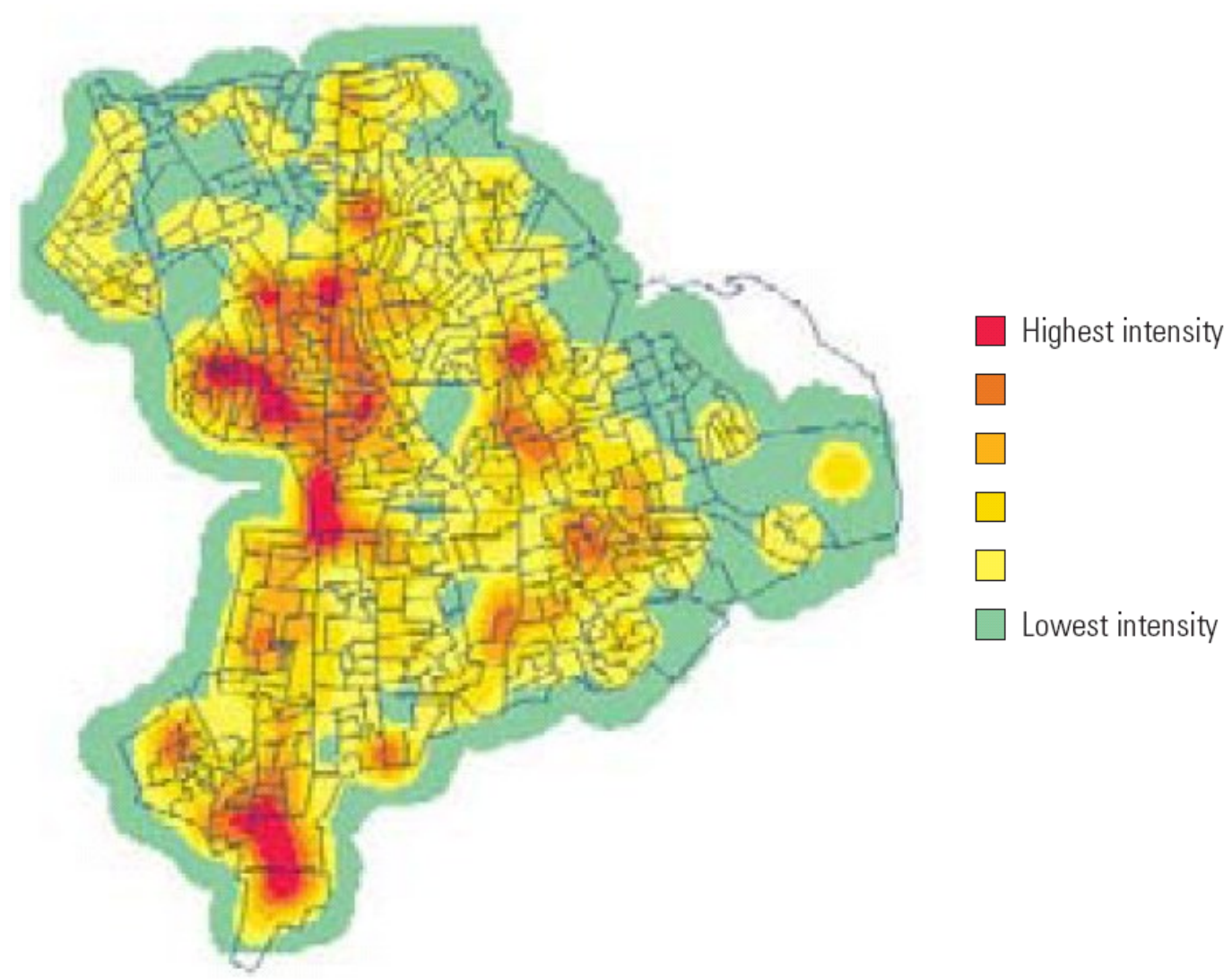

Figure 1. Example of a hotspot map generated using quartic kernel density estimation (Source: Eck, Chainey, Cameron, Leitner, \& Wilson, 2005).

\section{Traditional Methods of Hotspot Mapping}

Kernel density estimation (moving window technique). As previously

mentioned, crime analysts are now able to use a GIS and past crime data to generate traditional (i.e., retrospective) hotspot maps. According to Johnson et al. (2005), kernel density estimation (KDE), also referred to as the moving window technique, is the most common method for generating retrospective hotspot maps. The first step in KDE involves generating a two-dimensional grid that represents the area of interest, which is overlaid onto the geographical study area. Briefly, the grid consists of a series of cells with the exact number of cells in the grid varying as a result of the size of the study area and the size of each cell. Once the grid has been overlaid onto the study area, the next 
step involves assigning a value to each cell. This value specifies the intensity of crime risk within each cell with higher risk intensity values indicating a hotspot and lower values indicating a cold spot. In KDE, the risk intensity value is calculated by first drawing a circle with a predetermined ratio (i.e., bandwidth) from the midpoint (i.e., centre or centroid) of each cell. All crimes that occur within that circle are used to calculate the risk intensity value. More specifically, a mathematical equation is used to calculate the risk intensity value for a particular cell that considers two things: (1) the number of crimes that occurred within the circle and (2) the distance between each of those crimes and the midpoint (closer crimes are weighted more heavily than crimes farther away). ${ }^{8}$

The following is an example of a KDE quartic function used by Bailey and Gatrell (1995):

$$
\lambda_{\tau}(s)=Y \sum_{d i s t} \frac{3}{\pi \tau^{2}}\left(1-\frac{d^{2}}{\tau^{2}}\right)^{2}
$$

where $\lambda_{\tau}(s)=$ risk-intensity value for cell $s$

$\tau=$ bandwidth

$d_{i} \quad=$ distance of each point (i) within the bandwidth from the centroid of the cell.

Once the hotspot function has been applied to all of the cells in the grid, the risk intensity values can then be grouped into intervals and colour coded to produce a continuous surface like the one shown in Figure 1. It is important to note that the user must specify two parameters when conducting KDE: (1) the cell size and (2) the bandwidth. Although some GISs, such as Hotspot Detective (Ratcliffe, 2002), will

\footnotetext{
${ }^{8}$ Although there are several mathematical equations available to calculate the risk intensity values when using $\mathrm{KDE}$, all of the equations consider these two variables.
} 
provide default settings for these parameters after analyzing the input data, these two parameters are often arbitrarily set by the user (Chainey, Tompson, \& Uhlig, 2008).

Spatial ellipses. Spatial ellipses have also been used to identify and map hotspots of crime. Typically, the use of spatial ellipses involves first identifying the densest concentration of points on the map (i.e., hot clusters) and then applying a "standard deviational ellipse" to each dense area to produce elliptical clusters like the ones shown in Figure 2 (Chainey et al., 2008). Two of the more common methods of applying spatial ellipses to crime data are: (1) hierarchical clustering and (2) K-means clustering.

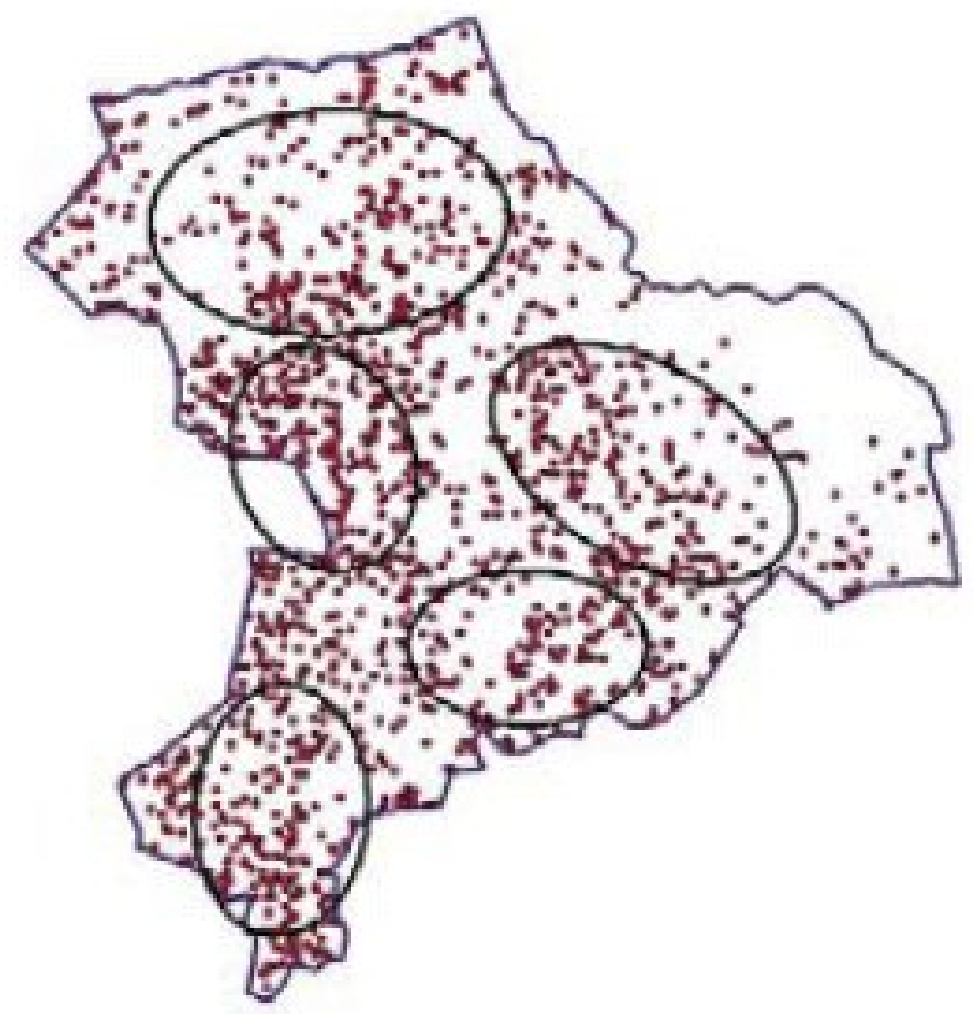

Figure 2. Example of K-means elliptical clusters (Source: Eck et al., 2005). 
Hierarchical clustering. The hierarchical clustering method focused on in this dissertation is the nearest neighbour hierarchical clustering (Nnh) routine available in CrimeStat, a software package commonly used for the spatial analysis of crime site locations (Levine, 2010). As explained by Levine, the Nnh routine clusters crimes together based on two criteria: (1) the threshold distance, which is determined by the Nnh routine and specifies how close the crimes must be to one another in space in order to be clustered together, and (2) the minimum number of points to be included in the cluster, which is specified by the user. Crimes can either be clustered together to form ellipses or convex hulls. Ellipses are oval-like shapes that enclose all of the points within a particular cluster (like the ellipses shown in Figure 2), whereas convex hulls are polygons that are drawn around the points in the cluster and are not necessarily uniform in shape (i.e., the exact shape of the convex hull will vary depending on the layout of the points within that cluster).

Briefly, the Nnh routine identifies crimes that are close to one another in space. The Nnh routine then decides whether or not to cluster these crimes together based on the two previously mentioned criteria. More specifically, the crimes are grouped together to form a first-order cluster (i.e., ellipse or convex hull) if they are: (1) closer together than the threshold distance and (2) the number of crimes that are close to one another exceeds the minimum number of points required to form a cluster. Grouping the first-order clusters can often result in the occurrence of second-order clusters (and grouping secondorder clusters can result in the occurrence of third-order clusters, etc.). Thus, the Nnh routine is repeated until all the clusters converge into one cluster or until clusters can no 
longer be found that meet the two criteria (the latter possibility is much more likely to occur in the data than the former). ${ }^{9}$

K-means clustering. The K-means clustering technique applies a certain number (K) of spatial ellipses to the crime data by partitioning the various crime site locations into clusters. It is important to note that the number of spatial ellipses (i.e., K) is specified by the user and is not empirically determined. An example of a K-means hotspot map where the user specified that $\mathrm{K}=5$ is shown in Figure 2. Although the K-means clustering technique can be useful for grouping crime site locations, it is important to note that crime hotspots do not naturally form spatial ellipses (i.e., using the outermost crime site locations to draw a shape that encompasses all of the crimes within a particular cluster would likely not result in a spatial ellipse). Thus, maps resulting from this technique do not represent the actual spatial distribution of crime (Eck et al., 2005).

\section{Prospective Hotspot Mapping}

As previously mentioned, traditional methods of hotspot mapping are retrospective in nature as they rely on existing crime data to determine the hotspots of previously committed crimes. Practitioners, however, often use these retrospective hotspot maps in order to determine where to allocate resources for the purpose of deterring future crime. The assumption is that hotspots based on past crimes will be the same as hotspots for future crime. Thus, the use of retrospective hotspot maps to predict future crime will only be effective if hotspots are stable over time. However, past research has shown that this is not always the case. Indeed, hotspots often shift over time (e.g., Barr \& Pease, 1990; Johnson \& Bowers, 2004b; Johnson, Lab, \& Bowers, 2008).

\footnotetext{
${ }^{9}$ Note that the Nnh routine calculates a new distance threshold each time it is run (i.e., the distance threshold for identifying second-order clusters will be different from the one used to identify first-order clusters).
} 
Given that the effectiveness of retrospective hotspot mapping techniques for predicting future crime locations is limited by the fact that hotspots are fluid, rather than stable, Bowers et al. (2004) developed a new hot-spotting method, which they referred to as prospective mapping. The hope was that prospective hotspot mapping would be more accurate at predicting future crime than the direct application of traditional retrospective hotspots.

Bowers et al.'s (2004) prospective mapping technique is a modified version of the moving window (or KDE) technique that was previously discussed. Like the moving window technique, a grid is first overlaid onto the study area. Risk intensity values are then calculated for each cell by applying a mathematical function. These risk intensity values indicate where future hotspots (higher values) and cold spots (lower values) are likely to occur. The following is the mathematical formula developed by Bowers et al. ${ }^{10}$ :

$$
\lambda_{\tau}(s)=\sum_{c_{i} \leq \tau \cap e_{i} \leq v}\left(\frac{1}{\left(1+c_{i}\right)}\right) \frac{1}{\left(1+e_{i}\right)}
$$

Where, $\lambda_{\tau}(s)=$ risk intensity value for cell $s$

$\tau=$ spatial bandwidth $v=$ temporal bandwidth

$\mathrm{c}_{\mathrm{i}}=$ number of cells between each point (i) within the bandwidth and the cell

$\mathrm{e}_{\mathrm{i}}=$ weeks elapsed for each point (i) within the temporal bandwidth

Although similar to the quartic formula proposed by Bailey and Gatrell (1995), Bowers et al.'s (2004) function does differ in several meaningful ways. First, the new function relies on a spatial bandwidth that is empirically derived from the crime data being used to generate the prospective map. More specifically, the spatial bandwidth is

\footnotetext{
${ }^{10}$ Note that the formula provided here was reported in Johnson, Bowers, Birks, and Pease (2009).
} 
defined as the distance over which the crime data has been shown to be communicable.

Second, Bowers et al.'s function is different in that it contains not only an empirically derived spatial bandwidth, but an empirically derived temporal bandwidth as well, which represents the time elapsed since the crimes occurred. Specifically, the temporal bandwidth parameter is determined by the time period over which the crime data has been shown to be communicable. ${ }^{11}$ Time is also used as a weighting variable in Bowers et al.'s approach in that crime events that occurred more recently are weighted more heavily than crime events that occurred less recently. Time is not included as a weighting variable in the traditional hotspot mapping approaches. Finally, the prospective mapping equation is different in that it does not rely on the midpoint (or centroid) of the cell. Instead, this formula focuses on the number of cells separating the crime point and the cell of interest (i.e., the cell that the risk intensity value is being calculated for). An example of a map produced by the prospective hot-spotting method is shown in Figure 3. The darker shades indicate where higher levels of future crime are predicted to occur (i.e., hotspot), whereas the lighter shades indicate where lower levels of future crime are predicted to occur (i.e., cold spot).

\footnotetext{
${ }^{11}$ Note that the bandwidth specified in the various formulae available for traditional methods of hotspot methods is typically referring to a spatial bandwidth. Although not explicitly stated in the formula, the traditional hotspot mapping approaches do have a temporal bandwidth as well. It is determined by the amount of data used to generate the maps. For example, if one month of crime data is used to generate a KDE map then one month represents the temporal bandwidth.
} 


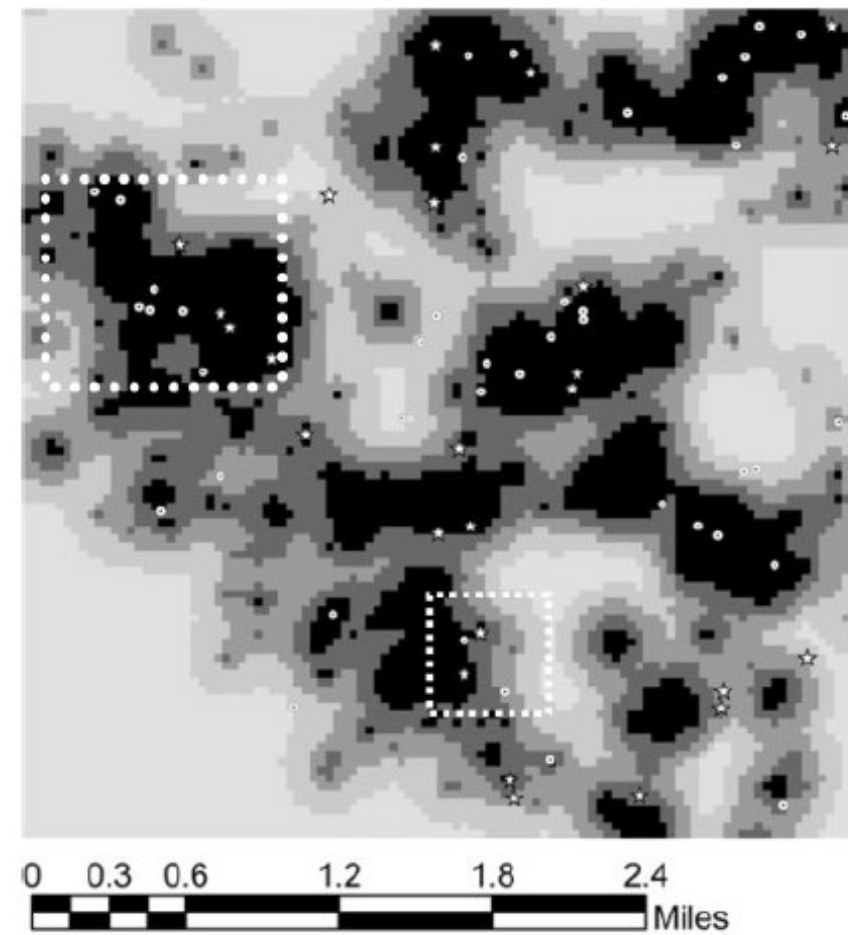

\section{Legend \\ म. Next 2 days \\ Next 7 days}

Prospective risk intensity

$1270.2314-1270.9417$

1270.9418 - 1274.8167

1274.8168 - 1282.9209

$1282.9210-1298.2926$

$1298.2927-1479.4883$

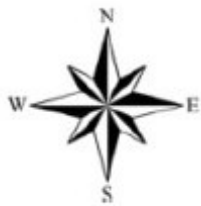

Figure 3. Example of a hotspot map generated using the prospective hotspot mapping method (Source: Bowers et al., 2004).

\section{Measures of Effectiveness}

Once Bowers et al. (2004) developed their prospective method of hot-spotting, the next natural step involved comparing its effectiveness at predicting future crime to other, more traditional, methods of hotspot mapping (i.e., retrospective hot-spotting). A variety of measures of effectiveness can potentially be used for this purpose. According to Bowers et al. these include:

1. Hit rate - The percentage of future crimes that are captured within the predicted hotspot area.

2. Hotspot area - Both the total area across all hotspots and the average area of each individual hotspot. 
3. Search efficiency rate - The number of crimes correctly predicted per kilometre squared.

4. Number of hotspots - The number of hotspots generated by the technique.

5. Area-to-perimeter ratios - Both the overall and average area-to-perimeter ratio (i.e., the area of the hotspot divided by its perimeter).

In 2008, Chainey et al. highlighted some of the disadvantages associated with these measures of hot-spotting effectiveness. One significant issue they raised was the fact that the hit rate does not take into account the area covered by the hotspots, which impacts the usefulness of this measure. For example, the hit rate of a particular hotspot mapping technique may be $100 \%$, but if the hotspots cover $100 \%$ of the total study area then a high hit rate is no longer valuable from an operational standpoint. Although the search efficiency rate could be a more useful measure of effectiveness for practitioners than the hit rate, it does not allow researchers to make comparisons between study areas of various sizes (i.e., search efficiency rate does not allow for comparisons across different geographic regions).

Predictive accuracy index. As a result of the aforementioned shortcomings of Bowers et al.'s (2004) measures of hot-spotting effectiveness, Chainey et al. (2008) introduced the predictive accuracy index (PAI) as an improved means of assessing the predictive accuracy of various hotspot mapping methods. More specifically, the PAI is a ratio of two statistics that are similar to those proposed by Bowers et al.: (1) the hit rate (i.e., the percentage of future crimes falling within the predicted hotspots) and (2) the area percentage (i.e., the proportion of the entire study area that is covered by the predicted hotspots). The following formula can be used to calculate the PAI: 


$$
\text { Predictive accuracy index }=\frac{\text { Hit rate }}{\text { Area percentage }}=\frac{(n / N) * 100}{(a / A)^{* 100}}
$$

where $n$ equals the number of future crimes falling within the predicted hotspots, $N$ equals the total number of future crimes, $a$ equals the total area of predicted hotspots, and $A$ equals the total area of the study.

A PAI value of 1 indicates that the hit rate and the area percentage are the same (e.g., $50 \%$ of future crimes occurred in $50 \%$ of the total area). A PAI value greater than 1 indicates that the percentage of future crimes found in the predicted hotspots was greater than the percentage of the total area that the hotspots occupied (e.g., finding $80 \%$ of future crimes in $40 \%$ of the total area would result in a PAI value of 2 ). Thus, higher PAI values indicate greater efficiency (i.e., a greater percentage of predicted crimes occur in a smaller proportion of the total study area).

According to Chainey et al. (2008), the PAI is an improved measure of crime forecasting accuracy given that it considers the number of future crimes captured by the predicted hotspots in comparison to the proportion of the total area that the hotspots occupy. In addition, the PAI is a measure that allows for comparisons across geographic regions that vary in size. It is important to note that the hit rate and area percentage must first be determined before the PAI can be calculated. Thus, researchers and practitioners are still able to consider hit rate and area percentage when using the PAI.

\section{Effectiveness of Hot-Spotting Methods}

Retrospective hot-spotting methods. In 2008, Chainey et al. used their newly developed PAI to assess the predictive accuracy of five different traditional (i.e., retrospective) hot-spotting methods: (1) point mapping, (2) thematic mapping of 
geographic boundary areas (e.g., Census areas), (3) spatial ellipses, (4) grid thematic mapping, and (5) kernel density estimation (KDE). Chainey et al.'s data consisted of $x-y$ coordinates for crimes that occurred in North/Central London, UK, during a two-year period (2002 and 2003). Four different crime types were included in the study: (1) residential burglary, (2) street crime (i.e., robbery of personal property and theft from the person), (3) theft from motor vehicles, and (4) theft of motor vehicles. Chainey et al. found that KDE consistently outperformed the other hot-spotting methods examined (i.e., KDE had the highest PAI values) across all four crime types. In addition, Chainey et al. found that across all five hotspot mapping techniques the highest PAI values were obtained for street crime, which suggests that hotspot accuracy will vary from one crime type to another even when the same hot-spotting method is used to generate the map.

Similarly, Van Patten, McKeldin-Coner, and Cox (2009) used burglary data from Roanoke, VA, to examine various retrospective hot-spotting methods and found that KDE produced the highest PAI values when longer time periods of past crime data (i.e., two or three years) were used to generate the hotspot maps. In contrast, a procedure based on the Nnh convex hull method was found to be superior when shorter time periods of past crime data (i.e., one year) were used. Van Patten et al. did not offer an explanation for why one hot-spotting method would be most accurate when using shorter time periods of past crime, whereas another hot-spotting method would be most accurate when using longer time periods.

In another study, Tompson and Townsley (2010) examined whether the predictive accuracy of maps produced by KDE, which is a retrospective hot-spotting technique, could be improved by incorporating more specific temporal information (i.e., time of 
day) into the analysis. Using the exact same street crime data as Chainey et al. (2008), Tompson and Townsley first divided the data into three different groups based on the temporal period during which the crime occurred: (1) morning (7 am until 2:59 pm), (2) afternoon (3 pm until 10:59 pm), or (3) overnight (11 pm until 6:59 am). Next, three hotspot maps (i.e., morning, afternoon, evening) were generated using the KDE hotspotting technique. The three hotspot maps were then used to predict future street crime that occurred during the same temporal period (e.g., morning hotspot map was used to predict future street crime that also occurred during the morning) and during a different temporal period (e.g., the morning hotspot map was used to predict future street crime that occurred during the afternoon).

Using the PAI to assess accuracy, Tompson and Townsley (2010) found that predictive accuracy could be enhanced by incorporating the temporal period into the analysis (e.g., the PAI value was higher when applying the morning hotspot map to future morning street crime than when applying the morning hotspot map to future afternoon or overnight crimes), but only for the times of day where greater space-time clustering was evident. More specifically, predictive accuracy increased when morning and overnight hotspot maps were used to predict future morning and overnight street crime, respectively. In contrast, the PAI value did not improve when the afternoon hotspot map was used to predict future afternoon crimes. ${ }^{12}$

One explanation for the results obtained in Tompson and Townsley's (2010) study is that the routine activities of offenders, as well as victims, vary depending on the time of day examined. Thus, using a morning hotspot map to predict future morning

\footnotetext{
${ }^{12}$ Although Tompson and Townsley (2010) found that predictive accuracy for morning and overnight street crimes could be enhanced by incorporating time of day information into the analyses, time of day was not examined in the current study due to the unavailability of time of day Canadian crime data.
} 
crime results in more accurate predictions because it more accurately captures the routine activities of offenders and victims during that particular time of day. In addition to time of day, the routine activities of offenders and victims will also likely differ during the week than during the weekend. As a result, these findings suggest that hotspot maps generated using weekend crime data will be more accurate at predicting weekend crime versus weekday crime (and hotspot maps generated using weekday crime data will be more accurate at predicting future weekday crime).

More recently, Hart and Zandbergen (2012) examined the predictive accuracy of eight different traditional hotspot techniques, with KDE and Nnh being the two methods of direct relevance to the current study. The data consisted of $x-y$ coordinates for crimes that occurred during January 1, 2007, and December 31, 2008, in six different jurisdictions: (1) Albuquerque, NM, (2) Arlington, TX, (3) Charlotte-Mecklenburg Police Department, NC, (4) Las Vegas, NV, (5) San Diego, CA, and (6) Tampa, FL. The crime data from 2007 was used to generate the hotspot surfaces for each of the eight techniques, whereas the 2008 data were used to assess their predictive accuracy. In addition, seven different crime types were included in the study: (1) assault, (2) auto burglary (i.e., theft from a motor vehicle), (3) auto theft, (4) burglary, (5) drug offences, (6) homicide, and (7) robbery. As well, predictive accuracy was assessed using three different measures: (1) hit rate, (2) PAI, and (3) recapture rate index; ${ }^{13}$ however, only the hit rate and PAI results will be focused on here.

Hart and Zandbergen (2012) found that regardless of the mapping technique used, predictive accuracy varied across the various jurisdictions and crime types examined. For

\footnotetext{
13 The recapture rate index is the ratio of 2007 crime density to 2008 crime density standardized for changes in the total number of crimes in 2007 and 2008 (Levine, 2008).
} 
example, hit rates were consistently the lowest for homicides and the highest for drug offences. PAI values, however, were typically the lowest for burglary. PAI values were not consistently highest for any particular crime type across the various hotspot mapping techniques examined. When comparing the predictive accuracy of KDE to that of Nnh, KDE consistently produced the most accurate maps in terms of hit rate across all jurisdictions and crime types. Nnh, however, always produced the most accurate maps when assessed by PAI.

Prospective hot-spotting methods. Very few studies to date have actually examined the effectiveness of prospective hot-spotting for predicting future crime. Bowers et al. (2004), however, did assess effectiveness when they first proposed their prospective hot-spotting technique. More specifically, Bowers et al. used burglary data from Merseyside, UK, to compare the effectiveness of prospective hotspot mapping (based on a spatial bandwidth of $400 \mathrm{~m}$, as found by Johnson \& Bowers, 2004) to two traditional hot-spotting methods, neither of which uses a temporal weighting: (1) a retrospective moving window technique (using a spatial bandwidth of $200 \mathrm{~m}$, as recommended by Ratcliffe, 2000) and (2) police beats (generated by identifying the six police beats that had experienced the greatest number of burglaries). For each hotspotting method, the maps were generated using two months' worth of data (August and September, 1997), which was the time over which Johnson and Bowers (2004) found burglary in this area to be communicable. Two days' (October 1 and 2, 1997) and one week's (October 1 to 7,1997 ) worth of data were used to test the effectiveness of the hotspotting methods at predicting future crime. 
Overall, Bowers et al. (2004) found prospective mapping to be more effective at predicting future crimes than the two traditional methods of hot-spotting, particularly when predicting crime that occurred within the 2-day timeframe. More specifically, prospective hot-spotting was found to be more effective in terms of both hit rate and search efficiency when predicting both 2 days' and 1 week's worth of future burglaries (see Table 2). While Bowers et al. did not calculate PAI for their analyses this can easily be done using the information provided in their article. Consistent with their results, PAI was higher for prospective mapping compared to the other two methods when predicting crime that occurred within the 2-day and 1-week timeframe (see Table 2). These results indicate that prospective hot-spotting has advantages over more traditional hot-spotting methods, such as the moving window technique and police beats.

Table 2. Relative prediction effectiveness of the different hot-spotting techniques (Adapted from Bowers et al., 2004).

\begin{tabular}{lcccccc}
\hline \multirow{2}{*}{$\begin{array}{c}\text { Mapping } \\
\text { Technique }\end{array}$} & \multicolumn{2}{c}{ Hit Rate } & \multicolumn{2}{c}{ Search efficiency } & \multicolumn{2}{c}{ PAI } \\
\cline { 2 - 7 } & 2 days & 1 week & 2 day $/ \mathrm{km}^{2}$ & 1 week $/ \mathrm{km}^{2}$ & 2 days & 1 week \\
\hline Prospective & $62 \%$ & $64 \%$ & 2.96 & 8.33 & 2.60 & 2.69 \\
Retrospective & $46 \%$ & $56 \%$ & 2.22 & 7.22 & 1.93 & 2.35 \\
Beat & $12 \%$ & $24 \%$ & 0.59 & 3.34 & 0.54 & 1.07 \\
\hline
\end{tabular}

Similar to Bowers et al. (2004), Johnson, Bowers, Birks, and Pease (2009) also compared the predictive accuracy of the prospective mapping technique, which they referred to as ProMap, to two traditional hot-spotting methods: (1) KDE and (2) police beats. In contrast to Bowers et al., however, Johnson, Bowers, et al. also generated crime risk surfaces based on chance using a simple Monte Carlo simulation approach as well as 
risk surfaces based on a ProMap algorithm that incorporated data on three factors that could impact burglary risk within each cell - the physical attributes of housing (i.e., the number of residential dwellings in each cell), road infrastructure (i.e., the number of road sections, the length of each road, and the road classification in each cell), and social barriers (i.e., the difference in area affluence classification between each cell and those that neighbour it).

Crime data for this study consisted of residential burglary occurring in a $5 \mathrm{~km} \mathrm{x} 5$ km square grid in South Liverpool between September 1, 1996, and November 30, 1997. Data for the first 12 months were used to identify the space-time clustering for the area, which then determined the temporal and spatial bandwidths for the ProMap approach, ${ }^{14}$ and the remaining data were used to generate the maps and assess predictive accuracy. Specifically, two months' worth of data were used to generate each map and data from the following seven days were used to test predictive accuracy. The results from Johnson, Bowers, et al.'s (2009) study indicate that the ProMap method consistently outperformed chance and the KDE method at predicting future crime. In contrast, the thematic police beat approach appeared to perform at accuracy levels comparable to chance. Finally, the incorporation of data about each cell's physical attributes of housing and road infrastructure further improved on the performance of the ProMap model, whereas the inclusion of data on the social barriers of each cell had no impact on predictive accuracy.

Overall, the results from these two studies (i.e., Bowers et al., 2004; Johnson, Bowers, et al., 2009) suggest that prospective mapping could prove to be more operationally useful than traditional hot-spotting methods. That being said, it is currently unclear how various prospective hot-spotting methods will fare using test samples that

\footnotetext{
${ }^{14}$ Johnson, Bowers, et al. (2009) found a near repeat space-time pattern of 500 metres and two months.
} 
incorporate longer time periods (e.g., 1 month) or whether there is an optimal time period for testing prospective hotspot maps. Although an empirically derived temporal bandwidth has been considered a strength of the prospective hot-spotting approach, it is possible that the optimal time period for generating maps is dependent on the amount of crime data available for analysis rather than on the empirically derived temporal bandwidth (i.e., more crime data might mean more accurate hotspot maps). Given that the precise pattern of space-time clustering varies depending on crime type and geographic region, it seems likely that the ideal timeframe for testing (and generating) predictive risk surfaces will also vary across these two factors.

In conclusion, although the effectiveness of prospective hot-spotting methods at predicting future crime has yet to be studied extensively, preliminary results indicate that prospective hot-spotting outperforms traditional hot-spotting methods and could prove operationally useful to police in predicting (and potentially reducing) future crime. Thus, future research in this area is certainly warranted.

\section{The Current Study}

Drawing on existing research, the current study consisted of four phases. Phase 1 determined the exact space-time clustering of several crime types (burglary, theft from motor vehicle, and common assault) across various Canadian cities (Edmonton, AB, Saint John, NB, and Moose Jaw, SK). Phase 2 used the time and distance over which crime clusters (as found in Phase 1) to generate prospective risk surfaces for the various crime types and cities. Using PAI, the accuracy of the prospective risk surfaces was compared to that of two traditional hot-spotting methods: (1) kernel density estimation (KDE) and (2) nearest neighbour hierarchical clustering (Nnh). Phase 3 examined 
whether the accuracy of prospective hot-spotting could be improved by considering three variables: whether the crimes occurred during the weekend or weekday, the time period of data used to generate the prospective maps, and the time period of data used to test the accuracy of the prospective maps. Finally, Phase 4 investigated whether the boost account could explain near repeat burglary in one Canadian city (Edmonton, AB). Specifically, solved crime data were used to determine whether near repeat burglaries were more likely to be committed by the same offender than more distant burglaries. The exact procedures involved in each of these phases are described in more detail below.

\section{Phase 1 - Space-Time Patterns in Canadian Crime}

\section{Method}

Data. An official request for data was sent out to various police agencies across Canada with three city police forces agreeing to provide data for the current study: (1) Edmonton, AB, (2) Moose Jaw, SK, and (3) Saint John, NB. Conveniently, these three cities represent Canadian cities of varying population, area, and population density (see Table 3 for a comparison across the three cities).

Table 3. Demographics for Edmonton, Moose Jaw, and Saint John from 2006 census (Source: Statistics Canada, 2008).

\begin{tabular}{lccc}
\hline City & Population & Area $\left(\mathrm{km}^{2}\right)$ & Population density $\left(\right.$ per $\left.\mathrm{km}^{2}\right)$ \\
\hline Edmonton & 730372 & 684.37 & 1067.2 \\
Saint John & 68043 & 315.49 & 215.70 \\
Moose Jaw & 32132 & 46.82 & 686.30 \\
\hline
\end{tabular}


The data from each region consisted of offence locations and the date of each offence $^{15}$ across three different crime types - residential burglary, theft from a motor vehicle (TFMV), and common assault - that occurred between January 1, 2007, and December 31,2008 . It is important to note that the various police agencies only provided data on confirmed offences (i.e., an officer was sent out and an official report was filed). For the purpose of this dissertation, residential burglary is defined as a crime that occurs when an offender enters a residential dwelling with the intent to burglarize the home. Theft from a motor vehicle is similar to burglary except that the offender enters a motor vehicle instead of a residential dwelling in order to take something that they are not the owner of. Common assault is considered the least serious type of assault and includes behaviours such as slapping, punching, pushing, and face-to-face threats. Aggravated assaults, assaults with a weapon, and assaults causing bodily harm are not included in common assaults.

Due to privacy concerns, Edmonton and Saint John both provided the crime site location data as geo-coded $x-y$ coordinates ${ }^{16}$ that had been offset by a constant value unknown to me. This did not impact the analyses in any way, but did ensure that the $x-y$

\footnotetext{
${ }^{15}$ Note that the Edmonton Police Service provided both an "occurrence from" date (i.e., start date) and an "occurrence to" date (i.e., end date) for each offence. In cases where those dates differed (e.g., resident was away for several days so could not determine exactly when their house had been burglarized), the start date was used as the occurrence date, which is an approach adopted in other near repeat research (e.g., Block \& Fujita, 2013). The Moose Jaw Police Service provided the date the offence was reported in place of an occurrence date. Although the report date will not always be the same as the occurrence date (particularly for theft from a motor vehicle and burglary where the victim would likely not have been present for the offence), the report date was used to represent the occurrence date for all the Moose Jaw analyses in this dissertation. Finally, the Saint John Police Force provided occurrence dates that were a combination of report dates and actual occurrence dates (i.e., the report date was used for offences where the exact occurrence date was unknown). It is acknowledged that these differences in the crime data may impact comparisons that can be made across the three police forces.

${ }^{16}$ It is now standard practice in many police forces around the world to obtain geo-coded $x-y$ coordinates for all offence and offender home locations. This is typically done by the first responder when they visit the scenes through the use of a Global Positioning System (GPS). GPS provides an extremely accurate estimate of location (at the scale of $+/$ - feet usually).
} 
coordinate data provided could not be used to determine an exact address for the offence. Moose Jaw provided offence locations in standard address format. However, the offence locations had to be in a projected $x-y$ coordinate format in order to complete the Phase 1 analyses. As a result, the GPS Visualizer geocoding tool (Schneider, 2013), a free online program, was used to first convert the Moose Jaw addresses into a latitude and longitude format. Next, a tool within ArcView (v 10.1), a desktop GIS, was used to convert the coordinates from latitude and longitude to a projected $x-y$ format (specifically, the offence locations for Moose Jaw were converted to the Universal Transverse Mercator (UTM) geographic coordinate system).

Prior to the analyses, the Edmonton, Moose Jaw, and Saint John data files were screened in their entirety and any offence with missing $x-y$ coordinates, incomplete address information, ${ }^{17}$ or missing dates were excluded from the analyses. Table 4 provides the total number of incidents, the number of incidents with missing data, and the final total number of incidents occurring during 2007 and 2008 across the three cities for each crime type. Notice that relatively low levels of missing data were found across the nine data files (percentage of missing data ranged from $0.29 \%$ to $6.67 \%$ ). Notice as well that the volume of crime was found to vary across the three cities as a function of population. Specifically, the highest number of incidents across each crime type were found in the most populated city (i.e., Edmonton), whereas the lowest number of incidents across each crime type were found in the least populated city (i.e., Moose Jaw).

\footnotetext{
${ }^{17}$ For example, some of the offence addresses provided by the Moose Jaw Police Service were at the block level, which was insufficient for the analyses in the current study. These data had to be excluded.
} 
Table 4. Number of incidents for each data file.

\begin{tabular}{|c|c|c|c|c|}
\hline City & Crime Type & $\begin{array}{c}\text { Total Incidents } \\
(1 / 1 / 07 \text { to } 12 / 31 / 08)\end{array}$ & $\begin{array}{l}\text { Incidents with } \\
\text { Missing Data }\end{array}$ & $\begin{array}{l}\text { Final Total } \\
\text { Incidents }\end{array}$ \\
\hline \multirow[t]{3}{*}{ Edmonton } & Burglary & 8009 & $36(4.49 \%)$ & 7973 \\
\hline & TFMV & 23665 & $789(3.33 \%)$ & 22876 \\
\hline & $\begin{array}{l}\text { Common } \\
\text { Assault }\end{array}$ & 7239 & $213(2.94 \%)$ & 7026 \\
\hline \multirow[t]{3}{*}{ Moose Jaw } & Burglary & 344 & $1(0.29 \%)$ & 343 \\
\hline & TFMV & 378 & $12(3.17 \%)$ & 366 \\
\hline & $\begin{array}{l}\text { Common } \\
\text { Assault }\end{array}$ & 450 & $30(6.67 \%)$ & 420 \\
\hline \multirow[t]{3}{*}{ Saint John } & Burglary & 462 & $2(0.43 \%)$ & 460 \\
\hline & TFMV & 740 & $14(1.89 \%)$ & 726 \\
\hline & $\begin{array}{l}\text { Common } \\
\text { Assault }\end{array}$ & 1790 & $40(2.23 \%)$ & 1750 \\
\hline
\end{tabular}

Phase 1 data. Although the data files provided by the police agencies consisted of all confirmed offences that took place between January 1, 2007, and December 31, 2008, only crimes that occurred during 2007 were used in this first phase of analyses (the rest of the data were used in subsequent phases of the study). This ensured that the data used to determine space-time clustering did not overlap with the data used to generate and test the maps, which prevents a bias in favour of the prospective hot-spotting approach. In total, nine data files were included in Phase 1 - one for each of the three different crime types across each of the three cities. Table 5 provides the number of offences included in each data file for the first phase of analyses. 
Table 5. Number of incidents for each data file used in Phase 1.

\begin{tabular}{lccc}
\hline \multirow{2}{*}{ City } & \multicolumn{3}{c}{ Crime Type } \\
\cline { 2 - 4 } & Burglary & TFMV & Common Assault \\
\hline Edmonton & 4031 & 12037 & 3394 \\
Saint John & 221 & 394 & 877 \\
Moose Jaw & 148 & 137 & 222 \\
\hline
\end{tabular}

Procedure. As previously mentioned, the first phase of the current study examined how crime clusters together in space and time across various Canadian cities and across various crime types. In order to determine the precise space-time patterns of Canadian crime, Ratcliffe's (2009) near repeat calculator (v 1.3) was used. The steps followed when using the near repeat tool are outlined below (Ratcliffe, 2009):

1. First, using Microsoft Excel, where the data were stored, each of the nine data files was converted to a comma separated values (.csv) format. Within this format, each data point within the data file had $x-y$ coordinates denoting the crime site location and the date on which the crime occurred, with each row representing a different crime.

2. Once a particular data file was loaded into the near repeat calculator, the following program parameters had to be specified: spatial bandwidth, number of spatial bands, temporal bandwidth, number of temporal bands, and significance level. The same as Johnson and Bowers (2004a), the current study used a spatial bandwidth of 100 metres, a temporal bandwidth of 7 days, and a significance 
level of .01. The number of spatial bands was set to 14 and the number of temporal bands was set to $10 .^{18}$

3. Next, the use of either Manhattan or Euclidean distance for the calculations had to be specified. The Euclidean (direct) distance uses Pythagorean's equation to measure the direct distance between two points, whereas the Manhattan (indirect) distance adds the difference between the $x$-coordinates of the two points to the difference between the $y$-coordinates of the two points (see Figure 4). Manhattan distances are only useful if the data originated from a geographic area that consists of road networks based on uniform grids and if offender travel routes are known. Given that this was not the case in the current study, Euclidean distances were used. $^{19}$

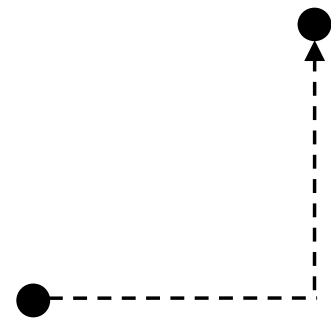

Manhattan distance

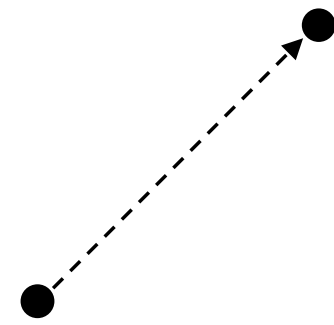

Euclidean distance

Figure 4. Manhattan versus Euclidean distance.

\footnotetext{
${ }^{18}$ Determining the number of spatial and temporal bands depends on how far and how long the near repeat pattern is expected to extend (Ratcliffe, 2009). In Johnson et al.'s (2007) study, where they examined the space-time patterns of burglary across ten different cities, they found the farthest near repeat effect to be 1200 metres (Canberra, Australia) and the longest near repeat effect to be 8 weeks (Philadelphia, USA). Thus, 10 temporal bands (at 1 week per band) and 14 spatial bands (at 100 metres per band) were selected in the current study because it was expected that the near repeat effects would not extend beyond 1400 metres and 10 weeks.

${ }^{19}$ Upon inspection, many of the streets in Edmonton, Moose Jaw, and Saint John do appear to follow a grid-like pattern, but these grid patterns are not consistent (i.e., the distance between each block in the grid is not uniform). As well, not all streets in the city follow a grid-like pattern and offender travel routes are unknown.
} 
4. The final step in the procedure involved running the near repeat calculator. Briefly, this program compares the actual space-time pattern observed in the data to that which would be expected based on chance. The expected pattern is generated by randomly redistributing the date values across the various spatial points. Each reallocation of the date values is referred to as a Monte Carlo iteration. The number of iterations that run depends on the significance value selected. In the current study, a $p$-value of .01 was selected, which means that 100 Monte Carlo iterations were run. The observed space-time pattern was only considered significant if it occurred by chance in zero or 1 of the 100 iterations.

Once the near repeat calculator completed all of its iterations, the program produced two tables as output: (1) an observed over mean expected frequencies table and (2) a statistical significance table. The observed over mean expected frequency is a ratio that represents the difference between the average expected cell values and the values actually observed for each cell (see Figure 5). For example, the value 1.89 in Figure 5 indicates that houses within 1 to 100 metres of the initially burglarized house are $89 \%$ more likely to be victimized within 30 days of the initial offence than would be expected based on chance. The observed over mean expected frequencies table also indicates which values are significant at both the user specified $p$-value and at $p<.05$ (bolding and colour of values are used to indicate significance in the output). The statistical significance table is simply a table that indicates the exact $p$-value for the finding at each temporal and spatial band (i.e., within each cell). 


\begin{tabular}{|c|c|c|c|c|c|c|}
\hline & $\begin{array}{c}\text { 0 to } 30 \\
\text { days }\end{array}$ & $\begin{array}{c}\mathbf{3 1} \text { to } \\
\text { 60 days }\end{array}$ & $\begin{array}{c}\mathbf{6 1} \text { to } \\
\mathbf{9 0} \text { days }\end{array}$ & $\begin{array}{c}\mathbf{9 1} \text { to } \\
\mathbf{1 2 0} \\
\text { days }\end{array}$ & $\begin{array}{c}\mathbf{1 2 1} \text { to } \\
\mathbf{1 5 0} \\
\text { days }\end{array}$ & $\begin{array}{c}\mathbf{1 5 1} \text { tc } \\
\mathbf{1 8 0} \\
\text { days }\end{array}$ \\
\hline $\begin{array}{c}\text { Same } \\
\text { location }\end{array}$ & 3.11 & 2.04 & 0.29 & 1.66 & 0.38 & 1.90 \\
\hline $\begin{array}{c}\mathbf{1} \text { to 100 } \\
\text { meters }\end{array}$ & $\mathbf{1 . 8 9}$ & 1.18 & 1.01 & 0.79 & 0.69 & 0.74 \\
\hline $\begin{array}{c}\mathbf{1 0 1} \text { to } \mathbf{2 0 0} \\
\text { meters }\end{array}$ & $\mathbf{1 . 5 9}$ & 1.06 & 0.96 & 0.79 & 0.78 & \\
\hline $\begin{array}{c}\mathbf{2 0 1} \text { to } 300 \\
\text { meters }\end{array}$ & $\mathbf{1 . 4 9}$ & 1.07 & 1.08 & & & \\
\hline $\begin{array}{c}\mathbf{3 0 1} \text { to } \mathbf{4 0 0} \\
\text { meters }\end{array}$ & 1.05 & 1.02 & & & & \\
\end{tabular}

Figure 5. Example of an observed over mean expected frequencies table (Source:

Ratcliffe, 2009).

Hypotheses. Based on the results obtained in previous studies (e.g., Johnson et al., 2007; Summers et al., 2007), it was expected that burglaries and thefts from a motor vehicle would cluster together in space and time across each of the three Canadian cities examined. The exact space-time patterns, however, were expected to vary across the two crime types and from one city to the next. Given the inconsistent findings in regards to violent offences (e.g., Kikuchi et al., 2010; Ratcliffe \& Rengert, 2008), it was unknown whether common assaults would show a significant space-time pattern. Given the results obtained in Johnson et al.'s (2007) study where the exact space-time patterns were found to vary across each region regardless of target density (see Table 1), hypotheses regarding city-specific space-time patterns were not made.

\section{Results}

The observed over mean frequencies (i.e., odds ratios) and statistical significance tables produced as output by the near repeat calculator are presented in Appendix A. As 
outlined by Ratcliffe (2009), these tables can be used to determine whether significant space-time clustering is present in the data (i.e., whether there is an increased risk that another crime will occur within close space-time proximity to the initial crime).

Specifically, a significant and meaningful near repeat victimization pattern is present when the odds ratios close in space and time to the initial crime incident (i.e., cells near the upper left of the matrix) are: (1) equal to or greater than 1.20 and (2) significant at the $p$-level specified by the user (recall that a $p$-level of .01 was specified in the current study). When examining the tables, it is possible that cells farther away from the original crime (e.g., cells in the lower right of the matrix) may be statistically significant based on chance. These random significant cells do not represent a meaningful victimization pattern unless there are other significant cells nearby and a risk decay pattern is evident. ${ }^{20}$ Following Ratcliffe's (2009) approach, the tables in Appendix A were examined for significant near repeat space-time clustering and the results for each data file are summarized in Table 6 . The near repeat space-time pattern results will now be discussed in more detail for each crime type across all three cities.

\footnotetext{
${ }^{20}$ A "risk decay pattern" refers to a gradual reduction in odds ratios and $p$-values over several nearby cells. So, for example, a significant cell surrounded by non-significant cells does not demonstrate a risk decay pattern, and as a result, that cell does not represent a meaningful victimization pattern
} 
Table 6. Summary of Phase 1 results.

\begin{tabular}{llcc}
\hline \multirow{2}{*}{ City } & Crime Type & \multicolumn{2}{c}{ Risk } \\
\cline { 3 - 4 } & & Space & Time \\
\hline \multirow{2}{*}{ Edmonton } & Burglary & $500 \mathrm{~m}$ & 1 week \\
& TFMV & $200 \mathrm{~m}$ & 1 week \\
& Common Assault & n.s. & n.s. \\
\hline Moose Jaw & Burglary & n.s. & n.s. \\
& TFMV & n.s. & n.s. \\
& Common Assault & n.s. & n.s. \\
\hline \multirow{2}{*}{ Saint John } & Burglary & n.s. & n.s. \\
& TFMV & $100 \mathrm{~m}$ & 1 week \\
& Common Assault & n.s. & n.s. \\
\hline
\end{tabular}

Edmonton. The results of the near repeat analysis for the Edmonton burglary data indicate that significant space-time clustering is present with houses within 500 metres of a burglarized house being at an increased risk of also being burglarized for a period of 7 days. Specifically, houses within 100, 101-200, 201-300, 301-400, and 401-500 metres of the initial burglary are at a $164 \%, 79 \%, 39 \%, 29 \%$, and $27 \%$ increased risk of also being burglarized, respectively, within the week following the initial incident (see Appendix A). The results indicate that there was also a significant repeat victimization pattern found with the risk of previously burglarized houses being burglarized again being $315 \%$ greater than chance for one week following the initial crime. This risk drops to $97 \%$ and 90\% during 1-2 weeks and 2-3 weeks following the initial burglary, respectively.

The results from the Phase 1 analyses for the Edmonton TFMV data file indicate that significant near repeat space-time clustering is also present with vehicles within 200 metres of an initial TFMV being at an increased risk of also being victimized for a period 
of 7 days. Specifically, vehicles within 100 and 101-200 metres of the initial TFMV are at a $30 \%$ and $20 \%$ increased risk of also being victimized, respectively, within the week following the initial incident. The results indicate that there was also a significant repeat victimization pattern found with the risk of a vehicle in the same location being targeted again being $67 \%$ greater than chance for one week following the initial TFMV. ${ }^{21}$

In contrast to Edmonton burglary and TFMV, a significant near repeat space-time pattern was not found for the Edmonton common assault data file. This indicates that people in close space-time proximity to a previous common assault incident were not at an increased risk of also being victimized. However, a significant repeat pattern was found with individuals at the same location as a previous common assault being at a $38 \%$ increased risk of also becoming a victim of common assault for 1 week following the original crime. $^{22}$

Moose Jaw. The results from the Phase 1 analyses indicate that none of the three Moose Jaw data files (i.e., burglary, TFMV, and common assault) demonstrate significant near repeat space-time clustering, nor were there any indications of a significant repeat victimization pattern across the Moose Jaw data files.

Saint John. Similar to Moose Jaw, the Phase 1 analyses found no indication of a significant near repeat space-time pattern for both the Saint John burglary and common assault data files. The Saint John burglary data file, however, did demonstrate a significant repeat victimization pattern with previously burglarized houses being at a

\footnotetext{
${ }^{21}$ Note that the near repeat calculator determines repeat patterns based on offences that occur at the same location (i.e., same $x-y$ coordinates) as the initial offence. Thus, in the case of TFMV, it is possible that the significant repeat pattern represents the same vehicle being targeted again in the exact same location as the initial TFMV. However, the significant repeat pattern may also represent a different vehicle being targeted in the same location as the initial offence.

${ }^{22}$ Similar to TFMV, the significant repeat pattern could represent the same person being victimized a second time at the same location. It could also represent a different person being victimized at the same $x-y$ coordinates as the initial assault.
} 
$636 \%$ increased risk of being burglarized again for 7 days following the initial burglary. The results indicate that there is also a significant repeat victimization pattern present in the Saint John common assault data file with individuals at the same location as a previous common assault being at a $93 \%$ greater risk of also becoming the victim of common assault for 1 week following the initial incident.

In contrast to the other two crime types, the results from the Phase 1 analyses for the Saint John TFMV data file indicate that significant near repeat space-time clustering is present with vehicles within 100 metres of an initial TFMV being at an increased risk of also being targeted for a period of 7 days. Specifically, vehicles within 100 metres of the initial TFMV are at a $67 \%$ increased risk of also being the target of TFMV within the week following the initial incident. The results indicate that there was also a significant repeat victimization pattern found with the risk of a vehicle being targeted at the same location as the initial TFMV being 214\% and 130\% greater for 1 week and 2 weeks following the initial crime, respectively.

Sample size. Based on the Phase 1 results, only three of the nine data files demonstrated significant near repeat space-time clustering. The lack of significant findings for the three common assault data files were not entirely unexpected given the inconsistent results in previous studies that have examined the space-time clustering of violent offences. The lack of significant findings for the Moose Jaw burglary, Moose Jaw TFMV, and Saint John burglary data files, however, was more surprising given that prior studies using burglary data have consistently found significant near repeat space-time patterns. Previous research has found significant near repeat space-time clustering for TFMV as well. 
Insufficient sample size does offer one potential explanation for the nonsignificant findings. Recall that Johnson et al. (2007) found significant space-time patterns of near repeat burglary for ten cities in five different countries. The smallest sample used in Johnson et al.'s study consisted of 951 incidents. In contrast, the sample sizes for the Saint John burglary, Moose Jaw burglary, and Moose Jaw TFMV data files were substantially lower at 221, 148, and 137 incidents, respectively (see Table 7). Thus, to further investigate the impact of sample size on the findings, the Phase 1 analyses were re-run using data from both 2007 and 2008 in order to increase the sample size of each data file.

Table 7. Number of incidents by year for each data file.

\begin{tabular}{llccc}
\hline \multirow{2}{*}{ City } & Crime Type & \multicolumn{3}{c}{ Number of Incidents } \\
\cline { 3 - 4 } & & 2007 & 2008 & All \\
\hline \multirow{2}{*}{ Edmonton } & Burglary & 4031 & 3942 & 7973 \\
& TFMV & 12037 & 10839 & 22876 \\
& Common Assault & 3394 & 3632 & 7026 \\
\hline \multirow{2}{*}{ Moose Jaw } & Burglary & 148 & 195 & 344 \\
& TFMV & 137 & 229 & 366 \\
& Common Assault & 222 & 198 & 420 \\
\hline \multirow{2}{*}{ Saint John } & Burglary & 221 & 239 & 460 \\
& TFMV & 394 & 332 & 726 \\
& Common Assault & 877 & 873 & 1750 \\
\hline
\end{tabular}

The near repeat space-time pattern results for each data file, with the addition of the 2008 data, are presented in Table 8 . Significant near repeat space-time patterns were identified for both the Moose Jaw TFMV and Saint John burglary data files when data from both 2007 and 2008 were included. Specifically, for the 2007-2008 Moose Jaw 
TFMV data file, vehicles within 500 metres of an initial TFMV were at an increased risk of also being targeted for a period of 7 days. For the 2007-2008 Saint John burglary data file, houses within 100 metres of a burglarized house were at an increased risk of also being burglarized for a period of 7 days. Interestingly, significant space-time patterns were also found for Moose Jaw TFMV and Saint John burglary data files when only the 2008 data were included in the analyses, despite the fact that sample size did not increase substantially when going from 2007 to 2008 for those particular data files. The exact near repeat space-time patterns for the 2008 Moose Jaw TFMV and Saint John burglary data files were identical to those found for the 2007-2008 Moose Jaw TFMV and Saint John burglary data files (i.e., 500 metres and 7 days for 2008 Moose Jaw TFMV and 100 metres and 7 days for 2008 Saint John burglary). ${ }^{23}$ Thus, the findings suggest that sample size may not be the real issue for the 2007 Moose Jaw TFMV and Saint John burglary data files, but rather something to do with the 2007 data for those specific data files.

${ }^{23}$ Although additional significant near repeat space-time patterns were found when including both 2007 and 2008 data in the analyses, it was decided that the original 2007 space-time pattern results would be used for subsequent phases. This ensured that the space-time pattern data did not overlap with the data used to assess predictive accuracy, which could have given the prospective hot-spotting technique an unfair advantage over the two traditional mapping methods. 
Table 8. Summary of near repeat space-time pattern results across each year.

\begin{tabular}{|c|c|c|c|c|}
\hline \multirow{2}{*}{ City } & \multirow{2}{*}{ Crime Type } & \multicolumn{3}{|c|}{ Risk (space, time) } \\
\hline & & 2007 & 2008 & All \\
\hline \multirow[t]{3}{*}{ Edmonton } & Burglary & $500 \mathrm{~m}, 1$ week & 700 m, 1 week & 700 m, 1 week \\
\hline & TFMV & 200 m, 1 week & 100 m, week & $---*$ \\
\hline & Common Assault & n.s. & n.s. & n.s. \\
\hline \multirow[t]{3}{*}{ Moose Jaw } & Burglary & n.s. & n.s. & n.s. \\
\hline & TFMV & n.s. & $500 \mathrm{~m}, 1$ week & $500 \mathrm{~m}, 1$ week \\
\hline & Common Assault & n.s. & n.s. & n.s. \\
\hline \multirow[t]{3}{*}{ Saint John } & Burglary & n.s. & 100 m, 1 week & 100 m, 1 week \\
\hline & TFMV & $100 \mathrm{~m}, 1$ week & 100 m, 1 week & $600 \mathrm{~m}, 1$ week \\
\hline & Common Assault & n.s. & n.s. & n.s. \\
\hline
\end{tabular}

*Note. The Edmonton TFMV data file that included crime data from both 2007 and 2008 was too large for the near repeat calculator to analyze.

Adjustment of temporal bands. As previously mentioned, significant near repeat space-time clustering was found for three of the nine data files - Edmonton burglary, Edmonton TFMV, and Saint John TFMV. The exact pattern was found to vary in terms of distance, but the time remained consistent at 1 week across all three data files. Given that all three significant patterns were limited to the first temporal band (i.e., 1 week), it is impossible to determine whether the patterns are actually driven by even shorter temporal increases in risk. To further investigate this issue, the Phase 1 analyses were run again using two shorter temporal bands. Following Youstin et al.'s (2011) methodology, the two shorter temporal bands were set at 1 day and 4 days. ${ }^{24}$

\footnotetext{
${ }^{24}$ Note that although additional analyses were run using the shorter 1-day and 4-day temporal bands, it was decided that the near repeat space-time pattern results found when using the original 7-day temporal band were the ones that would be used to generate the prospective hot-spotting maps in Phases 2 and 3 , the rationale being that this approach is in line with the two studies to date that have actually examined the accuracy of prospective hot-spotting (i.e., Bowers et al., 2004; Johnson, Bowers, et al., 2009).
} 
The results using the 1-day and 4-day temporal bandwidths, as well as the results for the initial 7-day temporal bandwidths, are presented in Table 9. Only one previously non-significant near repeat space-time pattern became significant through the use of shorter temporal bandwidths. Specifically, the Saint John burglary data file demonstrated significant space-time clustering of 100 metres and 4 days and 100 metres and 1 day at the 4-day and 1-day temporal bandwidths, respectively.

In addition, different near repeat space-time patterns were found for the Edmonton burglary and Edmonton TFMV data files when these two new temporal bandwidths were used. Specifically, the Edmonton burglary data file demonstrated significant space-time clustering of 500 metres and 4 days and 500 metres and 1 day at the 4-day and 1-day temporal bandwidths, respectively. The Edmonton TFMV data file demonstrated significant space-time clustering of 300 metres and 4 days and 400 metres and 1 day at the 4-day and 1-day temporal bandwidths, respectively.

Finally, the Saint John TFMV also demonstrated a slightly different near repeat space-time pattern with the 1-day and 4-day temporal bands. The Saint John TFMV data file demonstrated significant space-time clustering of 100 metres and 4 days and 100 metres and 1 day at the 4-day and 1-day temporal bandwidths, respectively. 
Table 9. Near repeat space-time patterns using 1-day, 4-day, and 7-day temporal bandwidths.

\begin{tabular}{llccc}
\hline \multirow{2}{*}{ City } & Crime Type & \multicolumn{3}{c}{ Risk (space, time) } \\
\cline { 3 - 5 } & & 1-day & 4-day & 7-day \\
\hline \multirow{2}{*}{ Edmonton } & Burglary & $500 \mathrm{~m}, 2$ days & $500 \mathrm{~m}, 4$ days & $500 \mathrm{~m}, 1$ week \\
& TFMV & $400 \mathrm{~m}, 2$ days & $300 \mathrm{~m}, 4$ days & $200 \mathrm{~m}, 1$ week \\
& Common Assault & n.s. & n.s. & n.s. \\
\hline Moose Jaw & Burglary & n.s. & n.s. & n.s. \\
& TFMV & n.s. & n.s. & n.s. \\
& Common Assault & n.s. & n.s. & n.s. \\
\hline Saint John & Burglary & $100 \mathrm{~m}, 1$ day & $100 \mathrm{~m}, 4$ days & n.s. \\
& TFMV & $100 \mathrm{~m}, 1$ day & $100 \mathrm{~m}, 4$ days & 100 m, 1 week \\
& Common Assault & n.s. & n.s. & n.s. \\
\hline
\end{tabular}

Note. Just the 2007 data were used for these analyses.

\section{Discussion}

To summarize, the results from Phase 1 indicate that significant near repeat spacetime clustering is present in just three of the nine data files examined: (1) Edmonton burglary, (2) Edmonton TFMV, and (3) Saint John TFMV. As hypothesized, the exact space-time pattern was found to vary from one data file to the next. The results also indicate that significant repeat victimization was present in all of the Edmonton and Saint John data files, but was not present in the three Moose Jaw data files.

The finding that none of the common assault data files exhibited significant near repeat space-time clustering is not surprising given that previous studies have had mixed results in regards to violent offences (e.g., Kikuchi et al., 2010; Ratcliffe \& Rengert, 2008). Of those studies that have found significant space-time patterns for violent 
offences, all have focused on a specific type of violent crime - gun violence (i.e., Haberman \& Ratcliffe, 2012; Ratcliffe \& Rengert, 2008; Wells et al., 2012; Youstin et al., 2011). This of course was not the case in the present study. As well, gun violence is arguably a more serious violent crime than common assault. Thus, crime severity and homogeneity of the crime type are two factors that may impact the significance of near repeat space-time patterns for violent offences. In addition, the boost account suggests that near repeat crime is primarily committed by the same offender. Thus, if the boost account is a viable explanation for near repeat crime, then the Phase 1 results could suggest that common assault is less likely to be the result of repeat offending (i.e., the same offender), which might explain the lack of significant near repeat space-time clustering.

Contrary to what was expected, significant space-time clustering was not found for the Moose Jaw burglary, Moose Jaw TFMV, and Saint John burglary data files. The burglary findings are particularly surprising given that every space-time pattern study to date has found significant near repeat space-time clustering when examining burglary data. Given the relatively large discrepancy between the sample sizes associated with the Moose Jaw and Saint John data files and the sample sizes in other near repeat research (e.g., Johnson et al., 2007), it was thought that insufficient sample size could be a potential explanation for the lack of significant space-time clustering in the current study. To investigate this concern, additional analyses were carried out using data from both 2007 and 2008 in order to increase the sample size of each data file.

Based on the results of these analyses, it is unclear whether the small sample size explains the non-significant near repeat pattern results for the Moose Jaw burglary, 
Moose Jaw TFMV, and Saint John burglary data files. On the one hand, significant near repeat space-time patterns were identified for both the Moose Jaw TFMV and Saint John burglary data files when data from both 2007 and 2008 were included. These significant findings could be the result of the inclusion of additional crime incidents. However, significant space-time patterns were also found for Moose Jaw TFMV and Saint John burglary data files when only the 2008 data were included in the analyses, and 2008 samples sizes were not substantially different from the 2007 samples sizes. Thus, the significant space-time clustering found for the 2007-2008 data may not be the result of a larger sample size, but may simply be explained by the significant 2008 results.

As previously mentioned, significant near repeat space-time clustering was found for just three of the nine data files - Edmonton burglary, Edmonton TFMV, and Saint John TFMV. The exact pattern was found to vary in terms of distance, which was expected, but the time remained consistent at 1 week across all three data files. Given that all three significant patterns were limited to the first temporal band (i.e., 1 week), it was impossible to determine whether the patterns were actually driven by even shorter temporal increases in risk. To investigate this issue, the Phase 1 analyses were run again following Youstin et al.'s (2011) methodology of using two shorter temporal bandwidths - 1-day and 4-day. The use of a 1-day temporal bandwidth also helps identify whether the significant near repeat patterns are likely the result of spree offending by repeat offenders (Youstin et al., 2011). More specifically, spree offending occurs when the same offender commits a high frequency of crime during a relatively short timeframe, typically hours or days (Boba Santos, 2013). 
Based on the results from the additional temporal band analyses, only one previously non-significant near repeat space-time pattern became significant through the use of shorter temporal bands (i.e., Saint John burglary). This finding suggests that this particular space-time clustering may be driven primarily by spree offending. There was also evidence of spree offending in the Edmonton burglary, Edmonton TFMV, and Saint John TFMV data files. These findings offer support for the boost explanation of near repeat crime since spree offending can likely be attributed to the same offender. However, it is also important to note that the terms "near repeat crime" and "spree offending" do not refer to the same phenomenon since there are likely different motivating factors at play (Youstin et al., 2011).

Limitations. There are several limitations to the Phase 1 analyses. However, many, if not all, of these limitations are inherent to any research involving crime data and are not exclusive to near repeat research. In addition, it is important to note that many of the limitations raised here apply to subsequent phases of this dissertation as well. As a result, these data issues are not discussed in detail for every phase.

One major limitation associated with the use of crime data in research is that not all crime is reported to police (Mosher, Miethe, \& Hart, 2011). In addition, reporting rates varying greatly as a function of crime type (e.g., Chaplin, Flatley, \& Smith, 2011). Fortunately for the current study, reporting rates are typically quite high for burglary. For example, when examining the results from the 2010/11 British Crime Survey, Chaplin et al. found reporting rates of $82 \%$ when something was stolen and $79 \%$ when nothing was stolen. Unfortunately, Chaplin et al. also found reporting rates for TFMV and assault involving minor or no injury to be much lower at only $37 \%$ and $34 \%$, respectively. These 
findings suggest that TFMV and common assault were likely underrepresented in the crime data used in the current study. This underreporting of some crime types offers another potential explanation for the lack of significant near repeat space-time patterns for the common assault data files. Alternatively, it could still be that the near repeat phenomenon simply does not apply to common assault, particularly since TFMV has reporting rates comparable to common assault and significant near repeat space-time clustering was still found in the Edmonton TFMV and Saint John TFMV data files.

There are also several aspects of data coding that could have impacted the Phase 1 results. First, certain offences may have involved multiple crime types. For example, residential burglary could also involve assault if the resident was home at the time of the burglary and was assaulted by the offender. In cases such as these it is standard practice in some police agencies to code only the most serious offence (i.e., assault), which would result in the loss of data relevant to the burglary near repeat space-time pattern analyses. Second, the $x-y$ coordinates for some burglaries may not have been precise enough to distinguish near repeat crime from repeat crime. For example, if two different apartment units in the same building were burglarized a few days apart it is possible that they were coded as having the same $x-y$ coordinates, thus suggesting they represent repeat crime when they actually represent near repeat crime. Similarly, two TFMVs occurring in the same parking lot may also have been coded with the same $x-y$ coordinates, thus representing repeat rather than near repeat crime. This coding issue could have resulted in an overrepresentation of repeat crime in the data files, which would increase the chances of finding a significant repeat victimization pattern, and an underrepresentation of near repeat patterns of crime (the Phase 1 analyses revealed significant repeat victimization 
patterns in all of the Edmonton and Saint John data files). It is also important to note that the accuracy of space-time analyses is dependent on geocoding quality, which could vary from one police agency to the next and from one police officer to the next (Hart \& Zandbergen, 2012).

Finally, the Phase 1 results were also limited by the fact that it is not always possible to determine an exact occurrence date for a crime, which could impact the accuracy of space-time clustering analyses. For example, if a resident is away on vacation for a week and discovers the burglary upon their return then their house could have been burglarized at any point during the 7-day timeframe that they were out of town. It is important to note, however, that inaccurate occurrence dates are more of a concern for offences where the victim would likely not have been present for the offence (e.g., burglary and TFMV) rather than for offences where the victim would have been present (e.g., common assault). There were also differences in terms of how the occurrence date was represented across the three police agencies, which could limit the extent to which direct comparisons of space-time patterns can be made across geographic regions. ${ }^{25}$ However, it is important to note that these crime data issues are inherent to any police database. Thus, the results presented in Phase 1 mimic those that any crime analyst would find when examining near repeat space-time clustering using police data.

\section{Phase 2 - Generating and Assessing Prospective Risk Surfaces}

Recall that Phase 2 involved using the time and distance over which crime clusters (as found in Phase 1) to generate prospective risk surfaces for the various crime types and cities. The goal of Phase 2 was to determine whether the prospective hot-

\footnotetext{
${ }^{25}$ See footnote 15 for a description of how the occurrence date varied across the three police agencies.
} 
spotting risk surfaces outperformed traditional hotspot mapping methods in terms of predictive accuracy.

\section{Method}

Data. The data used in Phase 2 were similar to the data used in Phase 1. However, given that it is the prospective hot-spotting technique that is of interest to the current study, only the three data files where significant near repeat space-time clustering was found in Phase 1 were used in Phase 2 (i.e., Edmonton burglary, Edmonton TFMV, and Saint John TFMV). The remaining six data files were not included in this phase. In addition, only crimes that occurred between January 1 and December 31, 2008, were used in Phase 2 so that the data used to generate and test the maps did not overlap with the data used to determine space-time clustering. The data were broken down into three blocks of time: (1) January, February, and March, (2) May, June, and July, and (3) September, October, and November. For each of the three blocks of time, the first two months were used to generate the risk surfaces and the following month was used to assess their predictive accuracy. ${ }^{26}$ Using three different blocks of time in the current study will help determine whether the findings are consistent across multiple development and test samples.

\footnotetext{
${ }^{26}$ Two months was selected as the timeframe used to generate the maps because it follows the methodology used by Bowers et al. (2004) for their traditional hot-spotting maps. Bowers et al., however, opted to use just two days and one week to assess predictive accuracy. Given that the sample sizes in the current study were smaller than the burglary sample used by Bowers et al., particularly for the Saint John TFMV data file, it was decided that predictive accuracy would be assessed using one month of crime data to ensure sufficient test samples. Given that hotspots shift over time, it was possible that using a longer time period (i.e., one month) to assess map accuracy, rather than a shorter time period (i.e., two days or one week), could negatively impact map performance. However, it would have impacted the various hotspot mapping techniques equally. As well, note that Phase 3 further examined the specific timeframe used to assess predictive accuracy by using both two weeks' and two months' worth of crime data. Also note that although not used in the Phase 2 analyses, data from April, August, and December were used in the Phase 3 analyses as a result of Phase 3 relying on two months, rather than one month, to assess predictive accuracy.
} 
Procedure. As previously mentioned, Phase 2 involved using the distance and time over which crime was found to be communicable in Phase 1 to generate risk surfaces. In addition to prospective hot-spotting, crime maps were also generated using two traditional methods of hot-spotting: (1) kernel density estimation (KDE) and (2) nearest neighbour hierarchical clustering (Nnh). Hotspot maps were generated for the three data files that demonstrated significant near repeat space-time clustering in Phase 1 (i.e., Edmonton burglary, Edmonton TFMV, and Saint John TFMV). Thus, in total, nine hotspot maps were generated for the two traditional mapping techniques (three maps for each of the three blocks of time) and 18 hotspot maps were generated for the prospective mapping methods. ${ }^{27}$ Once all maps had been generated, the accuracy of each mapping technique was assessed and compared to the other two methods.

Data preparation. Before the hotspot maps could be generated using the various mapping techniques, the data had to be properly formatted. The data preparation procedure involved the following steps:

1. First, using Microsoft Excel, where the data were stored, each of the three data files were converted to a dBase (.dbf) format. Recall that the data files had already been examined to ensure that each record included $x-y$ coordinates for the offence location and the date on which the offence was reported.

2. Next, the three data files were split based on offence date and saved as separate .dbf files. More specifically, crimes that occurred between January 1 and February 29, 2008, May 1 and June 30, 2008, and September 1 and October 31, 2008, were sorted into three separate data files used to generate the maps, whereas crimes that

\footnotetext{
${ }^{27}$ The reason why 18 maps were generated for the prospective hot-spotting technique, instead of just nine, is explained shortly.
} 
occurred between March 1-31, 2008, July 1-31, 2008, and November 1-30, 2008, were sorted into three separate data files used to assess predictive accuracy. Crimes that did not occur within this period were not included in the data files for Phase 2. For the prospective hot-spotting approach, crimes that occurred between February 23-29, 2008, June 24-30, 2008, and October 25-31, 2008, were also used to generate the maps since the prospective hot-spotting approach relied on an empirically derived temporal bandwidth based on the Phase 1 results (i.e., 7 days).

3. Next, the maps were generated using three specific hot-spotting methods, each having their own procedure.

Once the data files were split based on offence date (i.e., step 2 above), it became clear that sample size would likely be problematic for the Saint John TFMV Phase 2 analyses. Specifically, Saint John TFMV generation samples ranged from 20 to 76 crimes for the hotspot mapping techniques with 2-month temporal bandwidths and from 1 to 14 for the prospective hot-spotting method with a 7-day temporal bandwidth. It was decided that analyses would still be conducted using the smaller Saint John TFMV samples, but these analyses were primarily intended to demonstrate what impact (if any) sample size had on the sorts of analyses being conducted. 
Kernel density estimation (moving window) maps. Kernel density estimation (KDE) was selected as one of the two traditional hot-spotting methods to examine in the current study because it is currently the most common method of generating retrospective hotspot maps (Johnson et al., 2005). In addition, Bowers et al.'s (2004) prospective mapping technique is actually a modified version of KDE.

In the current study, CrimeStat (v 3.3) was used to generate the risk surfaces based on the KDE technique. As mentioned previously, CrimeStat is a software program that was developed for the spatial analysis of crime site locations (Levine, 2010). CrimeStat allows the user to accomplish a wide range of analytical tasks. However, for this part of the dissertation, only the interpolation routine in CrimeStat was used. The process of developing risk surfaces using KDE involved several steps. These are outlined by Levine (2010) as follows:

1. Each data file used to generate the hotspot maps, which consisted of $x-y$ coordinates for each crime site location as well as the day on which each crime was reported, was read separately into CrimeStat and a rectangular grid was overlaid on top of the study area. The size of the grid was specific to the region being studied, therefore two different grids needed to be generated for the two cities examined in Phase 2 (i.e., Edmonton and Saint John). Specifically, for each geographic region, the $x-y$ coordinates of the most south-west part of the study area served as the coordinates for the bottom-left corner of the rectangle, whereas the $x-y$ coordinates of the most north-east part of the study area served as the coordinates for the rectangle's upper-right corner. Following Bowers et al.'s (2004) methodology, the cell size for each grid was set at $50 \mathrm{~m}$. 
2. Next, CrimeStat's interpolation routine ${ }^{28}$ was run for each of the three data files used to generate the maps. In order to run this routine, the user must specify a variety of different parameters. First, a single kernel density estimate was selected since the data consisted of single crime site locations. Second, a quartic method of interpolation was selected, which is very similar to the quartic function used by Bailey and Gatrell (1995). The specific quartic formula used by CrimeStat to generate the hotspot maps takes the following form:

Outside the specified radius, $h: \quad g\left(x_{j}\right)=0$

Within the specified radius, $h: \quad g\left(x_{j}\right)=\sum\left\{\left[\frac{3}{h^{2} * \pi}\right] *\left[1-\frac{d_{i j}^{2}}{h^{2}}\right]^{2}\right\}$

where $g\left(x_{j}\right)$ equals the risk intensity value for cell $x_{j}, d_{i j}$ equals the distance between a crime site location and any reference point in the region, and $h$ equals the radius of the search area (i.e., bandwidth).

Third, a fixed interval bandwidth was selected. As recommended by Ratcliffe (2000), the specific interval unit used (i.e., $h$ ) was 200 metres. Finally, probabilities were selected as the output units.

3. KDE maps produced by CrimeStat's interpolation routine can be saved in a variety of formats. In the current study, the output (i.e., the generated maps) was saved as shape (.shp) files, which can be viewed within ArcView. These three steps were repeated for each data file until all nine KDE maps had been produced.

28 The CrimeStat interpolation routine is a set of tools that involve the generalization of incident locations to an entire area by assigning density estimates (Levine, 2010). 
Nearest neighbour hierarchical clustering maps. As mentioned above, a variety of clustering techniques are available to produce hotspot maps. Thus, it was decided that nearest neighbour hierarchical clustering (Nnh) would be included in the current study as the second traditional hot-spotting method. CrimeStat was again used to generate risk surfaces based on the Nnh technique. Specifically, the 'hot spot' analysis routine in CrimeStat was used to generate the Nnh maps. The process of developing risk surfaces using the Nnh method involved several steps. These are outlined by Levine (2010) as follows:

1. Each data file used to generate the hotspot maps was read separately into CrimeStat and a rectangular grid was overlaid on top of the study (see Step 1 as described in the KDE section for more detail).

2. Next, CrimeStat's 'hot spot' analysis routine was run for each data file. In order to run this routine, the user must select from several different options that are available as well as specify a variety of different parameters. In the current study, the nearest neighbour hierarchical clustering option was first selected (the 'hot spot' analysis routine is capable of running a variety of different clustering methods). Second, under type of search radius, the fixed distance option was selected. Ideally, a radius of 200 metres would be specified, which is identical to the search area radius used when producing the KDE maps. However, due to the relatively small sample size of the data files, particularly of the three Saint John TFMV data files, clusters would likely not be found at a radius of 200 metres. Given that 0.5 miles $(\approx 800$ metres $)$ is the maximum recommended radius distance for crime incidents (Levine, 2010), the radius was increased to 800 
metres. Third, a minimum points per cluster of 5 was selected (the default recommended value is 10 , but again, this value was lowered to 5 as a result of the relatively small sample sizes used to generate the maps). Finally, the number of Monte Carlo simulations for the current study was set at $100 .^{29}$

3. Nnh maps produced by CrimeStat's 'hot spot' analysis routine can be saved in a variety of formats. In the current study, the outputs were again saved as .shp files for the purpose of viewing the generated maps within ArcView. In addition, CrimeStat provides the output as both ellipses and convex hulls. The convex hull maps were used in the current study since their clusters are more defined than the ellipses, which would make them more useful from a policing standpoint (Levine, 2010). These steps were repeated for each data file until all nine Nnh maps had been produced.

Prospective hotspot mapping (modified moving window) maps. Finally, risk surfaces for the prospective hotspot mapping technique, which is the mapping method of most interest in the current study, were produced by using the interpolation routine in CrimeStat, which simulated the ProMap approach originally developed by Bowers et al. (2004). The process of developing the prospective hotspot maps was very similar to the KDE approach except that the temporal bandwidth and spatial bandwidth were both determined by the space-time pattern results found in Phase 1 (i.e., both bandwidths were

\footnotetext{
${ }^{29}$ Although the parameters for the Nnh approach could have been adjusted for each data file based on sample size, it was decided to keep the parameters consistent across all nine data files. This ensured that more direct comparisons could be made across the three blocks of time for each of the three data files (i.e., Edmonton burglary, Edmonton TFMV, and Saint John TFMV) and even across crime types (i.e., burglary and TFMV) and geographic regions (i.e., Edmonton and Saint John). As well, the results did not show the convex hulls to be overly large in area for the data files with the larger sample sizes (such as the Edmonton TFMV data files) and as a result, the 800 -metre radius, as well as the minimum 5 points per cluster, were not viewed as problematic.
} 
empirically derived). As well, the prospective hot-spotting approach involved applying a temporal weighting (see number 4 below), whereas the KDE approach did not. The procedure for developing the prospective hot-spotting maps is as follows:

1. Each data file used to generate the hotspot maps was read separately into CrimeStat and a rectangular grid was overlaid on top of the study area (see Step 1 as described in the KDE section for more detail).

2. Next, identical to the KDE approach, CrimeStat's interpolation routine was run for each of the data files used to generate the maps. As previously mentioned in the KDE section, the user must specify a variety of different parameters in order to run this routine. First, a single kernel density estimate was selected since the data consisted of single crime site locations. Second, a quartic method of interpolation was selected, which is very similar to the quartic function used by Bailey and Gatrell (1995). The specific quartic formula used by CrimeStat to generate the hotspot maps takes the following form:

Outside the specified radius, $h: \quad g\left(x_{j}\right)=0$

Within the specified radius, $h: \quad g\left(x_{j}\right)=\sum\left\{\left[\frac{3}{h^{2} * \pi}\right] *\left[1-\frac{d_{i j}^{2}}{h^{2}}\right]^{2}\right\}$ where $g\left(x_{j}\right)$ equals the risk intensity value for cell $x_{j}, d_{i j}$ equals the distance between a crime site location and any reference point in the region, and $h$ equals the radius of the search area (i.e., bandwidth).

Third, a fixed interval bandwidth was selected. In contrast to the KDE approach, the spatial bandwidth used in the prospective hotspot mapping technique was empirically derived. More specifically, the spatial bandwidth was determined based on the distance over which the crime data had been shown to be 
communicable in Phase 1. Based on the results presented in Table 6, the interval unit (i.e., $h$ ) specified in CrimeStat for each data file was as follows: Edmonton burglary $=500$ metres, Edmonton TFMV $=200$ metres, and Saint John TFMV = 100 metres.

3. Recall that the prospective hot-spotting approach utilizes spatial and temporal bandwidths that are both empirically derived. Although the CrimeStat interpolation routine does not allow the user to specify a temporal bandwidth, the temporal bandwidth was implemented in the current study simply by restricting the amount of crime data used to generate the prospective hot-spotting maps based on the distance over which crime was found to be communicable in Phase $1 .^{30}$ More specifically, the amount of crime data used to generate the prospective hot-spotting maps was limited to 7 days for Edmonton burglary, Edmonton TFMV, and Saint John TFMV, as found in Phase 1. Although an empirically derived temporal bandwidth has been proposed as a strength of the prospective hot-spotting technique, it could actually put this approach at a disadvantage in the current study for the data files with smaller sample sizes. As well, the 7-day temporal bandwidth determined by the Phase 1 results in the current study is much smaller than that found in other prospective hot-spotting research (Bowers et al. (2004) and Johnson, Summers, and Pease (2009), for example, both obtained empirically derived temporal bandwidths of two months). As a result, it was decided that the Phase 2 analyses would be run twice for the prospective hotspotting method: once with the empirically derived 7-day temporal bandwidth and

\footnotetext{
${ }^{30}$ As previously mentioned, the duration of crime data used to generate the hotspot maps can be thought of as the temporal bandwidth, even if a temporal bandwidth is not explicitly stated in the formula used to determine risk.
} 
once with the same 2-month temporal bandwidth used for the KDE and Nnh maps. The differences in predictive accuracy between the two temporal bandwidths would then be compared.

4. Bowers et al.'s (2004) modified moving window formula also considers time as a weighting variable, with crimes occurring more recently being weighted more heavily than crimes occurring less recently. Thus, time was used as a weighting variable in the current study as well by selecting that option within CrimeStat's interpolation routine. Finally, probabilities were selected as the output units.

5. As mentioned in the KDE section, the maps produced by CrimeStat's interpolation routine can be saved in a variety of formats. In the current study, the outputs were again saved as .shp files for the purposes of generated maps within ArcView. These three steps were repeated for each data file until all 18 prospective hot-spotting maps had been produced (three data files $\mathrm{x}$ three blocks of time $\mathrm{x}$ two temporal bandwidths).

Assessing accuracy. Once all 36 hotspot maps had been generated, the crimes in the test samples were plotted onto the maps in ArcView to determine the predictive accuracy of each method (i.e., did the predicted hotspots accurately capture future crime?). Chainey et al.'s (2008) predictive accuracy index (PAI) was used to assess map accuracy. PAI was selected because it allows for comparisons across different crime types and geographic regions.

Given that hit rate and area percentage must be determined before PAI can be calculated $(\mathrm{PAI}=$ hit rate/area percentage $)$, these two measures were also considered (recall that hit rate is the percentage of future crimes falling within the predicted hotspots, 
whereas area percentage is the proportion of the entire study area that is covered by predicted hotspots). In the current study, hit rate and area percentage were determined through tools available in ArcView. In Bowers et al.'s (2004) study, hotspots were defined as the $20 \%$ of total cells with the highest risk intensity values. However, in the Phase 2 analyses, this $20 \%$ guideline did not need to be implemented as the hotspots always covered $20 \%$ or less of the total study area, regardless of the mapping technique used to generate the map. ${ }^{31}$

Recall that hotspot maps were generated across three blocks of time for each data file (i.e., Edmonton burglary, Edmonton TFMV, and Saint John TFMV). These three blocks of time allowed for the calculation of means and $95 \%$ confidence intervals (CIs) for hit rate, area percentage, and PAI. Once PAI values, means, and 95\% CIs had been calculated for all of the mapping methods, these values were visually compared across each crime type and geographic region to determine which method is the most effective at predicting future crime for each of the three blocks of time examined. More specifically, when comparing PAI means across data files, the 95\% CIs were used to help determine whether differences were meaningful (overlapping 95\% CIs suggest the difference is not significant). Given that the means and 95\% CIs were based on an extremely small sample size (i.e., 3), statistical tests to compare the means were not conducted.

\footnotetext{
${ }^{31}$ The two study areas examined in the current study were much larger than the one examined by Bowers et al. (2004), which likely explains why the $20 \%$ guideline did not need to be implemented (Bowers et al. examined a study area of $22.70 \mathrm{~km}^{2}$ compared to $948.10 \mathrm{~km}^{2}$ and $255.35 \mathrm{~km}^{2}$ for Edmonton and Saint John, respectively). As well, the crime incidents in Bowers et al.'s study were more spread out across the entire study area, whereas the two study areas examined in the current study had more area where crime did not occur.
} 
Note that the approach described here is consistent with previous research. In most prospective hot-spotting research, visual inspection of the results (in a purely subjective fashion) is the norm (e.g., Bowers et al., 2004). However, some researchers have gone as far as I have and compared 95\% CIs to get a sense for whether differences between predictive accuracy measures are meaningful (e.g., Chainey et al., 2008).

Hypotheses. Based on the results obtained by Bowers et al. (2004), it was expected that the risk surfaces produced using the prospective hotspot mapping technique would have greater predictive accuracy (e.g., higher PAI values) than the risk surfaces produced by the two traditional hot-spotting techniques. It was also expected that this finding would be consistent across all three data files (i.e., Edmonton burglary, Edmonton TFMV, and Saint John TFMV). In addition, this finding was expected to be robust with the prospective hot-spotting method outperforming the other two mapping techniques regardless of the block of time used to generate the maps (i.e., findings would be consistent across all three blocks of time). Finally, based on previous research (e.g., Chainey et al., 2008), it was hypothesized that KDE would consistently outperform Nnh.

\section{Results}

For illustrative purposes, four of the 36 maps generated for Phase 2 are presented in Figures 6, 7, 8, and 9. These figures are the maps generated for each of the four mapping techniques (i.e., KDE, Nnh, and prospective hot-spotting using both a 7-day and 2-month bandwidth) for the Edmonton burglary data file when crime data from January and February, 2008, were used to generate the maps and data from March was used to assess predictive accuracy. Note that for the KDE and two prospective hot-spotting 
techniques the maps are actually zoomed in versions since it was not possible to see the risk intensity shading when zoomed out, as a result of the size of the study area. The Nnh maps, however, present the full study area. Additional map examples are provided in Appendix B. ${ }^{32}$

\footnotetext{
${ }^{32}$ Note that not all 36 Phase 2 maps are provided in Appendix B. Instead, the goal was to simply provide a sufficient number of map examples for illustrative purposes rather than all of the maps that were generated. Thus, one map from each geographic location and crime type (i.e., Edmonton burglary, Edmonton TFMV, and Saint John TFMV) for each of the four hot-spotting methods is provided.
} 


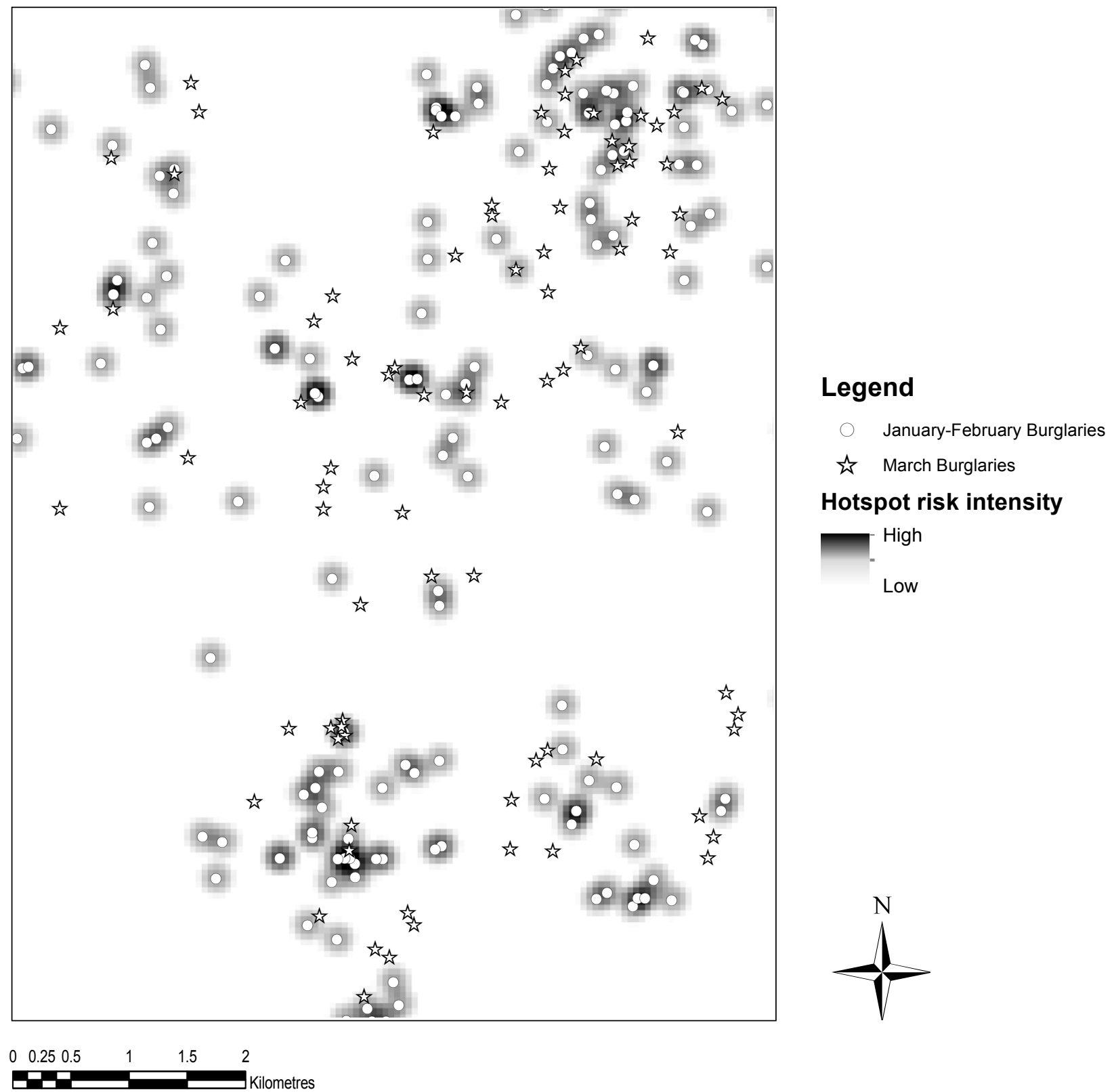

Figure 6. Phase 2: KDE map for Edmonton burglary January-February. 


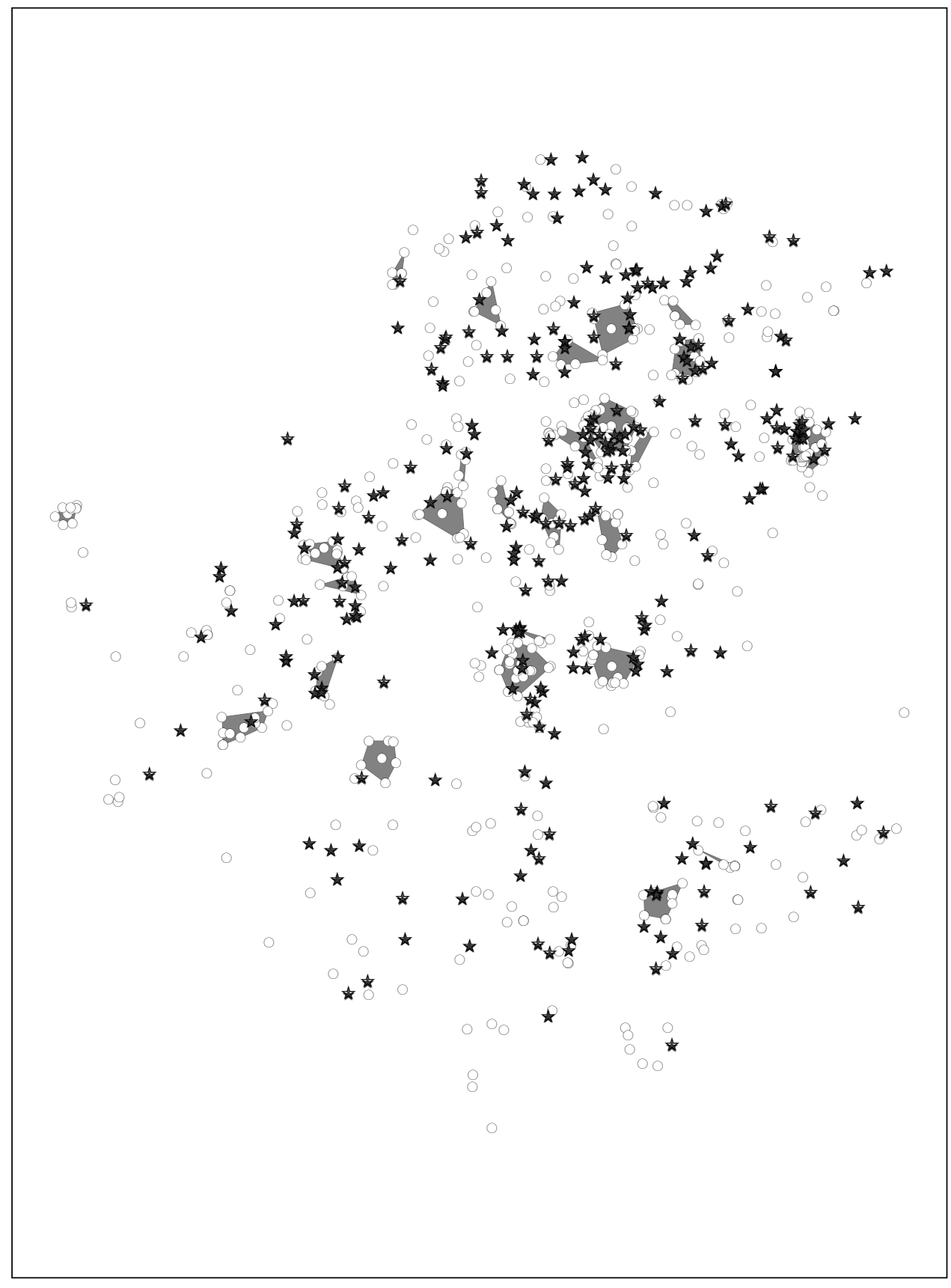

\section{Legend}

January-February Burglaries

$\star \quad$ March Burglaries

Nnh Hotspots

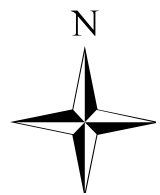

Kilometres

Figure 7. Phase 2: Nnh map for Edmonton burglary January-February. 


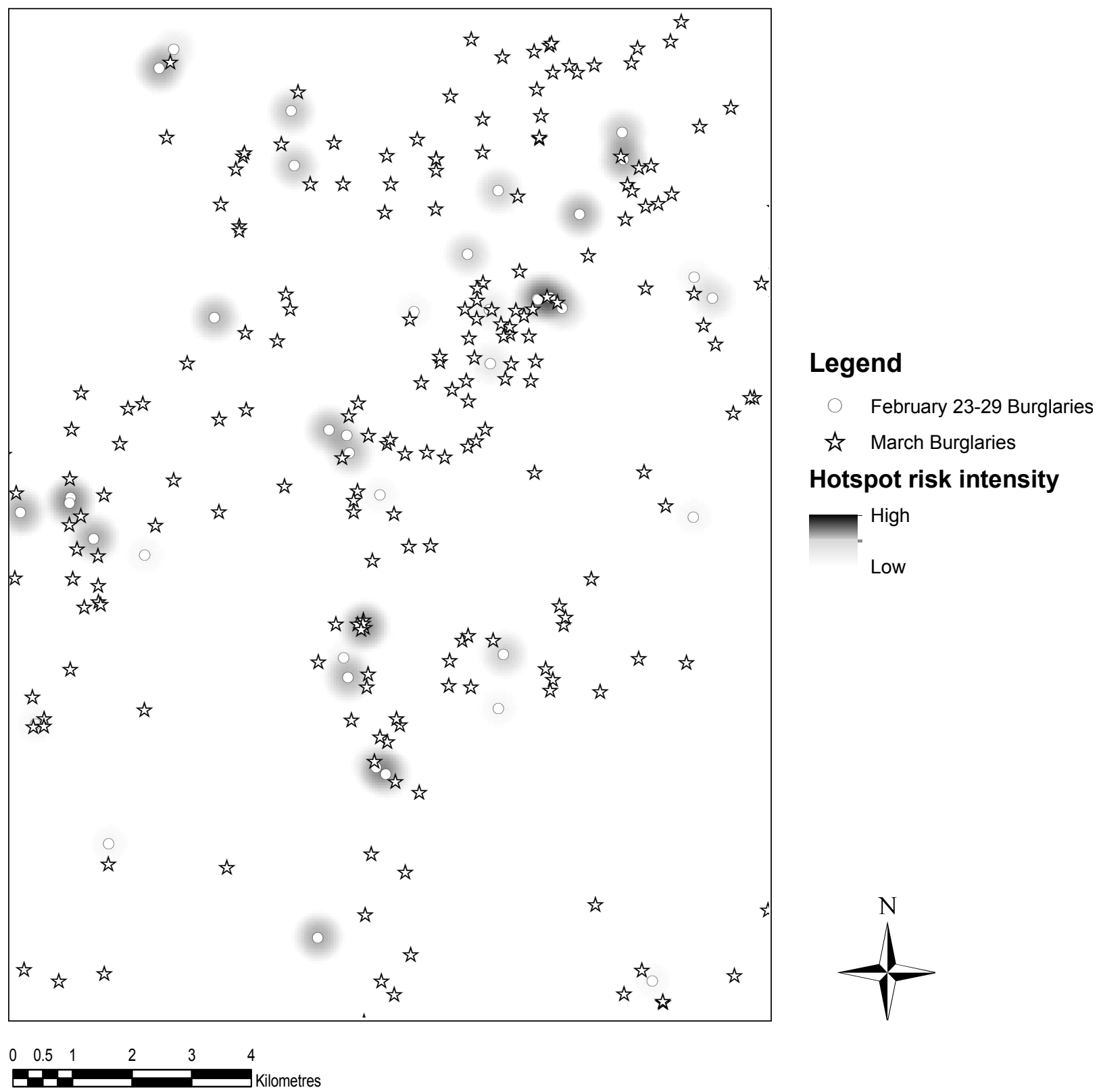

Figure 8. Phase 2: Prospective hot-spotting map (7-day temporal bandwidth) for Edmonton burglary February 23-29. 


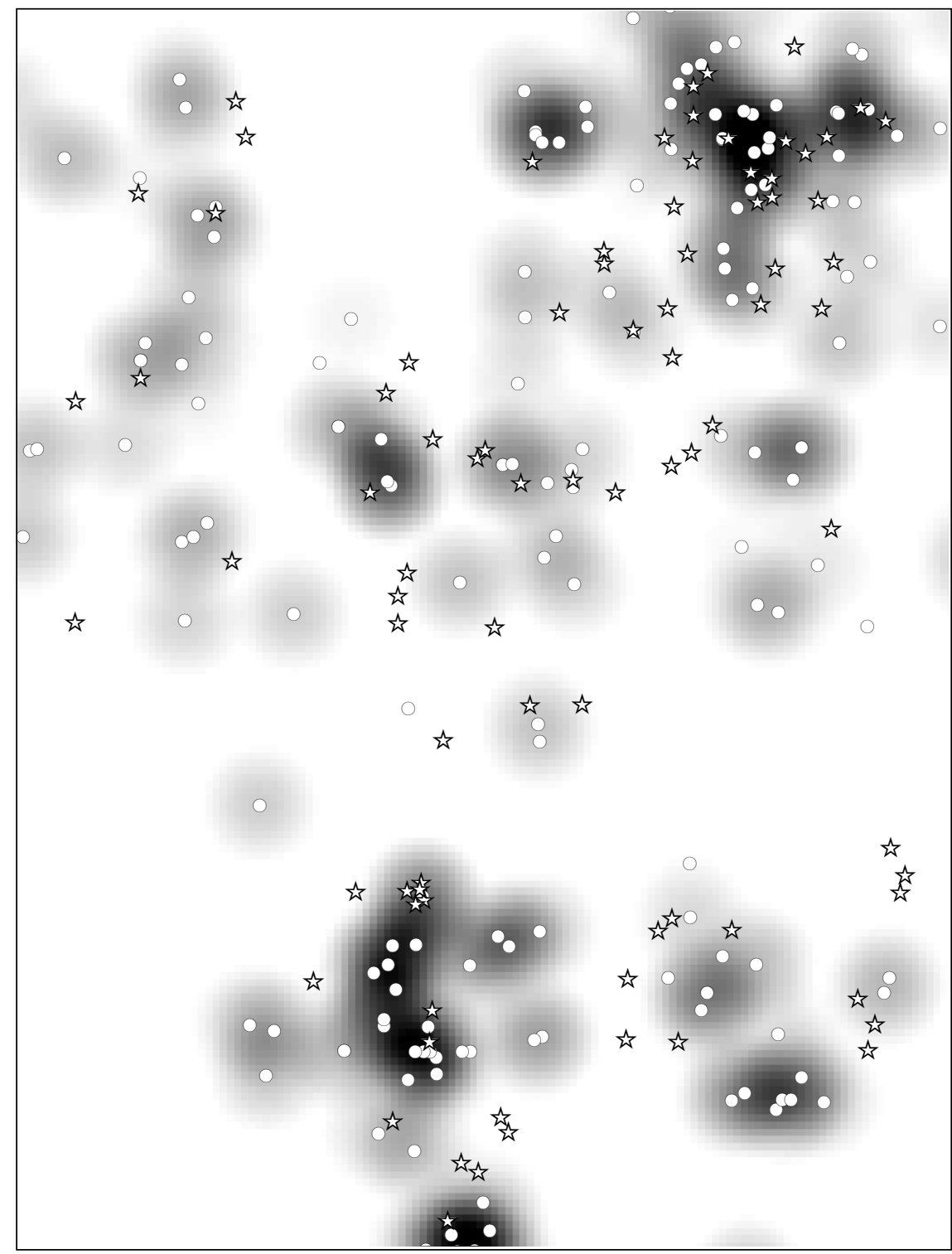

\section{Legend}

January-February Burglaries

is March Burglaries

\section{Hotspot risk intensity}

High

Low

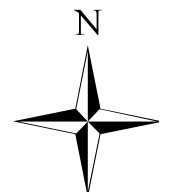

$0 \quad 0.250 .5$

1.5

Kilometres

Figure 9. Phase 2: Prospective hot-spotting map (2-month temporal bandwidth) for Edmonton burglary January-February. 
The predictive accuracy results for all 36 maps generated in Phase 2 are presented in Table 10. Although additional information is presented in Table 10, the columns of particular interest to the Phase 2 results are the hit rate (i.e., the percentage of future crimes falling within the predicted hotspots), area percentage (i.e., the proportion of the entire study area that is covered by the predicted hotspots), and PAI (i.e., a ratio of hit rate over area percentage), as they represent the three measurements examined in the current study to assess predictive accuracy.

Typically, police agencies would prefer higher hit rates and lower area percentages. Also, as previously mentioned, a PAI value of 1 indicates that the hit rate and the area percentage are the same (e.g., $50 \%$ of future crimes occurred in $50 \%$ of the total area). A PAI value greater than 1 indicates that the percentage of future crimes found in the predicted hotspots was greater than the percentage of the total area that the hotspots occupied (e.g., finding $80 \%$ of future crimes in $40 \%$ of the total area would result in a PAI value of 2). Thus, higher PAI values in Table 10 indicate greater efficiency (i.e., a greater percentage of predicted crimes occur in a smaller proportion of the total study area). The predictive accuracy results will now be discussed in more detail for each hotspot mapping technique across all of the data files examined.

As mentioned previously, the sample sizes for the Saint John TFMV data files used to generate the hotspot maps were small, particularly for the prospective hotspotting maps with the 7-day temporal bandwidth. As expected, the Phase 2 analyses suggest that these small sample sizes are problematic when attempting to generate hotspot maps. As shown in Table 10, regardless of the hotspot mapping approach examined, the Saint John TFMV PAI values were highly inconsistent across the three 
blocks of time. Specifically, the Saint John TFMV PAI values ranged from 2.95 to 44.84 $(M=25.10 ; S D=21.05 ; 95 \% \mathrm{CI}[-4.07,54.27])$ for $\mathrm{KDE}$, from 5.02 to $62.17(M=$ 86.46; $S D=95.92 ; 95 \%$ CI $[-46.48 ; 219.39])$ for Nnh, from 0 to $44.17(M=14.72 ; S D=$ $25.50 ; 95 \%$ CI $[-20.62,50.06])$ for prospective hot-spotting with a 7-day temporal bandwidth, and from 6.78 to $40.68(M=24.47 ; S D=16.99 ; 95 \%$ CI $[0.91,48.02])$ for prospective hot-spotting with a 2-month temporal bandwidth. The highly inconsistent predictive accuracy findings across the three blocks of time for the Saint John TFMV data files suggest that the Phase 2 results are highly sensitive to small sample sizes used to generate the hotspot maps. Thus, it was decided that the results from the Saint John TFMV analyses would not be used to compare the different hot-spotting approaches being examined in Phase 2. These results will not be discussed any further in the Results section. 
Table 10. Predictive accuracy for the Phase 2 maps.

\begin{tabular}{|c|c|c|c|c|c|c|c|c|c|c|c|c|}
\hline $\begin{array}{l}\text { Generation } \\
\text { Sample }\end{array}$ & $\begin{array}{c}\text { Test } \\
\text { Sample }\end{array}$ & $\begin{array}{c}\text { Crimes in } \\
\text { Generation } \\
\text { Sample }\end{array}$ & $\begin{array}{l}\text { Test Sample } \\
\text { Crimes in } \\
\text { Hotspots }\end{array}$ & $\begin{array}{c}\text { Total Test } \\
\text { Sample } \\
\text { Crimes }\end{array}$ & $\begin{array}{c}\text { Hit Rate } \\
(\%)\end{array}$ & $\begin{array}{l}\text { Hit Rate } \\
\text { Mean } \\
{[95 \% \text { CI }]}\end{array}$ & $\begin{array}{c}\text { Hotspot } \\
\text { Area } \\
\left(\mathrm{km}^{2}\right)\end{array}$ & $\begin{array}{c}\text { Total } \\
\text { Study Area } \\
\left(\mathrm{km}^{2}\right)\end{array}$ & Area \% & $\begin{array}{c}\text { Area \% } \\
\text { Mean } \\
{[95 \% \text { CI }]}\end{array}$ & PAI & $\begin{array}{c}\text { PAI Mean } \\
{[95 \% \text { CI] }}\end{array}$ \\
\hline \multicolumn{13}{|c|}{ KDE EdBurg } \\
\hline JanFeb & Mar & 497 & 95 & 291 & 32.65 & \multirow{3}{*}{$\begin{array}{c}36.81 \\
(31.40 \\
42.22)\end{array}$} & 43.62 & 948.10 & 4.60 & \multirow{3}{*}{$\begin{array}{r}5.68 \\
(4.36 \\
6.99)\end{array}$} & 7.10 & \multirow{3}{*}{$\begin{array}{c}6.54 \\
(5.85 \\
7.22)\end{array}$} \\
\hline MayJun & Jul & 701 & 170 & 421 & 40.38 & & 60.55 & 948.10 & 6.39 & & 6.32 & \\
\hline SeptOct & Nov & 672 & 144 & 385 & 37.40 & & 57.33 & 948.10 & 6.05 & & 6.19 & \\
\hline \multicolumn{13}{|c|}{ KDE EdTFMV } \\
\hline JanFeb & Mar & 1411 & 471 & 818 & 57.58 & \multirow{3}{*}{$\begin{array}{c}62.30 \\
(56.47 \\
68.14)\end{array}$} & 92.91 & 948.10 & 9.80 & \multirow{3}{*}{$\begin{array}{l}12.01 \\
(9.31 \\
14.71)\end{array}$} & 5.88 & \multirow{3}{*}{$\begin{array}{c}5.25 \\
(4.44 \\
6.06)\end{array}$} \\
\hline MayJun & Jul & 2024 & 631 & 961 & 65.66 & & 120.66 & 948.10 & 12.73 & & 5.16 & \\
\hline SeptOct & Nov & 2083 & 624 & 980 & 63.67 & & 127.90 & 948.10 & 13.49 & & 4.72 & \\
\hline \multicolumn{13}{|c|}{ KDE SJTFMV } \\
\hline JanFeb & Mar & 20 & 8 & 22 & 36.36 & \multirow{3}{*}{$\begin{array}{l}38.23 \\
(-4.56 \\
81.02)\end{array}$} & 2.07 & 255.35 & 0.81 & \multirow{3}{*}{$\begin{array}{r}2.06 \\
(0.55 \\
3.57)\end{array}$} & 44.84 & \multirow{3}{*}{$\begin{array}{r}25.10 \\
(-4.07 \\
54.27)\end{array}$} \\
\hline MayJun & Jul & 73 & 3 & 36 & 8.33 & & 7.21 & 255.35 & 2.82 & & 2.95 & \\
\hline SeptOct & Nov & 76 & 14 & 20 & 70.00 & & 6.50 & 255.35 & 2.55 & & 27.50 & \\
\hline \multicolumn{13}{|c|}{ Nnh EdBurg } \\
\hline JanFeb & Mar & 497 & 52 & 291 & 17.87 & \multirow{3}{*}{$\begin{array}{c}21.74 \\
(15.11 \\
28.36)\end{array}$} & 13.73 & 948.10 & 1.45 & \multirow{3}{*}{$\begin{array}{r}2.35 \\
(1.14 \\
3.57)\end{array}$} & 12.34 & \multirow{3}{*}{$\begin{array}{c}9.73 \\
(6.60 \\
12.86)\end{array}$} \\
\hline MayJun & Jul & 701 & 114 & 421 & 27.08 & & 30.39 & 948.10 & 3.21 & & 8.45 & \\
\hline SeptOct & Nov & 672 & 78 & 385 & 20.26 & & 22.85 & 948.10 & 2.41 & & 8.40 & \\
\hline \multicolumn{13}{|c|}{ Nnh EdTFMV } \\
\hline JanFeb & Mar & 1411 & 362 & 818 & 44.25 & \multirow{3}{*}{$\begin{array}{c}47.23 \\
(42.88 \\
51.58)\end{array}$} & 49.42 & 948.10 & 5.21 & \multirow{3}{*}{$\begin{array}{c}6.93 \\
(4.79 \\
9.07)\end{array}$} & 8.49 & \multirow{3}{*}{$\begin{array}{r}7.00 \\
(5.21 \\
8.79)\end{array}$} \\
\hline MayJun & Jul & 2024 & 451 & 961 & 46.93 & & 70.04 & 948.10 & 7.39 & & 6.35 & \\
\hline SeptOct & Nov & 2083 & 495 & 980 & 50.51 & & 77.68 & 948.10 & 8.19 & & 6.17 & \\
\hline
\end{tabular}




\begin{tabular}{|c|c|c|c|c|c|c|c|c|c|c|c|c|}
\hline $\begin{array}{l}\text { Generation } \\
\text { Sample }\end{array}$ & $\begin{array}{c}\text { Test } \\
\text { Sample }\end{array}$ & $\begin{array}{l}\text { Crimes in } \\
\text { Generation } \\
\text { Sample }\end{array}$ & $\begin{array}{l}\text { Test Sample } \\
\text { Crimes in } \\
\text { Hotspots }\end{array}$ & $\begin{array}{l}\text { Total Test } \\
\text { Sample } \\
\text { Crimes }\end{array}$ & $\begin{array}{c}\text { Hit Rate } \\
(\%)\end{array}$ & $\begin{array}{l}\text { Hit Rate } \\
\text { Mean } \\
{[95 \% \mathrm{CI}]}\end{array}$ & $\begin{array}{l}\text { Hotspot } \\
\text { Area } \\
\left(\mathrm{km}^{2}\right)\end{array}$ & $\begin{array}{c}\text { Total } \\
\text { Study Area } \\
\left(\mathrm{km}^{2}\right)\end{array}$ & Area \% & $\begin{array}{c}\text { Area \% } \\
\text { Mean } \\
{[95 \% \text { CI] }}\end{array}$ & PAI & $\begin{array}{r}\text { PAI Mean } \\
\text { [95\% CI] }\end{array}$ \\
\hline \multicolumn{13}{|c|}{ Nnh SJTFMV } \\
\hline JanFeb & Mar & 20 & 9 & 22 & 40.91 & \multirow{3}{*}{$\begin{array}{l}29.56 \\
(-2.71 \\
61.84)\end{array}$} & 0.54 & 255.35 & 0.21 & \multirow{3}{*}{$\begin{array}{c}0.50 \\
(0.14 \\
0.86)\end{array}$} & 192.18 & \multirow{3}{*}{$\begin{array}{c}86.46 \\
(-46.48 \\
219.39)\end{array}$} \\
\hline MayJun & Jul & 73 & 1 & 36 & 2.78 & & 1.41 & 255.35 & 0.55 & & 5.02 & \\
\hline SeptOct & Nov & 76 & 9 & 20 & 45.00 & & 1.85 & 255.35 & 0.72 & & 62.17 & \\
\hline \multicolumn{13}{|c|}{$\begin{array}{l}\text { ProMap EdBurg } \\
\text { (7 days) }\end{array}$} \\
\hline Feb23-29 & March & 58 & 64 & 291 & 21.99 & \multirow{3}{*}{$\begin{array}{c}23.16 \\
(16.74 \\
29.58)\end{array}$} & 30.04 & 948.10 & 3.17 & \multirow{3}{*}{$\begin{array}{c}4.23 \\
(2.84 \\
5.62)\end{array}$} & 6.94 & \multirow{3}{*}{$\begin{array}{c}5.61 \\
(3.85 \\
7.37)\end{array}$} \\
\hline Jun24-30 & July & 82 & 119 & 421 & 28.27 & & 49.01 & 948.10 & 5.17 & & 5.47 & \\
\hline Oct25-31 & Nov & 65 & 74 & 385 & 19.22 & & 41.25 & 948.10 & 4.35 & & 4.42 & \\
\hline \multicolumn{13}{|c|}{$\begin{array}{l}\text { ProMap EdTFMV } \\
\text { ( } 7 \text { days) }\end{array}$} \\
\hline Feb23-29 & March & 167 & 132 & 818 & 16.14 & \multirow{3}{*}{$\begin{array}{c}15.83 \\
(14.15 \\
17.51)\end{array}$} & 17.04 & 948.10 & 1.80 & \multirow{3}{*}{$\begin{array}{c}2.13 \\
(1.71 \\
2.55)\end{array}$} & 8.98 & \multirow{3}{*}{$\begin{array}{c}7.54 \\
(5.80 \\
9.29)\end{array}$} \\
\hline Jun24-30 & July & 215 & 162 & 961 & 16.86 & & 22.67 & 948.10 & 2.39 & & 7.05 & \\
\hline Oct25-31 & Nov & 187 & 142 & 980 & 14.49 & & 20.80 & 948.10 & 2.19 & & 6.60 & \\
\hline \multicolumn{13}{|c|}{$\begin{array}{l}\text { ProMap SJTFMV } \\
\text { (7 days) }\end{array}$} \\
\hline Feb23-29 & Mar & 1 & 0 & 22 & 0.00 & \multirow{3}{*}{$\begin{array}{c}1.67 \\
(-2.33 \\
5.67)\end{array}$} & 0.03 & 255.35 & 0.01 & \multirow{3}{*}{$\begin{array}{c}0.10 \\
(-0.01 \\
0.20)\end{array}$} & 0.00 & \multirow{3}{*}{$\begin{array}{c}14.72 \\
(-20.62, \\
50.06)\end{array}$} \\
\hline Jun24-30 & Jul & 14 & 0 & 36 & 0.00 & & 0.41 & 255.35 & 0.16 & & 0.00 & \\
\hline Oct25-31 & Nov & 11 & 1 & 20 & 5.00 & & 0.29 & 255.35 & 0.11 & & 44.17 & \\
\hline \multicolumn{13}{|c|}{$\begin{array}{l}\text { ProMap EdBurg } \\
\text { ( } 2 \text { months) }\end{array}$} \\
\hline JanFeb & Mar & 497 & 193 & 291 & 66.32 & \multirow{3}{*}{$\begin{array}{l}71.85 \\
(62.76 \\
80.94)\end{array}$} & 152.89 & 948.10 & 16.13 & \multirow{3}{*}{$\begin{array}{l}18.38 \\
(15.61, \\
21.15)\end{array}$} & 4.11 & \multirow{3}{*}{$\begin{array}{l}3.92 \\
(3.61 \\
4.23)\end{array}$} \\
\hline MayJun & Jul & 701 & 333 & 421 & 79.10 & & 189.03 & 948.10 & 19.94 & & 3.97 & \\
\hline SeptOct & Nov & 672 & 270 & 385 & 70.13 & & 180.80 & 948.10 & 19.07 & & 3.68 & \\
\hline
\end{tabular}




\begin{tabular}{|c|c|c|c|c|c|c|c|c|c|c|c|c|}
\hline $\begin{array}{l}\text { Generation } \\
\text { Sample }\end{array}$ & $\begin{array}{c}\text { Test } \\
\text { Sample }\end{array}$ & $\begin{array}{l}\text { Crimes in } \\
\text { Generation } \\
\text { Sample }\end{array}$ & $\begin{array}{l}\text { Test Sample } \\
\text { Crimes in } \\
\text { Hotspots }\end{array}$ & $\begin{array}{l}\text { Total Test } \\
\text { Sample } \\
\text { Crimes }\end{array}$ & $\begin{array}{c}\text { Hit Rate } \\
\text { (\%) }\end{array}$ & $\begin{array}{c}\text { Hit Rate } \\
\text { Mean } \\
{[95 \% \text { CI] }}\end{array}$ & $\begin{array}{c}\text { Hotspot } \\
\text { Area } \\
\left(\mathrm{km}^{2}\right)\end{array}$ & $\begin{array}{c}\text { Total } \\
\text { Study Area } \\
\left(\mathrm{km}^{2}\right)\end{array}$ & Area \% & $\begin{array}{c}\text { Area \% } \\
\text { Mean } \\
{[95 \% \text { CI] }}\end{array}$ & PAI & $\begin{array}{c}\text { PAI Mean } \\
{[95 \% \text { CI] }}\end{array}$ \\
\hline \multicolumn{13}{|c|}{$\begin{array}{l}\text { ProMap EdTFMV } \\
\text { ( } \text { months) }\end{array}$} \\
\hline JanFeb & Mar & 1411 & 462 & 818 & 56.48 & \multirow{3}{*}{$\begin{array}{r}61.42 \\
(55.35 \\
67.49)\end{array}$} & 89.90 & 948.10 & 9.48 & \multirow{3}{*}{$\begin{array}{l}11.64 \\
(9.01 \\
14.27)\end{array}$} & 5.96 & \multirow{3}{*}{$\begin{array}{r}5.34 \\
(4.54 \\
6.13)\end{array}$} \\
\hline MayJun & Jul & 2024 & 623 & 961 & 64.83 & & 117.32 & 948.10 & 12.37 & & 5.24 & \\
\hline SeptOct & Nov & 2083 & 617 & 980 & 62.96 & & 123.83 & 948.10 & 13.06 & & 4.82 & \\
\hline \multicolumn{13}{|c|}{$\begin{array}{l}\text { ProMap SJTFMV } \\
\text { (2 months) }\end{array}$} \\
\hline JanFeb & Mar & 20 & 2 & 22 & 9.09 & \multirow{3}{*}{$\begin{array}{l}11.55 \\
(1.11 \\
21.98)\end{array}$} & 0.57 & 255.35 & 0.22 & \multirow{3}{*}{$\begin{array}{c}0.60 \\
(0.15 \\
1.06)\end{array}$} & 40.68 & 24.47 \\
\hline MayJun & Jul & 73 & 2 & 36 & 5.56 & & 2.09 & 255.35 & 0.82 & & 6.78 & \multirow{2}{*}{$\begin{array}{l}(0.91, \\
48.02)\end{array}$} \\
\hline SeptOct & Nov & 76 & 4 & 20 & 20.00 & & 1.97 & 255.35 & 0.77 & & 25.94 & \\
\hline
\end{tabular}


Traditional hot-spotting methods. KDE and Nnh were the two traditional hotspotting methods examined in Phase 2. Based on the results presented in Table 10, the predictive accuracy for both traditional mapping techniques was found to vary across the data files examined.

Kernel density estimation (KDE). The results presented in Table 10 indicate that the PAI values remained fairly consistent across the three blocks of time for the Edmonton burglary and Edmonton TFMV data files. Specifically, the PAI values varied from 6.19 to 7.10 across the three Edmonton burglary data files $(M=6.54 ; S D=0.49$; $95 \%$ CI $[5.85,7.22])$ and varied from 4.72 and 5.88 across the three Edmonton TFMV data files $(M=5.25 ; S D=0.58 ; 95 \% \mathrm{CI}[4.44,6.06])$. The overlapping $95 \%$ CIs suggest that mean PAI value was comparable between the Edmonton burglary and Edmonton TFMV data files. When examining hit rate, the results were again fairly consistent across the three blocks of time for the Edmonton TFMV (ranged from 57.58 to $63.67 ; M=$ 62.30; $S D=4.21 ; 95 \% \mathrm{CI}[56.47,68.14])$ and Edmonton burglary (ranged from 32.65 to $40.38 ; M=36.81 ; S D=3.90 ; 95 \%$ CI $[31.40,42.22])$ data files. As indicated by the nonoverlapping 95\% CIs, mean hit rate was higher for the Edmonton TFMV data files than for the Edmonton burglary data files. Mean area percentage, however, was lower for Edmonton burglary (ranged from4.60 to $6.39 ; M=5.68 ; S D=0.95 ; 95 \%$ CI $[4.36,6.99]$ ) than Edmonton TFMV (ranged from 9.80 to $13.49 ; M=12.01 ; S D=1.95 ; 95 \%$ CI [9.31, 14.71]), as indicated by non-overlapping 95\% CIs.

Nearest neighbour hierarchical clustering (Nnh). As shown in Table 10, the predictive accuracy results for the Nnh hotpot mapping approach follow similar trends to those found for the KDE technique. Specifically, the PAI values remain fairly consistent 
across the three blocks of time for the Edmonton burglary (ranged from 8.40 to $12.34 ; M$ $=9.73 ; S D=2.26 ; 95 \%$ CI $[6.60,12.86]$ ) and Edmonton TFMV (ranged from 6.17 to $8.49 ; M=7.00 ; S D=1.29 ; 95 \%$ CI $[5.21,8.79])$ data files with the PAI values being slightly higher for Edmonton burglary than for Edmonton TFMV, but with overlapping 95\% CIs. When examining hit rate, consistent values were found for the Edmonton TFMV (ranged from 44.25 to $50.51 ; M=47.23 ; S D=3.3 .14 ; 95 \%$ CI $[42.88,51.58]$ ) and the Edmonton burglary (ranged from 17.87 to $27.08 ; M=21.74 ; S D=4.78 ; 95 \% \mathrm{CI}$ $[15.11,28.36])$ data files. Mean hit rate was again higher for the Edmonton TFMV data files than for the Edmonton burglary data files, as indicated by the non-overlapping 95\% CIs. Mean area percentage was again lower for Edmonton burglary data files (ranged from 1.45 to $3.21 ; M=2.35 ; S D=0.88 ; 95 \%$ CI $[1.14,3.57])$ than for Edmonton TFMV data files (ranged from 5.21 to $8.19 ; M=6.93 ; S D=1.54 ; 95 \%$ CI $[4.79,9.07]$ ), with non-overlapping 95\% CIs.

KDE versus Nhh. Next, the results presented in Table 10 were examined to determine whether the KDE or Nnh hotspot mapping approach resulted in higher predictive accuracy. The answer to that varies depending on which measure of predictive accuracy was examined. When examining mean PAI value, the Nnh approach resulted in a slightly higher rate of predictive accuracy for both Edmonton burglary and Edmonton TFMV; however, these differences were not likely meaningful as they are accompanied by overlapping 95\% CIs. Mean area percentage was lower for the Edmonton burglary and Edmonton TFMV Nnh maps than for the KDE maps; these differences were accompanied by non-overlapping 95\% CIs. The lower area percentages appear to be accounting for the slightly higher PAI values since mean hit rate was higher for the KDE 
approach for both Edmonton burglary and Edmonton TFMV (recall that PAI = hit rate/area percentage); again, with non-overlapping 95\% CIs.

Prospective hot-spotting. Recall that it is actually the prospective hot-spotting method that is of the most interest to the current dissertation. Maps in Phase 2 were generated using the 7-day empirically derived temporal bandwidth (as found in Phase 1) as well as a 2-month temporal bandwidth due to sample size concerns regarding the crime data used to generate the 7-day temporal bandwidth maps.

Prospective hot-spotting - 7-day temporal bandwidth. The results presented in Table 10 indicate that, similar to the trends observed with the KDE and Nnh hotspot mapping approaches, the PAI values for the prospective hot-spotting approach remain fairly consistent across the three blocks of time for the Edmonton burglary and Edmonton TFMV data files. Specifically, the PAI values varied from 4.42 to 6.94 across the three Edmonton burglary data files $(M=5.61 ; S D=1.27 ; 95 \% \mathrm{CI}[3.85,7.37])$ and from 6.60 to 8.98 across the three Edmonton TFMV data files $(M=7.54 ; S D=1.26 ; 95 \%$ CI $[5.80$, 9.29]). As indicated by the overlapping $95 \%$ CIs, the mean PAI value was comparable between Edmonton burglary and Edmonton TFMV. In terms of hit rate, the values were found to be relatively consistent for the Edmonton TFMV data files (ranged from 14.49 to $16.86 ; M=15.83 ; S D=1.21 ; 95 \% \mathrm{CI}[14.15,17.51])$ and the Edmonton burglary data files (ranged from 19.22 to $28.27 ; M=23.16 ; S D=4.63 ; 95 \%$ CI $[16.74,29.58]$ ). Opposite of what was found for KDE and Nnh, the mean hit rate was higher for Edmonton burglary than for Edmonton TFMV; however, this difference was likely not meaningful as it was accompanied by overlapping 95\% CIs. Area percentages were also fairly consistent across the three blocks of time for both Edmonton burglary (ranged from 
3.17 to $5.17 ; M=4.23 ; S D=1.01 ; 95 \%$ CI $[2.84,5.62]$ ) and Edmonton TFMV (ranged from 1.80 to $2.39 ; M=2.13 ; S D=0.30 ; 95 \%$ CI $[1.71,2.55])$. Again opposite of the KDE and Nnh results, the mean area percentage was found to be lower for Edmonton TFMV than for Edmonton burglary. Unlike the hit rate results, however, the difference in mean area percentage was accompanied by non-overlapping $95 \%$ CIs.

Prospective hot-spotting - 2-month temporal bandwidth. As shown in Table 10, the PAI values remain fairly consistent across all three Edmonton burglary (ranged from 3.68 to $4.11 ; M=3.92 ; S D=0.22 ; 95 \%$ CI $[3.61,4.23]$ ) and Edmonton TFMV (ranged from 4.82 to $5.96 ; M=5.34 ; S D=0.57 ; 95 \% \mathrm{CI}[4.54,6.13])$ data files when generating the maps using the prospective hot-spotting approach with a 2-month temporal bandwidth. The mean PAI was higher for Edmonton TFMV than Edmonton burglary, with non-overlapping 95\% CIs. When examining hit rate, the values were again found to be relatively consistent for the Edmonton burglary (ranged from 66.32 to $79.10 ; M=$ 71.85; $S D=6.56 ; 95 \%$ CI $[62.76,80.94])$ and Edmonton TFMV data files (ranged from 56.48 to $64.83 ; M=61.42 ; S D=4.38 ; 95 \%$ CI $[55.35,67.49])$. Similar to the prospective hot-spotting approach with a 7-day temporal bandwidth, mean hit rate was slightly higher for Edmonton burglary than for Edmonton TFMV; however, this difference was accompanied by overlapping 95\% CIs. Also similar to the prospective hot-spotting approach with a 7-day temporal bandwidth, the mean area percentage was lower for Edmonton TFMV (ranged from 9.48 to $13.06 ; M=11.64 ; S D=1.90 ; 95 \%$ CI [9.01, 14.27]) than for Edmonton burglary (ranged from 16.13 to $19.94 ; M=18.38 ; S D=2.00$; 95\% CI $[15.61,21.15])$, with non-overlapping 95\% CIs. Thus, lower area percentages, 
rather than higher hit rates, accounted for the lower mean PAI value for Edmonton TFMV.

Prospective hot-spotting - 7-day versus 2-month temporal bandwidth. Next, the results presented in Table 10 were examined to determine whether the 7-day or 2-month temporal bandwidth resulted in higher predictive accuracy for the prospective hotspotting method. When examining mean PAI values, the 7-day temporal bandwidth resulted in higher rates of predictive accuracy for both Edmonton burglary and Edmonton TFMV; however, non-overlapping 95\% CIs were not found.

When examining hit rate, the 2-month temporal bandwidth consistently outperformed the 7-day temporal bandwidth for both Edmonton burglary and Edmonton TFMV, with non-overlapping 95\% CIs. Results, however, were the opposite for the area percentage with the 7-day temporal bandwidth outperforming the 2-month temporal bandwidth for both Edmonton burglary and Edmonton TFMV, with non-overlapping $95 \%$ CIs. 
Prospective hot-spotting versus traditional hot-spotting techniques. The final part of Phase 2 involved comparing the predictive accuracy of the prospective hotspotting technique to that of the two traditional hot-spotting techniques. Whether differences exist in predictive accuracy between the traditional hotspot mapping methods and the prospective hot-spotting technique with a 7-day temporal bandwidth will be examined first. This will be followed by a comparison of the predictive accuracy between the traditional hotspot mapping approaches and the prospective hot-spotting method using a 2-month temporal bandwidth.

As indicated by overlapping 95\% CIs, mean PAI value was found to be comparable between the prospective hot-spotting technique with a 7-day temporal bandwidth and the two traditional hotspot mapping methods for both Edmonton burglary and Edmonton TFMV. For Edmonton burglary, the mean hit rate for the prospective hotspotting technique with a 7-day temporal bandwidth was found to be comparable to that of the Nnh approach, with overlapping 95\% CIs, and lower than the KDE approach, with non-overlapping 95\% CIs. For Edmonton TFMV, the prospective hot-spotting method with a 7-day temporal bandwidth resulted in a lower mean hit rate than both the Nnh and KDE approaches, as indicated by non-overlapping CIs. Mean area percentage was comparable between the prospective hot-spotting approach with a 7-day temporal bandwidth and the two traditional hotspot mapping methods, with overlapping $95 \%$ CIs, for Edmonton burglary. For Edmonton TFMV, the prospective hot-spotting technique with a 7-day temporal bandwidth resulted in a mean area percentage lower than both traditional hotspot mapping approaches, with non-overlapping 95\% CIs. 
With the prospective hot-spotting approach using a 2-month temporal bandwidth, the mean PAI value was lower than the KDE and Nnh approaches for Edmonton burglary, as indicated by non-overlapping 95\% CIs. For Edmonton TFMV, however, the mean PAI value for the prospective hot-spotting technique with a 2-month temporal bandwidth was found to be comparable to the mean PAI value for both traditional hotspot mapping methods, with overlapping 95\% CIs. Mean hit rate for Edmonton burglary was considerably higher for the prospective hot-spotting technique using a 2-month temporal bandwidth than for the KDE and Nnh approaches, as indicated by non-overlapping $95 \%$ CIs. For Edmonton TFMV, mean hit rate was comparable between the prospective hotspotting method using a 2-month temporal bandwidth and KDE, with overlapping 95\% CIs, but was higher for the prospective hot-spotting method than for Nnh, with nonoverlapping 95\% CIs. For Edmonton burglary, mean area percentage was higher for the prospective hot-spotting approach with a 2-month temporal bandwidth than for either traditional hotspot mapping method. Finally, mean area percentage for Edmonton TFMV, however, was comparable between the prospective hot-spotting method using a 2-month temporal bandwidth and the two traditional hotspot mapping approaches, as demonstrated by overlapping $95 \%$ CIs.

\section{Discussion}

Recall that, due to sample size concerns for the Saint John TFMV data files, only the Edmonton burglary and Edmonton TFMV data files were used to compare predictive accuracy across the various hotspot mapping techniques. Overall, these results from Phase 2 do not support the hypothesis that risk surfaces produced using the prospective hotspot mapping techniques have greater predictive accuracy than the risk surfaces 
produced by the two traditional hot-spotting techniques. This is especially true when the PAI is focused on, which is arguably the most appropriate measure of accuracy. For example, the mean PAI value was found to be comparable across all the various hotspot mapping techniques for Edmonton TFMV and the mean PAI value for Edmonton burglary was actually higher for the two traditional hotspot mapping techniques (i.e., $\mathrm{KDE}$ and Nnh) than for the prospective hot-spotting approach with a 2-month temporal bandwidth. With a few exceptions, the analysis of hit rates and area percentage revealed similar patterns of findings (i.e., generally speaking, these results also didn't support the hypothesis that prospective hot-spotting techniques would be more effective than traditional hot-spotting techniques).

In addition, it was hypothesized that KDE would consistently outperform Nnh, but that hypothesis was also not supported by the Phase 2 results. The Nnh approach actually produced higher mean PAI values than the KDE approach for Edmonton burglary and Edmonton TFMV, but overlapping 95\% CIs suggest that these differences were negligible. When considering the mean hit rate, the KDE approach did outperform the Nnh approach for both Edmonton burglary and Edmonton TFMV. Non-overlapping 95\% CIs suggest that these differences in hit rate could be more meaningful than the PAI results from a practical standpoint. Interestingly, the opposite trend was observed for the mean area percentage with the Nnh approach resulting in lower values than the KDE approach (again with non-overlapping 95\% CIs). Thus, the hit rate and area percentage results are something that police agencies would need to consider when selecting a hotspot mapping approach (i.e., is the reduction in area percentage that occurs when using the Nnh approach worth the decrease in hit rate, or would KDE be a more 
appropriate choice given that additional resources would be needed to cover the additional area percentage).

Although some differences emerged between the various hotspot mapping techniques in terms of predictive accuracy, as highlighted in the Phase 2 results section, common trends emerged when examining hit rate, area percentage, and PAI values within the four hot-spotting methods examined. For example, hit rate and PAI values were consistently more stable for the Edmonton burglary and Edmonton TFMV data files than for the Saint John TFMV data files across all of the hotspot mapping approaches, which supports the decision to exclude the Saint John TFMV analyses when comparing the predictive accuracy of the various hotspot mapping approaches. Given that the Saint John TFMV data files are those with the lowest number of crimes (used to generate the various maps) this finding could suggest that predictive accuracy will be more robust and stable across time when more crimes are used to generate hot-spotting maps. This suggests that jurisdictions with lower crime rates should rely on longer time frames to generate hotspot maps. This would increase the number of crimes used to generate hot-spotting maps, which in turn should help reduce the variability in predictive accuracy achieved across different blocks of time.

For the most part, PAI values were found to be reasonably comparable between the Edmonton burglary data file and the Edmonton TFMV data file within each hotspot mapping approach. Interestingly, however, PAI values were consistently highest for the January-February maps and lowest for the September-October maps for the Edmonton burglary and Edmonton TFMV data files. This could suggest that offender spatial behaviour is more stable in Winter than in Fall, perhaps relating to the ease of travel in 
the warmer months compared to the colder months. However, these differences in PAI values were quite small overall so speculating about what these results mean for offender spatial behaviour is not necessarily warranted.

Another interesting finding was the fact that Edmonton burglary resulted in lower hit rates and area percentages than Edmonton TFMV for both traditional hotspot mapping approaches (i.e., KDE and Nnh). This trend, however, was reversed for the prospective hot-spotting techniques using 7-day and 2-month temporal bandwidths with hit rates and area percentages tending to be higher for Edmonton burglary than for Edmonton TFMV. One possible explanation for this finding is the use of an empirically derived spatial bandwidth for prospective hot-spotting, based on the Phase 1 results. Recall that KDE used a spatial bandwidth of 200 metres for both Edmonton burglary and Edmonton TFMV. Based on the Phase 1 results, however, the prospective hot-spotting technique employed a spatial bandwidth of 500 metres for Edmonton burglary and 200 metres for Edmonton TFMV. Thus, the 500-metre spatial bandwidth could explain the increase in hit rate and area percentage for Edmonton burglary for the prospective hot-spotting approaches since a larger spatial bandwidth would result in a larger hotspot area (which would also result in a larger area percentage), which in turn would likely lead to an increase in hit rate as well since future crime would be more likely to be located in hotspots that cover more of the total study area. As the results suggest, however, mean PAI is not necessarily increased through the use of a larger spatial bandwidth. This highlights how larger spatial bandwidths can impact the various predictive accuracy measures examined in the current study. 
Compared to the PAI values in Bowers et al.'s (2004) and Chainey et al.'s (2008) research, it is interesting that the PAI values obtained in the Phase 2 analyses appear to be substantially larger. For example, the PAI values for the prospective hot-spotting technique when applied to residential burglary in Bowers et al.'s study were found to be 2.60 and 2.69 when two days' and one week's worth of crime data, respectively, were used to assess predictive accuracy. In the current study, the PAI values ranged from 4.42 to 6.94 for the Edmonton burglary data files when the prospective hot-spotting technique with a 7-day temporal bandwidth was used to generate the maps. The PAI values for the Edmonton burglary data files were even higher when the KDE and Nnh approaches were used to generate the maps (ranged from 6.19 to 12.34).

Recall that Bowers et al. (2004) limited the hotspot area to approximately $20 \%$ of the total study area; thus, $20 \%$ actually represents the area percentage in their study. In the current study, the area percentage never exceeded $20 \%$, regardless of the hotspot technique and data file examined (although the prospective hot-spotting technique with the 2-month temporal bandwidth did approach 20\% when applied to the Edmonton burglary data files). For the prospective hot-spotting mapping approach with a 7-day temporal bandwidth, for example, the area percentage varied from 3.17 to 5.17 for the Edmonton burglary data files, which is substantially lower than Bowers et al.'s $20 \%$. Thus, the lower area percentages appear to account for the higher PAI values in the current study when compared to the predictive accuracy results obtained in previous hotspot mapping research.

In addition, the total study area for Edmonton was noticeably larger than the study areas of previous hot-spotting research as well. For example, the total study area for 
Edmonton was $948.10 \mathrm{~km}^{2}$. In contrast, the total study area for Bowers et al.'s (2004) study was only $22.70 \mathrm{~km}^{2}$. This difference likely resulted in a study area in the current study that was much more heterogeneous, in terms of crime activity, than the study area examined by Bowers et al. For example, there would have been a larger area in the current study where crime simply could not occur (e.g., residential burglary could not occur in areas covered by forests or bodies of water). As a consequence, the target backcloth (i.e., the availability of suitable targets) was likely more evenly distributed in Bowers et al.'s study area. Recall that area percentage is the ratio between the area covered by the hotspots and the total study area. Thus, a larger study area that includes areas where crime can actually not occur would result in unrealistically low area percentages, which in turn would lead to inflated PAI values (like those potentially obtained in the current study).

Ideally, those areas where crime cannot occur (e.g., forests, lakes, parks, etc.) would be removed from the study area in order to produce more accurate area percentages, which in turn would produce more valid PAI values. This was not possible in the current study as a result of Edmonton having shifted their crime site locations by a constant value unknown to the author. This alteration to the data makes it impossible to overlay additional information, such as the location of lakes, onto the study area. As a result, caution should be exercised when interpreting the area percentage and PAI results from an applied standpoint, as well as when comparing the PAI values found in the current study to those obtained in previous studies.

Limitations. There are several limitations to the Phase 2 analyses that warrant discussion. Given that the crime data were identical to that used in Phase 1, other than the 
fact that they were from 2008 instead of 2007, all of the data limitations and concerns raised in the Phase 1 discussion also apply to Phase 2. For the sake of brevity, these limitations will not be discussed again. Also similar to Phase 1, sample size appeared to be problematic for some of the Phase 2 analyses. As previously mentioned, sample size was clearly an issue for the Saint John TFMV data files, as demonstrated by the unstable hit rate and PAI results. This instability was observed across each of the hotspot mapping methods used. Sample size was also more problematic for the prospective hot-spotting approach using a 7-day temporal bandwidth than for the other hotspot mapping methods since a tighter temporal bandwidth results in a corresponding reduction in the crime data used to generate the maps.

Another limitation in Phase 2 (perhaps the limitation most germane to the objectives of the current study) is the fact that the prospective hot-spotting approach used here is not identical to that used by Bowers et al. (2004). As mentioned in the Phase 2 methods, the ProMap approach originally developed by Bowers et al. was simulated in the current study, through the use of the interpolation routine in CrimeStat, rather than replicated directly. Although admittedly not ideal, the simulation of the original ProMap approach in the current study was unavoidable since the software used by Bowers et al. to generate their prospective hot-spotting maps was developed by the authors and is unable to be accessed by other researchers. In the current study, support was not found for the hypothesis that the prospective hot-spotting approach would outperform the traditional hotspot mapping techniques in terms of predictive accuracy. However, it is possible that different results would have been found if Bowers et al.'s ProMap approach had been 
directly replicated in the current study (i.e., perhaps the ProMap approach would have outperformed the KDE and Nnh approaches).

Finally, as mentioned earlier, although the calculation of the PAI values is not a subjective process $(\mathrm{PAI}=$ hit rate/area percentage $)$, the comparison of PAI values is relatively subjective. Although means and 95\% CIs were calculated in the current study to facilitate the assessment of comparisons, it was still not possible to use advanced statistical analyses to compare the mean PAI values and determine statistical significance. Currently, the cutoff between what constitutes an important difference between PAI values (e.g., across mapping approaches) is quite arbitrary and accepted norms have yet to be established. This is obviously another limitation to the Phase 2 analyses. Having said that, however, this limitation is not unique to the current study. The way in which the predicative accuracy results have been calculated, presented, interpreted, and compared in the current study is in line with prior hotspot mapping research.

\section{Phase 3 - Improving the Accuracy of Prospective Risk Surfaces}

The main purpose of Phase 3 was to determine whether it is possible to improve the predictive accuracy of risk surfaces when using the prospective hot-spotting technique. However, given that the prospective hot-spotting technique was not found to outperform the two traditional hotspot mapping techniques (i.e., KDE and Nnh) in Phase 2, risk surfaces were also generated in Phase 3 using the KDE and Nnh approaches. ${ }^{33}$ Specifically, Phase 3 examined three specific strategies aimed at improving the predictive accuracy of the hotspot maps. First, risk surfaces were generated that incorporated more specific temporal information into the analysis (i.e., whether the crimes occurred during a

\footnotetext{
${ }^{33}$ In addition, prospective hot-spotting risk surfaces were generated in Phase 3 using both temporal bandwidths from Phase 2 (i.e., 7-day and 2-month) when possible.
} 
weekday or weekend). Second, the time period of data used to generate the risk surfaces was varied ( 2 weeks, 1 month, and 2 months) to determine whether longer time periods result in more accurate risk surfaces. ${ }^{34}$ Finally, the time period used to test the accuracy of the risk surfaces was varied ( 2 weeks, 1 month, and 2 months) to determine whether risk surfaces have greater predictive accuracy when applied to more immediate crime.

It was originally planned that all three data files that demonstrated significant near repeat space-time clustering in Phase 1 (i.e., Edmonton burglary, Edmonton TFMV, and Saint John TFMV) would be used to examine the three strategies in Phase 3. However, given the findings from Phase 2, which suggested that sample size was problematic in the Saint John TFMV analyses, it was decided that only the Edmonton burglary and Edmonton TFMV data files would be included in Phase 3. More details for each of the strategies examined are provided below.

\section{Strategy 1: Weekday and Weekend Maps}

Data. The data used for this part of Phase 3 was the same as the three blocks of data used in Phase 2 for Edmonton burglary and Edmonton TFMV. Recall that in Phase 2, offences that occurred between January 1 and February 29, 2008, May 1 and June 30, 2008, and September 1 and October 31, 2008, were used to generate the hotspot maps, whereas offences that occurred one month following those three time blocks were used to assess predictive accuracy.

Procedure. First, the data files for both Edmonton crime types (i.e., burglary and TFMV), for each block of time, were split in two based on whether the offences occurred during a weekday or weekend. More specifically, crimes that occurred from Monday to Friday were placed in a weekday .dbf file, whereas crimes that occurred on Saturday or

\footnotetext{
${ }^{34}$ Specifically, this strategy manipulated the temporal bandwidth used to generate the hotspot maps.
} 
Sunday were placed in a weekend .dbf file. Next, using the offences from each generation sample (i.e., January 1-February 29, May 1-June 30, September 1-October 31), weekday and weekend hotspot maps were generated for Edmonton burglary and Edmonton TFMV. For this strategy, maps were generated using three different techniques: KDE, Nnh, and prospective hot-spotting with a 2 -month temporal bandwidth. ${ }^{35}$ The procedure for these three mapping approaches is outlined in the $\mathrm{KDE}, \mathrm{Nnh}$, and prospective hotspot mapping sections of Phase 2. In total, 36 new hotspot maps were produced in Phase 3 for Strategy 1 (i.e., 12 maps for each of the three hotspot mapping method - one weekend map and one weekday map for each of the three blocks of time for both the Edmonton burglary and Edmonton TFMV data files).

Once all 36 hotspot maps had been generated, the maps were then used to predict future crime that occurred: (1) during the same time of the week (e.g., weekday crime data was used to predict future weekday crime data) and (2) during the opposing time of the week (e.g., weekday crime data was used to predict weekend crime). Chainey et al.'s (2008) predictive accuracy index was again used to assess map accuracy (see Phase 2 for more details).

Hypotheses. Based on routine activity theory, and the general findings of Tompson and Townsley (2010), it was expected that PAI values would increase when hotspot maps were used to predict future crimes that occurred during the same time of the week (i.e., weekday maps to predict weekday crimes and weekend maps to predict weekend crimes). In addition, it was expected that hotspot maps that were specific to a

\footnotetext{
${ }^{35}$ Note that only the prospective hot-spotting technique with a 2-month temporal bandwidth was examined in Strategy 1 as the 7-day temporal bandwidth would result in low sample sizes, particularly for the weekend data files.
} 
particular time of week would result in higher PAI values than the general (i.e., time independent) hotspot maps generated in Phase 2.

Results. The maps produced for Strategy 1 in Phase 3 are similar to those produced by the KDE, Nnh, and prospective hot-spotting (2-month temporal bandwidth) techniques in Phase 2, except that they relied specifically on either weekend or weekday data. As a result, additional map examples are not provided here. ${ }^{36}$ The predictive accuracy results for all of the maps generated in Strategy 1 are presented in Table 11. Some of the predictive accuracy results from Phase 2 are also included in this table to allow for easy comparison between those maps generated using the weekday/weekend breakdown and those generated without this time of week breakdown.

The columns in Table 11 that are of particular interest to the Strategy 1 results are the hit rate (i.e., the percentage of future crimes falling within the predicted hotspots), area percentage (i.e., the proportion of the entire study area that is covered by the predicted hotspots), and PAI (i.e., a ratio of hit rate over area percentage), as they represent the three measurements examined in the current study to assess predictive accuracy. Means and 95\% confidence intervals (CIs) are also reported in Table 11 for each of the three accuracy measures (means and 95\% CIs are calculated based on the accuracy results across the three blocks of time). As previously mentioned, police agencies would typically prefer higher hit rates and lower area percentages. As well, higher PAI values in Table 11 indicate greater efficiency (i.e., a greater percentage of predicted crimes occur in a smaller proportion of the total study area). The predictive accuracy results will now be discussed in more detail.

\footnotetext{
${ }^{36}$ Refer back to Figures 6, 7, 8, and 9 in Phase 2 and Appendix B for examples of hotspot maps generated using each of the various hotspot mapping approaches (i.e., KDE, Nnh, and prospective hot-spotting).
} 
Table 11. Predictive accuracy results for Phase 3: Strategy 1 maps.

\begin{tabular}{|c|c|c|c|c|c|c|c|c|c|c|c|c|}
\hline $\begin{array}{l}\text { Generation } \\
\text { Sample }\end{array}$ & $\begin{array}{c}\text { Test } \\
\text { Sample }\end{array}$ & $\begin{array}{l}\text { Crimes in } \\
\text { Generation } \\
\text { Sample }\end{array}$ & $\begin{array}{l}\text { Test Sample } \\
\text { Crimes in } \\
\text { Hotspots }\end{array}$ & $\begin{array}{l}\text { Total Test } \\
\text { Sample } \\
\text { Crimes }\end{array}$ & $\begin{array}{c}\text { Hit Rate } \\
(\%)\end{array}$ & $\begin{array}{l}\text { Hit Rate } \\
\text { Mean } \\
{[95 \% \text { CI] }}\end{array}$ & $\begin{array}{c}\text { Hotspot } \\
\text { Area } \\
\left(\mathrm{km}^{2}\right)\end{array}$ & $\begin{array}{c}\text { Total } \\
\text { Study Area } \\
\left(\mathrm{km}^{2}\right)\end{array}$ & Area \% & $\begin{array}{c}\text { Area \% } \\
\text { Mean } \\
{[95 \% \text { CI] }}\end{array}$ & PAI & $\begin{array}{c}\text { PAI Mean } \\
{\left[\begin{array}{l}95 \% \\
\text { CI }]\end{array}\right.}\end{array}$ \\
\hline \multicolumn{13}{|l|}{ KDE EdBurg } \\
\hline *JanFeb & Mar & 497 & 95 & 291 & 32.65 & 36.81 & 43.62 & 948.10 & 4.60 & 5.68 & 7.10 & 6.54 \\
\hline *MayJun & Jul & 701 & 170 & 421 & 40.38 & \multirow{2}{*}{$\begin{array}{l}{[31.40,} \\
42.22]\end{array}$} & 60.55 & 948.10 & 6.39 & \multirow{2}{*}{$\begin{array}{c}{[4.36,} \\
6.99]\end{array}$} & 6.32 & \multirow{2}{*}{$\begin{array}{l}{[5.85} \\
7.22]\end{array}$} \\
\hline *SeptOct & Nov & 672 & 144 & 385 & 37.40 & & 57.33 & 948.10 & 6.05 & & 6.19 & \\
\hline JanFebWkdy & MarWkdy & 387 & 55 & 196 & 28.06 & \multirow{3}{*}{$\begin{array}{c}32.15 \\
{[17.30} \\
47.00]\end{array}$} & 35.95 & 948.10 & 3.79 & \multirow{3}{*}{$\begin{array}{c}4.60 \\
{[3.62} \\
5.59]\end{array}$} & 7.40 & \multirow{3}{*}{$\begin{array}{c}7.02 \\
{[6.49} \\
7.55]\end{array}$} \\
\hline MayJunWkdy & JulWkdy & 520 & 111 & 327 & 33.94 & & 48.49 & 948.10 & 5.11 & & 6.64 & \\
\hline SeptOctWkdy & NovWkdy & 524 & 93 & 270 & 34.44 & & 46.45 & 948.10 & 4.90 & & 7.03 & \\
\hline JanFebWkdy & MarWknd & 387 & 28 & 95 & 29.47 & \multirow{3}{*}{$\begin{array}{c}32.74 \\
{[17.61} \\
47.86]\end{array}$} & 35.95 & 948.10 & 3.79 & \multirow{3}{*}{$\begin{array}{r}4.60 \\
{[3.62} \\
5.59]\end{array}$} & 7.77 & \multirow{3}{*}{$\begin{array}{c}7.16 \\
{[6.01} \\
8.31]\end{array}$} \\
\hline MayJunWkdy & JulWknd & 520 & 36 & 94 & 38.30 & & 48.49 & 948.10 & 5.11 & & 7.49 & \\
\hline SeptOctWkdy & NovWknd & 524 & 35 & 115 & 30.43 & & 46.45 & 948.10 & 4.90 & & 6.21 & \\
\hline JanFebWknd & MarWknd & 109 & 10 & 95 & 10.53 & \multirow{3}{*}{$\begin{array}{l}12.08 \\
{[6.50,} \\
17.66]\end{array}$} & 12.25 & 948.10 & 1.29 & \multirow{3}{*}{$\begin{array}{c}1.71 \\
{[1.19} \\
2.24]\end{array}$} & 8.15 & \multirow{3}{*}{$\begin{array}{c}7.11 \\
{[4.29} \\
9.93]\end{array}$} \\
\hline MayJunWknd & JulWknd & 181 & 16 & 94 & 17.02 & & 19.18 & 948.10 & 2.02 & & 8.42 & \\
\hline SeptOctWknd & NovWknd & 148 & 10 & 115 & 8.70 & & 17.32 & 948.10 & 1.83 & & 4.76 & \\
\hline JanFebWknd & MarWkdy & 109 & 24 & 196 & 12.24 & \multirow{3}{*}{$\begin{array}{l}13.40 \\
{[7.21,} \\
19.59]\end{array}$} & 12.25 & 948.10 & 1.29 & \multirow{3}{*}{$\begin{array}{c}1.71 \\
{[1.19} \\
2.24]\end{array}$} & 9.48 & \multirow{3}{*}{$\begin{array}{r}7.99 \\
{[6.20} \\
9.78]\end{array}$} \\
\hline MayJunWknd & JulWkdy & 181 & 49 & 327 & 14.98 & & 19.18 & 948.10 & 2.02 & & 7.41 & \\
\hline SeptOctWknd & NovWkdy & 148 & 35 & 270 & 12.96 & & 17.32 & 948.10 & 1.83 & & 7.10 & \\
\hline \multicolumn{13}{|l|}{ KDE EdTFMV } \\
\hline$* J a n F e b$ & Mar & 1411 & 471 & 818 & 57.58 & \multirow{3}{*}{$\begin{array}{c}62.30 \\
{[56.47} \\
68.14]\end{array}$} & 92.91 & 948.10 & 9.80 & \multirow{3}{*}{$\begin{array}{l}12.01 \\
{[9.31} \\
14.71]\end{array}$} & 5.88 & \multirow{3}{*}{$\begin{array}{c}5.25 \\
{[4.44} \\
6.06]\end{array}$} \\
\hline *MayJun & Jul & 2024 & 631 & 961 & 65.66 & & 120.66 & 948.10 & 12.73 & & 5.16 & \\
\hline *SeptOct & Nov & 2083 & 624 & 980 & 63.67 & & 127.90 & 948.10 & 13.49 & & 4.72 & \\
\hline
\end{tabular}




\begin{tabular}{|c|c|c|c|c|c|c|c|c|c|c|c|c|}
\hline $\begin{array}{l}\text { Generation } \\
\text { Sample }\end{array}$ & $\begin{array}{c}\text { Test } \\
\text { Sample }\end{array}$ & $\begin{array}{c}\text { Crimes in } \\
\text { Generation } \\
\text { Sample }\end{array}$ & $\begin{array}{l}\text { Test Sample } \\
\text { Crimes in } \\
\text { Hotspots }\end{array}$ & $\begin{array}{l}\text { Total Test } \\
\text { Sample } \\
\text { Crimes }\end{array}$ & $\begin{array}{c}\text { Hit Rate } \\
\text { (\%) }\end{array}$ & $\begin{array}{l}\text { Hit Rate } \\
\text { Mean } \\
{[95 \% \text { CI }]}\end{array}$ & $\begin{array}{l}\text { Hotspot } \\
\text { Area } \\
\left(\mathrm{km}^{2}\right)\end{array}$ & $\begin{array}{c}\text { Total } \\
\text { Study Area } \\
\left(\mathrm{km}^{2}\right)\end{array}$ & Area \% & $\begin{array}{c}\text { Area \% } \\
\text { Mean } \\
{[95 \% \mathrm{CI}]}\end{array}$ & PAI & $\begin{array}{c}\text { PAI Mean } \\
{[95 \% \text { CI] }}\end{array}$ \\
\hline \multicolumn{13}{|c|}{ KDE EdTFMV } \\
\hline JanFebWkdy & MarWkdy & 1038 & 269 & 527 & 51.04 & 55.48 & 77.29 & 948.10 & 8.15 & 9.85 & 6.26 & 5.69 \\
\hline MayJunWkdy & JulWkdy & 1392 & 404 & 693 & 58.30 & \multirow{2}{*}{$\begin{array}{l}{[50.09,} \\
60.87]\end{array}$} & 96.91 & 948.10 & 10.22 & \multirow{2}{*}{$\begin{array}{l}{[7.71,} \\
12.00]\end{array}$} & 5.70 & \multirow{2}{*}{$\begin{array}{c}{[4.89} \\
6.49]\end{array}$} \\
\hline SeptOctWkdy & NovWkdy & 1520 & 382 & 669 & 57.10 & & 106.00 & 948.10 & 11.18 & & 5.11 & \\
\hline JanFebWkdy & MarWknd & 1038 & 158 & 291 & 54.30 & \multirow{3}{*}{$\begin{array}{c}57.47 \\
{[53.66} \\
61.29]\end{array}$} & 77.29 & 948.10 & 8.15 & \multirow{3}{*}{$\begin{array}{c}9.85 \\
{[7.71} \\
12.00]\end{array}$} & 6.66 & \multirow{3}{*}{$\begin{array}{c}5.91 \\
{[4.94} \\
6.87]\end{array}$} \\
\hline MayJunWkdy & JulWknd & 1392 & 158 & 268 & 58.96 & & 96.91 & 948.10 & 10.22 & & 5.77 & \\
\hline SeptOctWkdy & NovWknd & 1520 & 184 & 311 & 59.16 & & 106.00 & 948.10 & 11.18 & & 5.29 & \\
\hline JanFebWknd & MarWknd & 373 & 92 & 291 & 31.62 & \multirow{3}{*}{$\begin{array}{c}32.80 \\
{[25.16} \\
40.44]\end{array}$} & 34.48 & 948.10 & 3.64 & \multirow{3}{*}{$\begin{array}{c}4.94 \\
{[3.36} \\
6.52]\end{array}$} & 8.69 & \multirow{3}{*}{$\begin{array}{c}6.86 \\
{[4.42} \\
9.31]\end{array}$} \\
\hline MayJunWknd & JulWknd & 632 & 104 & 268 & 38.81 & & 54.73 & 948.10 & 5.77 & & 6.72 & \\
\hline SeptOctWknd & NovWknd & 563 & 87 & 311 & 27.97 & & 51.28 & 948.10 & 5.41 & & 5.17 & \\
\hline JanFebWknd & MarWkdy & 373 & 153 & 527 & 29.03 & \multirow{3}{*}{$\begin{array}{c}33.49 \\
{[27.31} \\
39.67]\end{array}$} & 34.48 & 948.10 & 3.64 & \multirow{3}{*}{$\begin{array}{c}4.94 \\
{[3.36} \\
6.52]\end{array}$} & 7.98 & \multirow{3}{*}{$\begin{array}{c}6.92 \\
{[5.61} \\
8.22]\end{array}$} \\
\hline MayJunWknd & JulWkdy & 632 & 263 & 693 & 37.95 & & 54.73 & 948.10 & 5.77 & & 6.57 & \\
\hline SeptOctWknd & NovWkdy & 563 & 224 & 669 & 33.48 & & 51.28 & 948.10 & 5.41 & & 6.19 & \\
\hline \multicolumn{13}{|l|}{ Nnh EdBurg } \\
\hline *JanFeb & Mar & 497 & 52 & 291 & 17.87 & \multirow{3}{*}{$\begin{array}{c}21.74 \\
{[15.11} \\
28.36]\end{array}$} & 13.73 & 948.10 & 1.45 & \multirow{3}{*}{$\begin{array}{c}2.35 \\
{[1.14} \\
3.57]\end{array}$} & 12.34 & \multirow{3}{*}{$\begin{array}{c}9.73 \\
{[6.60} \\
12.86]\end{array}$} \\
\hline *MayJun & Jul & 701 & 114 & 421 & 27.08 & & 30.39 & 948.10 & 3.21 & & 8.45 & \\
\hline *SeptOct & Nov & 672 & 78 & 385 & 20.26 & & 22.85 & 948.10 & 2.41 & & 8.40 & \\
\hline JanFebWkdy & MarWkdy & 387 & 29 & 196 & 14.80 & \multirow{3}{*}{$\begin{array}{r}16.38 \\
{[14.05} \\
18.72]\end{array}$} & 9.58 & 948.10 & 1.01 & \multirow{3}{*}{$\begin{array}{c}1.63 \\
{[0.83} \\
2.43]\end{array}$} & 14.64 & \multirow{3}{*}{$\begin{array}{l}10.88 \\
{[5.93} \\
15.82]\end{array}$} \\
\hline MayJunWkdy & JulWkdy & 520 & 53 & 327 & 16.21 & & 20.37 & 948.10 & 2.15 & & 7.54 & \\
\hline SeptOctWkdy & NovWkdy & 524 & 49 & 270 & 18.15 & & 16.47 & 948.10 & 1.74 & & 10.45 & \\
\hline JanFebWkdy & MarWknd & 387 & 16 & 95 & 16.84 & \multirow{3}{*}{$\begin{array}{c}19.86 \\
{[14.24} \\
25.48]\end{array}$} & 9.58 & 948.10 & 1.01 & \multirow{3}{*}{$\begin{array}{c}1.63 \\
{[0.83} \\
2.43]\end{array}$} & 16.66 & \multirow{3}{*}{$\begin{array}{l}12.85 \\
{[8.24} \\
17.47]\end{array}$} \\
\hline MayJunWkdy & JulWknd & 520 & 23 & 94 & 24.47 & & 20.37 & 948.10 & 2.15 & & 11.39 & \\
\hline SeptOctWkdy & NovWknd & 524 & 21 & 115 & 18.26 & & 16.47 & 948.10 & 1.74 & & 10.51 & \\
\hline
\end{tabular}




\begin{tabular}{|c|c|c|c|c|c|c|c|c|c|c|c|c|}
\hline $\begin{array}{l}\text { Generation } \\
\text { Sample }\end{array}$ & $\begin{array}{c}\text { Test } \\
\text { Sample }\end{array}$ & $\begin{array}{l}\text { Crimes in } \\
\text { Generation } \\
\text { Sample }\end{array}$ & $\begin{array}{l}\text { Test Sample } \\
\text { Crimes in } \\
\text { Hotspots }\end{array}$ & $\begin{array}{l}\text { Total Test } \\
\text { Sample } \\
\text { Crimes }\end{array}$ & $\begin{array}{c}\text { Hit Rate } \\
(\%)\end{array}$ & $\begin{array}{c}\text { Hit Rate } \\
\text { Mean } \\
{[95 \% \mathrm{CI}]}\end{array}$ & $\begin{array}{c}\text { Hotspot } \\
\text { Area } \\
\left(\mathrm{km}^{2}\right)\end{array}$ & $\begin{array}{c}\text { Total } \\
\text { Study Area } \\
\left(\mathrm{km}^{2}\right)\end{array}$ & Area \% & $\begin{array}{c}\text { Area \% } \\
\text { Mean } \\
{[95 \% \mathrm{CI}]}\end{array}$ & PAI & $\begin{array}{c}\text { PAI Mean } \\
{[95 \% \text { CI] }}\end{array}$ \\
\hline \multicolumn{13}{|l|}{ Nnh EdBurg } \\
\hline JanFebWknd & MarWknd & 109 & 2 & 95 & 2.11 & 2.57 & 0.89 & 948.10 & 0.09 & 0.14 & 22.43 & 13.18 \\
\hline MayJunWknd & JulWknd & 181 & 2 & 94 & 2.13 & \multirow{2}{*}{$\begin{array}{l}{[1.48,} \\
3.66]\end{array}$} & 2.18 & 948.10 & 0.23 & \multirow{2}{*}{$\begin{array}{c}{[0.03,} \\
0.25]\end{array}$} & 9.25 & \multirow{2}{*}{$\begin{array}{l}{[4.16,} \\
40.69]\end{array}$} \\
\hline SeptOctWknd & NovWknd & 148 & 4 & 115 & 3.48 & & 0.93 & 948.10 & 0.10 & & 35.60 & \\
\hline JanFebWknd & MarWkdy & 109 & 3 & 196 & 1.53 & \multirow{3}{*}{$\begin{array}{c}2.47 \\
{[0.96} \\
3.99]\end{array}$} & 0.89 & 948.10 & 0.09 & \multirow{3}{*}{$\begin{array}{c}0.14 \\
{[0.03} \\
0.25]\end{array}$} & 16.30 & \multirow{3}{*}{$\begin{array}{c}18.33 \\
{[13.03} \\
23.64)\end{array}$} \\
\hline MayJunWknd & JulWkdy & 181 & 12 & 327 & 3.67 & & 2.18 & 948.10 & 0.23 & & 15.95 & \\
\hline SeptOctWknd & NovWkdy & 148 & 6 & 270 & 2.22 & & 0.93 & 948.10 & 0.10 & & 22.75 & \\
\hline \multicolumn{13}{|l|}{ Nnh EdTFMV } \\
\hline *JanFeb & Mar & 1411 & 362 & 818 & 44.25 & 47.23 & 49.42 & 948.10 & 5.21 & 6.93 & 8.49 & 7.00 \\
\hline *MayJun & Jul & 2024 & 451 & 961 & 46.93 & \multirow{2}{*}{$\begin{array}{c}{[42.88} \\
51.58]\end{array}$} & 70.04 & 948.10 & 7.39 & \multirow{2}{*}{$\begin{array}{l}{[4.79,} \\
9.07]\end{array}$} & 6.35 & \multirow{2}{*}{$\begin{array}{l}{[5.21} \\
8.79]\end{array}$} \\
\hline *SeptOct & Nov & 2083 & 495 & 980 & 50.51 & & 77.68 & 948.10 & 8.19 & & 6.17 & \\
\hline JanFebWkdy & MarWkdy & 1038 & 195 & 527 & 37.00 & \multirow{3}{*}{$\begin{array}{c}40.40 \\
{[35.59} \\
45.22]\end{array}$} & 36.79 & 948.10 & 3.88 & \multirow{3}{*}{$\begin{array}{r}5.07 \\
{[3.55} \\
6.60]\end{array}$} & 9.54 & \multirow{3}{*}{$\begin{array}{c}8.14 \\
{[6.44} \\
9.83]\end{array}$} \\
\hline MayJunWkdy & JulWkdy & 1392 & 279 & 693 & 40.26 & & 50.12 & 948.10 & 5.29 & & 7.62 & \\
\hline SeptOctWkdy & NovWkdy & 1520 & 294 & 669 & 43.95 & & 57.42 & 948.10 & 6.06 & & 7.26 & \\
\hline JanFebWkdy & MarWknd & 1038 & 118 & 291 & 40.55 & \multirow{3}{*}{$\begin{array}{c}39.92 \\
{[38.69} \\
41.14]\end{array}$} & 36.79 & 948.10 & 3.88 & \multirow{3}{*}{$\begin{array}{r}5.07 \\
{[3.55} \\
6.60]\end{array}$} & 10.45 & \multirow{3}{*}{$\begin{array}{c}8.17 \\
{[5.30} \\
11.03]\end{array}$} \\
\hline MayJunWkdy & JulWknd & 1392 & 108 & 268 & 40.30 & & 50.12 & 948.10 & 5.29 & & 7.62 & \\
\hline SeptOctWkdy & NovWknd & 1520 & 121 & 311 & 38.91 & & 57.42 & 948.10 & 6.06 & & 6.42 & \\
\hline JanFebWknd & MarWknd & 373 & 47 & 291 & 16.15 & \multirow{3}{*}{$\begin{array}{c}17.19 \\
{[12.10} \\
22.28]\end{array}$} & 8.89 & 948.10 & 0.94 & \multirow{3}{*}{$\begin{array}{c}1.53 \\
{[0.79} \\
2.28]\end{array}$} & 17.23 & \multirow{3}{*}{$\begin{array}{l}12.13 \\
{[5.80} \\
18.45]\end{array}$} \\
\hline MayJunWknd & JulWknd & 632 & 57 & 268 & 21.27 & & 18.83 & 948.10 & 1.99 & & 10.71 & \\
\hline SeptOctWknd & NovWknd & 563 & 44 & 311 & 14.15 & & 15.89 & 948.10 & 1.68 & & 8.44 & \\
\hline JanFebWknd & MarWkdy & 373 & 83 & 527 & 15.75 & \multirow{3}{*}{$\begin{array}{c}18.58 \\
{[13.86} \\
23.31]\end{array}$} & 8.89 & 948.10 & 0.94 & \multirow{3}{*}{$\begin{array}{c}1.53 \\
{[0.79} \\
2.28]\end{array}$} & 16.80 & 12.86 \\
\hline MayJunWknd & JulWkdy & 632 & 155 & 693 & 22.37 & & 18.83 & 948.10 & 1.99 & & 11.26 & \multirow{2}{*}{$\begin{array}{l}{[8.11} \\
17.62]\end{array}$} \\
\hline SeptOctWknd & NovWkdy & 563 & 118 & 669 & 17.64 & & 15.89 & 948.10 & 1.68 & & 10.52 & \\
\hline
\end{tabular}




\begin{tabular}{|c|c|c|c|c|c|c|c|c|c|c|c|c|}
\hline $\begin{array}{l}\text { Generation } \\
\text { Sample }\end{array}$ & $\begin{array}{c}\text { Test } \\
\text { Sample }\end{array}$ & $\begin{array}{l}\text { Crimes in } \\
\text { Generation } \\
\text { Sample }\end{array}$ & $\begin{array}{c}\text { Test Sample } \\
\text { Crimes in } \\
\text { Hotspots }\end{array}$ & $\begin{array}{l}\text { Total Test } \\
\text { Sample } \\
\text { Crimes }\end{array}$ & $\begin{array}{c}\text { Hit Rate } \\
(\%)\end{array}$ & $\begin{array}{l}\text { Hit Rate } \\
\text { Mean } \\
{[95 \% \text { CI }]}\end{array}$ & $\begin{array}{l}\text { Hotspot } \\
\text { Area } \\
\left(\mathrm{km}^{2}\right)\end{array}$ & $\begin{array}{c}\text { Total } \\
\text { Study Area } \\
\left(\mathrm{km}^{2}\right)\end{array}$ & Area \% & $\begin{array}{c}\text { Area \% } \\
\text { Mean } \\
{[95 \% \mathrm{CI}]}\end{array}$ & PAI & $\begin{array}{c}\text { PAI Mean } \\
{[95 \% \text { CI] }}\end{array}$ \\
\hline \multicolumn{13}{|c|}{ ProMap EdBurg } \\
\hline *JanFeb & Mar & 497 & 193 & 291 & 66.32 & 71.85 & 152.89 & 948.10 & 16.13 & 18.38 & 4.11 & 3.92 \\
\hline *MayJun & Jul & 701 & 333 & 421 & 79.10 & \multirow{2}{*}{$\begin{array}{l}{[62.76,} \\
80.94]\end{array}$} & 189.03 & 948.10 & 19.94 & \multirow{2}{*}{$\begin{array}{l}{[15.61,} \\
21.15]\end{array}$} & 3.97 & \multirow{2}{*}{$\begin{array}{l}{[3.61,} \\
4.23]\end{array}$} \\
\hline *SeptOct & Nov & 672 & 270 & 385 & 70.13 & & 180.80 & 948.10 & 19.07 & & 3.68 & \\
\hline JanFebWkdy & MarWkdy & 387 & 113 & 196 & 57.65 & \multirow{3}{*}{$\begin{array}{r}65.96 \\
{[54.42} \\
77.51]\end{array}$} & 132.32 & 948.10 & 13.96 & \multirow{3}{*}{$\begin{array}{c}16.12 \\
{[13.44} \\
18.81]\end{array}$} & 4.13 & \multirow{3}{*}{$\begin{array}{c}4.09 \\
{[3.91} \\
4.27]\end{array}$} \\
\hline MayJunWkdy & JulWkdy & 520 & 243 & 327 & 74.31 & & 167.77 & 948.10 & 17.69 & & 4.20 & \\
\hline SeptOctWkdy & NovWkdy & 524 & 178 & 270 & 65.93 & & 158.49 & 948.10 & 16.72 & & 3.94 & \\
\hline JanFebWkdy & MarWknd & 387 & 59 & 95 & 62.11 & \multirow{3}{*}{$\begin{array}{c}67.97 \\
{[57.40} \\
78.54]\end{array}$} & 132.32 & 948.10 & 13.96 & \multirow{3}{*}{$\begin{array}{c}16.12 \\
{[13.44} \\
18.81]\end{array}$} & 4.45 & \multirow{3}{*}{$\begin{array}{r}4.23 \\
{[3.83} \\
4.63]\end{array}$} \\
\hline MayJunWkdy & JulWknd & 520 & 72 & 94 & 76.60 & & 167.77 & 948.10 & 17.69 & & 4.33 & \\
\hline SeptOctWkdy & NovWknd & 524 & 75 & 115 & 65.22 & & 158.49 & 948.10 & 16.72 & & 3.90 & \\
\hline JanFebWknd & MarWknd & 109 & 28 & 95 & 29.47 & \multirow{3}{*}{$\begin{array}{c}40.79 \\
{[27.20} \\
54.38]\end{array}$} & 60.79 & 948.10 & 6.41 & \multirow{3}{*}{$\begin{array}{c}8.19 \\
{[6.04} \\
10.33]\end{array}$} & 4.60 & \multirow{3}{*}{$\begin{array}{c}4.94 \\
{[4.52} \\
5.37]\end{array}$} \\
\hline MayJunWknd & JulWknd & 181 & 44 & 94 & 46.81 & & 87.63 & 948.10 & 9.24 & & 5.06 & \\
\hline SeptOctWknd & NovWknd & 148 & 53 & 115 & 46.09 & & 84.49 & 948.10 & 8.91 & & 5.17 & \\
\hline JanFebWknd & MarWkdy & 109 & 67 & 196 & 34.18 & \multirow{3}{*}{$\begin{array}{c}39.67 \\
{[32.50} \\
46.83]\end{array}$} & 60.79 & 948.10 & 6.41 & \multirow{3}{*}{$\begin{array}{c}8.19 \\
{[6.04} \\
10.33]\end{array}$} & 5.33 & \multirow{3}{*}{$\begin{array}{c}4.90 \\
{[4.22} \\
5.57]\end{array}$} \\
\hline MayJunWknd & JulWkdy & 181 & 132 & 327 & 40.37 & & 87.63 & 948.10 & 9.24 & & 4.37 & \\
\hline SeptOctWknd & NovWkdy & 148 & 120 & 270 & 44.44 & & 84.49 & 948.10 & 8.91 & & 4.99 & \\
\hline \multicolumn{13}{|c|}{ ProMap EdTFMV } \\
\hline *JanFeb & Mar & 1411 & 462 & 818 & 56.48 & \multirow{3}{*}{$\begin{array}{r}61.42 \\
{[55.35} \\
67.49]\end{array}$} & 89.90 & 948.10 & 9.48 & \multirow{3}{*}{$\begin{array}{l}11.64 \\
{[9.01} \\
14.27]\end{array}$} & 5.96 & \multirow{3}{*}{$\begin{array}{c}5.34 \\
{[4.54} \\
6.13]\end{array}$} \\
\hline *MayJun & Jul & 2024 & 623 & 961 & 64.83 & & 117.32 & 948.10 & 12.37 & & 5.24 & \\
\hline *SeptOct & Nov & 2083 & 617 & 980 & 62.96 & & 123.83 & 948.10 & 13.06 & & 4.82 & \\
\hline JanFebWkdy & MarWkdy & 1038 & 267 & 527 & 50.66 & \multirow{3}{*}{$\begin{array}{c}55.06 \\
{[49.75} \\
60.38]\end{array}$} & 74.86 & 948.10 & 7.90 & \multirow{3}{*}{$\begin{array}{c}9.56 \\
{[7.47} \\
11.65]\end{array}$} & 6.42 & \multirow{3}{*}{$\begin{array}{r}5.82 \\
{[5.01} \\
6.63]\end{array}$} \\
\hline MayJunWkdy & JulWkdy & 1392 & 400 & 693 & 57.72 & & 94.42 & 948.10 & 9.96 & & 5.80 & \\
\hline SeptOctWkdy & NovWkdy & 1520 & 380 & 669 & 56.80 & & 102.67 & 948.10 & 10.83 & & 5.25 & \\
\hline
\end{tabular}




\begin{tabular}{|c|c|c|c|c|c|c|c|c|c|c|c|c|}
\hline $\begin{array}{l}\text { Generation } \\
\text { Sample }\end{array}$ & $\begin{array}{c}\text { Test } \\
\text { Sample }\end{array}$ & $\begin{array}{l}\text { Crimes in } \\
\text { Generation } \\
\text { Sample }\end{array}$ & $\begin{array}{l}\text { Test Sample } \\
\text { Crimes in } \\
\text { Hotspots }\end{array}$ & $\begin{array}{l}\text { Total Test } \\
\text { Sample } \\
\text { Crimes }\end{array}$ & $\begin{array}{c}\text { Hit Rate } \\
(\%)\end{array}$ & $\begin{array}{c}\text { Hit Rate } \\
\text { Mean } \\
{[95 \% \mathrm{CI}]}\end{array}$ & $\begin{array}{l}\text { Hotspot } \\
\text { Area } \\
\left(\mathrm{km}^{2}\right)\end{array}$ & $\begin{array}{c}\text { Total } \\
\text { Study Area } \\
\left(\mathrm{km}^{2}\right)\end{array}$ & Area \% & $\begin{array}{c}\text { Area \% } \\
\text { Mean } \\
{[95 \% \mathrm{CI}]}\end{array}$ & PAI & $\begin{array}{c}\text { PAI Mean } \\
{[95 \% \text { CI] }}\end{array}$ \\
\hline \multicolumn{13}{|c|}{ ProMap EdTFMV } \\
\hline JanFebWkdy & MarWknd & 1038 & 153 & 291 & 52.58 & 56.42 & 74.86 & 948.10 & 7.90 & 9.56 & 6.66 & 5.97 \\
\hline MayJunWkdy & JulWknd & 1392 & 155 & 268 & 57.84 & \multirow{2}{*}{$\begin{array}{l}{[51.76,} \\
61.08]\end{array}$} & 94.42 & 948.10 & 9.96 & \multirow{2}{*}{$\begin{array}{l}{[7.47,} \\
11.65]\end{array}$} & 5.81 & \multirow{2}{*}{$\begin{array}{c}{[5.10} \\
6.84]\end{array}$} \\
\hline SeptOctWkdy & NovWknd & 1520 & 183 & 311 & 58.84 & & 102.67 & 948.10 & 10.83 & & 5.43 & \\
\hline JanFebWknd & MarWknd & 373 & 92 & 291 & 31.62 & \multirow{3}{*}{$\begin{array}{c}32.57 \\
{[25.01} \\
40.12]\end{array}$} & 34.03 & 948.10 & 3.59 & \multirow{3}{*}{$\begin{array}{c}4.88 \\
{[3.31} \\
6.44]\end{array}$} & 8.81 & \multirow{3}{*}{$\begin{array}{c}6.91 \\
{[4.38} \\
9.44]\end{array}$} \\
\hline MayJunWknd & JulWknd & 632 & 103 & 268 & 38.43 & & 53.99 & 948.10 & 5.69 & & 6.75 & \\
\hline SeptOctWknd & NovWknd & 563 & 86 & 311 & 27.65 & & 50.68 & 948.10 & 5.35 & & 5.17 & \\
\hline JanFebWknd & MarWkdy & 373 & 152 & 527 & 28.84 & \multirow{3}{*}{$\begin{array}{c}33.33 \\
{[27.21} \\
39.44]\end{array}$} & 34.03 & 948.10 & 3.59 & \multirow{3}{*}{$\begin{array}{r}4.88 \\
{[3.31} \\
6.44]\end{array}$} & 8.03 & \multirow{3}{*}{$\begin{array}{r}6.97 \\
{[5.67} \\
8.27]\end{array}$} \\
\hline MayJunWknd & JulWkdy & 632 & 261 & 693 & 37.66 & & 53.99 & 948.10 & 5.69 & & 6.61 & \\
\hline SeptOctWknd & NovWkdy & 563 & 224 & 669 & 33.48 & & 50.68 & 948.10 & 5.35 & & 6.26 & \\
\hline
\end{tabular}

*The predictive accuracy results for these rows are the same as those presented in Phase 2 (see Table 10). 
Comparison of hotspot mapping approaches. Based on the overall results presented in Table 11, some predictive accuracy trends found in Phase 2 were again found in Strategy 1 of Phase 3. For example, the Nnh approach consistently resulted in lower mean area percentages than both the $\mathrm{KDE}$ and prospective hot-spotting approaches across the various data files for both crime types examined. However, the Nnh hotspot mapping technique also consistently resulted in lower mean hit rates than the other two hotspot mapping techniques. The overall trends also suggest that the Nnh approach resulted in the most unstable PAI values, as indicated by the larger range of PAI values across the three blocks of time and the wider $95 \%$ CIs.

When comparing the various hotspot mapping approaches using the mean PAI values, the prospective hot-spotting method overall resulted in lower PAI values than the two traditional hotspot mapping approaches for the Edmonton burglary data files (as indicated by non-overlapping $95 \%$ CIs). The exception to this trend was applying the weekend maps to future weekend crimes where mean PAI values were comparable across the three hotspot mapping techniques. As well, the various hotspot mapping techniques, mostly resulted in comparable PAI values when examining the Edmonton TFMV data files (as indicated by overlapping 95\% CIs). As shown in Table 11, the PAI values tended to be higher for the Nnh approach than for the KDE approach for both the Edmonton burglary and TFMV data files; however, the overlapping 95\% CIs suggest that these differences were slight and are not necessarily meaningful.

Weekday/weekend hotspot maps vs. general hotspot maps. The results presented in Table 11 allow for a comparison within each hotspot mapping approach between the predictive accuracy of the general maps generated in Phase 2 and the more specific 
weekday/weekend hotspot maps generated in Strategy 1 of Phase 3. Across all three hotspot mapping techniques, the weekday and weekend hotspot maps tended to produce PAI values that were slightly higher than the general hotspot maps, regardless of whether the weekday/weekend maps were used to predict crimes that occurred during corresponding (e.g., weekday map used to predict weekday crime) or opposing (e.g., weekday map used to predict weekend crime) times of the week. This trend was similar for both the Edmonton burglary and Edmonton TFMV data files. However, the overlapping 95\% CIs again suggest that these differences were not overly meaningful.

Time of week. The results presented in Table 11 were also examined to determine whether weekday/weekend hotspot maps used to predict future crimes that occurred during the same time of the week were more accurate than those used to predict future crimes that occurred during the opposing time of the week (e.g., using weekday maps to predict weekday crimes versus using weekday maps to predict weekend crimes). Regardless of the hotspot mapping technique examined and across both Edmonton burglary and Edmonton TFMV data files, weekday/weekend hotspot maps used to predict future crimes that occurred during the same time of the week resulted in PAI values that were comparable to those found when weekday/weekend hotspot maps were used to predict future crimes that occurred during the opposing time of the week.

The results do indicate, however, that maps generated using the weekend data consistently resulted in lower mean hit rates and area percentages across all three hotspot mapping techniques. For example, for the Edmonton TFMV data file, weekday maps generated using the prospective hot-spotting approach resulted in hit rates varying from 50.66 to $57.72(M=55.06 ; S D=3.84 ; 95 \% \mathrm{CI}[49.75,60.38])$ when applied to future 
weekday crime and from 52.58 to $58.84(M=56.42 ; S D=3.36 ; 95 \%$ CI $[51.76,61.08])$ when applied to future weekend crime. In contrast, weekend maps generated using the prospective hot-spotting approach only resulted in hit rates ranging from 27.65 to 31.62 $(M=32.57 ; S D=5.45 ; 95 \% \mathrm{CI}[25.01,40.12])$ when applied to future weekend crime and from 28.84 to $37.66(M=33.33 ; S D=4.41 ; 95 \%$ CI $[27.21,39.44])$ when applied to future weekday crime. It seems unlikely that this finding was the result of a sample size issue since 109 to 181 crimes were used to generate the Edmonton burglary weekend hotspot maps and 373 to 632 crimes were used to generate the Edmonton TFMV weekend hotspot maps.

\section{Strategy 2: Time Period Used to Generate the Maps}

Data. The data used for Strategy 2 was the same as the Edmonton burglary and TFMV data used in Phase 2. However, the time period used to generate the maps (i.e., the temporal bandwidth) was varied to determine whether using data from longer time periods resulted in greater predictive accuracy. As in Phase 2, maps were generated and tested using data from three different blocks of time. See Table 12 for a breakdown of the timeframes used to generate and test the hotspot maps. 
Table 12. Breakdown of crimes used to generate and test the risk surfaces in Phase 3:

Strategy $2 .^{37}$

Map generated using crimes that occurred between:
Map tested using crimes that occurred between:

February 16-29, 2008

February 1-29, 2008

March 1-31, 2008

January 1-February 29, 2008

June 17-30, 2008

June 1-30, 2008

July 1-31, 2008

May 1-June 30, 2008

October 18-31, 2008

October 1-31, 2008

November 1-30, 2008

September 1-October 31, 2008

Procedure. Following the procedures explained in the hotspot mapping section of Phase 2, KDE, Nnh, and prospective risk surfaces were generated using crimes that occurred within a 2 week, 1 month, and 2 month timeframe. More specifically, across each of the three hotspot mapping techniques, six hotspot maps were generated for each data file (i.e., Edmonton burglary and TFMV) using offences that occurred within the three time periods. Thus, in total, 36 new hotspot maps were generated for Strategy $2 .^{38}$

Once all 36 hotspot maps had been generated the crimes that occurred between March 1-31, July1-31, and November 1-30, 2008, were plotted onto their respective maps in ArcView in order to determine the predictive accuracy when using two weeks', one

\footnotetext{
${ }^{37}$ Note that in addition to the timeframes listed in Table 12, the prospective risk surfaces generated in Phase 2 using the empirically-derived 7-day temporal bandwidth were also examined in Strategy 2. These maps were generated using data from the following timeframes: (1) February 23-29, (2) June 24-30, and (3) October 25-31, 2008.

${ }^{38}$ Note that the maps generated using 2 months' of data were the same as the maps generated in Phase 2.
} 
month's, and two months' worth of data to generate the maps. Chainey et al.'s (2008) predictive accuracy index was again used to assess map accuracy.

Hypotheses. It was hypothesized that using a longer time period to generate the maps (i.e., 2 months) would result in higher PAI values than using shorter time periods (i.e., 2 weeks or 1 month). This hypothesis was based on the fact that the use of longer time periods would result in more data (i.e., more crimes), which should provide a more reliable basis to make predictions about the locations of future crimes.

Results. The predictive accuracy results for the maps generated in Strategy 2 are presented in Table 13. The columns in Table 13 that are of particular interest to the Strategy 2 results again include the hit rate, area percentage, and PAI. Means and 95\% CIs are also presented in Table 13 for each of the three accuracy measures examined (means and 95\% CIs were calculated for each temporal bandwidth based on the accuracy results across all three blocks of time). 
Table 13. Predictive accuracy of Phase 3: Strategy 2 maps.

\begin{tabular}{|c|c|c|c|c|c|c|c|c|c|c|c|c|}
\hline Generation Sample & $\begin{array}{c}\text { Test } \\
\text { Sample }\end{array}$ & $\begin{array}{c}\text { Crimes in } \\
\text { Generation } \\
\text { Sample }\end{array}$ & $\begin{array}{l}\text { Test Sample } \\
\text { Crimes in } \\
\text { Hotspots }\end{array}$ & $\begin{array}{l}\text { Total Test } \\
\text { Sample } \\
\text { Crimes }\end{array}$ & $\begin{array}{c}\text { Hit Rate } \\
(\%)\end{array}$ & $\begin{array}{c}\text { Hit Rate } \\
\text { Mean } \\
{[95 \% \text { CI] }}\end{array}$ & $\begin{array}{c}\text { Hotspot } \\
\text { Area } \\
\left(\mathrm{km}^{2}\right)\end{array}$ & $\begin{array}{c}\text { Total } \\
\text { Study Area } \\
\left(\mathrm{km}^{2}\right)\end{array}$ & Area \% & $\begin{array}{c}\text { Area \% } \\
\text { Mean } \\
{[95 \% \text { CI] }}\end{array}$ & PAI & $\begin{array}{l}\text { PAI Mean } \\
{[95 \% \text { CI }]}\end{array}$ \\
\hline \multicolumn{13}{|l|}{ KDE EdBurg } \\
\hline Feb16-29 & March & 137 & 43 & 291 & 14.78 & 14.20 & 14.04 & 948.10 & 1.48 & 1.67 & 9.98 & 8.58 \\
\hline Jun17-30 & July & 154 & 57 & 421 & 13.54 & \multirow{2}{*}{$\begin{array}{c}{[13.34} \\
15.06]\end{array}$} & 17.14 & 948.10 & 1.81 & \multirow{2}{*}{$\begin{array}{c}{[1.44,} \\
1.91]\end{array}$} & 7.49 & \multirow{2}{*}{$\begin{array}{l}{[6.81} \\
10.34]\end{array}$} \\
\hline Oct18-31 & Nov & 149 & 55 & 385 & 14.29 & & 16.39 & 948.10 & 1.73 & & 8.26 & \\
\hline Feb & March & 266 & 72 & 291 & 24.74 & 24.66 & 25.87 & 948.10 & 2.73 & 3.30 & 9.07 & 7.61 \\
\hline Jun & July & 354 & 98 & 421 & 23.28 & \multirow{2}{*}{$\begin{array}{l}{[22.79} \\
26.54]\end{array}$} & 35.40 & 948.10 & 3.73 & \multirow{2}{*}{$\begin{array}{l}{[2.59,} \\
4.02]\end{array}$} & 6.23 & \multirow{2}{*}{$\begin{array}{c}{[5.65} \\
9.58]\end{array}$} \\
\hline Oct & Nov & 337 & 100 & 385 & 25.97 & & 32.67 & 948.10 & 3.45 & & 7.54 & \\
\hline *JanFeb & March & 497 & 95 & 291 & 32.65 & \multirow{3}{*}{$\begin{array}{c}36.81 \\
{[31.40} \\
42.22]\end{array}$} & 43.62 & 948.10 & 4.60 & \multirow{3}{*}{$\begin{array}{c}5.68 \\
{[4.36} \\
6.99]\end{array}$} & 7.10 & \multirow{3}{*}{$\begin{array}{r}6.54 \\
{[5.85} \\
7.22]\end{array}$} \\
\hline *MayJun & July & 701 & 170 & 421 & 40.38 & & 60.55 & 948.10 & 6.39 & & 6.32 & \\
\hline *SeptOct & Nov & 672 & 144 & 385 & 37.40 & & 57.33 & 948.10 & 6.05 & & 6.19 & \\
\hline \multicolumn{13}{|l|}{ KDE EdTFMV } \\
\hline Feb16-29 & March & 330 & 217 & 818 & 26.53 & 29.15 & 31.90 & 948.10 & 3.36 & \multirow{3}{*}{$\begin{array}{r}4.05 \\
{[3.22} \\
4.89]\end{array}$} & 7.88 & \multirow{3}{*}{$\begin{array}{c}7.25 \\
{[6.38} \\
8.11]\end{array}$} \\
\hline Jun17-30 & July & 430 & 299 & 961 & 31.11 & \multirow{2}{*}{$\begin{array}{l}{[25.87} \\
32.42]\end{array}$} & 40.86 & 948.10 & 4.31 & & 7.22 & \\
\hline Oct18-31 & Nov & 443 & 292 & 980 & 29.80 & & 42.56 & 948.10 & 4.49 & & 6.64 & \\
\hline Feb & March & 684 & 344 & 818 & 42.05 & 45.93 & 56.20 & 948.10 & 5.93 & 7.59 & 7.09 & 6.16 \\
\hline Jun & July & 1002 & 471 & 961 & 49.01 & \multirow{2}{*}{$\begin{array}{c}{[41.02} \\
50.85]\end{array}$} & 77.80 & 948.10 & 8.21 & \multirow{2}{*}{$\begin{array}{c}{[5.57} \\
9.60]\end{array}$} & 5.97 & \multirow{2}{*}{$\begin{array}{c}{[4.98} \\
7.35]\end{array}$} \\
\hline Oct & Nov & 1068 & 458 & 980 & 46.73 & & 81.81 & 948.10 & 8.63 & & 5.42 & \\
\hline *JanFeb & March & 1411 & 471 & 818 & 57.58 & 62.30 & 92.91 & 948.10 & 9.80 & 12.01 & 5.88 & 5.25 \\
\hline *MayJun & July & 2024 & 631 & 961 & 65.66 & \multirow{2}{*}{$\begin{array}{c}{[56.47} \\
68.14]\end{array}$} & 120.66 & 948.10 & 12.73 & \multirow{2}{*}{$\begin{array}{l}\text { [9.31, } \\
14.71]\end{array}$} & 5.16 & \multirow{2}{*}{$\begin{array}{c}{[4.44} \\
6.06]\end{array}$} \\
\hline *SeptOct & Nov & 2083 & 624 & 980 & 63.67 & & 127.90 & 948.10 & 13.49 & & 4.72 & \\
\hline
\end{tabular}




\begin{tabular}{|c|c|c|c|c|c|c|c|c|c|c|c|c|}
\hline Generation Sample & $\begin{array}{c}\text { Test } \\
\text { Sample }\end{array}$ & $\begin{array}{l}\text { Crimes in } \\
\text { Generation } \\
\text { Sample }\end{array}$ & $\begin{array}{l}\text { Test Sample } \\
\text { Crimes in } \\
\text { Hotspots }\end{array}$ & $\begin{array}{l}\text { Total Test } \\
\text { Sample } \\
\text { Crimes }\end{array}$ & $\begin{array}{c}\text { Hit Rate } \\
(\%)\end{array}$ & $\begin{array}{c}\text { Hit Rate } \\
\text { Mean } \\
{[95 \% \mathrm{CI}]}\end{array}$ & $\begin{array}{c}\text { Hotspot } \\
\text { Area } \\
\left(\mathrm{km}^{2}\right)\end{array}$ & $\begin{array}{c}\text { Total } \\
\text { Study Area } \\
\left(\mathrm{km}^{2}\right)\end{array}$ & Area \% & $\begin{array}{c}\text { Area \% } \\
\text { Mean } \\
{[95 \% \mathrm{CI}]}\end{array}$ & PAI & $\begin{array}{c}\text { PAI Mean } \\
{[95 \% \text { CI] }}\end{array}$ \\
\hline \multicolumn{13}{|l|}{ Nnh EdBurg } \\
\hline Feb16-29 & March & 137 & 17 & 291 & 5.84 & \multirow{3}{*}{$\begin{array}{c}3.76 \\
{[1.26} \\
6.26]\end{array}$} & 2.76 & 948.10 & 0.29 & \multirow{3}{*}{$\begin{array}{c}0.22 \\
{[0.11} \\
0.32]\end{array}$} & 20.07 & \multirow{3}{*}{$\begin{array}{c}17.39 \\
{[10.40} \\
24.38]\end{array}$} \\
\hline Jun17-30 & July & 154 & 12 & 421 & 2.85 & & 1.32 & 948.10 & 0.14 & & 20.53 & \\
\hline Oct18-31 & Nov & 149 & 10 & 385 & 2.60 & & 2.13 & 948.10 & 0.22 & & 11.58 & \\
\hline Feb & March & 266 & 28 & 291 & 9.62 & \multirow{3}{*}{$\begin{array}{l}10.61 \\
{[8.38,} \\
12.84]\end{array}$} & 5.48 & 948.10 & 0.58 & \multirow{3}{*}{$\begin{array}{c}0.85 \\
{[0.47} \\
1.24]\end{array}$} & 16.64 & \multirow{3}{*}{$\begin{array}{c}13.33 \\
{[7.48} \\
19.19]\end{array}$} \\
\hline Jun & July & 354 & 41 & 421 & 9.74 & & 10.77 & 948.10 & 1.14 & & 8.57 & \\
\hline Oct & Nov & 337 & 48 & 385 & 12.47 & & 8.00 & 948.10 & 0.84 & & 14.78 & \\
\hline *JanFeb & March & 497 & 52 & 291 & 17.87 & \multirow{3}{*}{$\begin{array}{c}21.74 \\
{[15.11} \\
28.36]\end{array}$} & 13.73 & 948.10 & 1.45 & \multirow{3}{*}{$\begin{array}{c}2.35 \\
{[1.14} \\
3.57]\end{array}$} & 12.34 & \multirow{3}{*}{$\begin{array}{c}9.73 \\
{[6.60} \\
12.86]\end{array}$} \\
\hline *MayJun & July & 701 & 114 & 421 & 27.08 & & 30.39 & 948.10 & 3.21 & & 8.45 & \\
\hline *SeptOct & Nov & 672 & 78 & 385 & 20.26 & & 22.85 & 948.10 & 2.41 & & 8.40 & \\
\hline \multicolumn{13}{|l|}{ Nnh EdTFMV } \\
\hline Feb16-29 & March & 330 & 104 & 818 & 12.71 & \multirow{3}{*}{$\begin{array}{c}14.60 \\
{[11.96} \\
17.25]\end{array}$} & 5.72 & 948.10 & 0.60 & \multirow{3}{*}{$\begin{array}{c}1.24 \\
{[0.47} \\
2.01]\end{array}$} & 21.07 & \multirow{3}{*}{$\begin{array}{l}13.64 \\
{[4.70} \\
22.58]\end{array}$} \\
\hline Jun17-30 & July & 430 & 140 & 961 & 14.57 & & 14.68 & 948.10 & 1.55 & & 9.41 & \\
\hline Oct18-31 & Nov & 443 & 162 & 980 & 16.53 & & 15.00 & 948.10 & 1.58 & & 10.45 & \\
\hline Feb & March & 684 & 195 & 818 & 23.84 & \multirow{3}{*}{$\begin{array}{c}29.51 \\
{[22.46,} \\
36.56]\end{array}$} & 23.66 & 948.10 & 2.50 & \multirow{3}{*}{$\begin{array}{r}3.56 \\
{[2.25} \\
4.87]\end{array}$} & 9.55 & \multirow{3}{*}{$\begin{array}{r}8.46 \\
{[7.13} \\
9.78]\end{array}$} \\
\hline Jun & July & 1002 & 298 & 961 & 31.01 & & 36.81 & 948.10 & 3.88 & & 7.99 & \\
\hline Oct & Nov & 1068 & 330 & 980 & 33.67 & & 40.80 & 948.10 & 4.30 & & 7.82 & \\
\hline *JanFeb & March & 1411 & 362 & 818 & 44.25 & \multirow{3}{*}{$\begin{array}{c}47.23 \\
{[42.88} \\
51.58]\end{array}$} & 49.42 & 948.10 & 5.21 & \multirow{3}{*}{$\begin{array}{c}6.93 \\
{[4.79} \\
9.07]\end{array}$} & 8.49 & \multirow{3}{*}{$\begin{array}{c}7.00 \\
{[5.21} \\
8.79]\end{array}$} \\
\hline *MayJun & July & 2024 & 451 & 961 & 46.93 & & 70.04 & 948.10 & 7.39 & & 6.35 & \\
\hline *SeptOct & Nov & 2083 & 495 & 980 & 50.51 & & 77.68 & 948.10 & 8.19 & & 6.17 & \\
\hline
\end{tabular}




\begin{tabular}{|c|c|c|c|c|c|c|c|c|c|c|c|c|}
\hline Generation Sample & $\begin{array}{c}\text { Test } \\
\text { Sample }\end{array}$ & $\begin{array}{l}\text { Crimes in } \\
\text { Generation } \\
\text { Sample }\end{array}$ & $\begin{array}{l}\text { Test Sample } \\
\text { Crimes in } \\
\text { Hotspots }\end{array}$ & $\begin{array}{l}\text { Total Test } \\
\text { Sample } \\
\text { Crimes }\end{array}$ & $\begin{array}{c}\text { Hit Rate } \\
(\%)\end{array}$ & $\begin{array}{c}\text { Hit Rate } \\
\text { Mean } \\
{[95 \% \mathrm{CI}]}\end{array}$ & $\begin{array}{l}\text { Hotspot } \\
\text { Area } \\
\left(\mathrm{km}^{2}\right)\end{array}$ & $\begin{array}{c}\text { Total } \\
\text { Study Area } \\
\left(\mathrm{km}^{2}\right)\end{array}$ & Area \% & $\begin{array}{c}\text { Area \% } \\
\text { Mean } \\
{[95 \% \mathrm{CI}]}\end{array}$ & PAI & $\begin{array}{c}\text { PAI Mean } \\
{[95 \% \text { CI] }}\end{array}$ \\
\hline \multicolumn{13}{|l|}{ ProMap EdBurg } \\
\hline *Feb23-29 & March & 58 & 64 & 291 & 21.99 & \multirow{3}{*}{$\begin{array}{c}23.16 \\
{[16.74} \\
29.58]\end{array}$} & 30.04 & 948.10 & 3.17 & \multirow{3}{*}{$\begin{array}{c}4.23 \\
{[2.84,} \\
5.62]\end{array}$} & 6.94 & \multirow{3}{*}{$\begin{array}{c}5.61 \\
{[3.85} \\
7.37]\end{array}$} \\
\hline *Jun24-30 & July & 82 & 119 & 421 & 28.27 & & 49.01 & 948.10 & 5.17 & & 5.47 & \\
\hline$*$ Oct $25-31$ & Nov & 65 & 74 & 385 & 19.22 & & 41.25 & 948.10 & 4.35 & & 4.42 & \\
\hline Feb16-29 & March & 137 & 114 & 291 & 39.18 & \multirow{3}{*}{$\begin{array}{c}40.09 \\
{[35.59} \\
44.60]\end{array}$} & 63.09 & 948.10 & 6.65 & \multirow{3}{*}{$\begin{array}{c}7.78 \\
{[6.42} \\
9.14]\end{array}$} & 5.89 & \multirow{3}{*}{$\begin{array}{r}5.20 \\
{[4.25} \\
6.15]\end{array}$} \\
\hline Jun17-30 & July & 154 & 184 & 421 & 43.71 & & 79.85 & 948.10 & 8.42 & & 5.19 & \\
\hline Oct18-31 & Nov & 149 & 144 & 385 & 37.40 & & 78.40 & 948.10 & 8.27 & & 4.52 & \\
\hline Feb & March & 266 & 159 & 291 & 54.64 & \multirow{3}{*}{$\begin{array}{c}57.82 \\
{[52.12} \\
63.53]\end{array}$} & 104.64 & 948.10 & 11.04 & \multirow{3}{*}{$\begin{array}{c}12.92 \\
{[10.54} \\
15.30]\end{array}$} & 4.95 & \multirow{3}{*}{$\begin{array}{c}4.51 \\
{[3.97} \\
5.04]\end{array}$} \\
\hline Jun & July & 354 & 263 & 421 & 62.47 & & 136.51 & 948.10 & 14.40 & & 4.34 & \\
\hline Oct & Nov & 337 & 217 & 385 & 56.36 & & 126.26 & 948.10 & 13.32 & & 4.23 & \\
\hline *JanFeb & March & 497 & 193 & 291 & 66.32 & \multirow{3}{*}{$\begin{array}{c}71.85 \\
{[62.76} \\
80.94]\end{array}$} & 152.89 & 948.10 & 16.13 & \multirow{3}{*}{$\begin{array}{c}18.38 \\
{[15.61} \\
21.15]\end{array}$} & 4.11 & \multirow{3}{*}{$\begin{array}{c}3.92 \\
{[3.61} \\
4.23]\end{array}$} \\
\hline *MayJun & July & 701 & 333 & 421 & 79.10 & & 189.03 & 948.10 & 19.94 & & 3.97 & \\
\hline *SeptOct & Nov & 672 & 270 & 385 & 70.13 & & 180.80 & 948.10 & 19.07 & & 3.68 & \\
\hline \multicolumn{13}{|l|}{ ProMap EdTFMV } \\
\hline *Feb23-29 & March & 167 & 132 & 818 & 16.14 & \multirow{3}{*}{$\begin{array}{c}15.83 \\
{[14.15} \\
17.51]\end{array}$} & 17.04 & 948.10 & 1.80 & \multirow{3}{*}{$\begin{array}{c}2.13 \\
{[1.71} \\
2.55]\end{array}$} & 8.98 & \multirow{3}{*}{$\begin{array}{c}7.54 \\
{[5.80} \\
9.29]\end{array}$} \\
\hline *Jun24-30 & July & 215 & 162 & 961 & 16.86 & & 22.67 & 948.10 & 2.39 & & 7.05 & \\
\hline$*$ Oct $25-31$ & Nov & 187 & 142 & 980 & 14.49 & & 20.80 & 948.10 & 2.19 & & 6.60 & \\
\hline Feb16-29 & March & 330 & 218 & 818 & 26.65 & \multirow{3}{*}{$\begin{array}{r}29.05 \\
{[25.87} \\
32.23]\end{array}$} & 31.63 & 948.10 & 3.34 & \multirow{3}{*}{$\begin{array}{c}4.01 \\
{[3.19} \\
4.83]\end{array}$} & 7.99 & \multirow{3}{*}{$\begin{array}{c}7.31 \\
{[6.35} \\
8.27]\end{array}$} \\
\hline Jun17-30 & July & 430 & 300 & 961 & 31.22 & & 40.40 & 948.10 & 4.26 & & 7.33 & \\
\hline Oct18-31 & Nov & 443 & 287 & 980 & 29.29 & & 42.05 & 948.10 & 4.44 & & 6.60 & \\
\hline Feb & March & 684 & 343 & 818 & 41.93 & \multirow{3}{*}{$\begin{array}{c}45.52 \\
{[40.80} \\
50.23]\end{array}$} & 55.20 & 948.10 & 5.82 & \multirow{3}{*}{$\begin{array}{c}7.44 \\
{[5.48} \\
9.39]\end{array}$} & 7.20 & \multirow{3}{*}{$\begin{array}{r}6.23 \\
{[4.99} \\
7.47]\end{array}$} \\
\hline Jun & July & 1002 & 468 & 961 & 48.70 & & 76.31 & 948.10 & 8.05 & & 6.05 & \\
\hline Oct & Nov & 1068 & 450 & 980 & 45.92 & & 80.01 & 948.10 & 8.44 & & 5.44 & \\
\hline
\end{tabular}




\begin{tabular}{|c|c|c|c|c|c|c|c|c|c|c|c|c|}
\hline Generation Sample & $\begin{array}{c}\text { Test } \\
\text { Sample }\end{array}$ & $\begin{array}{l}\text { Crimes in } \\
\text { Generation } \\
\text { Sample }\end{array}$ & $\begin{array}{l}\text { Test Sample } \\
\text { Crimes in } \\
\text { Hotspots }\end{array}$ & $\begin{array}{l}\text { Total Test } \\
\text { Sample } \\
\text { Crimes }\end{array}$ & $\begin{array}{c}\text { Hit Rate } \\
(\mathbf{\%})\end{array}$ & $\begin{array}{c}\text { Hit Rate } \\
\text { Mean } \\
{[95 \% \mathrm{CI}]}\end{array}$ & $\begin{array}{c}\text { Hotspot } \\
\text { Area } \\
\left(\mathrm{km}^{2}\right)\end{array}$ & $\begin{array}{c}\text { Total } \\
\text { Study Area } \\
\left(\mathrm{km}^{2}\right)\end{array}$ & Area \% & $\begin{array}{c}\text { Area \% } \\
\text { Mean } \\
{[95 \% \text { CI] }}\end{array}$ & PAI & $\begin{array}{c}\text { PAI Mean } \\
{[95 \% \text { CI }]}\end{array}$ \\
\hline \multicolumn{13}{|l|}{ ProMap EdTFMV } \\
\hline *JanFeb & March & 1411 & 462 & 818 & 56.48 & \multirow{3}{*}{$\begin{array}{r}61.42 \\
{[55.35} \\
67.49]\end{array}$} & 89.90 & 948.10 & 9.48 & \multirow{3}{*}{$\begin{array}{l}11.64 \\
{[9.01,} \\
14.27]\end{array}$} & 5.96 & \multirow{3}{*}{$\begin{array}{c}5.34 \\
{[4.54} \\
6.13]\end{array}$} \\
\hline *MayJun & July & 2024 & 623 & 961 & 64.83 & & 117.32 & 948.10 & 12.37 & & 5.24 & \\
\hline *SeptOct & Nov & 2083 & 617 & 980 & 62.96 & & 123.83 & 948.10 & 13.06 & & 4.82 & \\
\hline
\end{tabular}

*The predictive accuracy results for these rows are the same as those presented Phase 2 in Table 10. 
Comparison of hotspot mapping approaches. As shown in Table 13, some familiar overall accuracy trends again emerged in the Strategy 2 analyses. For example, the Nnh approach consistently resulted in lower mean hit rates and area percentages than both the KDE and prospective hot-spotting approaches. As well, the PAI values were the most unstable across the three blocks of time examined for the Nnh approach, as indicated by the wider $95 \%$ CIs in Table 13 . For the Edmonton burglary data files, the prospective hot-spotting approach resulted in noticeably lower mean PAI values than both the KDE and Nnh approaches across all three temporal bandwidths examined, as indicated by the non-overlapping 95\% CIs. Mean PAI values for the Edmonton TFMV data files, however, were comparable across all three hotspot mapping approaches. In addition, the prospective hot-spotting approach resulted in substantially higher mean hit rates for the Edmonton burglary data files than the two traditional hotspot mapping approaches. However, that increase in hit rate came with a corresponding increase in area percentage.

Temporal bandwidth manipulation. Recall that the Strategy 2 analyses involved manipulating the temporal bandwidth in order to explore the impact this had on predictive accuracy. Examining the data presented in Table 13, the mean PAI value actually decreased when going from shorter temporal bandwidths (i.e., 2 weeks) to longer temporal bandwidths (i.e., 2 months). For example, for the Edmonton TFMV data files, the prospective hot-spotting maps resulted in PAI values ranging from 6.60 to $7.99(M=$ $7.31 ; S D=0.69 ; 95 \%$ CI $[6.35,8.27])$ when generated using two weeks' worth of crime data, from 5.44 to $7.20(M=6.23 ; S D=0.89 ; 95 \%$ CI $[4.99,7.47])$ when generated using one month's worth of crime data, and from 4.82 to $5.96(M=5.34 ; S D=0.57 ; 95 \% \mathrm{CI}$ 
$[4.54,6.13])$ when generated using two months' worth of crime data. Although the overlapping 95\% CIs when going from the 2-week to 1-month to 2-month temporal bandwidths suggest that these decreasing PAI values may not be meaningful, this trend still warrants mention since this finding was consistently observed across all three hotspot mapping techniques and across both Edmonton burglary and Edmonton TFMV data files.

As well, overall results indicate that the mean hit rate increases considerably when going from shorter to longer time periods used to generate the maps with almost all non-overlapping 95\% CIs. For example, for the Edmonton TFMV data files, the prospective hot-spotting maps generated using the 2-week temporal bandwidth resulted in hit rates ranging from 26.65 to $31.22(M=29.05 ; S D=2.29 ; 95 \%$ CI $[25.87,32.23])$, whereas the 2-month temporal bandwidth resulted in hit rates ranging from 56.48 to $64.83(M=61.42 ; S D=4.38 ; 95 \%$ CI $[55.35,67.49])$. This increase in mean hit rate was accompanied by an increase in mean area percentage as well, although at a lesser rate of increase than the hit rate and with overlapping 95\% CIs across the three temporal bandwidths. For example, for the Edmonton TFMV data files, the prospective hotspotting maps generated using the 2-week temporal bandwidth resulted in area percentages ranging from 3.34 to $4.44(M=4.01 ; S D=0.59 ; 95 \%$ CI $[3.19,4.83])$, whereas the 2-month temporal bandwidth resulted in area percentages ranging from 9.48 to $13.06(M=11.64 ; S D=1.90 ; 95 \% \mathrm{CI}[9.01,14.27])$.

\section{Strategy 3: Time Period Used to Assess Predictive Accuracy}

Data. The data used for this part of Phase 3 was the same as the Edmonton burglary and Edmonton TFMV data used in Phase 2. However, Strategy 3 involved varying the time period used to assess predictive accuracy to determine whether shorter 
time periods resulted in greater predictive accuracy. As in Phase 2, KDE, Nnh, and prospective hot-spotting maps were generated and tested using data from three different blocks of time. See Table 14 for a breakdown of the timeframes used to generate and test the hotspot maps.

Table 14. Breakdown of crimes used to generate and test the risk surfaces in Phase 3:

Strategy $3 .^{39}$

Map generated using crimes that occurred between:
Map tested using crimes that occurred between:

March 1-14, 2008

January 1-February 29, 2008

March 1-31, 2008

March 1-April 30, 2008

July 1-14, 2008

May 1-June 30, 2008

July 1-31, 2008

July 1-August 30, 2008

November 1-14, 2008

September 1-October 31, 2008

November 1-30, 2008

November 1-December 31, 2008

Procedure. The risk surfaces used in this part of Phase 3 were identical to those produced for Edmonton burglary and TFMV in Phase 2. In total, there were three maps for the two Edmonton data files (one map for each block of time). In order to determine whether the mapping techniques were more accurate at predicting crimes that occurred more immediately following the generation of the maps, the next step involved plotting

\footnotetext{
${ }^{39}$ Note that Strategy 3 was also applied to the Phase 2 maps generated using the prospective hot-spotting technique with a 7-day temporal bandwidth. Recall that those maps were generated using crimes that occurred between: (1) February 23-29, (2) June 24-30, and (3) October 25-31, 2008.
} 
the crimes that occurred within 2 weeks, 1 month, and 2 months since the generation of the maps onto their respective risk surfaces in ArcView. Chainey et al.'s (2008) predictive accuracy index was again used to assess map accuracy.

Hypotheses. Based on past research that has found hotspots to shift over time (e.g., Barr \& Pease, 1990; Johnson \& Bowers, 2004b; Johnson, Lab, \& Bowers, 2008), it was hypothesized that higher PAI values would result when predicting the location of crimes that were closer in time to those crimes used to generate the risk surface (i.e., 2 weeks). These results were expected to be consistent across all three blocks of time and for both Edmonton burglary and TFMV.

Results. The predictive accuracy results for the maps generated in Strategy 2 are presented in Table 15. Consistent with Strategies 1 and 2, the columns in Table 15 that are of particular interest to the Strategy 3 results include the hit rate, area percentage, and PAI. Means and 95\% CIs are also presented in Table 15 for each of the three accuracy measures examined. 
Table 15. Predictive accuracy of Phase 3: Strategy 3 maps.

\begin{tabular}{|c|c|c|c|c|c|c|c|c|c|c|c|c|}
\hline Generation Sample & $\begin{array}{c}\text { Test } \\
\text { Sample }\end{array}$ & $\begin{array}{l}\text { Crimes in } \\
\text { Generation } \\
\text { Sample }\end{array}$ & $\begin{array}{l}\text { Test Sample } \\
\text { Crimes in } \\
\text { Hotspots }\end{array}$ & $\begin{array}{l}\text { Total Test } \\
\text { Sample } \\
\text { Crimes }\end{array}$ & $\begin{array}{c}\text { Hit Rate } \\
(\%)\end{array}$ & $\begin{array}{c}\text { Hit Rate } \\
\text { Mean } \\
{[95 \% \mathrm{CI}]}\end{array}$ & $\begin{array}{l}\text { Hotspot } \\
\text { Area } \\
\left(\mathrm{km}^{2}\right)\end{array}$ & $\begin{array}{c}\text { Total } \\
\text { Study Area } \\
\left(\mathrm{km}^{2}\right)\end{array}$ & Area \% & $\begin{array}{c}\text { Area \% } \\
\text { Mean } \\
{[95 \% \mathrm{CI}]}\end{array}$ & PAI & $\begin{array}{c}\text { PAI Mean } \\
{[95 \% \text { CI] }}\end{array}$ \\
\hline \multicolumn{13}{|l|}{ KDE EdBurg } \\
\hline JanFeb & Mar 1-14 & 497 & 51 & 153 & 33.33 & \multirow{3}{*}{$\begin{array}{c}38.64 \\
{[28.95} \\
48.32]\end{array}$} & 43.62 & 948.10 & 4.60 & \multirow{3}{*}{$\begin{array}{c}5.68 \\
{[4.36} \\
6.99]\end{array}$} & 7.25 & \multirow{3}{*}{$\begin{array}{c}6.83 \\
{[5.78} \\
7.88]\end{array}$} \\
\hline MayJun & Jul 1-14 & 701 & 81 & 174 & 46.55 & & 60.55 & 948.10 & 6.39 & & 7.29 & \\
\hline SeptOct & Nov 1-14 & 672 & 67 & 186 & 36.02 & & 57.33 & 948.10 & 6.05 & & 5.96 & \\
\hline$* J a n F e b$ & March & 497 & 95 & 291 & 32.65 & \multirow{3}{*}{$\begin{array}{c}36.81 \\
{[31.40} \\
42.22]\end{array}$} & 43.62 & 948.10 & 4.60 & \multirow{3}{*}{$\begin{array}{c}5.68 \\
{[4.36} \\
6.99]\end{array}$} & 7.10 & \multirow{3}{*}{$\begin{array}{r}6.54 \\
{[5.85} \\
7.22]\end{array}$} \\
\hline *MayJun & July & 701 & 170 & 421 & 40.38 & & 60.55 & 948.10 & 6.39 & & 6.32 & \\
\hline *SeptOct & Nov & 672 & 144 & 385 & 37.40 & & 57.33 & 948.10 & 6.05 & & 6.19 & \\
\hline JanFeb & MarApr & 497 & 181 & 566 & 31.98 & \multirow{3}{*}{$\begin{array}{c}36.64 \\
{[30.62} \\
42.67]\end{array}$} & 43.62 & 948.10 & 4.60 & \multirow{3}{*}{$\begin{array}{c}5.68 \\
{[4.36} \\
6.99]\end{array}$} & 6.95 & \multirow{3}{*}{$\begin{array}{r}6.50 \\
{[5.93} \\
7.06]\end{array}$} \\
\hline MayJun & JulAug & 701 & 319 & 786 & 40.59 & & 60.55 & 948.10 & 6.39 & & 6.36 & \\
\hline SeptOct & NovDec & 672 & 269 & 720 & 37.36 & & 57.33 & 948.10 & 6.05 & & 6.18 & \\
\hline \multicolumn{13}{|l|}{ KDE EdTFMV } \\
\hline JanFeb & Mar 1-14 & 1411 & 201 & 353 & 56.94 & \multirow{3}{*}{$\begin{array}{c}62.47 \\
{[55.77} \\
69.16]\end{array}$} & 92.91 & 948.10 & 9.80 & \multirow{3}{*}{$\begin{array}{l}12.01 \\
{[9.31} \\
14.71]\end{array}$} & 5.81 & \multirow{3}{*}{$\begin{array}{c}5.26 \\
{[4.54} \\
5.97]\end{array}$} \\
\hline MayJun & Jul 1-14 & 2024 & 309 & 469 & 65.88 & & 120.66 & 948.10 & 12.73 & & 5.18 & \\
\hline SeptOct & Nov 1-14 & 2083 & 288 & 446 & 64.57 & & 127.90 & 948.10 & 13.49 & & 4.79 & \\
\hline *JanFeb & March & 1411 & 471 & 818 & 57.58 & \multirow{3}{*}{$\begin{array}{c}62.30 \\
{[56.47} \\
68.14]\end{array}$} & 92.91 & 948.10 & 9.80 & \multirow{3}{*}{$\begin{array}{l}12.01 \\
{[9.31} \\
14.71]\end{array}$} & 5.88 & \multirow{3}{*}{$\begin{array}{r}5.25 \\
{[4.44} \\
6.06]\end{array}$} \\
\hline *MayJun & July & 2024 & 631 & 961 & 65.66 & & 120.66 & 948.10 & 12.73 & & 5.16 & \\
\hline *SeptOct & Nov & 2083 & 624 & 980 & 63.67 & & 127.90 & 948.10 & 13.49 & & 4.72 & \\
\hline JanFeb & MarApr & 1411 & 998 & 1631 & 61.19 & \multirow{3}{*}{$\begin{array}{c}62.88 \\
{[60.78} \\
64.97]\end{array}$} & 92.91 & 948.10 & 9.80 & \multirow{3}{*}{$\begin{array}{l}12.01 \\
{[9.31} \\
14.71]\end{array}$} & 6.24 & \multirow{3}{*}{$\begin{array}{c}5.33 \\
{[4.20} \\
6.45]\end{array}$} \\
\hline MayJun & JulAug & 2024 & 1236 & 1928 & 64.11 & & 120.66 & 948.10 & 12.73 & & 5.04 & \\
\hline SeptOct & NovDec & 2083 & 1116 & 1762 & 63.34 & & 127.90 & 948.10 & 13.49 & & 4.69 & \\
\hline
\end{tabular}




\begin{tabular}{|c|c|c|c|c|c|c|c|c|c|c|c|c|}
\hline Generation Sample & $\begin{array}{c}\text { Test } \\
\text { Sample }\end{array}$ & $\begin{array}{l}\text { Crimes in } \\
\text { Generation } \\
\text { Sample }\end{array}$ & $\begin{array}{l}\text { Test Sample } \\
\text { Crimes in } \\
\text { Hotspots }\end{array}$ & $\begin{array}{l}\text { Total Test } \\
\text { Sample } \\
\text { Crimes }\end{array}$ & $\begin{array}{c}\text { Hit Rate } \\
(\%)\end{array}$ & $\begin{array}{c}\text { Hit Rate } \\
\text { Mean } \\
{[95 \% \mathrm{CI}]}\end{array}$ & $\begin{array}{l}\text { Hotspot } \\
\text { Area } \\
\left(\mathrm{km}^{2}\right)\end{array}$ & $\begin{array}{c}\text { Total } \\
\text { Study Area } \\
\left(\mathrm{km}^{2}\right)\end{array}$ & Area \% & $\begin{array}{c}\text { Area \% } \\
\text { Mean } \\
{[95 \% \mathrm{CI}]}\end{array}$ & PAI & $\begin{array}{c}\text { PAI Mean } \\
{[95 \% \text { CI] }}\end{array}$ \\
\hline \multicolumn{13}{|l|}{ Nnh } \\
\hline JanFeb & Mar 1-14 & 497 & 29 & 153 & 18.95 & \multirow{3}{*}{$\begin{array}{c}24.05 \\
{[13.54} \\
34.55]\end{array}$} & 13.73 & 948.10 & 1.45 & \multirow{3}{*}{$\begin{array}{c}2.35 \\
{[1.14} \\
3.57]\end{array}$} & 13.09 & \multirow{3}{*}{$\begin{array}{c}10.59 \\
{[7.37} \\
13.82]\end{array}$} \\
\hline MayJun & Jul 1-14 & 701 & 57 & 174 & 32.76 & & 30.39 & 948.10 & 3.21 & & 10.22 & \\
\hline SeptOct & Nov $1-14$ & 672 & 38 & 186 & 20.43 & & 22.85 & 948.10 & 2.41 & & 8.48 & \\
\hline *JanFeb & March & 497 & 52 & 291 & 17.87 & \multirow{3}{*}{$\begin{array}{c}21.74 \\
{[15.11,} \\
28.36]\end{array}$} & 13.73 & 948.10 & 1.45 & \multirow{3}{*}{$\begin{array}{c}2.35 \\
{[1.14} \\
3.57]\end{array}$} & 12.34 & \multirow{3}{*}{$\begin{array}{c}9.73 \\
{[6.60} \\
12.86]\end{array}$} \\
\hline *MayJun & July & 701 & 114 & 421 & 27.08 & & 30.39 & 948.10 & 3.21 & & 8.45 & \\
\hline *SeptOct & Nov & 672 & 78 & 385 & 20.26 & & 22.85 & 948.10 & 2.41 & & 8.40 & \\
\hline JanFeb & MarApr & 497 & 97 & 566 & 17.14 & \multirow{3}{*}{$\begin{array}{c}21.46 \\
{[15.61,} \\
27.31]\end{array}$} & 13.73 & 948.10 & 1.45 & \multirow{3}{*}{$\begin{array}{c}2.35 \\
{[1.14} \\
3.57]\end{array}$} & 11.83 & \multirow{3}{*}{$\begin{array}{c}9.60 \\
{[6.83} \\
12.37]\end{array}$} \\
\hline MayJun & JulAug & 701 & 201 & 786 & 25.57 & & 30.39 & 948.10 & 3.21 & & 7.98 & \\
\hline SeptOct & NovDec & 672 & 156 & 720 & 21.67 & & 22.85 & 948.10 & 2.41 & & 8.99 & \\
\hline \multicolumn{13}{|l|}{ Nnh EdTFMV } \\
\hline JanFeb & Mar 1-14 & 1411 & 161 & 353 & 45.61 & \multirow{3}{*}{$\begin{array}{c}47.46 \\
{[42.25} \\
52.68]\end{array}$} & 49.42 & 948.10 & 5.21 & \multirow{3}{*}{$\begin{array}{c}6.93 \\
{[4.79} \\
9.07]\end{array}$} & 8.75 & \multirow{3}{*}{$\begin{array}{c}7.05 \\
{[5.01} \\
9.09]\end{array}$} \\
\hline MayJun & Jul 1-14 & 2024 & 211 & 469 & 44.99 & & 70.04 & 948.10 & 7.39 & & 6.09 & \\
\hline SeptOct & Nov 1-14 & 2083 & 231 & 446 & 51.79 & & 77.68 & 948.10 & 8.19 & & 6.32 & \\
\hline *JanFeb & March & 1411 & 362 & 818 & 44.25 & \multirow{3}{*}{$\begin{array}{r}47.23 \\
{[42.88} \\
51.58]\end{array}$} & 49.42 & 948.10 & 5.21 & \multirow{3}{*}{$\begin{array}{c}6.93 \\
{[4.79} \\
9.07]\end{array}$} & 8.49 & \multirow{3}{*}{$\begin{array}{r}7.00 \\
{[5.21} \\
8.79]\end{array}$} \\
\hline *MayJun & July & 2024 & 451 & 961 & 46.93 & & 70.04 & 948.10 & 7.39 & & 6.35 & \\
\hline *SeptOct & Nov & 2083 & 495 & 980 & 50.51 & & 77.68 & 948.10 & 8.19 & & 6.17 & \\
\hline JanFeb & MarApr & 1411 & 781 & 1631 & 47.88 & \multirow{3}{*}{$\begin{array}{c}48.27 \\
{[45.62} \\
50.92]\end{array}$} & 49.42 & 948.10 & 5.21 & \multirow{3}{*}{$\begin{array}{c}6.93 \\
{[4.79} \\
9.07]\end{array}$} & 9.19 & \multirow{3}{*}{$\begin{array}{c}7.21 \\
{[4.84} \\
9.58]\end{array}$} \\
\hline MayJun & JulAug & 2024 & 898 & 1928 & 46.58 & & 70.04 & 948.10 & 7.39 & & 6.31 & \\
\hline SeptOct & NovDec & 2083 & 887 & 1762 & 50.34 & & 77.68 & 948.10 & 8.19 & & 6.14 & \\
\hline
\end{tabular}




\begin{tabular}{|c|c|c|c|c|c|c|c|c|c|c|c|c|}
\hline Generation Sample & $\begin{array}{l}\text { Test } \\
\text { Sample }\end{array}$ & $\begin{array}{l}\text { Crimes in } \\
\text { Generation } \\
\text { Sample }\end{array}$ & $\begin{array}{l}\text { Test Sample } \\
\text { Crimes in } \\
\text { Hotspots }\end{array}$ & $\begin{array}{l}\text { Total Test } \\
\text { Sample } \\
\text { Crimes }\end{array}$ & $\begin{array}{c}\text { Hit Rate } \\
\text { (\%) }\end{array}$ & $\begin{array}{c}\text { Hit Rate } \\
\text { Mean } \\
{[95 \% \mathrm{CI}]}\end{array}$ & $\begin{array}{c}\text { Hotspot } \\
\text { Area } \\
\left(\mathrm{km}^{2}\right)\end{array}$ & $\begin{array}{c}\text { Total } \\
\text { Study Area } \\
\left(\mathrm{km}^{2}\right)\end{array}$ & Area \% & $\begin{array}{c}\text { Area \% } \\
\text { Mean } \\
{[95 \% \mathrm{CI}]}\end{array}$ & PAI & $\begin{array}{l}\text { PAI Mean } \\
{[95 \% \text { CI }]}\end{array}$ \\
\hline \multicolumn{13}{|l|}{$\begin{array}{l}\text { ProMap EdBurg } \\
\text { ( } 7 \text { days) }\end{array}$} \\
\hline Feb23-29 & Mar 1-14 & 58 & 29 & 153 & 18.95 & \multirow{3}{*}{$\begin{array}{c}24.05 \\
{[13.54} \\
34.55]\end{array}$} & 30.04 & 948.10 & 3.17 & 4.23 & 5.98 & 5.67 \\
\hline Jun24-30 & Jul 1-14 & 82 & 57 & 174 & 32.76 & & 49.01 & 948.10 & 5.17 & \multirow{2}{*}{$\begin{array}{l}{[2.84,} \\
5.62]\end{array}$} & 6.34 & \multirow{2}{*}{$\begin{array}{c}{[4.47} \\
6.87]\end{array}$} \\
\hline Oct25-31 & Nov $1-14$ & 65 & 38 & 186 & 20.43 & & 41.25 & 948.10 & 4.35 & & 4.70 & \\
\hline *Feb23-29 & March & 58 & 64 & 291 & 21.99 & \multirow{3}{*}{$\begin{array}{c}23.16 \\
{[16.74} \\
29.58]\end{array}$} & 30.04 & 948.10 & 3.17 & \multirow{3}{*}{$\begin{array}{c}4.23 \\
{[2.84} \\
5.62]\end{array}$} & 6.94 & \multirow{3}{*}{$\begin{array}{c}5.61 \\
{[3.85} \\
7.37]\end{array}$} \\
\hline *Jun24-30 & July & 82 & 119 & 421 & 28.27 & & 49.01 & 948.10 & 5.17 & & 5.47 & \\
\hline *Oct $25-31$ & Nov & 65 & 74 & 385 & 19.22 & & 41.25 & 948.10 & 4.35 & & 4.42 & \\
\hline Feb23-29 & MarApr & 58 & 120 & 566 & 21.20 & \multirow{3}{*}{$\begin{array}{c}21.77 \\
{[17.90} \\
25.65]\end{array}$} & 30.04 & 948.10 & 3.17 & \multirow{3}{*}{$\begin{array}{r}4.23 \\
{[2.84} \\
5.62]\end{array}$} & 6.69 & \multirow{3}{*}{$\begin{array}{r}5.31 \\
{[3.63} \\
6.99]\end{array}$} \\
\hline Jun24-30 & JulAug & 82 & 195 & 786 & 24.81 & & 49.01 & 948.10 & 5.17 & & 4.80 & \\
\hline Oct25-31 & NovDec & 65 & 139 & 720 & 19.31 & & 41.25 & 948.10 & 4.35 & & 4.44 & \\
\hline \multicolumn{13}{|l|}{$\begin{array}{l}\text { ProMap EdTFMV } \\
\text { ( } 7 \text { days) }\end{array}$} \\
\hline Feb23-29 & Mar 1-14 & 167 & 57 & 353 & 16.15 & \multirow{3}{*}{$\begin{array}{c}15.63 \\
{[13.79} \\
17.48]\end{array}$} & 17.04 & 948.10 & 1.80 & \multirow{3}{*}{$\begin{array}{c}2.13 \\
{[1.71} \\
2.55]\end{array}$} & 8.98 & \multirow{3}{*}{$\begin{array}{r}7.46 \\
{[5.60} \\
9.32]\end{array}$} \\
\hline Jun24-30 & Jul 1-14 & 215 & 78 & 469 & 16.63 & & 22.67 & 948.10 & 2.39 & & 6.96 & \\
\hline Oct25-31 & Nov $1-14$ & 187 & 63 & 446 & 14.13 & & 20.80 & 948.10 & 2.19 & & 6.44 & \\
\hline *Feb23-29 & March & 167 & 132 & 818 & 16.14 & \multirow{3}{*}{$\begin{array}{c}15.83 \\
{[14.15} \\
17.51]\end{array}$} & 17.04 & 948.10 & 1.80 & \multirow{3}{*}{$\begin{array}{c}2.13 \\
{[1.71} \\
2.55]\end{array}$} & 8.98 & \multirow{3}{*}{$\begin{array}{c}7.54 \\
{[5.80} \\
9.29]\end{array}$} \\
\hline *Jun24-30 & July & 215 & 162 & 961 & 16.86 & & 22.67 & 948.10 & 2.39 & & 7.05 & \\
\hline *Oct25-31 & Nov & 187 & 142 & 980 & 14.49 & & 20.80 & 948.10 & 2.19 & & 6.60 & \\
\hline Feb23-29 & MarApr & 167 & 287 & 1631 & 17.60 & \multirow{3}{*}{$\begin{array}{l}16.03 \\
{[13.91,} \\
18.16]\end{array}$} & 17.04 & 948.10 & 1.80 & \multirow{3}{*}{$\begin{array}{c}2.13 \\
{[1.71} \\
2.55]\end{array}$} & 9.79 & \multirow{3}{*}{$\begin{array}{c}7.70 \\
{[5.19} \\
10.21]\end{array}$} \\
\hline Jun24-30 & JulAug & 215 & 308 & 1928 & 15.98 & & 22.67 & 948.10 & 2.39 & & 6.68 & \\
\hline Oct25-31 & NovDec & 187 & 256 & 1762 & 14.53 & & 20.80 & 948.10 & 2.19 & & 6.62 & \\
\hline
\end{tabular}




\begin{tabular}{|c|c|c|c|c|c|c|c|c|c|c|c|c|}
\hline Generation Sample & $\begin{array}{c}\text { Test } \\
\text { Sample }\end{array}$ & $\begin{array}{l}\text { Crimes in } \\
\text { Generation } \\
\text { Sample }\end{array}$ & $\begin{array}{l}\text { Test Sample } \\
\text { Crimes in } \\
\text { Hotspots }\end{array}$ & $\begin{array}{l}\text { Total Test } \\
\text { Sample } \\
\text { Crimes }\end{array}$ & $\begin{array}{l}\text { Hit Rate } \\
\text { (\%) }\end{array}$ & $\begin{array}{l}\text { Hit Rate } \\
\text { Mean } \\
{[95 \% \text { CI }]}\end{array}$ & $\begin{array}{l}\text { Hotspot } \\
\text { Area } \\
\left(\mathrm{km}^{2}\right)\end{array}$ & $\begin{array}{c}\text { Total } \\
\text { Study Area } \\
\left(\mathrm{km}^{2}\right)\end{array}$ & Area \% & $\begin{array}{c}\text { Area \% } \\
\text { Mean } \\
{[95 \% \mathrm{CI}]}\end{array}$ & PAI & $\begin{array}{c}\text { PAI Mean } \\
{[95 \% \text { CI] }}\end{array}$ \\
\hline \multicolumn{13}{|l|}{$\begin{array}{l}\text { ProMap EdBurg } \\
\text { ( } 2 \text { months) }\end{array}$} \\
\hline JanFeb & Mar 1-14 & 497 & 103 & 153 & 67.32 & \multirow{3}{*}{$\begin{array}{c}72.99 \\
{[59.88,} \\
86.10]\end{array}$} & 152.89 & 948.10 & 16.13 & \multirow{3}{*}{$\begin{array}{l}18.38 \\
{[15.61,} \\
21.15]\end{array}$} & 4.17 & \multirow{3}{*}{$\begin{array}{c}3.98 \\
{[3.47} \\
4.49]\end{array}$} \\
\hline MayJun & Jul 1-14 & 701 & 146 & 174 & 83.91 & & 189.03 & 948.10 & 19.94 & & 4.21 & \\
\hline SeptOct & Nov $1-14$ & 672 & 126 & 186 & 67.74 & & 180.80 & 948.10 & 19.07 & & 3.55 & \\
\hline *JanFeb & March & 497 & 193 & 291 & 66.32 & \multirow{3}{*}{$\begin{array}{c}71.85 \\
{[62.76,} \\
80.94]\end{array}$} & 152.89 & 948.10 & 16.13 & \multirow{3}{*}{$\begin{array}{c}18.38 \\
{[15.61} \\
21.15]\end{array}$} & 4.11 & \multirow{3}{*}{$\begin{array}{c}3.92 \\
{[3.61} \\
4.23]\end{array}$} \\
\hline *MayJun & July & 701 & 333 & 421 & 79.10 & & 189.03 & 948.10 & 19.94 & & 3.97 & \\
\hline *SeptOct & Nov & 672 & 270 & 385 & 70.13 & & 180.80 & 948.10 & 19.07 & & 3.68 & \\
\hline JanFeb & MarApr & 497 & 395 & 566 & 69.79 & \multirow{3}{*}{$\begin{array}{c}74.09 \\
{[67.55} \\
80.63]\end{array}$} & 152.89 & 948.10 & 16.13 & \multirow{3}{*}{$\begin{array}{l}18.38 \\
{[15.61,} \\
21.15)\end{array}$} & 4.33 & \multirow{3}{*}{$\begin{array}{c}4.05 \\
{[3.70} \\
4.39]\end{array}$} \\
\hline MayJun & JulAug & 701 & 622 & 786 & 79.13 & & 189.03 & 948.10 & 19.94 & & 3.97 & \\
\hline SeptOct & NovDec & 672 & 528 & 720 & 73.33 & & 180.80 & 948.10 & 19.07 & & 3.85 & \\
\hline \multicolumn{13}{|l|}{$\begin{array}{l}\text { ProMap EdTFMV } \\
\text { ( } 2 \text { months) }\end{array}$} \\
\hline JanFeb & Mar 1-14 & 1411 & 198 & 353 & 56.09 & \multirow{3}{*}{$\begin{array}{c}61.24 \\
{[55.06,} \\
67.43]\end{array}$} & 89.90 & 948.10 & 9.48 & \multirow{3}{*}{$\begin{array}{l}11.64 \\
{[9.01} \\
14.27]\end{array}$} & 5.92 & \multirow{3}{*}{$\begin{array}{c}5.32 \\
{[4.58,} \\
6.06]\end{array}$} \\
\hline MayJun & Jul 1-14 & 2024 & 300 & 469 & 63.97 & & 117.32 & 948.10 & 12.37 & & 5.17 & \\
\hline SeptOct & Nov 1-14 & 2083 & 284 & 446 & 63.68 & & 123.83 & 948.10 & 13.06 & & 4.88 & \\
\hline *JanFeb & March & 1411 & 462 & 818 & 56.48 & \multirow{3}{*}{$\begin{array}{r}61.42 \\
{[55.35} \\
67.49]\end{array}$} & 89.90 & 948.10 & 9.48 & \multirow{3}{*}{$\begin{array}{l}11.64 \\
{[9.01} \\
14.27]\end{array}$} & 5.96 & \multirow{3}{*}{$\begin{array}{c}5.34 \\
{[4.54} \\
6.13]\end{array}$} \\
\hline *MayJun & July & 2024 & 623 & 961 & 64.83 & & 117.32 & 948.10 & 12.37 & & 5.24 & \\
\hline *SeptOct & Nov & 2083 & 617 & 980 & 62.96 & & 123.83 & 948.10 & 13.06 & & 4.82 & \\
\hline JanFeb & MarApr & 1411 & 984 & 1631 & 60.33 & \multirow{3}{*}{$\begin{array}{c}61.93 \\
{[59.97} \\
63.88]\end{array}$} & 89.90 & 948.10 & 9.48 & \multirow{3}{*}{$\begin{array}{l}11.64 \\
{[9.01} \\
14.27]\end{array}$} & 6.36 & \multirow{3}{*}{$\begin{array}{r}5.41 \\
{[4.25} \\
6.57]\end{array}$} \\
\hline MayJun & JulAug & 2024 & 1215 & 1928 & 63.02 & & 117.32 & 948.10 & 12.37 & & 5.09 & \\
\hline SeptOct & NovDec & 2083 & 1100 & 1762 & 62.43 & & 123.83 & 948.10 & 13.06 & & 4.78 & \\
\hline
\end{tabular}

*The predictive accuracy results for these rows are the same as those presented in Phase 2 (see Table 10). 
Comparison of hotspot mapping approaches. As shown in Table 15, the Nnh approach again consistently resulted in lower mean hit rates and area percentages than both KDE and the prospective hot-spotting approach with a 2-month temporal bandwidth. However, mean hit rates and area percentages were found to be comparable between the Nnh approach and the prospective hot-spotting approach with a 7-day temporal bandwidth for the Edmonton burglary data files. For the Edmonton burglary data files, the prospective hot-spotting approach with a 2-month temporal bandwidth consistently resulted in considerably lower mean PAI values than the two traditional hotspot mapping approaches, as indicated by the non-overlapping 95\% CIs. Specifically, the prospective hot-spotting map generated using a 2-month temporal bandwidth achieved mean PAI values ranging from 3.92 to 4.05 for the Edmonton burglary data files across the various time periods used to assess predictive accuracy. The KDE and Nnh maps, however, achieved mean PAI values ranging from 6.50 to 6.83 and from 9.60 to 10.59 , respectively, for the Edmonton burglary data files when crime data from different lengths of time were used to assess predictive accuracy. Mean PAI values for the Edmonton TFMV data files, however, were comparable across all of the hotspot mapping approaches. In addition, the prospective hot-spotting approach again resulted in noticeably higher mean hit rates and area percentages for the Edmonton burglary data files than the two traditional hotspot mapping approaches.

Time period used to assess predictive accuracy. Recall that the Strategy 3 analyses involved manipulating the length of time used to assess predictive accuracy. Examining the data presented in Table 15, the mean PAI values remained extremely stable within each hotspot mapping technique when assessing predictive accuracy using 
crime data that occurred within shorter (i.e., 2 weeks) to longer (i.e., 2 months) periods of time. For example, the Edmonton TFMV prospective hot-spotting map with a 2-month temporal bandwidth resulted in mean PAI values varying from 5.32 to 5.41 across the three time periods used to assess predictive accuracy (i.e., 2 weeks, 1 month, and 2 months). Given that just the time period used to assess accuracy was manipulated in Strategy 3 and not the maps themselves, the mean area percentage remained identical across the three time periods used to assess predictive accuracy. However, the mean hit rates remained fairly consistent as well within each of the hotspot mapping techniques. For example, the Edmonton TFMV prospective hot-spotting map with a 2-month temporal bandwidth resulted in mean hit rates varying from 61.24 to 61.93 across the three time periods used to assess predictive accuracy (i.e., 2 weeks, 1 month, and 2 months).

\section{Discussion}

Strategy 1. Recall that Phase 3 involved the examination of three specific strategies intended to improve the predictive accuracy of the hotspot maps. Strategy 1 attempted to improve predictive accuracy by developing maps specific to the time of the week during which the offences occurred. More specifically, weekday and weekend hotspot maps were generated for Edmonton burglary and Edmonton TFMV. Those maps were then used to predict future crimes that occurred during the same or opposing time of the week. Based on routine activity theory, and the general findings of Tompson and Townsley (2010), it was expected that PAI values would increase when hotspot maps were used to predict future crimes that occurred during the same time of the week (i.e., weekday maps to predict weekday crimes and weekend maps to predict weekend crimes). 
In addition, it was expected that hotspot maps specific to a particular time of week would result in higher PAI values than the general (i.e., time independent) hotspot maps generated in Phase 2.

The results, however, did not provide support for the Strategy 1 hypotheses. Although there was a trend observed where the weekday/weekend specific maps produced higher PAI values than the general maps across all three hotspot mapping techniques and across both data files (i.e., Edmonton burglary and Edmonton TFMV), these differences were only slight and thus, not likely meaningful from an applied standpoint. As well, this increase in PAI values appears to be driven by a decrease in area percentage rather than an increase in hit rate, particularly for the weekend-specific maps. Given that the weekday/weekend maps were produced using smaller sample sizes than the general maps, a reduction in area percentage is not surprising. In addition, the results suggest that the weekday/weekend maps produce comparable levels of predictive accuracy regardless of whether the maps were applied to the same (e.g., weekday map to predict weekday crimes) or opposing (e.g., weekday map to predict weekend crimes) time of week.

The lack of support for the Strategy 1 hypotheses is interesting considering the results obtained by Tompson and Townsley (2010). Recall that Tompson and Townsley examined street crime and found that the predictive accuracy of KDE hotspot maps could be improved by incorporating more specific temporal information (i.e., time of day) into the analysis. More specifically, Tompson and Townsley found that predictive accuracy, as assessed by the PAI, increased when morning and overnight hotspot maps were used to predict future morning and overnight street crime, respectively. These findings can be 
explained by the fact that the routine activities of offenders and victims vary depending on the time of day examined. Thus, using a morning hotspot map to predict future morning crime results in more accurate predictions because it more accurately captures the routine activities of offenders and victims during that particular time of day.

Unfortunately, time of day of the offence was not available in the Canadian crime data used in the current study. However, it was assumed that the routine activities of offenders and victims would also likely differ between weekdays and weekends. For example, people would be more likely to be home during the weekend than during the week (when people are often at work) and thus, one might expect burglary activity to also vary across days of the week. TFMV activity may shift as well depending on time of week. For example, during the week, when people are working, TFMVs may be more likely to occur in the business district, whereas TFMVs committed during the weekend may be more likely to occur in residential or entertainment areas. Although the results did not support these assumptions, there are some potential explanations for this.

As mentioned in the Phase 1 discussion, there are some limitations that are inherent to any research involving crime data. One of these limitations includes the fact that it is not always possible to determine an exact occurrence date for a crime. In the case of burglary, if a resident is away on vacation for a week and discovers the burglary upon their return then their house could have been burglarized at any point during the 7day timeframe that they were out of town. For the Edmonton data files, both a possible start and end date for the offence were provided. In cases where the start and end dates differed, the start date was used as the occurrence date, which is an approach adopted in other near repeat research (e.g., Block \& Fujita, 2013). In the Edmonton 2008 burglary 
data file, the start and end dates were found to differ in $35.2 \%$ of the offences. In the Edmonton 2008 TFMV data file, the start and end dates were found to differ in $54.2 \%$ of the offences. Thus, the offence dates used in the current study could explain the lack of support for the Strategy 1 hypotheses with many offences potentially being incorrectly assigned to the weekday data file when the offences actually occurred on the weekend, and vice versa. Inaccurate offence dates would have been less problematic in Tompson and Townsley's (2010) study since they focused on street crime where the victim was present for the crime (street crime included incidents of either personal robbery or theft from the person).

Beyond this explanation, it is also possible that time of day is more influential in the routine activities of offenders than time of week, which could account for the lack of support for the Strategy 1 hypotheses; however, given the likely problems with offence dates in the current study, it seems premature to draw any firm conclusions about this. Time of year may be another factor to consider when generating hotspot maps since it is likely to impact the routine activities of victims and offenders as well, particularly in Canada with its relatively extreme seasons.

Strategy 2. Strategy 2 examined whether it was possible to improve the predictive accuracy of the hotspot maps by altering the time period used to generate the maps (i.e., the temporal bandwidth). It was hypothesized that using a longer time period to generate the maps (i.e., 2 months) would result in higher PAI values than using shorter time periods (i.e., 2 weeks or 1 month). The rationale behind this hypothesis was the idea that the use of longer time periods would result in more data (i.e., more crimes), which in 
turn would provide a more reliable basis to make predictions about the locations of future crimes.

The results again did not support this hypothesis. The results suggest that predictive accuracy, as assessed by PAI values, actually decreases when going from shorter to longer temporal bandwidths across all three hotspot mapping techniques and across both Edmonton burglary and Edmonton TFMV data files. That being said, these differences were slight and as indicated by the overlapping 95\% CIs, likely not large enough to be meaningful from an applied standpoint. It is important to note that the mean hit rates did increase substantially when going from shorter to longer time periods used to generate the maps.

Unfortunately, the increase in hit rate was accompanied by a corresponding increase in area percentage, which resulted in the PAI values remaining relatively stable across the increasing temporal bandwidths. This increase in area percentage at longer temporal bandwidths can be explained by the larger number of crimes used to generate the risk surfaces. Recall that hotspot maps are typically produced by applying a particular mathematical formula, which varies depending on the hotspot mapping approach, to all crimes that have occurred during a particular timeframe (for example, 2 months). This mathematical formula is applied to nearby cells as well in order to produce the risk surfaces. Thus, the more crimes there are in the sample used to generate the hotspot maps, the more cells that the mathematical formula gets applied to (the formula gets applied to the cell where each crime is located as well as to the cells near the crime), which produces larger hotspots that in turn results in a larger area percentage. 
Although the findings from Strategy 2 suggest that generating hotspot maps using longer periods of time is not an effective way of increasing the predictive accuracy of prospective hot spotting, police agencies should still keep this option in mind when developing their hotspot maps. As noted previously, increasing the temporal bandwidth (i.e., generating the hotspot maps using a longer period of time) did markedly increase the hit rates obtained and thus, if sufficient resources are available for the police to handle the increased area over which they would have to boost police presence, then this may still be a viable crime prevention option. The 1-month temporal bandwidth could provide a good compromise between achieving a higher hit rate while still maintaining a reasonable area percentage.

What constitutes a reasonable area percentage over which to increase police presence will depend on the availability of resources. If resources are limited, police agencies could still use longer time periods to generate the hotspot maps and then use the maps to update citizens online about the risk of crime in their area. This would encourage residents to be more vigilant in locking their vehicles and houses, for example, as well as be on the lookout for potential crime.

Strategy 3. Finally, Strategy 3 examined whether predictive accuracy could be increased by varying the period of time used to assess predictive accuracy. It was hypothesized that higher PAI values would result when predicting the location of crimes that were closer in time to those crimes used to generate the risk surface (e.g., 2 weeks vs. 2 months). The results from Strategy 3, however, did not support this hypothesis. Specifically, the PAI values, as well as the hit rates, remained remarkably stable when predicting crimes that occurred within shorter (i.e., 2 weeks) versus longer periods (i.e., 2 
months) of time since the generation of the hotspot map. This finding could actually prove particularly useful to police agencies as it suggests that hotspot maps do not necessarily need to be updated on a frequent basis in order to maintain similar levels of predictive accuracy. This could save the police valuable time.

The Strategy 3 hypothesis was based on previous research that has demonstrated how hotspots can be expected to shift over time (e.g., Barr \& Pease, 1990; Johnson \& Bowers, 2004b; Johnson, Lab, \& Bowers, 2008). Although the Strategy 3 findings could suggest that hotspots in Edmonton are more stable than in other jurisdictions, it is more likely that the 2-month time period was simply not long enough to capture the hotspots' fluidity. Perhaps if 6- or 12-month time periods had been used instead, in addition to the three time periods examined in Strategy 3, then the predictive accuracy results would have differed across the time periods examined.

Limitations. Although some limitations have already been raised when discussing the findings from each strategy used in Phase 3, there are additional limitations that apply to Phase 3 that should also be discussed. As highlighted in previous phases of this dissertation, and as touched upon in the Strategy 1 discussion, there are potentially problematic issues with the data that we need to keep in mind. While not unique to the current study, the lack of a reliable occurrence date is of particular concern within this phase of analysis. That being said, it is important to remember that the data used in the current study are the exact same data relied upon by the police and this analysis therefore provides a realistic idea of what police agencies can expect when utilizing these hotspot mapping techniques in the field. 
Consistent with Phase 2, another limitation to Phase 3 is the reliance on 95\% CIs and means that are calculated based on a very small sample size (i.e., 3). This likely resulted in wider CIs than a larger sample size would have, which would have impacted the interpretation of the findings in the current study. In addition, this small sample size does not allow for the means to be compared through statistical analyses. Although visual inspection of the results is standard practice in hotspot accuracy research, this limitation still warrants mention.

Another limitation in Phase 3 is that the hotspot strategies examined all focused solely on crime data to generate the hotspot maps and did not consider other variables that could have improved predictive accuracy. While this is consistent with previous research, this approach neglects the "place-based factors that provide an optimal setting for burglaries" (Moreto et al., 2013, p.1). Moreto et al. emphasize how:

prevention strategies addressing residential burglary...must incorporate both the spatial and temporal patterns of recent known burglary incidents and the environmental risks of micro-level places if it is to yield the most efficient and actionable information for police resource allocation and prevention efforts. (emphasis added, p. 22)

The three strategies examined in Phase 3 do consider the spatial and temporal patterns of known crime incidents, but they neglect the environmental risks of micro-level places (e.g., accessibility, population density, target backcloth, etc.). Unfortunately, the Canadian crime data provided for the current study did not allow for the examination of place-based risk factors since all $x-y$ coordinates were offset by an unknown value. However, this would be an important avenue for future research. For example, Groff and 
LaVigne (2001) developed a hotspot risk surface based on opportunity factors, such as land use, housing tenure, and proximity to likely offenders. Their model was particularly useful at predicting where crime would not occur. Thus, incorporating Groff and LaVigne's model into the development of prospective hot-spotting maps could improve their predictive accuracy. In another study, Beavon, Brantingham, and Brantingham (1994) examined the risk of victimization based on accessibility and traffic flow and found a positive correlation between crime rates and these two environmental variables, which highlights the potential importance of considering urban background in the development of prospective hotspot maps.

\section{Phase 4 - Testing the Boost Account}

Recall that the boost account suggests that repeat and near repeat burglaries are the result of the same offender returning to burglarize a dwelling that they have successfully burglarized in the past. The purpose of the fourth and final phase of this dissertation was to test the boost account as an explanation for the occurrence of near repeat burglary in one Canadian city, Edmonton, AB.

\section{Method}

Data. The data used to test the boost account consisted of solved burglaries that occurred in Edmonton, AB, between January 1, 2007, and December 31, 2008. More specifically, the dataset included geo-coded $x-y$ coordinates for each offence location, the date on which each offence occurred, and an offender identifier for each offence, which made it possible to match each crime to the offender responsible (in an anonymous fashion). All of these burglaries were classified as cleared by charge or cleared otherwise. Examples of cleared otherwise include death of offender, offender under 12 years of age, 
and complainant declines to lay charges. Note that attempted burglaries were not included in the dataset. Although the original dataset consisted of 863 solved burglaries, 15 offences had missing $x-y$ coordinate data, and one offence was missing an offender identifier. Thus, the final dataset used in Phase 4 consisted of 847 solved burglaries.

Procedure. Closely following the procedure used by Johnson, Summers, and Pease (2009), every burglary in the dataset was compared to every other burglary. The distance and time between each event pair was recorded to form a contingency table representing how many burglary pairs occurred within the various space-time intervals examined. Next, the number of times the same offender was linked to both burglaries within a pair at each space-time interval was recorded within the contingency table. That number was converted to a percentage, which represents the proportion of pairs at each space-time interval where the same offender was linked to both burglaries. Finally, the percentage of burglary pairs committed by the same offender at closer space-time intervals was visually compared to those at farther space-time intervals to determine whether burglary pairs occurring closer together in space and time were more likely to be committed by the same offender than those occurring farther apart in space and time. Similar to Phases 2 and 3, statistical analyses to compare the percentages were not possible. However, this approach is consistent with Johnson, Summers, and Pease's methodology.

SPSS (v. 21) was used to generate all possible unique crime pairs and to determine the number of crime pairs where one or more of the same offenders were involved in both crimes, as well as the total number of crime pairs at space-time intervals of 100 metres and two weeks. Phase 4 also involved determining whether a significant 
near repeat space-time pattern was present in the Edmonton solved burglary data. The near repeat space-time clustering of the Phase 4 data were examined using the same methodology outlined in Phase $1 .^{40}$

Hypotheses. Based on the results obtained by Johnson, Summers, and Pease (2009), it was expected that solved burglaries that occurred closer to one another in space and time would more likely be the work of the same offender than burglaries that occurred farther apart in space and time.

\section{Results}

As previously mentioned, the final dataset used in Phase 4 consisted of 847 solved residential burglaries that occurred in Edmonton, AB, from January 1, 2007, to December 31, 2008. These 847 burglaries resulted in 358281 unique crime pairs. The percentages of burglary pairs for each space-time interval where one or more offenders were involved in both offences are presented in Table 16. Take note that the values presented in Table 16 are percentages. Thus, a value of 100 indicates that the same offender was involved in both burglaries for every crime pair at that particular space-time interval. In contrast, a value of 0 indicates that the same offender was not involved in both burglaries for any crime pair at that particular space-time interval. A value of 50 indicates that the same offender was involved in both burglaries for half of the crime pairs at that particular space-time interval.

Appendix $\mathrm{C}$ presents the actual frequencies used to calculate the percentages at each space-time interval in Table 16 (i.e., Appendix C presents the number of crime pairs

\footnotetext{
${ }^{40}$ This part of Phase 4 was identical to Phase 1 . However, this repetition of the Phase 1 analyses was necessary since Phase 4 used slightly different Edmonton burglary data than Phase 1 (i.e., the Phase 1 data consisted of all reported burglaries that occurred during 2008, whereas the Phase 4 data consisted of solved burglaries that occurred during 2007 and 2008). Thus, the exact near repeat space-time pattern for Edmonton burglary could change from Phase 1 to Phase 4.
} 
where both crimes were committed by the same offender as well as the total number of crime pairs at each space-time interval). Note that the space-time intervals presented in Table 16 are the same as those used by Johnson, Summers, and Pease (2009).

Specifically, distance varies by 100-metre intervals from the same location up until 1 kilometre (a greater than 1 kilometre cell is included in the table as well). Similarly, time varies by 2-week intervals from 14 days up until 112 days (a greater than 112 days cell is included in the table as well).

Table 16. Percentage of burglary pairs for each space-time interval where one or more offenders were involved in both offences.

\begin{tabular}{lccccccccc}
\hline $\begin{array}{l}\text { Distance } \\
\text { between } \\
\text { offences }\end{array}$ & \multicolumn{7}{c}{ Days between offences } \\
\cline { 2 - 9 } Same & 74 & 28 & 42 & 56 & 70 & 84 & 98 & 112 & $112+$ \\
\hline $1-100 \mathrm{~m}$ & 74.07 & 25.00 & 33.33 & 0.00 & 0.00 & 0.00 & 0.00 & 0.00 & 1.08 \\
$101-200 \mathrm{~m}$ & 59.09 & 0.00 & 0.00 & 0.00 & 7.69 & 0.00 & 0.00 & 0.00 & 0.74 \\
$201-300 \mathrm{~m}$ & 40.74 & 0.00 & 7.69 & 0.00 & 5.56 & 0.00 & 0.00 & 0.00 & 0.81 \\
$301-400 \mathrm{~m}$ & 36.17 & 4.17 & 9.09 & 0.00 & 0.00 & 0.00 & 0.00 & 0.00 & 0.00 \\
$401-500 \mathrm{~m}$ & 48.78 & 5.88 & 0.00 & 0.00 & 0.00 & 0.00 & 7.69 & 0.00 & 0.54 \\
$501-600 \mathrm{~m}$ & 36.36 & 0.00 & 0.00 & 0.00 & 0.00 & 0.00 & 11.11 & 0.00 & 0.18 \\
$601-700 \mathrm{~m}$ & 38.60 & 2.78 & 0.00 & 3.85 & 3.85 & 0.00 & 0.00 & 0.00 & 0.52 \\
$701-800 \mathrm{~m}$ & 42.31 & 5.26 & 0.00 & 0.00 & 3.45 & 0.00 & 0.00 & 3.03 & 0.16 \\
$801-900 \mathrm{~m}$ & 21.62 & 5.41 & 0.00 & 3.57 & 0.00 & 0.00 & 0.00 & 0.00 & 0.00 \\
$901 \mathrm{~m}-1 \mathrm{~km}$ & 31.37 & 0.00 & 0.00 & 0.00 & 0.00 & 0.00 & 0.00 & 0.00 & 0.00 \\
$1 \mathrm{~km}+$ & 0.59 & 0.48 & 0.26 & 0.11 & 0.03 & 0.04 & 0.03 & 0.03 & 0.06 \\
\hline
\end{tabular}

Note. There were no crime pairs that occurred at the same location between 84 and 112 days of each other.

The results presented in Table 16 indicate that for repeat burglary victimization (i.e., crime pairs that occurred at the exact same location), both crimes were cleared to the 
same offender $75 \%$ of the time when the two crimes occurred within 14 and 28 days of one another. Similarly, crime pairs that occurred closest to each other in space and time (i.e., the cells near the upper left of the contingency table) were more likely to involve one or more of the same offenders than crime pairs that occurred farther apart in space and time (i.e., the cells near the lower right of the contingency table). More specifically, examining the values presented in Table 16 reveals that crime pairs occurring within 800 metres and 14 days of one another demonstrated the highest percentages of being committed by one or more of the same offenders.

The next part of the Phase 4 analyses involved determining the near repeat spacetime pattern for the Edmonton solved burglary data. The observed over mean frequencies (i.e., odds ratios) and statistical significance tables produced as output by the near repeat calculator are presented in Appendix D. Recall from Phase 1, and as outlined by Ratcliffe (2009), that a significant and meaningful near repeat victimization pattern is present when the odds ratios close in space and time to the initial crime incident (i.e., cells near the upper left of the matrix) are: (1) equal to or greater than 1.20 and (2) significant at the $p$-level specified by the user (a $p$-level of .01 was specified in the current study).

Results of the near repeat analysis for the Edmonton solved burglary data indicate that significant space-time clustering is present with houses within 700 metres of a burglarized house being at an increased risk of also being burglarized for a period of 7 days. Specifically, those houses within 100, 101-200, 201-300, 301-400, 401-500, 501600 , and $601-700$ metres of the initial burglary are at a $719 \%, 359 \%, 188 \%, 282 \%$, $239 \%, 115 \%$, and $125 \%$ increased risk of also being burglarized, respectively, within the week following the initial incident. The results indicate that there was also a significant 
repeat victimization pattern found with the risk of previously burglarized houses being burglarized again being $650 \%$ greater than chance for one week following the initial crime.

\section{Discussion}

Although the percentages of crime pairs committed by one or more of the same offenders found in the current study (see Table 16) are not identical to those percentages obtained in Johnson, Summers, and Pease's (2009) study, the overall pattern of results are quite similar. More specifically, the results from Phase 4, as well as the results obtained by Johnson, Summers, and Pease, indicate that crime pairs occurring closer together in space and time are more likely to be committed by one or more of the same offenders than those crime pairs occurring farther apart, which supports the Phase 4 hypothesis. Thus, the findings obtained in the current study support the boost account as a viable explanation for the occurrence of near repeat burglary in Edmonton, AB. The results also offer additional support for the boost account as an explanation for near repeat crime in general since they are similar to those found by Johnson, Summers, and Pease.

In addition, a significant near repeat space-time pattern was found in the Edmonton solved burglary data. Specifically, houses within 700 metres of a burglarized house were found to be at an increased risk of also being burglarized for a period of 7 days. Thus, for the Phase 4 data, near repeat burglaries can be defined as those crimes that occurred within 700 metres and 7 days of one another. Interestingly, crime pairs occurring within 800 metres and 14 days of one another demonstrated the highest percentages of being committed by one or more of the same offenders, which is quite 
similar to the near repeat space-time pattern of 700 metres and 7 days. ${ }^{41}$ Thus, the percentages of crime pairs committed by the same offender are mostly highest in the cells that represent near repeat crime in the Phase 4 dataset, as found by the near repeat spacetime analysis. These findings are still in line with the boost account as an explanation for near repeat burglary.

Limitations. Although the results of Phase 4 are promising and support the hypothesis that the boost account offers a viable explanation for near repeat crime, there are several limitations to the Phase 4 analyses that need to be discussed. Similar to Phase 1, many of the limitations to Phase 4 are inherent to any research involving crime data and are not exclusive to near repeat research. For example, similar to Phase 1, only reported burglary data were represented in the Phase 4 dataset. As mentioned in Phase 1, not all crime is reported to police. Although reporting rates for burglary are typically quite high (e.g., $82 \%$ when something is stolen, $79 \%$ when nothing is stolen; Chaplin et al., 2011), Phase 4 had the additional limitation of examining only solved reported burglaries.

Similar to reporting rates, solve rates have been shown to vary across crime types and communities with violent crimes and smaller communities typically demonstrating higher clearance rates than property crimes and larger urban areas, for example (Paré, Felson, \& Ouimet, 2007). Thus, the Phase 4 analyses were not just limited by the fact that they only included reported burglary, but they were further limited by the fact that they

\footnotetext{
${ }^{41}$ Given that the significant near repeat pattern suggests that near repeat burglary crime pairs, for this particular dataset, are those that occurred within 700 metres and 7 days of one another, the percentage of crime pairs committed by one or more of the same offenders should have perhaps been examined at 7-day space intervals rather than 14-day space intervals. However, as can be seen in Appendix C, the number of crime pairs at each space-time interval was already quite low for many of the cells in the contingency table. Thus, the sample size was not ideal for a space interval of just 7 days.
} 
only included reported burglaries that had been solved by the police. Although reporting rates of burglary are typically high when something has been stolen (Chaplin et al., 2011), the same cannot be said for solve rates. In terms of burglary, the FBI (2013) has reported a clearance rate of $12.7 \%$ for all reported burglaries that occurred in the United States during 2012. Recall that for Phases 1 to 3 the Edmonton Police Services provided data that consisted of all reported residential burglaries occurring in 2007 and 2008. This made it possible to determine the exact clearance rate for 2007-2008 Edmonton burglary by comparing the number of total reported burglaries to the number of solved burglaries (i.e., the number of burglaries in the Phase 4 dataset). In 2007 and 2008, Edmonton had a total of 7973 reported residential burglaries. During that same timeframe, Edmonton had a total of 847 solved burglaries. This produces a clearance rate of $10.6 \%$. Thus, close to 90\% of residential burglary that occurred in Edmonton during 2007 and 2008 went unsolved. As previously mentioned, the Phase 4 results found support for the boost account as an explanation for near repeat burglary. However, given the $10.6 \%$ clearance rate, it is unknown whether the results obtained in Phase 4 would generalize to unsolved Edmonton burglary as well or whether the pattern of results apply only to solved crime.

Another limitation to Phase 4 was that only one crime type (i.e., residential burglary) was examined. Thus, it is unknown whether the boost account provides an explanation for near repeat crime in general or just near repeat burglary. Johnson, Summers, and Pease (2009) did examine two different crime types when testing the boost account of near repeat victimization. They found support for the boost account as an explanation for near repeat crime for both residential burglary and TFMV. However, it is still unknown whether their findings would extend to crime types beyond burglary and 
TFMV, particularly non-property crime. Thus far the boost account has been successfully tested in Edmonton in the current study and in Bournemouth, UK, by Johnson, Summers, and Pease. However, this does not guarantee that the boost account provides an explanation for near repeat crime in all other geographic regions as well.

It is important to note that although the Phase 4 analyses found support for the boost account as an explanation for near repeat crime, this does not mean that the flag account can be ruled out, especially since the flag account was not examined directly in the current study. Recall that according to the flag account, repeat and near repeat burglary is the result of different offenders, rather than the same offender, choosing to burglarize the same or nearby dwellings as a result of its particular attributes that flag the house as a suitable target (e.g., easily accessible, lacks an alarm system, no nearby neighbours). As shown in Table 16, even the crime pairs that occurred in close proximity to one another in space and time (i.e., the cells in the upper left of the contingency table) could not be attributed to the same offender $100 \%$ of the time. As a result, the Phase 4 findings indicate that the boost account cannot explain the occurrence of all near repeat crime; rather both the boost and flag accounts might need to be considered in order to fully explain near repeat crime. 


\section{General Discussion}

The current study sought to examine the space-time clustering of Canadian crime as well as the effectiveness of prospective hot-spotting methods for predicting future crime. In order to accomplish this task, this dissertation consisted of four phases.

Phase 1 determined the exact space-time clustering of several crime types (burglary, TFMV, and common assault) across three Canadian cities (Edmonton, AB, Saint John, NB, and Moose Jaw, MB). To summarize, Phase 1 results indicated that significant near repeat space-time clustering was present in the Edmonton burglary, Edmonton TFMV, and Saint John TFMV data files. However, as expected, the exact space-time clustering pattern was found to vary from one data file to the next. This is in line with previous near repeat space-time research (e.g., Behlendorf et al., 2012; Chen et al., 2013; Johnson et al., 2007; Townsley \& Oliveira, 2012), which highlights the importance for police agencies to examine near repeat space-time patterns with data that are specific to their jurisdiction as well as specific to crime type. Interestingly, none of the common assault data files examined in Phase 1 demonstrated significant near repeat space-time clustering. Thus, when combined with the inconsistent findings found in previous space-time research in regards to violent offences (e.g., Kikuchi et al., 2010; Ratcliffe \& Rengert, 2008), Phase 1 results from this dissertation suggest that the near repeat phenomenon may apply to some, but not all, violent offence types.

Phase 2 analyses used the time and distance over which crime clusters (as found in Phase 1) to generate prospective risk surfaces for the Edmonton burglary, Edmonton TFMV, and Saint John TFMV data files (these were focused on because significant space-time clustering was not found for the other data files). The accuracy of the 
prospective risk surfaces was compared to that of two traditional hot-spotting methods, KDE and Nnh. Overall, the results from Phase 2 did not support the hypothesis that risk surfaces produced using the prospective hotspot mapping technique would have greater predictive accuracy than the risk surfaces produced by the two traditional hot-spotting techniques, as assessed by the PAI.

The Phase 2 analyses of hit rates and area percentages revealed some interesting findings. More specifically, the hit rates achieved by the prospective hot-spotting method with a 2-month temporal bandwidth and KDE were higher than those obtained using the Nnh hotspot mapping method, however, these increases in hit rates were accompanied by increases in area percentages. Thus, police agencies need to consider their available resources when determining which hotspot mapping technique to use. If sufficient resources are available to patrol a high number of potential hotspot areas, it may be that the best choice is to use hot-spotting methods that result in higher hit rates (i.e., prospective hot-spotting and KDE). Conversely, if resources are scarce and fewer hotspot areas are desired, then Nnh may be the more appropriate choice. Another advantage associated with the prospective hot-spotting and $\mathrm{KDE}$ approaches is the fact that they produce risk intensity values for each cell in the hotspot area, with higher values indicating increased risk for crime. The Nnh hotspot mapping approach, on the other hand, produces hotspots based on the clustering of past crime, but does not assign varying risk intensity values to cells within those hotspots.

Although prospective hot-spotting did not outperform KDE and Nnh in Phase 2, Phase 3 examined whether it was possible to improve the accuracy of prospective hotspotting by considering three factors: whether the crimes occurred during the weekend or 
weekday, the time period of data used to generate the prospective map, and the time period of data used to test the accuracy of the prospective map. Overall, Phase 3 results suggested that regardless of hotspot mapping technique, the three strategies that were examined did not improve the predictive accuracy of the maps. However, some interesting trends did emerge, which may have practical implications. First, the Nnh approach produced maps that varied the most in their predictive accuracy, which suggests that caution should be exercised by police agencies when implementing this mapping technique. Second, hit rate and area percentage were consistently higher when larger samples were analysed. Thus, police agencies should choose longer time periods to generate their hotspot maps if they are more concerned with hit rate and have the resources to accommodate larger area percentages. Third, predictive accuracy was comparable when using hotspot maps to predict shorter (i.e., 2 weeks) and longer (i.e., 2 months) periods of future crime, which suggests that police agencies could conserve valuable time and resources by producing hotspot maps every couple of months or so rather than on a daily, or even weekly, basis.

Finally, Phase 4 investigated whether the boost account could explain near repeat burglary in Edmonton, AB. Specifically, solved crime data were used to determine whether near repeat burglaries were more likely to be committed by the same offender than more distant burglaries. Phase 4 results supported the hypothesis that burglaries that occur closer together in space and time (i.e., near repeats) were more likely to be committed by the same offender than more distant crime pairs. Thus, support was found for the boost account as an explanation for a reasonable portion of near repeat crime. 


\section{Implications of these Findings}

The findings presented in this dissertation have important implications. One set of implications is for the police with respect to crime prevention strategies. The other set of implications relates to our understanding of offending behaviour.

Evidence-based policing, which is the application of research findings to policing practices, has been on the rise since the early twenty-first century (Sherman, 2013). The hotspot mapping results presented in the current study have the potential to inform evidence-based policing in that they can be implemented by police as a crime prevention tool. Indeed, the sorts of space-time patterns and hotspot maps identified and presented in this dissertation can be used by the police in very practical ways to help combat crime. For example, the space-time clusters could be used by the police to determine high risk areas to target in their poster campaigns (warning residents that offenders are currently active). They could also be used to inform online bulletins for the public warning them that they may reside in a temporary high risk area. They could even be used to determine the most effective means to distribute police resources in space and time (e.g., where to assign patrol cars and in what quantity).

Based on previous research, it is expected that things such as targeted publicity in high risk areas would be an effective crime prevention strategy. Johnson and Bowers (2003), for example, acquired recorded crime data for a minimum of two years before and two years after the implementation of 21 burglary reduction projects in the UK. All 21 projects involved at least one form of publicity and many projects involved multiple forms (e.g., radio interviews, television appearances, surveys, posters, etc.). The results of their study suggest that the most effective burglary reduction projects were those that 
involved stand-alone publicity campaigns, which tended to be longer and more consistent types of publicity (e.g., educational campaigns, such as regular newsletters to residents about the actions taken by the project to prevent crime). In addition, reductions in burglary rates were found to coincide with more intense periods of publicity. Johnson and Bowers also found a reduction in burglary rates prior to the implementation of crime prevention projects, which they referred to as an anticipatory benefit due to the promotion of the crime prevention project. These findings, and similar results reported by others (e.g., Sidebottom, Thorpe, \& Johnson, 2009), highlight how hotspot-informed targeted publicity could potentially be an effective crime prevention tool.

The results presented in this dissertation also have implications with respect to our understanding of offending behaviours. In order to highlight these implications, it is useful to return to some of the issues discussed in the Introduction. Recall that several well-known theories of offender behaviour were presented in the literature review as explanations for near repeat crime. For example, the boost account suggests that repeat and near repeat burglaries result from the same offender returning to burglarize a dwelling (or a dwelling nearby) that they have successfully burglarized in the past. In contrast, the flag account suggests that repeat and near repeat burglary result from different offenders choosing to burglarize the same (or nearby dwellings) because the dwelling(s) have enduring attributes that flag it (them) as a suitable target. The Phase 4 analyses did find support for the boost account as an explanation for near repeat burglaries, although the boost account could not explain the occurrence of all near repeat crime. Thus, consistent with previous research (e.g., Bernasco, 2008; Johnson, 2008; 
Johnson, Summers, \& Pease, 2009), it seems that both the boost and flag accounts must be considered in order to fully explain near repeat crime.

Another theory discussed in the literature review was optimal foraging theory. Recall that optimal foraging theory proposes that offending behaviour is similar to animal foraging in that offenders want to minimize the time spent selecting an appropriate target while increasing the potential for rewards and reducing the risk of being apprehended (Johnson \& Bowers, 2004a). Consider the case of serial burglary. Over the short term, targeting houses located in close proximity to a house the burglar previously burglarized helps achieve these goals by cutting down on the time spent looking for appropriate targets and by increasing familiarity with the area (thus reducing the risk of apprehension). According to optimal foraging theory, however, animals must move to different areas as resources dry up and/or as the risk of predation increases. Consistent with this, over the long term offenders eventually have to offend in different areas either because suitable targets become scarce (e.g., through target hardening strategies initiated by home owners) or to avoid police attention. This helps explain why the risk of being burglarized in a particular area (following a previous burglary) decreases over time. Optimal foraging theory can potentially be applied to other crime types too, such as TFMV.

Thus, the near repeat space-time clustering results presented in Phase 1 are in line with optimal foraging theory in that the risk of near repeat crime subsides relatively soon (within seven days) after the initial offence is committed. This was found for all three of the data files where significant findings emerged (i.e., Edmonton burglary, Edmonton TFMV, and Saint John TFMV). The lack of significant space-time clustering for all of 
the common assault data files could suggest that optimal foraging theory is not a viable theory for that particular crime type. Future research would be needed to clarify why this is the case. It is possible that common assaults are more likely to be committed on the spur of the moment with less consideration being given to resource conservation. As well, target selection for common assault against a known acquaintance would arguably be different than target selection for common assault against a stranger.

Recall that routine activity theory was also discussed in the literature review. Routine activity theory argues that, within an environment considered appropriate for criminal activity, crime occurs when a motivated offender's routine activities intersect, in time and space, with a desirable target's routine activity space in the absence of appropriate guardians (e.g., watchful neighbours, police patrols, security devices, etc.; Cohen \& Felson, 1979). Thus, according to the routine activity theory, burglary is communicable because houses in close proximity to one another are all located within an offender's activity space, which results in those houses receiving greater exposure to the offender than suitable targets not located in their activity space. Similarly, the routine activity theory suggests that TFMV is communicable because vehicles in close proximity to an originally targeted vehicle are also located within an offender's activity space, thus achieving the intersection in time and space of the offender's and desirable target's routine activity space necessary for crime to occur.

Routine activity theory provided the basis for Phase 3: Strategy 1 where weekdayand weekend-specific hotspot maps were developed in an attempt to improve predictive accuracy. This strategy was adopted since it was assumed that routine activities during the week, for both offenders and victims, would differ from routine activities during the 
weekend. While other research has found support for routine activity theory as a viable explanation for spatial clustering and repeat victimization (Birks, Townsley, \& Stewart, 2012), the Phase 3 results did not find support for the theory. More specifically, routine activities appeared consistent throughout the week resulting in the weekday/weekend maps producing comparable levels of predictive accuracy regardless of whether the maps were applied to the same (e.g., weekday map to predict weekday crimes) or opposing (e.g., weekday map to predict weekend crimes) time of week. Although the routine activity theory was not supported by the Phase 3 results, there was the potential for many weekday crimes to be incorrectly classified as weekend crimes and vice versa, which would have negatively impacted Strategy 1's effectiveness.

\section{Limitations}

Limitations have already been presented in the discussion section for each phase of analysis. However, some overarching limitations will again be discussed here.

One main concern relates to limitations that are inherent to any research involving crime data such as this. For example, not all crime is reported to police and this fact could have impacted the analyses across all four phases. For example, in Phase 1 it is likely that unreported crime data could have made the near repeat space-time patterns more apparent in those data files where significant findings were not found. In addition, the inclusion of unreported crime could have altered the nature of the space-time patterns that were found, which in turn would have impacted the predictive accuracy of the prospective hotspotting approach (in Phase 2). Related to that this concern is the fact that not all crime is solved, which could have greatly impacted the Phase 4 analyses. If the solve rates for 
crimes such as burglary were higher, even more evidence for the boost account might have been obtained.

In addition, geocoding quality, which could vary from one police officer and agency to the next (Hart \& Zandbergen, 2012), could also have impacted the results. For example, if some crime site locations were geocoded at the block level then this could have masked significant near repeat space-time clustering (the incidents would appear as repeat victimization instead). The same can be said of date coding quality as well. Specifically, the accuracy of crime occurrence dates would have a serious impact on the analyses, particularly the weekday/weekend hotspot maps constructed in Phase 3. For example, if crimes were incorrectly coded as weekend crimes when they actually occurred during the week (and vice versa) then the predictive accuracy of the weekday/weekend maps would have been negatively impacted when applied to future crimes that occurred during the same time of the week.

Another key limitation to the Phase 2 and 3 analyses is the fact that Bowers et al.'s (2004) prospective hot-spotting technique had to be simulated through the use of options available within CrimeStat rather than directly replicated. Recall that Bowers et al. found prospective hot-spotting to be more effective at predicting future crime than two traditional methods of hotspot mapping (i.e., retrospective moving window technique and police beats). Thus, their results suggest that their originally proposed method of prospective hot-spotting does have advantages over traditional hotspot mapping approaches. Although a simulation of Bowers et al.'s prospective hot-spotting approach is not ideal, this approach was unavoidable in the current study since the software developed by Bowers et al. is not accessible by other users. Unfortunately, this does 
mean that the possibility exists that different results could have been found for Phases 2 and 3 if Bowers et al.'s prospective hot-spotting approach had been directly replicated.

Finally, the comparison of the predictive accuracy values in the current study was a fairly subjective process. Given the nature of the data it was not possible to use formal statistical tests to compare results across different data files (which is consistent with previous studies; e.g., Bowers et al., 2004; Chainey et al., 2008). Instead, means and 95\% CIs were calculated in an attempt to increase the objectivity of comparisons. This approach has been previously adopted by a few researchers when conducting hotspot mapping research (e.g., Tompson \& Townsley, 2010), but it is potentially problematic in the current study. For example, the calculations of means and 95\% CIs in the current study were based on a sample size of three, which makes the values potentially unreliable. An appropriate degree of caution must therefore be used when viewing these results.

\section{Future Directions}

Although the prospective hot-spotting approach tested in this dissertation did not outperform the two traditional hotspot mapping approaches, the results were still promising overall in terms of the use of hotspot maps as a prospective mapping tool. There are many avenues available for future research in this area and a few options will be presented here.

The significant near repeat space-time clustering found in Phase 1 suggest that additional research examining space-time clustering could prove useful, particularly since the exact space-time patterns observed in the literature (and in this dissertation) consistently vary across geographic locations and specific crime types. Thus, space-time 
pattern research in additional cities and across other crime types would be useful in order to see whether an effective crime prevention tool could be produced for various jurisdictions. In addition, given that research regarding the near repeat space-time clustering of violent crime is so mixed, future research should continue to examine different types of violent offences in order to identify the conditions under which significant patterns emerge.

The Phase 2 and 3 analyses revealed that prospective hot-spotting did not result in greater predictive accuracy than traditional hotspot mapping techniques and the strategies examined in the current study did little to improve predictive accuracy. In the future, it will be important to explore why Bowers et al.'s (2004) prospective hot-spotting technique outperformed traditional hotspot mapping approaches. To do this, more detailed information about their technique will be needed. It is also still possible that prospective hot-spotting techniques, of the type examined in this dissertation, could be improved using approaches that were not tested in the current study. As previously mentioned, one option for accomplishing this goal would be to include additional risk factors given that previous research has found significant relationships between crime locations and place-based risk factors such as target density and road infrastructure (e.g., Beavon et al., 1994; Groff \& LaVigne, 2001).

The results from Phase 4 indicate that the boost account offers a viable explanation for the occurrence of some near repeat crime. However, the boost and flag account are both needed in order to fully explain near repeat crime. There has been more research into the boost account than the flag account in the near repeat literature. Thus, future research exploring the flag account would be very worthwhile. One possibility for 
examining the flag account in future near repeat burglary research would be to compare the similarity of houses in close proximity to one another (with respect to appearance of wealth, concealment opportunities, escape routes, etc.) to the similarity of houses that are located farther apart (similar research could potentially be done for TFMV crimes as well). If the flag account offers a viable explanation for near repeat crime then it would be expected that houses in close proximity to one another would be rated more similar than houses farther apart. To carry out this research, some data security issues would first need to be resolved, as exact address data would be required. The police agencies that provided data for the current study were wary of providing such sensitive data.

Some research suggests that hotspot maps can be effectively implemented as a crime prevention tool (e.g., Mitchell, 2013). However, this research is scarce. Future research examining if and how various hotspot mapping methods, particularly prospective hot-spotting, can be successfully implemented by police is certainly warranted. Specifically, future research should focus on improving the accuracy of prospective hot-spotting as well as assessing its effectiveness as a crime prevention tool in applied settings. Some potential research questions for future research include: Can prospective hot-spotting be used effectively to distribute police resources and develop public awareness campaigns? Under what conditions does prospective hot-spotting prove most effective? Does crime rate decrease through the use of these hotspot maps (and the associated crime prevention strategies) or do hotspots of crime simply shift to other areas? 


\section{Conclusion}

The current study used Canadian data to examine near repeat space-time patterns and to develop and assess various prospective hotspot maps. Both of these approaches could potentially inform crime prevention strategies and prove useful in determining the most effective way to allocate police resources. The results presented in this dissertation emphasize the importance of determining near repeat space-time clustering based on specific geographic locations and crime types as exact space-time patterns clearly vary across contexts. The results also highlight the need for police agencies to seriously consider the availability of their resources when determining which hotspot approaches to use for predicting, and preventing, future crime. While hotspot mapping is already used by police to focus police resources, continued research is vital to ensure that police agencies are developing and utilizing hotspot maps in the most effective and efficient way possible. 


\section{References}

Ashton, J., Brown, I., Senior, B., \& Pease, K. (1998). Repeat victimisation: Offender accounts. International Journal of Risk, Security and Crime Prevention, 3, 269-279.

Bailey, T. C., \& Gatrell, A. C. (1995). Interactive spatial data analysis. Harlow, UK: Longman Group Limited.

Barr, R., \& Pease, K. (1990). Crime placement, displacement, and deflection. Crime and Justice: A Review of the Research, 12, 277-318.

Beavon, D. J. K., Brantingham, P. L., \& Brantingham, P. J. (1994). The influence of street networks on the patterning of property offenses. In R. V. Clarke (Ed.), Crime prevention studies, Vol. 2 (pp. 115-148). Monsey, NY: Criminal Justice Press.

Behlendorf, B., LaFree, G., \& Legault, R. (2012). Microcycles of violence: Evidence from terrorist attacks by ETA and the FMLN. Journal of Quantitative Criminology, $28,49-75$.

Bennell, C., \& Canter, D. V. (2002). Linking commercial burglaries by modus operandi: Tests using regression and ROC analysis. Science and Justice, 42, 153-164.

Bennett, T. (1995). Identifying, explaining and targeting burglary 'hot spots.' European Journal of Criminal Policy and Research, 3, 113-123.

Bennett, T., \& Wright, R. (1984). Burglars on burglary: Prevention and the offender. Aldershot, England: Gower.

Bernasco, W. (2008). Them again? Same-offender involvement in repeat and near repeat burglaries. European Society of Criminology, 5, 411-431.

Birks, D., Townsley, M., \& Stewart, A. (2012). Generative explanations of crime: Using simulation to test criminological theory. Criminology, 50, 221-254. 
Block, S., \& Fujita, S. (2013). Patterns of near repeat temporary and permanent motor vehicle thefts. Crime Prevention and Community Safety, 15, 151-167.

Boba Santos, R. (2013). Crime analysis with crime mapping ( $3^{\text {rd }}$ ed.). Beverly hills, CA: Sage.

Bowers, K. J., \& Johnson, S. D. (2004). Who commits near repeats? A test of the boost explanation. Western Criminology Review, 5, 12-24.

Bowers, K. J., Johnson, S. D., \& Pease, K. (2004). Prospective hot-spotting: The future of crime mapping? British Journal of Criminology, 44, 641-658.

Braithwaite, A., \& Johnson, S. D. (2012). Space-time modeling of insurgency and counterinsurgency in Iraq. Journal of Quantitative Criminology, 28, 31-48.

Budd, T. (1999). Burglary of domestic dwellings: Findings from the British Crime Survey. Home Office Statistical Bulletin 4/99. London: Home Office.

Chainey, S., Tompson, L., \& Uhlig, S. (2008). The utility of hotspot mapping for predicting spatial patterns of crime. Security Journal, 21, 4-28.

Chaplin, R., Flatley, J., \& Smith, K. (2011). Crime in England and Wales 2010/11: Findings from the British Crime Survey and police recorded crime ( $2^{\text {nd }}$ ed.). London: Home Office.

Chen, P., Yuan, H., \& Li, D. (2013). Space-time analysis of burglary in Beijing. Security Journal, 26, 1.15.

Cohen, L. E., \& Felson, M. (1979). Social change and crime rate trends: A routine activity approach. American Psychological Review, 44, 588-608. 
Eck, J. E., Chainey, S., Cameron, J. G., Leitner, M., \& Wilson, R. E. (2005). Mapping crime: Understanding hot spots. Retrieved March 10, 2009, from http://www.ojp.usdoj.gov/nij/maps/ncj209393.htm.

Ericsson, U. (1995). Straight from the horse's mouth. Forensic Update, 43, 23-25. Farrell, G., \& Pease, K. (1993). Once bitten, twice bitten: Repeat victimisation and its implications for crime prevention. The Home Office: Crime Prevention Paper 46.

Federal Bureau of Investigation. (2013). Crime in the United States, 2012. Retrieved November 14, 2013, from http://www.fbi.gov/about-us/cjis/ucr/crime-in-theu.s/2012/crime-in-the-u.s.-2012/offenses-known-to-lawenforcement/clearancetopic.pdf.

Gill, M., \& Pease, K. (1998). Repeat robbers: How are they different? In M. Gill (Ed.), Crime at work: Increasing the risk for offenders. Leicester, UK: Perpetuity Press. Groff, E. R., \& LaVigne, N. G. (2001). Mapping an opportunity surface of residential burglary. Journal of Research in Crime and Delinquency, 38, 257-278.

Haberman, C. P., \& Ratcliffe, J. H. (2012). The predictive policing challenges of near repeat armed street robberies. Policing, 6, 151-166.

Hart, T. C., \& Zandbergen, P. A. (2012). Effects of data quality on predictive hotspot mapping. Final report submitted to the National Institute of Justice, September 1.

Johnson, D. (2013). The space/time behaviour of dwelling burglars: Finding near repeat patterns in serial offender data. Applied Geography, 41, 139-146.

Johnson, S. D. (2008). Repeat burglary victimisation: A tale of two theories. Journal of Experimental Criminology, 4, 215-240. 
Johnson, S. D., Bernasco, W., Bowers, K. J., Elffers, H., Ratcliffe, J., Rengert, G., \& Townsley, M. (2007). Space-time patterns of risk: A cross national assessment of residential burglary victimization. Journal of Quantitative Criminology, 23, 201219.

Johnson, S. D., \& Bowers, K. J. (2003). Opportunity is in the eye of the beholder: The role of publicity in crime prevention. Criminology and Public Policy, 2, 497-524.

Johnson, S. D., \& Bowers, K. J. (2004a). The burglary as clue to the future: The beginnings of prospective hot-spotting. European Journal of Criminology, 1, 237255.

Johnson, S. D., \& Bowers, K. J. (2004b). The stability of space-time clusters of burglary. British Journal of Criminology, 44, 55-65.

Johnson, S. D., Bowers, K. J., Birks, D. J., \& Pease, K. (2009). Predictive mapping of crime by ProMap: Accuracy, units of analysis, and the environmental backcloth. In D. Weisburd, W. Bernasco \& G. J. N. Bruinsma (Eds.), Putting crime in its place (pp. 171-198). New York: Springer.

Johnson, S. D., Bowers, K. J., \& Pease, K. (2005). Predicting the future or summarising the past? Crime mapping as anticipation. In M. Smith \& N. Tilley (Eds.), Crime science: New approaches to preventing and detecting crime (pp. 145-163). London, UK: Willan Publishing.

Johnson, S. D., Lab, S. P., \& Bowers, K. J. (2008). Stable and fluid hotspots of crime: Differentiation and identification. Built Environment, 34, 32-45. 
Johnson, S. D., Summers, L., \& Pease, K. (2009). Offender as forager? A direct test of the boost account of victimization. Journal of Quantitative Criminology, 25, 181200.

Kikuchi, G., Amemiya, M., Shimada, T., Saito, T., \& Harada, Y. (2010, June). A spatiotemporal analysis of near repeat victimization in Japan. Paper presented at the Eighth National Crime Mapping Conference, Manchester, UK.

Kleemans, E. R. (2001). Repeat burglary victimization: Results of empirical research in the Netherlands. In G. Farrell \& K. Pease (Eds.), Crime prevention studies, Vol. 12: Repeat victimisation (pp. 53-68). Monsey, NY: Criminal Justice Press.

Knox, G. (1964). Epidemiology of childhood leukaemia in Northumberland and Durham. British Journal of Preventative \& Social Medicine, 18, 17-24.

Lauritsen, J. L., \& Davis Quinet, K. F. (1995). Repeat victimization among adolescents and young adults. Journal of Quantitative Criminology, 11, 143-166.

Lersch, K. M. (2004). Space, time, and crime. Durham, NC: Carolina Academic Press. Levine, N. (2008). The "hottest" part of a hotspot: Comments on "The utility of hotspot mapping for predicting spatial patterns of crime.” Security Journal, 21, 295-302.

Levine, N. (2010). CrimeStat: A spatial statistics program for the analysis of crime incident locations (version 3.3). Washington, DC: National Institute of Justice.

MacDonald, J. E., \& Gifford, R. (1989). Territorial cues and defensible space theory: The burglar's point of view. Journal of Experimental Psychology, 9, 193-205.

Maguire, E. M. W., \& Bennett, T. (1982). Burglary in a dwelling: The offence, the offender and the victim. London: Heinneman Educational Books. 
Marchione, E., \& Johnson, S. D. (2013). Spatial, temporal and spatio-temporal patterns of maritime piracy. Journal of Research in Crime and Delinquency, 50, 504-524.

Mitchell, R. J. (2013). Hot-spot randomized control works for Sacramento. The Police Chief, 80, 12.

Morgan, F. (2001). Repeat burglary in a Perth suburb: Indicator of short-term or longterm risk? In G. Farrell \& K. Pease (Eds.), Crime prevention studies, Vol. 12: Repeat victimisation (pp. 83-118). New York: Criminal Justice Press.

Moreto, W. D., Piza, E. L., \& Caplan, J. M. (2013). “A plague on both your houses?”: Risks, repeats, and reconsiderations of urban residential burglary. Justice Quarterly. Advance online publication. doi: 10.1080/07418825.2012.754921

Mosher, C. J., Miethe, T. D., \& Hart, T. C. (2013). The mismeasure of crime (2 ${ }^{\text {nd }}$ ed.). Thousand Oaks, CA: Sage.

Mukherjee, S., \& Carcach, C. (1998). Repeat victimisation in Australia: Extent, correlates and implications for crime prevention. Australian Institute of Criminology: Research and Public Policy Series No. 15.

Nee, C., \& Taylor, M. (1988). Residential burglary in the Republic of Ireland: A situational perspective. The Howard Journal, 27, 105-116.

Nee, C., \& Taylor, M. (2000). Examining burglars' target selection: Interview, experiment or ethnomethodology? Psychology, Crime \& Law, 6, 45-59.

Paré, P.-P., Felson, R. B., \& Ouimet, M. (2007). Community variation in crime clearance: A multilevel analysis with comments on assessing police performance. Journal of Quantitative Criminology, 23, 243-258. 
Pease, K. (1998). Repeat victimization: Taking stock. The Home Office: Police Research Group: Crime Detection and Prevention Series Paper 90.

Pitcher, A. B., \& Johnson, S. D. (2011). Exploring theories of victimization using a mathematical model of burglary. Journal of Research in Crime and Delinquency, 48, 83-109.

Ratcliffe, J. H. (2000). Aoristic analysis: The spatial interpretation of unspecific temporal events. International Journal of Geographic Information Science, 14, 669-679.

Ratcliffe, J. H. (2002). Hotspot Detective 2.0 for MapInfo Professional 7.0. Available online at http://jratcliffe.net/hsd/.

Ratcliffe, J. H. (2009). Near repeat calculator (v 1.3). Temple University, Philadelphia, PA and the National Institute of Justice, Washington, DC.

Ratcliffe, J. H., \& Rengert, G. F. (2008). Near-repeat patterns in Philadelphia shootings. Security Journal, 21, 58-76.

Sagovsky, A., \& Johnson, S. D. (2007). When does repeat burglary victimization occur? The Australian and New Zealand Journal of Criminology, 40, 1-26.

Schneider, A. (2013). GPS Visualizer Geocoding [online program]. Available at http://www.gpsvisualizer.com/geocoding.html

Sherman, L. W. (1992). Policing domestic violence: Experiments and dilemmas. New York: Macmillan.

Sherman, L. W. (2013). The rise of evidence-based policing: Targeting, testing, and tracking. In M. Tonry (Ed.), Crime and justice, Vol. 42 (pp. 1-75). Chicago, IL: University of Chicago Press. 
Short, M. B., D’Orsogna, M. R., Brantingham, P. J., \& Tita, G. E. (2009). Measuring and modeling repeat and near-repeat burglary effects. Journal of Quantitative Criminology, 25, 325-339.

Sidebottom, A., Thorpe, A., \& Johnson, S. D. (2009). Using targeted publicity to reduce opportunities for bicycle theft: A demonstration and replication. European Journal of Criminology, 6, 267-286.

Statistics Canada. (2008, November 5). Population and dwelling counts, for Canada, and census subdivisions (municipalities), 2006 and 2001 censuses - 100\% data.

Retrieved October 5, 2010, from

http://www12.statcan.gc.ca/census-recensement/2006/dp-pd/hlt/97-550/Index.cfm? $\mathrm{TPL}=\mathrm{P} 1 \mathrm{C} \& \mathrm{Page}=\mathrm{RETR} \& \mathrm{LANG}=\mathrm{Eng} \& \mathrm{~T}=301 \& \mathrm{~S}=3 \& \mathrm{O}=\mathrm{D}$.

Summers, L., Johnson, S. D., \& Pease, K. (2007). El robo de (objetos en) vehículos y su contagio a través del espacio y el tiempo: Aplicaciones de técnicas epidemiológicas. Revista Electronica de Investigacion Criminologica, 5, 1-22.

Tompson, L., \& Townsley, M. (2010). (Looking) Back to the future: Using space-time patterns to better predict the location of street crime. International Journal of Police Science \& Management, 12, 23-40.

Townsley, M., Homel, R., \& Chaseling, J. (2000). Repeat burglary victimisation: Spatial and temporal patterns. The Australian and New Zealand Journal of Criminology, $33,37-63$.

Townsley, M., Homel, R., \& Chaseling, J. (2003). Infectious burglaries: A test of the near repeat hypothesis. British Journal of Criminology, 43, 615-633. 
Townsley, M., Johnson, S. D., \& Ratcliffe, J. H. (2008). Space time dynamics of insurgent activity in Iraq. Security Journal, 21, 139-146.

Townsley, M., \& Oliveira, A. (2012). Space-time dynamics of maritime piracy. Security Journal. Advance online publication. doi: 10.1057/sj.2012.45

Tseloni, A., \& Pease, K. (1998). Nuisance phone calls to women in England and Wales. European Journal of Criminal Policy and Research, 6, 91-111.

Van Patten, I. T., McKeldin-Coner, J., \& Cox, D. (2009). A microspatial analysis of robbery: Prospective hot spotting in a small city. Crime Mapping: A journal of research and practice, $1,7-32$.

Wells, W., Wu, L., \& Ye, X. (2012). Patterns of near-repeat gun assaults in Houston. Journal of Research in Crime and Delinquency, 49, 186-212.

Winkel, F. W. (1991). Police, victims, and crime prevention: Some research-based recommendations on victim-oriented interventions. British Journal of Criminology, $31,250-265$.

Youstin, T. J., Nobles, M. R., Ward, J. T., \& Cook, C. L. (2011). Assessing the generalizability of the near repeat phenomenon. Criminal Justice and Behavior, 38, 1042-1063. 
Appendix A

Observed Over Mean Expected Frequencies and Statistical Significance Tables from Phase 1

Table A1. Observed over mean expected frequencies for Edmonton burglary data file.

\begin{tabular}{lcccccccccccc}
\hline & \multicolumn{10}{c}{ Number of Days } \\
\hline $\begin{array}{l}\text { Distance } \\
\text { (in metres) }\end{array}$ & 0 to 7 & 8 to 14 & 15 to 21 & 22 to 28 & 29 to 35 & 36 to 42 & 43 to 49 & 50 to 56 & 57 to 63 & 64 to 70 & $\begin{array}{c}\text { More } \\
\text { than } 70\end{array}$ \\
\hline Same location & $4.149^{* *}$ & $1.969^{* *}$ & $1.904^{* *}$ & 1.336 & 1.358 & 0.979 & 1.155 & 0.982 & 0.61 & 0.54 & 0.7 \\
1 to 100 & $2.643^{* *}$ & 1.05 & 0.845 & 0.961 & 0.919 & 0.976 & 0.996 & 0.951 & 0.912 & 0.993 & 0.927 \\
101 to 200 & $1.788^{* *}$ & 1.032 & 0.897 & 0.985 & 1.029 & $1.16^{*}$ & $1.139 *$ & 1.128 & 0.937 & 0.855 & 0.946 \\
201 to 300 & $1.395^{* *}$ & 1.018 & 1.042 & 1.054 & 1.108 & 0.989 & 1.085 & 0.928 & 0.916 & 1.022 & 0.967 \\
301 to 400 & $1.286^{* *}$ & 1.007 & 0.988 & 1.01 & 0.92 & 0.958 & 1.057 & 0.928 & $1.137^{*}$ & 1.017 & 0.983 \\
401 to 500 & $1.266^{* *}$ & $1.096^{*}$ & 0.999 & 0.994 & $1.12^{*}$ & 0.905 & 0.987 & 1.034 & 1.063 & 0.975 & 0.974 \\
501 to 600 & $1.079^{*}$ & 0.987 & 1.037 & 1.024 & 0.973 & 0.964 & 1.046 & 0.953 & 1.051 & 0.905 & 0.998 \\
601 to 700 & $1.143^{* *}$ & 0.965 & 0.968 & 0.987 & 1.06 & 1.051 & 0.959 & 1.025 & 0.881 & 1.011 & 0.997 \\
701 to 800 & $1.102^{*}$ & 0.989 & 1.043 & 0.966 & 1.01 & 0.966 & 1.016 & 1.034 & 1.013 & 1.023 & 0.991 \\
801 to 900 & $1.181^{* *}$ & 0.968 & 1.015 & 0.972 & 1.019 & 0.974 & 1.031 & 1.001 & 0.963 & $1.078^{* *}$ & 0.989 \\
901 to 1000 & $1.156^{* *}$ & 0.977 & 1.046 & 1.034 & 0.983 & 1.037 & $1.175^{* *}$ & 0.996 & 0.998 & 0.972 & 0.979 \\
1001 to 1100 & $1.117^{* *}$ & 1.026 & 1.056 & 0.99 & 1.026 & 1.041 & 1.036 & 1.023 & 0.978 & $1.056^{*}$ & 0.98 \\
1101 to 1200 & $1.091 *$ & 1.048 & 1.003 & 0.987 & 0.974 & 0.972 & 1.022 & 0.987 & 1.015 & 1.043 & 0.992 \\
1201 to 1300 & $1.117^{*}$ & 1.007 & 1.008 & 1.005 & 1.019 & 1.052 & 1.03 & 1.047 & 0.987 & 1.037 & 0.982 \\
1301 to 1400 & $1.07^{*}$ & $1.067 *$ & 0.98 & 1.035 & 1.042 & 0.974 & 1.021 & 1.052 & 0.934 & $1.055^{*}$ & 0.987 \\
More than 1400 & 0.995 & 1 & 1 & 1 & 1 & 1 & 0.999 & 1 & 1 & 1 \\
\hline
\end{tabular}

$* p<.05, * * p<.01$ 
Table A2. Statistical significance table for Edmonton burglary data file.

\begin{tabular}{|c|c|c|c|c|c|c|c|c|c|c|c|}
\hline \multirow[b]{2}{*}{$\begin{array}{l}\text { Distance } \\
\text { (in metres) }\end{array}$} & \multicolumn{11}{|c|}{ Number of Days } \\
\hline & 0 to 7 & 8 to 14 & 15 to 21 & 22 to 28 & 29 to 35 & 36 to 42 & 43 to 49 & 50 to 56 & 57 to 63 & 64 to 70 & $\begin{array}{l}\text { More } \\
\text { than } 70\end{array}$ \\
\hline Same location & 0.01 & 0.01 & 0.01 & 0.16 & 0.12 & 0.63 & 0.35 & 0.61 & 0.96 & 0.93 & 1 \\
\hline 1 to 100 & 0.01 & 0.37 & 0.91 & 0.63 & 0.82 & 0.61 & 0.51 & 0.7 & 0.83 & 0.52 & 1 \\
\hline 101 to 200 & 0.01 & 0.31 & 0.95 & 0.56 & 0.35 & 0.02 & 0.03 & 0.06 & 0.78 & 0.99 & 1 \\
\hline 201 to 300 & 0.01 & 0.41 & 0.26 & 0.2 & 0.05 & 0.58 & 0.09 & 0.89 & 0.91 & 0.36 & 1 \\
\hline 301 to 400 & 0.01 & 0.47 & 0.53 & 0.46 & 0.94 & 0.77 & 0.17 & 0.92 & 0.02 & 0.38 & 1 \\
\hline 401 to 500 & 0.01 & 0.03 & 0.49 & 0.52 & 0.03 & 0.96 & 0.58 & 0.27 & 0.14 & 0.69 & 1 \\
\hline 501 to 600 & 0.02 & 0.67 & 0.25 & 0.31 & 0.72 & 0.79 & 0.2 & 0.84 & 0.18 & 0.99 & 0.58 \\
\hline 601 to 700 & 0.01 & 0.76 & 0.79 & 0.58 & 0.09 & 0.17 & 0.84 & 0.27 & 1 & 0.42 & 0.74 \\
\hline 701 to 800 & 0.03 & 0.6 & 0.19 & 0.83 & 0.38 & 0.8 & 0.33 & 0.25 & 0.4 & 0.33 & 0.9 \\
\hline 801 to 900 & 0.01 & 0.81 & 0.34 & 0.72 & 0.28 & 0.77 & 0.31 & 0.48 & 0.86 & 0.01 & 0.95 \\
\hline 901 to 1000 & 0.01 & 0.73 & 0.09 & 0.21 & 0.68 & 0.18 & 0.01 & 0.56 & 0.51 & 0.77 & 1 \\
\hline 1001 to 1100 & 0.01 & 0.21 & 0.07 & 0.63 & 0.25 & 0.19 & 0.19 & 0.26 & 0.72 & 0.02 & 1 \\
\hline 1101 to 1200 & 0.02 & 0.1 & 0.46 & 0.66 & 0.77 & 0.82 & 0.26 & 0.56 & 0.36 & 0.13 & 0.94 \\
\hline 1201 to 1300 & 0.02 & 0.41 & 0.43 & 0.47 & 0.31 & 0.05 & 0.2 & 0.07 & 0.62 & 0.2 & 1 \\
\hline 1301 to 1400 & 0.02 & 0.02 & 0.73 & 0.18 & 0.14 & 0.81 & 0.2 & 0.07 & 0.98 & 0.03 & 0.98 \\
\hline More than 1400 & 1 & 0.97 & 0.83 & 0.58 & 0.92 & 0.46 & 0.99 & 0.82 & 0.12 & 0.93 & 0.01 \\
\hline
\end{tabular}


Table A3. Observed over mean expected frequencies for Edmonton TFMV data file.

\begin{tabular}{lccccccccccc}
\hline & \multicolumn{7}{c}{ Number of Days } \\
\hline $\begin{array}{l}\text { Distance } \\
\text { (in metres) }\end{array}$ & 0 to 7 & 8 to 14 & 15 to 21 & 22 to 28 & 29 to 35 & 36 to 42 & 43 to 49 & 50 to 56 & 57 to 63 & 64 to 70 & $\begin{array}{c}\text { More } \\
\text { than } 70\end{array}$ \\
\hline Same location & $1.669^{* *}$ & $1.142^{* *}$ & 1.051 & 1.02 & 1.011 & 0.867 & 1.023 & 0.996 & 0.927 & 0.969 & 0.961 \\
1 to 100 & $1.301^{* *}$ & 1.042 & 1.011 & 0.994 & 1.006 & 1.006 & 0.936 & 1.023 & 0.994 & 0.983 & 0.983 \\
101 to 200 & $1.204^{* *}$ & $1.044^{*}$ & $1.063^{* *}$ & $1.04^{*}$ & 1.01 & 0.951 & 0.982 & 0.985 & 0.97 & 0.966 & 0.987 \\
201 to 300 & $1.162^{* *}$ & $1.044^{*}$ & $1.055^{* *}$ & $1.074^{* *}$ & 0.999 & 0.982 & 0.991 & 0.992 & 0.996 & 1.008 & 0.983 \\
301 to 400 & $1.124^{* *}$ & $1.034^{*}$ & $1.034^{*}$ & 1.028 & 0.985 & 0.991 & 0.984 & 0.994 & 0.967 & 0.971 & 0.993 \\
401 to 500 & $1.105^{* *}$ & $1.045^{* *}$ & $1.065^{* *}$ & $1.028^{*}$ & 1.025 & 1.03 & 1.01 & 0.96 & 0.99 & 1.008 & 0.985 \\
501 to 600 & $1.099^{* *}$ & $1.026^{*}$ & $1.026^{*}$ & $1.035^{*}$ & 1.006 & 1.014 & 1.003 & 1.003 & 1.017 & 0.994 & 0.988 \\
601 to 700 & $1.092^{* *}$ & $1.06^{* *}$ & 1.002 & 1.006 & 0.998 & 0.98 & 0.997 & 1 & 1.009 & 1.006 & 0.992 \\
701 to 800 & $1.086^{* *}$ & $1.041^{* *}$ & $1.027^{* *}$ & 0.995 & 1.018 & 1.004 & 1.014 & 0.973 & 0.997 & 0.993 & 0.991 \\
801 to 900 & $1.061^{* *}$ & $1.026^{* *}$ & 1.02 & 1.01 & 0.989 & 1.002 & $1.024 *$ & 0.975 & 0.999 & 1.014 & 0.993 \\
901 to 1000 & $1.045^{* *}$ & 1.002 & 1.013 & 1.014 & 1.001 & 1.013 & 1.002 & 1.007 & 0.989 & 1.008 & 0.995 \\
1001 to 1100 & $1.04^{* *}$ & $1.027^{*}$ & 0.999 & 1.007 & $1.033^{*}$ & 1.015 & 1.016 & 1.016 & 1.013 & 0.98 & 0.992 \\
1101 to 1200 & $1.028^{*}$ & 1.013 & $1.027^{*}$ & 1.001 & 1.008 & 0.974 & 0.98 & 0.988 & 1.007 & 0.999 & 0.998 \\
1201 to 1300 & $1.039^{* *}$ & $1.044^{* *}$ & $1.022^{*}$ & $1.018^{*}$ & 1.009 & 0.993 & $1.023 *$ & 0.987 & 1.014 & 0.976 & 0.993 \\
1301 to 1400 & $1.056^{* *}$ & 1.008 & $1.025^{*}$ & 0.976 & 1.009 & 1.013 & $1.03 *$ & 0.998 & 0.991 & 1.016 & 0.993 \\
More than 1400 & 0.998 & 0.999 & 0.999 & 1 & 1 & 1 & 1 & 1 & 1 & 1 \\
\hline
\end{tabular}

$* p<.05, * * p<.01$ 
Table A4. Statistical significance table for Edmonton TFMV.

\begin{tabular}{|c|c|c|c|c|c|c|c|c|c|c|c|}
\hline \multirow[b]{2}{*}{$\begin{array}{l}\text { Distance } \\
\text { (in metres) }\end{array}$} & \multicolumn{11}{|c|}{ Number of Days } \\
\hline & 0 to 7 & 8 to 14 & 15 to 21 & 22 to 28 & 29 to 35 & 36 to 42 & 43 to 49 & 50 to 56 & 57 to 63 & 64 to 70 & $\begin{array}{l}\text { More } \\
\text { than } 70\end{array}$ \\
\hline Same location & 0.01 & 0.01 & 0.05 & 0.31 & 0.46 & 1 & 0.22 & 0.61 & 0.98 & 0.84 & 1 \\
\hline 1 to 100 & 0.01 & 0.11 & 0.4 & 0.57 & 0.41 & 0.45 & 0.96 & 0.28 & 0.58 & 0.7 & 0.99 \\
\hline 101 to 200 & 0.01 & 0.04 & 0.01 & 0.04 & 0.36 & 0.98 & 0.77 & 0.78 & 0.88 & 0.9 & 0.99 \\
\hline 201 to 300 & 0.01 & 0.02 & 0.01 & 0.01 & 0.54 & 0.82 & 0.7 & 0.64 & 0.57 & 0.36 & 1 \\
\hline 301 to 400 & 0.01 & 0.04 & 0.04 & 0.07 & 0.84 & 0.69 & 0.78 & 0.62 & 0.94 & 0.93 & 0.95 \\
\hline 401 to 500 & 0.01 & 0.01 & 0.01 & 0.04 & 0.07 & 0.07 & 0.28 & 0.99 & 0.75 & 0.32 & 1 \\
\hline 501 to 600 & 0.01 & 0.02 & 0.03 & 0.02 & 0.34 & 0.22 & 0.4 & 0.43 & 0.18 & 0.65 & 1 \\
\hline 601 to 700 & 0.01 & 0.01 & 0.38 & 0.34 & 0.53 & 0.92 & 0.66 & 0.47 & 0.29 & 0.35 & 1 \\
\hline 701 to 800 & 0.01 & 0.01 & 0.01 & 0.58 & 0.09 & 0.39 & 0.14 & 0.97 & 0.6 & 0.67 & 1 \\
\hline 801 to 900 & 0.01 & 0.01 & 0.07 & 0.2 & 0.86 & 0.48 & 0.03 & 0.97 & 0.51 & 0.18 & 0.99 \\
\hline 901 to 1000 & 0.01 & 0.46 & 0.12 & 0.12 & 0.45 & 0.17 & 0.49 & 0.32 & 0.82 & 0.25 & 0.98 \\
\hline 1001 to 1100 & 0.01 & 0.03 & 0.53 & 0.33 & 0.01 & 0.15 & 0.1 & 0.15 & 0.16 & 0.96 & 1 \\
\hline 1101 to 1200 & 0.03 & 0.16 & 0.03 & 0.45 & 0.25 & 0.97 & 0.93 & 0.9 & 0.29 & 0.58 & 0.74 \\
\hline 1201 to 1300 & 0.01 & 0.01 & 0.03 & 0.04 & 0.23 & 0.72 & 0.04 & 0.8 & 0.12 & 0.96 & 1 \\
\hline 1301 to 1400 & 0.01 & 0.25 & 0.02 & 1 & 0.26 & 0.15 & 0.03 & 0.55 & 0.77 & 0.1 & 1 \\
\hline More than 1400 & 1 & 1 & 1 & 0.98 & 0.92 & 0.33 & 0.94 & 0.08 & 0.42 & 0.31 & 0.01 \\
\hline
\end{tabular}


Table A5. Observed over mean frequencies for Edmonton common assault data file.

\begin{tabular}{lcccccccccccc}
\hline & \multicolumn{7}{c}{ Number of Days } \\
\hline $\begin{array}{l}\text { Distance } \\
\text { (in metres) }\end{array}$ & 0 to 7 & 8 to 14 & 15 to 21 & 22 to 28 & 29 to 35 & 36 to 42 & 43 to 49 & 50 to 56 & 57 to 63 & 64 to 70 & $\begin{array}{c}\text { More } \\
\text { than } 70\end{array}$ \\
\hline Same location & $1.377^{* *}$ & 1.158 & 1.045 & 1.028 & 1.069 & 1.088 & 1.114 & 0.962 & 0.898 & 1.094 & 0.953 \\
1 to 100 & 0.954 & 0.936 & 1.001 & 0.991 & 0.921 & 1.057 & 0.937 & 1.094 & 1.091 & 0.95 & 1.004 \\
101 to 200 & 1.031 & $1.102^{*}$ & 1.036 & $1.113^{*}$ & $1.098^{*}$ & 1.058 & 0.959 & 1.029 & 1.066 & 1.013 & 0.971 \\
201 to 300 & 0.998 & 1.064 & 0.984 & 1.005 & 1.001 & 1.015 & 1.034 & 1.049 & 0.983 & 0.905 & 0.997 \\
301 to 400 & 1.035 & 1.026 & 1.014 & 1.068 & 1.038 & 1.01 & 0.991 & $1.087^{*}$ & 1.006 & 1.081 & 0.98 \\
401 to 500 & 1.012 & 0.994 & 1.055 & $1.124^{* *}$ & 1.058 & 1.017 & 1.01 & 1.039 & $1.12^{* *}$ & 1.011 & 0.975 \\
501 to 600 & 0.99 & 1 & 1.047 & 0.987 & 0.992 & 0.996 & $1.055^{*}$ & 1.05 & 0.978 & 1.021 & 0.994 \\
601 to 700 & 0.993 & 1 & $1.082^{*}$ & 1.028 & 1.014 & 1.016 & 1.03 & 1.016 & 1.001 & 1.027 & 0.988 \\
701 to 800 & 1.027 & 1.021 & 1.049 & 1.043 & 0.979 & 1.007 & 1.023 & 1.029 & 1.037 & 1.046 & 0.985 \\
801 to 900 & 1.009 & 1.016 & 0.96 & 1.048 & 1.011 & 1.006 & 1.026 & 1.025 & 0.974 & 1.034 & 0.994 \\
901 to 1000 & 1.021 & 1.017 & 1.024 & 0.967 & 0.985 & 1.047 & $1.071^{*}$ & $1.067 * *$ & 0.997 & 1.044 & 0.987 \\
1001 to 1100 & 1.003 & 1.003 & 1.017 & 1.004 & 1.027 & 0.965 & $1.073^{*}$ & $1.06 *$ & 1.028 & 1.026 & 0.989 \\
1101 to 1200 & 1.026 & 0.992 & 1.009 & 0.996 & 1.023 & 0.952 & 1.054 & 1.023 & 1.029 & 1.041 & 0.992 \\
1201 to 1300 & 0.961 & 1.007 & 0.99 & 1.009 & 1.014 & 1.016 & 1.017 & 0.977 & 1.027 & 0.951 & 1.002 \\
1301 to 1400 & 1.033 & 0.968 & 0.961 & 1.017 & 0.974 & 0.992 & 0.963 & 0.984 & 0.996 & 0.958 & 1.009 \\
More than 1400 & 0.999 & 0.999 & 0.999 & 0.998 & 0.999 & 1 & 0.998 & 0.998 & 0.999 & 0.999 & $1.001^{*}$ \\
\hline
\end{tabular}

$* p<.05, * * p<.01$ 
Table A6. Statistical significance table for Edmonton common assault data file.

\begin{tabular}{|c|c|c|c|c|c|c|c|c|c|c|c|}
\hline \multirow[b]{2}{*}{$\begin{array}{l}\text { Distance } \\
\text { (in metres) }\end{array}$} & \multicolumn{11}{|c|}{ Number of Days } \\
\hline & 0 to 7 & 8 to 14 & 15 to 21 & 22 to 28 & 29 to 35 & 36 to 42 & 43 to 49 & 50 to 56 & 57 to 63 & 64 to 70 & $\begin{array}{l}\text { More } \\
\text { than } 70\end{array}$ \\
\hline Same location & 0.01 & 0.05 & 0.33 & 0.4 & 0.26 & 0.18 & 0.11 & 0.68 & 0.85 & 0.15 & 0.99 \\
\hline 1 to 100 & 0.7 & 0.75 & 0.53 & 0.6 & 0.83 & 0.22 & 0.79 & 0.14 & 0.15 & 0.75 & 0.4 \\
\hline 101 to 200 & 0.27 & 0.02 & 0.25 & 0.04 & 0.03 & 0.15 & 0.81 & 0.33 & 0.15 & 0.42 & 1 \\
\hline 201 to 300 & 0.55 & 0.09 & 0.64 & 0.44 & 0.5 & 0.41 & 0.28 & 0.12 & 0.61 & 0.99 & 0.64 \\
\hline 301 to 400 & 0.15 & 0.26 & 0.37 & 0.08 & 0.19 & 0.41 & 0.6 & 0.03 & 0.48 & 0.06 & 0.99 \\
\hline 401 to 500 & 0.44 & 0.54 & 0.09 & 0.01 & 0.07 & 0.34 & 0.39 & 0.2 & 0.01 & 0.44 & 1 \\
\hline 501 to 600 & 0.64 & 0.49 & 0.1 & 0.67 & 0.59 & 0.5 & 0.04 & 0.1 & 0.81 & 0.23 & 0.83 \\
\hline 601 to 700 & 0.59 & 0.5 & 0.02 & 0.17 & 0.38 & 0.3 & 0.23 & 0.27 & 0.47 & 0.25 & 0.98 \\
\hline 701 to 800 & 0.22 & 0.26 & 0.07 & 0.08 & 0.74 & 0.36 & 0.29 & 0.19 & 0.1 & 0.12 & 1 \\
\hline 801 to 900 & 0.4 & 0.32 & 0.93 & 0.06 & 0.42 & 0.4 & 0.18 & 0.23 & 0.77 & 0.17 & 0.82 \\
\hline 901 to 1000 & 0.21 & 0.33 & 0.22 & 0.89 & 0.65 & 0.06 & 0.04 & 0.01 & 0.56 & 0.11 & 0.99 \\
\hline 1001 to 1100 & 0.46 & 0.46 & 0.28 & 0.47 & 0.24 & 0.88 & 0.03 & 0.03 & 0.16 & 0.19 & 0.96 \\
\hline 1101 to 1200 & 0.18 & 0.64 & 0.38 & 0.55 & 0.23 & 0.9 & 0.06 & 0.24 & 0.23 & 0.08 & 0.91 \\
\hline 1201 to 1300 & 0.88 & 0.38 & 0.66 & 0.39 & 0.37 & 0.28 & 0.32 & 0.81 & 0.25 & 0.94 & 0.45 \\
\hline 1301 to 1400 & 0.1 & 0.86 & 0.92 & 0.32 & 0.8 & 0.63 & 0.92 & 0.74 & 0.57 & 0.93 & 0.05 \\
\hline More than 1400 & 0.87 & 0.81 & 0.93 & 0.99 & 0.8 & 0.66 & 0.99 & 1 & 0.91 & 0.89 & 0.02 \\
\hline
\end{tabular}


Table A7. Observed over mean expected frequencies for Moose Jaw burglary data file.

\begin{tabular}{lccccccccccc}
\hline & \multicolumn{10}{c}{ Number of Days } \\
\hline $\begin{array}{l}\text { Distance } \\
\text { (in metres) }\end{array}$ & 0 to 7 & 8 to 14 & 15 to 21 & 22 to 28 & 29 to 35 & 36 to 42 & 43 to 49 & 50 to 56 & 57 to 63 & 64 to 70 & $\begin{array}{c}\text { More } \\
\text { than } 70\end{array}$ \\
\hline Same location & 1.094 & 0.739 & $3.686^{* *}$ & 1.492 & 2.271 & 0.467 & 1.531 & 1.5 & 0.995 & 1.563 & 0.66 \\
1 to 100 & 1.659 & 0 & 0.576 & $3.554^{* *}$ & 1.1 & 0.547 & 1.747 & 1.238 & 0.518 & 0.939 \\
101 to 200 & 0.589 & 1.014 & 0.894 & 1.792 & 0.624 & 1.081 & 0.456 & 0.855 & 0.413 & 0.455 & 1.113 \\
201 to 300 & 0.656 & 1.616 & 0.661 & 1.632 & 1.073 & 0.454 & 0.693 & 1.131 & 0.839 & 0.837 & 1.019 \\
301 to 400 & 1.32 & 0.644 & 0.893 & 0.631 & 1.519 & 1.042 & 0.732 & 0.633 & 1.218 & 1.257 & 1.008 \\
401 to 500 & 1.045 & 0.772 & 1.065 & 0.523 & 1.31 & 0.961 & 0.672 & 0.699 & 1.024 & 0.637 & 1.077 \\
501 to 600 & 0.245 & 0.737 & 0.743 & 0.997 & 1.352 & 0.618 & 0.724 & 1 & 1.138 & 0.625 & $1.105^{*}$ \\
601 to 700 & 1.192 & 0.94 & 1.433 & $2.104^{* *}$ & 1.122 & 0.788 & 1.043 & 0.506 & 0.922 & 0.413 & 0.968 \\
701 to 800 & 1.307 & 1.054 & 0.954 & 0.719 & 0.986 & 1.407 & 0.407 & 0.952 & 1.552 & 0.853 & 0.988 \\
801 to 900 & 1.198 & 0.605 & 0.904 & 0.819 & 0.869 & 1.012 & 0.836 & 1.368 & 1.028 & 1.094 & 1.019 \\
901 to 1000 & 1.267 & 1.018 & 0.942 & 1.323 & 0.819 & 0.76 & $1.707 *$ & 0.781 & 1.422 & 1.071 & 0.936 \\
1001 to 1100 & 1.086 & 1.4 & 0.442 & 0.593 & 0.74 & 0.943 & 0.896 & 0.965 & 0.997 & 0.846 & 1.064 \\
1101 to 1200 & 1.399 & $1.565^{*}$ & 0.813 & 0.755 & 1.362 & 0.673 & 1.425 & 1.068 & 0.7 & 1.178 & 0.944 \\
1201 to 1300 & 1.071 & 0.864 & 0.986 & 0.929 & 0.641 & 0.887 & 0.885 & 0.934 & 0.501 & 1.09 & 1.073 \\
1301 to 1400 & 0.953 & 0.724 & 0.743 & 1.032 & 0.703 & 1.078 & 0.771 & 0.906 & 1.024 & 0.899 & 1.072 \\
More than 1400 & 0.961 & 1.008 & 1.043 & 0.965 & 0.992 & 1.06 & 1.034 & 1.034 & 1.011 & 1.053 & 0.991 \\
\hline
\end{tabular}

$* p<.05, * * p<.01$ 
Table A8. Statistical significance table for Moose Jaw burglary data file.

\begin{tabular}{|c|c|c|c|c|c|c|c|c|c|c|c|}
\hline \multirow[b]{2}{*}{$\begin{array}{l}\text { Distance } \\
\text { (in metres) }\end{array}$} & \multicolumn{11}{|c|}{ Number of Days } \\
\hline & 0 to 7 & 8 to 14 & 15 to 21 & 22 to 28 & 29 to 35 & 36 to 42 & 43 to 49 & 50 to 56 & 57 to 63 & 64 to 70 & $\begin{array}{l}\text { More } \\
\text { than } 70\end{array}$ \\
\hline Same location & 0.57 & 0.76 & 0.01 & 0.32 & 0.07 & 0.94 & 0.32 & 0.34 & 0.63 & 0.3 & 1 \\
\hline 1 to 100 & 0.29 & 1 & 0.81 & 0.01 & 0.54 & 0.88 & 0.27 & 0.49 & 0.9 & 1 & 0.75 \\
\hline 101 to 200 & 0.94 & 0.58 & 0.71 & 0.08 & 0.9 & 0.49 & 0.95 & 0.71 & 0.98 & 0.97 & 0.09 \\
\hline 201 to 300 & 0.89 & 0.05 & 0.91 & 0.05 & 0.49 & 0.98 & 0.91 & 0.35 & 0.73 & 0.72 & 0.35 \\
\hline 301 to 400 & 0.23 & 0.87 & 0.66 & 0.92 & 0.08 & 0.49 & 0.82 & 0.94 & 0.33 & 0.32 & 0.49 \\
\hline 401 to 500 & 0.49 & 0.84 & 0.52 & 0.95 & 0.23 & 0.62 & 0.9 & 0.89 & 0.52 & 0.89 & 0.11 \\
\hline 501 to 600 & 1 & 0.84 & 0.85 & 0.56 & 0.17 & 0.89 & 0.84 & 0.61 & 0.37 & 0.93 & 0.03 \\
\hline 601 to 700 & 0.3 & 0.63 & 0.12 & 0.01 & 0.4 & 0.84 & 0.5 & 0.96 & 0.64 & 0.98 & 0.69 \\
\hline 701 to 800 & 0.24 & 0.48 & 0.59 & 0.85 & 0.57 & 0.15 & 0.99 & 0.62 & 0.07 & 0.78 & 0.62 \\
\hline 801 to 900 & 0.26 & 0.94 & 0.7 & 0.79 & 0.75 & 0.5 & 0.78 & 0.12 & 0.48 & 0.43 & 0.39 \\
\hline 901 to 1000 & 0.23 & 0.45 & 0.6 & 0.15 & 0.84 & 0.82 & 0.02 & 0.83 & 0.11 & 0.42 & 0.92 \\
\hline 1001 to 1100 & 0.46 & 0.09 & 0.98 & 0.95 & 0.86 & 0.61 & 0.72 & 0.56 & 0.57 & 0.71 & 0.13 \\
\hline 1101 to 1200 & 0.08 & 0.02 & 0.85 & 0.84 & 0.1 & 0.91 & 0.11 & 0.45 & 0.89 & 0.25 & 0.95 \\
\hline 1201 to 1300 & 0.43 & 0.81 & 0.58 & 0.66 & 0.94 & 0.68 & 0.74 & 0.67 & 1 & 0.49 & 0.07 \\
\hline 1301 to 1400 & 0.6 & 0.89 & 0.82 & 0.48 & 0.89 & 0.46 & 0.86 & 0.68 & 0.55 & 0.67 & 0.08 \\
\hline More than 1400 & 0.86 & 0.39 & 0.12 & 0.9 & 0.6 & 0.06 & 0.24 & 0.21 & 0.38 & 0.14 & 0.85 \\
\hline
\end{tabular}


Table A9. Observed over mean expected frequencies for Moose Jaw TFMV data file.

\begin{tabular}{lcccccccccccc}
\hline & \multicolumn{10}{c}{ Number of Days } \\
\hline $\begin{array}{l}\text { Distance } \\
\text { (in metres) }\end{array}$ & 0 to 7 & 8 to 14 & 15 to 21 & 22 to 28 & 29 to 35 & 36 to 42 & 43 to 49 & 50 to 56 & 57 to 63 & 64 to 70 & $\begin{array}{c}\text { More } \\
\text { than } 70\end{array}$ \\
\hline Same location & 1.868 & 0 & 0 & 0 & 1.8 & 0 & 1.8 & 0 & 1.941 & 0 \\
1 to 100 & 0.846 & 0.99 & 1.1 & 1.238 & 1.523 & 0 & 1.96 & 1.347 & 1.768 & 0.884 & 0.917 \\
101 to 200 & 1.957 & 0 & 1.021 & 0 & $2.628^{*}$ & 0.892 & 1.076 & 0.961 & 1.671 & 1.8 & 0.875 \\
201 to 300 & 1.603 & 1.26 & 1.338 & 0.744 & 1.484 & 0.696 & 0.501 & 0.704 & 0.657 & 1.379 & 0.976 \\
301 to 400 & 0.903 & 0.825 & 0.433 & 0.459 & 1.511 & 1.136 & 0.417 & 0.588 & 1.016 & 1.728 & 1.056 \\
401 to 500 & 1.069 & 0.879 & 1.419 & 1.778 & 1.051 & 1.177 & 1.399 & 1.017 & 0.483 & 0.908 & 0.938 \\
501 to 600 & 1.079 & $2.003 *$ & 0.795 & 1.345 & 1.394 & 1.39 & 0.892 & 0.593 & 0.605 & 1.761 & 0.907 \\
601 to 700 & 0.404 & 1.129 & 1.007 & 1.38 & 1.405 & 1.05 & 1.207 & 1.019 & 1.055 & 0.393 & 0.999 \\
701 to 800 & 0.619 & $1.863 *$ & 1.168 & 0.807 & 0.724 & 1.3 & 1.048 & 1.495 & 0.921 & 1.146 & 0.946 \\
801 to 900 & 1.43 & 1.119 & 1.109 & 1.053 & 0.413 & 0.929 & 1.044 & 0.805 & 0.501 & 1.131 & 1.027 \\
901 to 1000 & 0.992 & 1.295 & 0.837 & 0.844 & 1.055 & 1.567 & 0.862 & 1.057 & 1.26 & 0.688 & 0.966 \\
1001 to 1100 & 1.239 & 0.489 & 1.011 & 0.409 & $1.951^{* *}$ & 0.699 & 0.251 & 1.442 & 1.185 & 0.788 & 1.019 \\
1101 to 1200 & 1.102 & 0.498 & 1.678 & 1.474 & 0.677 & 0.218 & 0.7 & 1.058 & 1.361 & 1.097 & 1.014 \\
1201 to 1300 & 1.294 & 0.957 & 1.523 & 1.175 & 0.67 & 0.617 & 0.56 & 1.058 & 0.706 & $1.718^{*}$ & 0.997 \\
1301 to 1400 & 1.061 & $1.821^{*}$ & 1.735 & $1.951^{*}$ & 0.876 & 0.432 & 0.832 & 0.561 & 0.956 & 0.823 & 0.948 \\
More than 1400 & 0.969 & 0.95 & 0.928 & 0.964 & 0.963 & 1.037 & 1.064 & 1.007 & 1.018 & 0.958 & 1.008 \\
\hline
\end{tabular}

$* p<.05, * * p<.01$ 
Table A10. Statistical significance data file for Moose Jaw TFMV data file.

\begin{tabular}{|c|c|c|c|c|c|c|c|c|c|c|c|}
\hline \multirow[b]{2}{*}{$\begin{array}{l}\text { Distance } \\
\text { (in metres) }\end{array}$} & \multicolumn{11}{|c|}{ Number of Days } \\
\hline & 0 to 7 & 8 to 14 & 15 to 21 & 22 to 28 & 29 to 35 & 36 to 42 & 43 to 49 & 50 to 56 & 57 to 63 & 64 to 70 & $\begin{array}{l}\text { More } \\
\text { than } 70\end{array}$ \\
\hline Same location & 0.4 & 1 & 1 & 1 & 0.47 & 1 & 0.42 & 1 & 0.37 & 1 & 0.41 \\
\hline 1 to 100 & 0.7 & 0.57 & 0.59 & 0.59 & 0.43 & 1 & 0.25 & 0.49 & 0.34 & 0.71 & 0.81 \\
\hline 101 to 200 & 0.17 & 1 & 0.55 & 1 & 0.03 & 0.64 & 0.62 & 0.63 & 0.27 & 0.21 & 0.9 \\
\hline 201 to 300 & 0.09 & 0.39 & 0.3 & 0.81 & 0.19 & 0.77 & 0.87 & 0.83 & 0.86 & 0.33 & 0.69 \\
\hline 301 to 400 & 0.68 & 0.73 & 0.94 & 0.94 & 0.14 & 0.46 & 0.95 & 0.95 & 0.55 & 0.15 & 0.23 \\
\hline 401 to 500 & 0.45 & 0.71 & 0.17 & 0.09 & 0.6 & 0.41 & 0.23 & 0.58 & 0.98 & 0.64 & 0.86 \\
\hline 501 to 600 & 0.49 & 0.03 & 0.76 & 0.28 & 0.24 & 0.22 & 0.64 & 0.9 & 0.87 & 0.1 & 0.96 \\
\hline 601 to 700 & 0.98 & 0.43 & 0.6 & 0.26 & 0.17 & 0.49 & 0.4 & 0.52 & 0.48 & 0.89 & 0.49 \\
\hline 701 to 800 & 0.94 & 0.03 & 0.35 & 0.8 & 0.89 & 0.23 & 0.48 & 0.13 & 0.61 & 0.38 & 0.85 \\
\hline 801 to 900 & 0.1 & 0.46 & 0.46 & 0.49 & 0.97 & 0.64 & 0.55 & 0.77 & 0.96 & 0.5 & 0.31 \\
\hline 901 to 1000 & 0.57 & 0.27 & 0.72 & 0.7 & 0.5 & 0.09 & 0.71 & 0.47 & 0.27 & 0.87 & 0.76 \\
\hline 1001 to 1100 & 0.28 & 0.97 & 0.51 & 0.99 & 0.01 & 0.87 & 1 & 0.1 & 0.34 & 0.76 & 0.32 \\
\hline 1101 to 1200 & 0.42 & 0.94 & 0.08 & 0.12 & 0.89 & 1 & 0.88 & 0.47 & 0.18 & 0.48 & 0.39 \\
\hline 1201 to 1300 & 0.2 & 0.63 & 0.1 & 0.39 & 0.91 & 0.95 & 0.92 & 0.47 & 0.84 & 0.03 & 0.5 \\
\hline 1301 to 1400 & 0.46 & 0.02 & 0.07 & 0.02 & 0.75 & 0.99 & 0.74 & 0.92 & 0.58 & 0.7 & 0.89 \\
\hline More than 1400 & 0.85 & 0.95 & 0.99 & 0.85 & 0.88 & 0.15 & 0.06 & 0.39 & 0.32 & 0.88 & 0.12 \\
\hline
\end{tabular}


Table A11. Observed over mean expected frequencies for Moose Jaw common assault data file.

\begin{tabular}{lcccccccccccc}
\hline & \multicolumn{10}{c}{ Number of Days } \\
\hline $\begin{array}{l}\text { Distance } \\
\text { (in metres) }\end{array}$ & 0 to 7 & 8 to 14 & 15 to 21 & 22 to 28 & 29 to 35 & 36 to 42 & 43 to 49 & 50 to 56 & 57 to 63 & 64 to 70 & $\begin{array}{c}\text { More } \\
\text { than } 70\end{array}$ \\
\hline Same location & 1.703 & 0.971 & 0.957 & 1.228 & 1.98 & 0.465 & $2.363^{*}$ & 0.508 & 0.782 & 0.775 & 0.887 \\
1 to 100 & 1.406 & 0.998 & 1.042 & 0.802 & 1.59 & 1.606 & 1.136 & 1.076 & 1.435 & $2.116^{*}$ & 0.82 \\
101 to 200 & 0.656 & 1.153 & 1.424 & 0.946 & 1.106 & $1.685^{*}$ & 1.113 & 1.062 & 0.856 & 0.762 & 0.946 \\
201 to 300 & 1.147 & 1.224 & 1.114 & 0.908 & 1.083 & 0.724 & 1.252 & 1.055 & 0.832 & 0.742 & 0.993 \\
301 to 400 & 0.809 & 1.364 & 1.157 & 1.085 & 0.793 & 1.201 & 0.902 & 1.318 & 1.036 & 1.415 & 0.935 \\
401 to 500 & 1.105 & 0.947 & 1.207 & 0.928 & 1.032 & 0.93 & 0.898 & 0.806 & 0.931 & 0.857 & 1.021 \\
501 to 600 & 0.807 & 0.637 & $1.465 *$ & 1.001 & 0.856 & 0.884 & 1.098 & 0.783 & 1.048 & 0.96 & 1.028 \\
601 to 700 & 0.666 & 0.81 & 1.041 & 1.312 & 0.931 & 0.662 & $1.439 * *$ & 1.061 & 0.926 & 1.394 & 0.986 \\
701 to 800 & 0.897 & 0.848 & 0.707 & 1.358 & 0.949 & 0.569 & 0.978 & 1.103 & $1.458^{*}$ & 0.871 & 1.019 \\
801 to 900 & 0.732 & 0.872 & 0.786 & 0.958 & 1.085 & 1.221 & 0.844 & 1.114 & 1.242 & 1.14 & 1.003 \\
901 to 1000 & 0.91 & 1.084 & 1.166 & 0.988 & 0.943 & 0.831 & 0.641 & 0.803 & 0.94 & 1.272 & 1.027 \\
1001 to 1100 & 0.715 & 0.819 & 0.761 & 1.157 & 1.259 & 0.846 & 1.118 & 1.324 & 1.125 & 0.794 & 1.007 \\
1101 to 1200 & 1.242 & 1.234 & 1.141 & 1.264 & 0.948 & 1.021 & 0.811 & 0.914 & 1.065 & 0.825 & 0.971 \\
1201 to 1300 & 1.238 & 0.766 & 0.972 & 1.355 & 0.594 & 0.916 & 1.085 & 0.952 & 1.019 & 0.834 & 1.019 \\
1301 to 1400 & 0.784 & 0.941 & 0.898 & 1.035 & 0.998 & 1.088 & 1.002 & 1.084 & 1.093 & 1.158 & 0.997 \\
More than 1400 & $1.041 *$ & 1.021 & 0.981 & 0.939 & 1.011 & 1.033 & 0.999 & 0.992 & 0.964 & 0.978 & 1.002 \\
\hline
\end{tabular}

$* p<.05, * * p<.01$ 
Table A12. Statistical significance table for Moose Jaw common assault data file.

\begin{tabular}{lcccccccccccc}
\hline & \multicolumn{8}{c}{ Number of Days } \\
\hline $\begin{array}{l}\text { Distance } \\
\text { (in metres) }\end{array}$ & 0 to 7 & 8 to 14 & 15 to 21 & 22 to 28 & 29 to 35 & 36 to 42 & 43 to 49 & 50 to 56 & 57 to 63 & 64 to 70 & $\begin{array}{c}\text { More } \\
\text { than } 70\end{array}$ \\
\hline Same location & 0.13 & 0.6 & 0.61 & 0.42 & 0.06 & 0.93 & 0.03 & 0.91 & 0.72 & 0.72 & 0.9 \\
1 to 100 & 0.22 & 0.63 & 0.49 & 0.72 & 0.12 & 0.14 & 0.41 & 0.55 & 0.26 & 0.02 & 1 \\
101 to 200 & 0.9 & 0.36 & 0.11 & 0.65 & 0.4 & 0.02 & 0.37 & 0.5 & 0.7 & 0.78 & 0.87 \\
201 to 300 & 0.33 & 0.18 & 0.38 & 0.69 & 0.39 & 0.91 & 0.18 & 0.46 & 0.75 & 0.93 \\
301 to 400 & 0.8 & 0.06 & 0.22 & 0.38 & 0.92 & 0.22 & 0.75 & 0.1 & 0.45 & 0.05 \\
401 to 500 & 0.32 & 0.66 & 0.18 & 0.63 & 0.44 & 0.68 & 0.7 & 0.8 & 0.66 & 0.77 \\
501 to 600 & 0.85 & 0.98 & 0.03 & 0.57 & 0.79 & 0.74 & 0.39 & 0.84 & 0.5 & 0.61 & 0.36 \\
601 to 700 & 0.97 & 0.83 & 0.42 & 0.1 & 0.7 & 0.97 & 0.01 & 0.39 & 0.63 & 0.06 & 0.71 \\
701 to 800 & 0.76 & 0.83 & 0.95 & 0.08 & 0.68 & 0.99 & 0.58 & 0.25 & 0.04 & 0.7 & 0.31 \\
801 to 900 & 0.95 & 0.77 & 0.9 & 0.6 & 0.36 & 0.17 & 0.84 & 0.33 & 0.1 & 0.26 & 0.47 \\
901 to 1000 & 0.72 & 0.34 & 0.16 & 0.58 & 0.66 & 0.9 & 0.98 & 0.95 & 0.64 & 0.07 & 0.15 \\
1001 to 1100 & 0.95 & 0.89 & 0.9 & 0.25 & 0.1 & 0.81 & 0.29 & 0.09 & 0.25 & 0.93 & 0.43 \\
1101 to 1200 & 0.1 & 0.12 & 0.22 & 0.12 & 0.65 & 0.43 & 0.86 & 0.74 & 0.41 & 0.82 & 0.81 \\
1201 to 1300 & 0.15 & 0.87 & 0.66 & 0.05 & 1 & 0.63 & 0.34 & 0.68 & 0.49 & 0.87 & 0.27 \\
1301 to 1400 & 0.88 & 0.66 & 0.74 & 0.44 & 0.49 & 0.29 & 0.5 & 0.36 & 0.27 & 0.22 & 0.55 \\
More than 1400 & 0.04 & 0.18 & 0.8 & 0.99 & 0.39 & 0.14 & 0.51 & 0.65 & 0.92 & 0.86 & 0.33 \\
\hline
\end{tabular}


Table A13. Observed over mean expected frequencies for Saint John burglary data file.

\begin{tabular}{lcccccccccccc}
\hline & \multicolumn{7}{c}{ Number of Days } \\
\hline $\begin{array}{l}\text { Distance } \\
\text { (in metres) }\end{array}$ & 0 to 7 & 8 to 14 & 15 to 21 & 22 to 28 & 29 to 35 & 36 to 42 & 43 to 49 & 50 to 56 & 57 to 63 & 64 to 70 & $\begin{array}{c}\text { More } \\
\text { than } 70\end{array}$ \\
\hline Same location & $7.364^{* *}$ & 1.707 & 3.126 & 0 & 2.02 & 0 & 0 & 2.329 & 0 & 1.356 & 0.344 \\
1 to 100 & 1.403 & 0.939 & 0.398 & 1.557 & 0.691 & 2.047 & 0.809 & 0.576 & 0.834 & 0.598 & 1.003 \\
101 to 200 & 0.86 & 0.762 & 1.203 & $2.06 * *$ & 0.356 & 1.037 & $2.014^{*}$ & 0.999 & 1.224 & 0.907 & 0.927 \\
201 to 300 & 1.478 & 1.341 & 1.46 & 0.792 & 1.215 & 1.084 & 1.222 & 1.21 & 0.891 & 0.607 & 0.902 \\
301 to 400 & 0.377 & $1.558^{* *}$ & 0.844 & 0.705 & 1.02 & 0.93 & 1.117 & 1.362 & 1.015 & 0.758 & 1.023 \\
401 to 500 & 1.126 & 0.78 & 1.079 & 0.62 & 1.071 & 0.88 & 0.816 & 0.869 & 1.107 & 1.34 & 1.025 \\
501 to 600 & 1.269 & 1.012 & 0.746 & 1.025 & 1.011 & 0.957 & $1.554 *$ & 0.476 & 1.063 & 1.362 & 0.972 \\
601 to 700 & 1.173 & 0.771 & 0.871 & 1.102 & 1.045 & 0.513 & 1.207 & 0.908 & 0.332 & 1.082 & 1.065 \\
701 to 800 & 1.299 & 1.085 & 1.082 & 0.894 & 0.72 & 1.15 & 0.812 & 0.766 & 1.271 & $1.556 *$ & 0.96 \\
801 to 900 & 0.886 & 0.792 & 1.094 & 0.448 & 0.965 & 1.415 & 1.214 & 1.485 & 0.894 & 0.493 & 1.026 \\
901 to 1000 & 0.89 & 1.099 & 1.079 & 0.759 & 1.443 & 0.847 & 0.965 & 1.018 & 0.931 & 0.297 & 1.034 \\
1001 to 1100 & 0.926 & 0.879 & 1.42 & 1.031 & 1.237 & 0.876 & 1.316 & 1.45 & 1.237 & 0.72 & 0.932 \\
1101 to 1200 & 1.318 & 1.274 & 0.729 & 0.814 & 0.778 & 0.987 & 1.068 & 0.589 & 1.315 & 1.351 & 0.986 \\
1201 to 1300 & 1.428 & 0.906 & 0.908 & 0.958 & 1.07 & 0.978 & 1.481 & 1.016 & 1.199 & 1.234 & 0.932 \\
1301 to 1400 & 0.665 & 1.055 & 1.048 & 0.814 & 0.874 & 0.864 & 0.797 & 1.06 & 1.219 & 1.394 & 1.02 \\
More than 1400 & 0.976 & 0.996 & 0.994 & 1.02 & 1.001 & 1.005 & 0.967 & 1 & 0.992 & 0.995 & 1.003 \\
\hline
\end{tabular}

$* p<.05, * * p<.01$ 
Table A14. Statistical significance table for Saint John burglary data file.

\begin{tabular}{|c|c|c|c|c|c|c|c|c|c|c|c|}
\hline \multirow[b]{2}{*}{$\begin{array}{l}\text { Distance } \\
\text { (in metres) }\end{array}$} & \multicolumn{11}{|c|}{ Number of Days } \\
\hline & 0 to 7 & 8 to 14 & 15 to 21 & 22 to 28 & 29 to 35 & 36 to 42 & 43 to 49 & 50 to 56 & 57 to 63 & 64 to 70 & $\begin{array}{l}\text { More } \\
\text { than } 70\end{array}$ \\
\hline Same location & 0.01 & 0.35 & 0.09 & 1 & 0.27 & 1 & 1 & 0.22 & 1 & 0.48 & 1 \\
\hline 1 to 100 & 0.22 & 0.68 & 0.96 & 0.14 & 0.77 & 0.05 & 0.71 & 0.89 & 0.68 & 0.89 & 0.53 \\
\hline 101 to 200 & 0.7 & 0.8 & 0.33 & 0.01 & 0.97 & 0.51 & 0.02 & 0.58 & 0.33 & 0.62 & 0.87 \\
\hline 201 to 300 & 0.1 & 0.17 & 0.13 & 0.8 & 0.28 & 0.46 & 0.29 & 0.31 & 0.68 & 0.95 & 0.98 \\
\hline 301 to 400 & 0.99 & 0.01 & 0.75 & 0.89 & 0.55 & 0.64 & 0.41 & 0.19 & 0.52 & 0.85 & 0.3 \\
\hline 401 to 500 & 0.34 & 0.85 & 0.41 & 0.93 & 0.47 & 0.79 & 0.75 & 0.72 & 0.41 & 0.13 & 0.3 \\
\hline 501 to 600 & 0.12 & 0.54 & 0.91 & 0.52 & 0.48 & 0.67 & 0.04 & 1 & 0.48 & 0.13 & 0.76 \\
\hline 601 to 700 & 0.23 & 0.85 & 0.75 & 0.45 & 0.52 & 1 & 0.34 & 0.65 & 1 & 0.43 & 0.11 \\
\hline 701 to 800 & 0.14 & 0.42 & 0.43 & 0.71 & 0.89 & 0.35 & 0.78 & 0.86 & 0.18 & 0.04 & 0.8 \\
\hline 801 to 900 & 0.72 & 0.84 & 0.39 & 1 & 0.59 & 0.13 & 0.31 & 0.08 & 0.69 & 0.98 & 0.29 \\
\hline 901 to 1000 & 0.75 & 0.35 & 0.4 & 0.83 & 0.08 & 0.72 & 0.61 & 0.54 & 0.61 & 1 & 0.29 \\
\hline 1001 to 1100 & 0.64 & 0.73 & 0.05 & 0.46 & 0.19 & 0.68 & 0.19 & 0.09 & 0.29 & 0.85 & 0.95 \\
\hline 1101 to 1200 & 0.14 & 0.17 & 0.89 & 0.84 & 0.82 & 0.53 & 0.51 & 0.98 & 0.13 & 0.18 & 0.67 \\
\hline 1201 to 1300 & 0.09 & 0.64 & 0.69 & 0.55 & 0.42 & 0.62 & 0.08 & 0.51 & 0.31 & 0.28 & 0.94 \\
\hline 1301 to 1400 & 0.98 & 0.47 & 0.5 & 0.78 & 0.75 & 0.74 & 0.78 & 0.44 & 0.26 & 0.13 & 0.36 \\
\hline More than 1400 & 0.92 & 0.67 & 0.63 & 0.09 & 0.43 & 0.4 & 0.98 & 0.52 & 0.71 & 0.67 & 0.18 \\
\hline
\end{tabular}


Table A15. Observed over mean expected frequencies for Saint John TFMV data file.

\begin{tabular}{lccccccccccccc}
\hline & \multicolumn{10}{c}{ Number of Days } \\
\hline $\begin{array}{l}\text { Distance } \\
\text { (in metres) }\end{array}$ & 0 to 7 & 8 to 14 & 15 to 21 & 22 to 28 & 29 to 35 & 36 to 42 & 43 to 49 & 50 to 56 & 57 to 63 & 64 to 70 & $\begin{array}{c}\text { More } \\
\text { than } 70\end{array}$ \\
\hline Same location & $3.137^{* *}$ & $2.298^{* *}$ & $2.133^{*}$ & 1.172 & 0.834 & 0.698 & 1.251 & 0.401 & 0.205 & 1.297 & 0.75 \\
1 to 100 & $1.672^{* *}$ & $1.42^{*}$ & 1.326 & 0.819 & 1.047 & 1.4 & 0.955 & 0.925 & 1.265 & 0.525 & 0.906 \\
101 to 200 & $1.323^{*}$ & 1.156 & 0.769 & 1.11 & $1.24^{*}$ & 0.878 & 1.128 & $1.273^{*}$ & $1.406^{* *}$ & $1.353^{*}$ & 0.9 \\
201 to 300 & $1.235^{*}$ & 1.167 & $1.372^{* *}$ & 1.151 & 0.856 & 1.175 & 1.127 & 0.982 & 1.136 & $1.322^{*}$ & 0.903 \\
301 to 400 & $1.416^{* *}$ & $1.217^{* *}$ & 1.055 & $1.27^{* *}$ & 0.939 & 0.979 & 1.087 & 0.994 & 1.191 & 1.074 & 0.92 \\
401 to 500 & $1.171^{*}$ & $1.167^{*}$ & 1.135 & 1.075 & $1.188^{*}$ & 0.971 & 0.913 & 1.017 & 0.974 & $1.24^{* *}$ & 0.945 \\
501 to 600 & 1.091 & $1.35^{* *}$ & 1.138 & $1.206^{*}$ & 1.046 & 0.882 & 0.91 & 0.907 & 1.154 & 0.891 & 0.96 \\
601 to 700 & 1.124 & 1.075 & 1.07 & 0.978 & 0.89 & 1.041 & 0.835 & 1.091 & 1.114 & 0.987 & 0.986 \\
701 to 800 & $1.229^{*}$ & 1 & 1.126 & 0.997 & 1.041 & 1.028 & 0.789 & 0.977 & 1.039 & $1.275^{* *}$ & 0.968 \\
801 to 900 & 0.934 & 0.955 & 1.144 & 0.861 & 1.05 & 0.983 & 0.976 & 1.01 & 0.921 & $1.409^{* *}$ & 0.988 \\
901 to 1000 & 1.048 & 1 & 0.954 & 1.07 & 0.942 & 0.8 & 0.971 & 0.899 & 1.056 & 1 \\
1001 to 1100 & 0.969 & 0.992 & 1.034 & 0.899 & 0.804 & 0.861 & 0.775 & 1.062 & 1.14 & 0.867 & 1.018 \\
1101 to 1200 & 1.021 & 1.194 & 0.99 & 1.057 & 0.828 & 0.855 & 1.029 & 0.787 & 0.81 & 1.139 & 1.018 \\
1201 to 1300 & 1.067 & 1.186 & 1.001 & 0.717 & 0.836 & 0.755 & 1.01 & 0.982 & 0.803 & 1.019 & 1.04 \\
1301 to 1400 & 0.688 & 0.622 & 1.214 & 0.984 & 1.104 & 0.973 & 0.739 & 0.945 & 0.973 & 0.553 & $1.076^{* *}$ \\
More than 1400 & 0.915 & 0.931 & 0.94 & 0.975 & 1.007 & 1.025 & 1.034 & 1.006 & 0.963 & 0.947 & $1.017^{*}$ \\
\hline
\end{tabular}

$* p<.05, * * p<.01$ 
Table A16. Statistical significance table for Saint John TFMV data file.

\begin{tabular}{|c|c|c|c|c|c|c|c|c|c|c|c|}
\hline \multirow[b]{2}{*}{$\begin{array}{l}\text { Distance } \\
\text { (in metres) }\end{array}$} & \multicolumn{11}{|c|}{ Number of Days } \\
\hline & 0 to 7 & 8 to 14 & 15 to 21 & 22 to 28 & 29 to 35 & 36 to 42 & 43 to 49 & 50 to 56 & 57 to 63 & 64 to 70 & $\begin{array}{l}\text { More } \\
\text { than } 70\end{array}$ \\
\hline Same location & 0.01 & 0.01 & 0.03 & 0.43 & 0.73 & 0.8 & 0.36 & 0.94 & 1 & 0.31 & 1 \\
\hline 1 to 100 & 0.01 & 0.04 & 0.07 & 0.87 & 0.51 & 0.05 & 0.61 & 0.64 & 0.21 & 0.99 & 0.99 \\
\hline 101 to 200 & 0.02 & 0.13 & 0.96 & 0.28 & 0.04 & 0.84 & 0.19 & 0.02 & 0.01 & 0.02 & 1 \\
\hline 201 to 300 & 0.03 & 0.08 & 0.01 & 0.09 & 0.95 & 0.09 & 0.21 & 0.58 & 0.15 & 0.02 & 1 \\
\hline 301 to 400 & 0.01 & 0.01 & 0.3 & 0.01 & 0.74 & 0.64 & 0.22 & 0.54 & 0.05 & 0.29 & 1 \\
\hline 401 to 500 & 0.02 & 0.04 & 0.12 & 0.19 & 0.04 & 0.63 & 0.81 & 0.46 & 0.57 & 0.01 & 0.99 \\
\hline 501 to 600 & 0.15 & 0.01 & 0.06 & 0.02 & 0.31 & 0.96 & 0.87 & 0.85 & 0.05 & 0.86 & 0.98 \\
\hline 601 to 700 & 0.14 & 0.25 & 0.24 & 0.64 & 0.89 & 0.32 & 0.99 & 0.12 & 0.11 & 0.53 & 0.79 \\
\hline 701 to 800 & 0.02 & 0.51 & 0.18 & 0.55 & 0.37 & 0.38 & 0.98 & 0.63 & 0.36 & 0.01 & 0.92 \\
\hline 801 to 900 & 0.81 & 0.65 & 0.08 & 0.95 & 0.35 & 0.59 & 0.59 & 0.48 & 0.72 & 0.01 & 0.72 \\
\hline 901 to 1000 & 0.35 & 0.52 & 0.65 & 0.31 & 0.69 & 0.94 & 0.61 & 0.78 & 0.36 & 0.5 & 0.28 \\
\hline 1001 to 1100 & 0.58 & 0.52 & 0.39 & 0.84 & 0.98 & 0.89 & 0.98 & 0.33 & 0.18 & 0.83 & 0.09 \\
\hline 1101 to 1200 & 0.45 & 0.07 & 0.56 & 0.35 & 0.93 & 0.9 & 0.46 & 0.98 & 0.88 & 0.17 & 0.21 \\
\hline 1201 to 1300 & 0.26 & 0.12 & 0.51 & 1 & 0.88 & 0.98 & 0.49 & 0.54 & 0.96 & 0.5 & 0.09 \\
\hline 1301 to 1400 & 0.99 & 1 & 0.08 & 0.57 & 0.28 & 0.63 & 0.98 & 0.7 & 0.62 & 1 & 0.01 \\
\hline More than 1400 & 1 & 1 & 0.99 & 0.88 & 0.35 & 0.12 & 0.06 & 0.37 & 0.94 & 1 & 0.03 \\
\hline
\end{tabular}


Table A17. Observed over mean expected frequencies for Saint John common assault data file.

\begin{tabular}{lcccccccccccc}
\hline & \multicolumn{7}{c}{ Number of Days } \\
\hline $\begin{array}{l}\text { Distance } \\
\text { (in metres) }\end{array}$ & 0 to 7 & 8 to 14 & 15 to 21 & 22 to 28 & 29 to 35 & 36 to 42 & 43 to 49 & 50 to 56 & 57 to 63 & 64 to 70 & $\begin{array}{c}\text { More } \\
\text { than } 70\end{array}$ \\
\hline Same location & $1.931^{* *}$ & 1.279 & 1.17 & 0.823 & 1.046 & 0.969 & 0.768 & 0.731 & 1.012 & 1.065 & 0.953 \\
1 to 100 & $1.251^{*}$ & 0.996 & 1.009 & 1.14 & 1.134 & 0.978 & 1.148 & 1.195 & 0.878 & 1.299 & 0.947 \\
101 to 200 & 0.915 & 0.867 & 1.085 & 0.919 & 1.049 & 0.891 & 1.134 & 0.884 & 0.969 & 0.878 & 1.021 \\
201 to 300 & 0.846 & 0.954 & 1.163 & 0.92 & 1.115 & 0.97 & 0.896 & $1.209^{*}$ & 1.009 & 0.907 \\
301 to 400 & 0.954 & 0.847 & 0.862 & 0.952 & 0.839 & 0.943 & 0.93 & 1.052 & 1.05 & 0.977 & $1.033^{* *}$ \\
401 to 500 & 1.006 & 0.963 & 0.945 & 1.109 & 0.876 & 1.088 & 0.953 & 1.096 & 0.929 & 1.024 & 1.001 \\
501 to 600 & 1.049 & 0.942 & 0.927 & 0.969 & 0.858 & 0.867 & 0.95 & 1.111 & 1.04 & 0.922 & 1.019 \\
601 to 700 & 1.036 & 0.914 & 0.874 & 1.083 & 1.052 & 1.088 & 1.027 & 1.028 & 0.982 & 1.026 & 0.995 \\
701 to 800 & 1.138 & $1.169 *$ & 1.066 & 1.134 & 1.09 & 1.012 & 1.074 & 0.927 & $1.216^{* *}$ & 0.957 & 0.958 \\
801 to 900 & 1.074 & 0.899 & 0.879 & 1.036 & 0.911 & 0.888 & 0.982 & 1.019 & 0.996 & 1.076 & 1.014 \\
901 to 1000 & 0.965 & 1.067 & 0.915 & 1.113 & $1.188^{*}$ & 1.003 & 0.976 & 1.017 & 1.006 & 0.997 & 0.987 \\
1001 to 1100 & 1.015 & 0.986 & 0.962 & 0.902 & 0.967 & $1.177^{*}$ & 1.088 & 0.873 & 1.116 & 1.09 & 0.992 \\
1101 to 1200 & 0.92 & 0.914 & $1.185^{*}$ & 1.055 & 1.128 & $1.158^{*}$ & 1.043 & 0.975 & 0.99 & 1.081 & 0.977 \\
1201 to 1300 & 0.954 & $1.162^{*}$ & $1.185^{*}$ & 0.955 & $1.19^{* *}$ & 0.979 & 1.079 & $1.137^{*}$ & 1.041 & 0.889 & 0.968 \\
1301 to 1400 & 1.071 & 1.088 & 1.065 & 0.916 & 1.111 & $1.162^{*}$ & 0.994 & 0.897 & 1.056 & 0.986 & 0.981 \\
More than 1400 & 0.996 & 1.001 & 1 & 0.998 & 0.994 & 0.996 & 0.998 & 0.997 & 0.994 & 1 & 1.001 \\
\hline
\end{tabular}

$* p<.05, * * p<.01$ 
Table A18. Statistical significance table for Saint John common assault data file.

\begin{tabular}{lccccccccccccc}
\hline & \multicolumn{10}{c}{ Number of Days } \\
\hline $\begin{array}{l}\text { Distance } \\
\text { (in metres) }\end{array}$ & 0 to 7 & 8 to 14 & 15 to 21 & 22 to 28 & 29 to 35 & 36 to 42 & 43 to 49 & 50 to 56 & 57 to 63 & 64 to 70 & $\begin{array}{c}\text { More } \\
\text { than } 70\end{array}$ \\
\hline Same location & 0.01 & 0.09 & 0.16 & 0.83 & 0.45 & 0.63 & 0.92 & 0.9 & 0.49 & 0.39 & 0.96 \\
1 to 100 & 0.04 & 0.6 & 0.52 & 0.16 & 0.23 & 0.61 & 0.2 & 0.1 & 0.86 & 0.05 & 1 \\
101 to 200 & 0.76 & 0.91 & 0.22 & 0.79 & 0.31 & 0.89 & 0.11 & 0.91 & 0.67 & 0.82 & 0.08 \\
201 to 300 & 0.97 & 0.74 & 0.06 & 0.89 & 0.13 & 0.6 & 0.94 & 0.02 & 0.54 & 0.83 & 0.48 \\
301 to 400 & 0.67 & 0.99 & 0.96 & 0.72 & 1 & 0.76 & 0.81 & 0.28 & 0.31 & 0.6 & 0.01 \\
401 to 500 & 0.48 & 0.69 & 0.82 & 0.1 & 0.96 & 0.15 & 0.76 & 0.1 & 0.8 & 0.44 & 0.46 \\
501 to 600 & 0.28 & 0.79 & 0.85 & 0.67 & 0.97 & 0.98 & 0.78 & 0.08 & 0.31 & 0.87 & 0.06 \\
601 to 700 & 0.3 & 0.9 & 0.98 & 0.14 & 0.27 & 0.15 & 0.35 & 0.33 & 0.62 & 0.39 & 0.69 \\
701 to 800 & 0.07 & 0.02 & 0.19 & 0.06 & 0.16 & 0.44 & 0.19 & 0.86 & 0.01 & 0.68 \\
801 to 900 & 0.14 & 0.92 & 0.94 & 0.31 & 0.89 & 0.92 & 0.54 & 0.41 & 0.47 & 0.17 & 0.09 \\
901 to 1000 & 0.72 & 0.25 & 0.92 & 0.07 & 0.03 & 0.49 & 0.68 & 0.45 & 0.47 & 0.55 & 0.94 \\
1001 to 1100 & 0.45 & 0.62 & 0.71 & 0.93 & 0.7 & 0.02 & 0.15 & 0.94 & 0.05 & 0.12 & 0.76 \\
1101 to 1200 & 0.83 & 0.89 & 0.02 & 0.25 & 0.07 & 0.04 & 0.38 & 0.61 & 0.54 & 0.23 & 0.97 \\
1201 to 1300 & 0.72 & 0.02 & 0.02 & 0.72 & 0.01 & 0.6 & 0.22 & 0.04 & 0.36 & 0.89 & 0.99 \\
1301 to 1400 & 0.19 & 0.11 & 0.24 & 0.91 & 0.09 & 0.03 & 0.55 & 0.95 & 0.27 & 0.57 & 0.97 \\
More than 1400 & 0.88 & 0.35 & 0.52 & 0.74 & 0.92 & 0.82 & 0.63 & 0.76 & 0.91 & 0.5 & 0.1 \\
\hline
\end{tabular}




\section{Appendix B}

Examples of Maps Generated for the Phase 2 Analyses

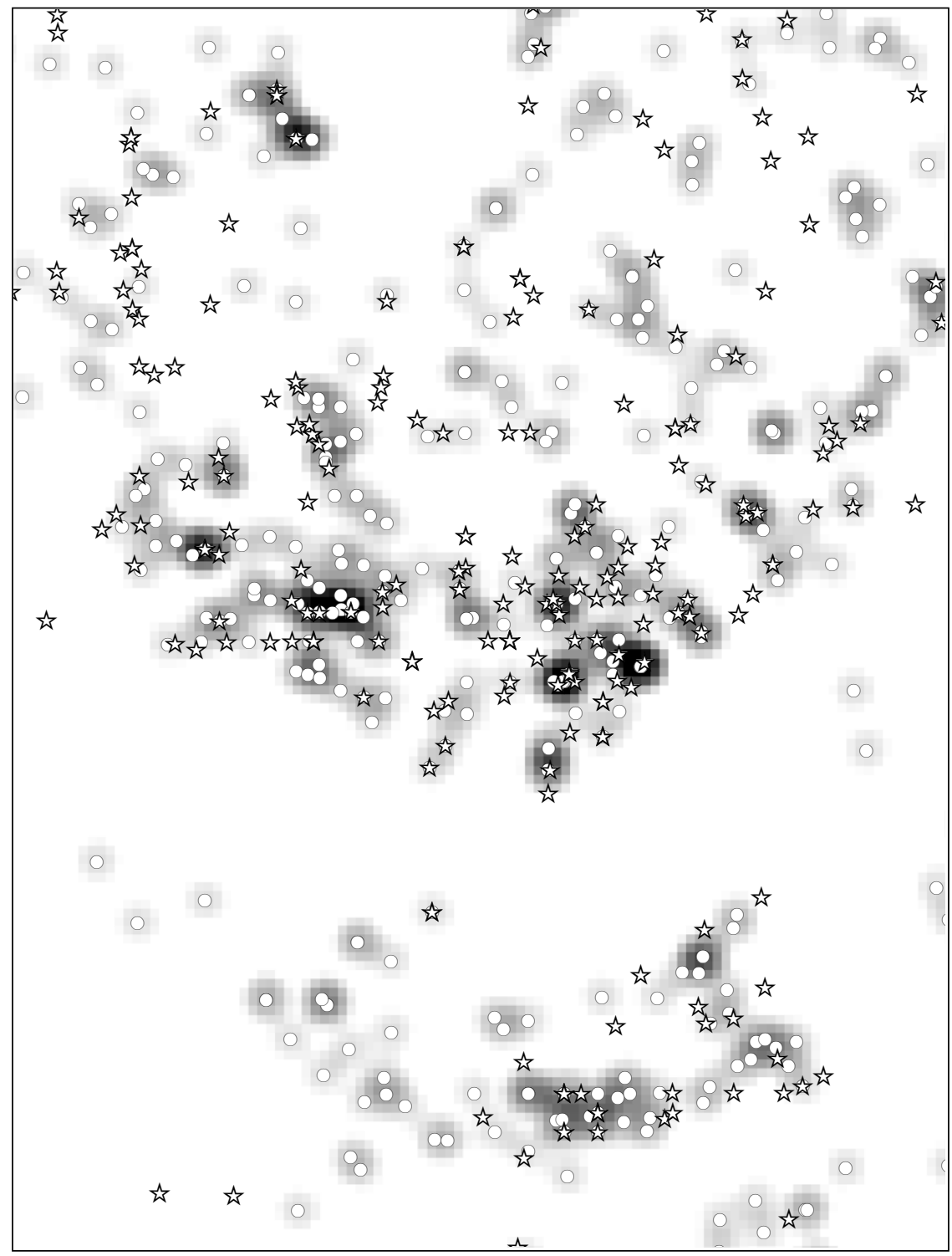

\section{Legend}

January-February TFMVs

is March TFMVs

Hotspot risk intensity
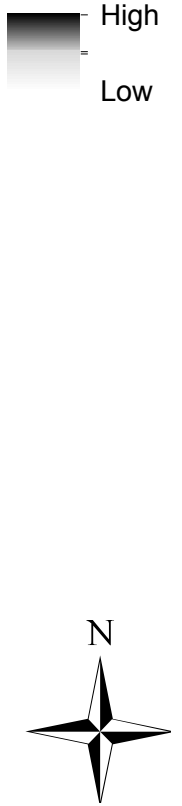

$\begin{array}{lll}0 & 0.25 & 0.5\end{array}$

$1 \quad 1.5$

Kilometres

Figure C1. Phase 2: KDE map for Edmonton TFMV January-February. 


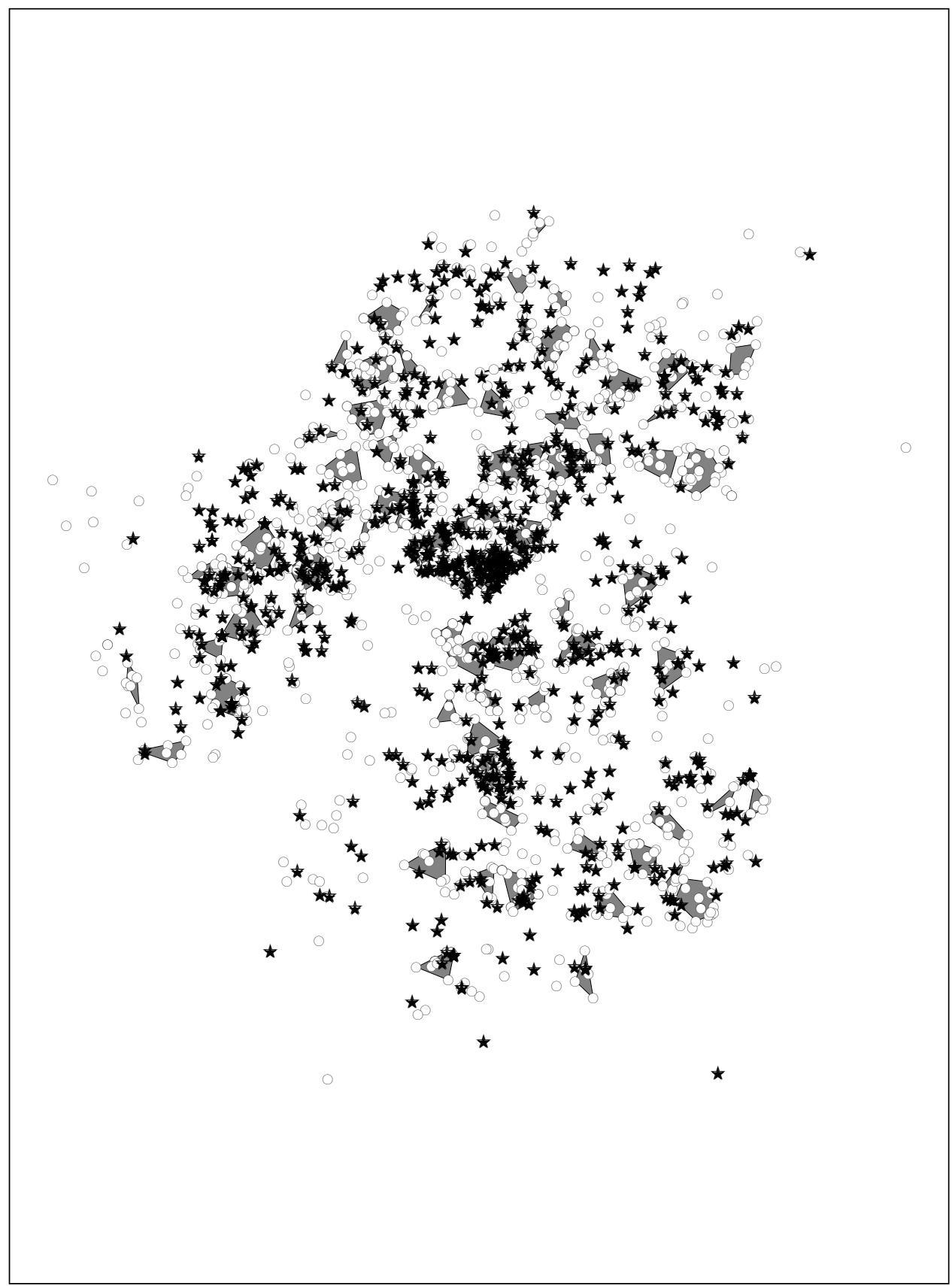

\section{Legend}

January-February TFMVs

$\star \quad$ March TFMVs

Nnh Hotspots

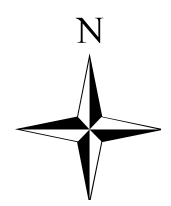

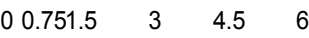

Kilometres

Figure C2. Phase 2: Nnh map for Edmonton TFMV January-February. 


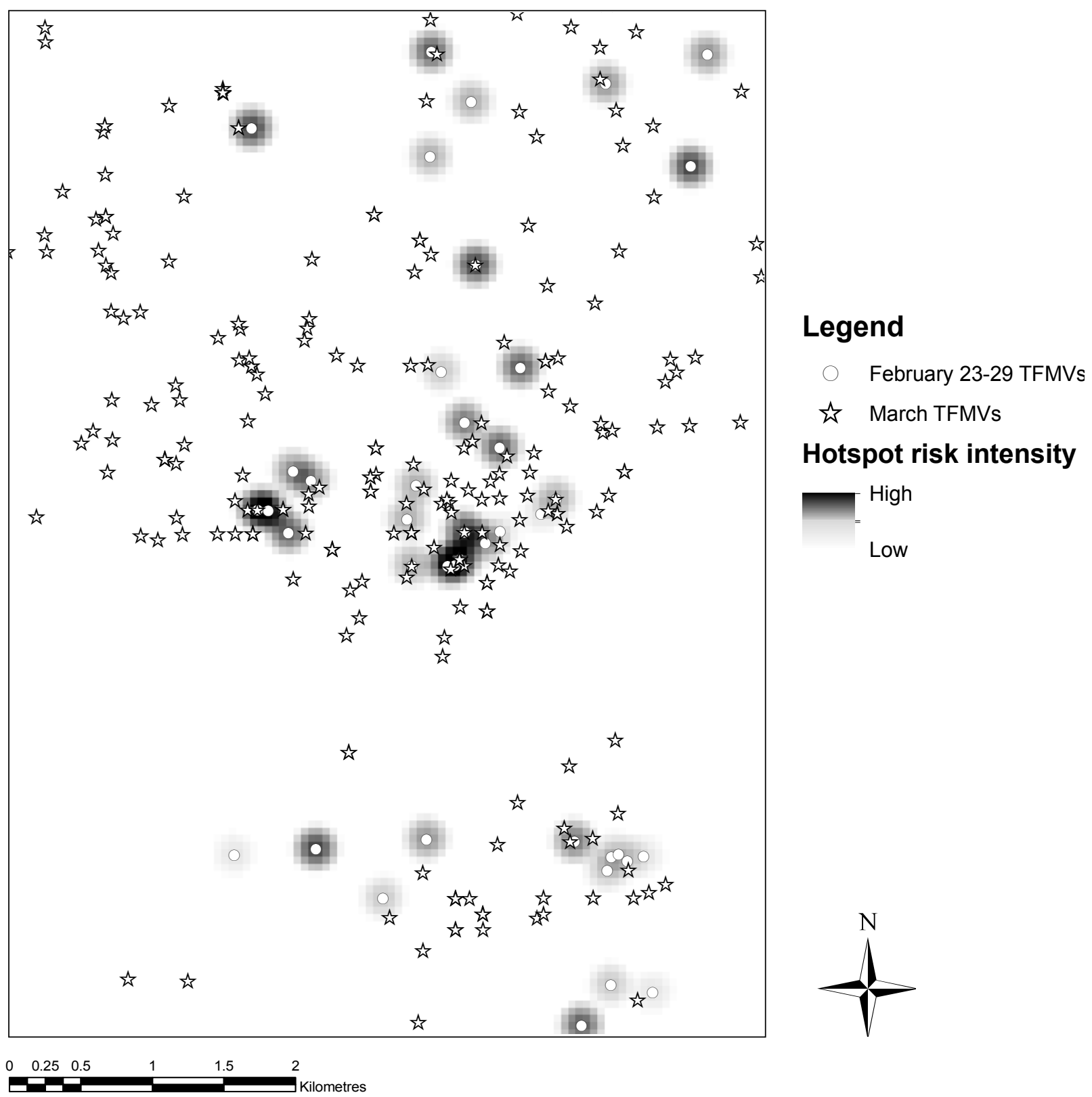

Figure C3. Phase 2: Prospective hot-spotting (7-day temporal bandwidth) map for Edmonton TFMV February 23-29. 


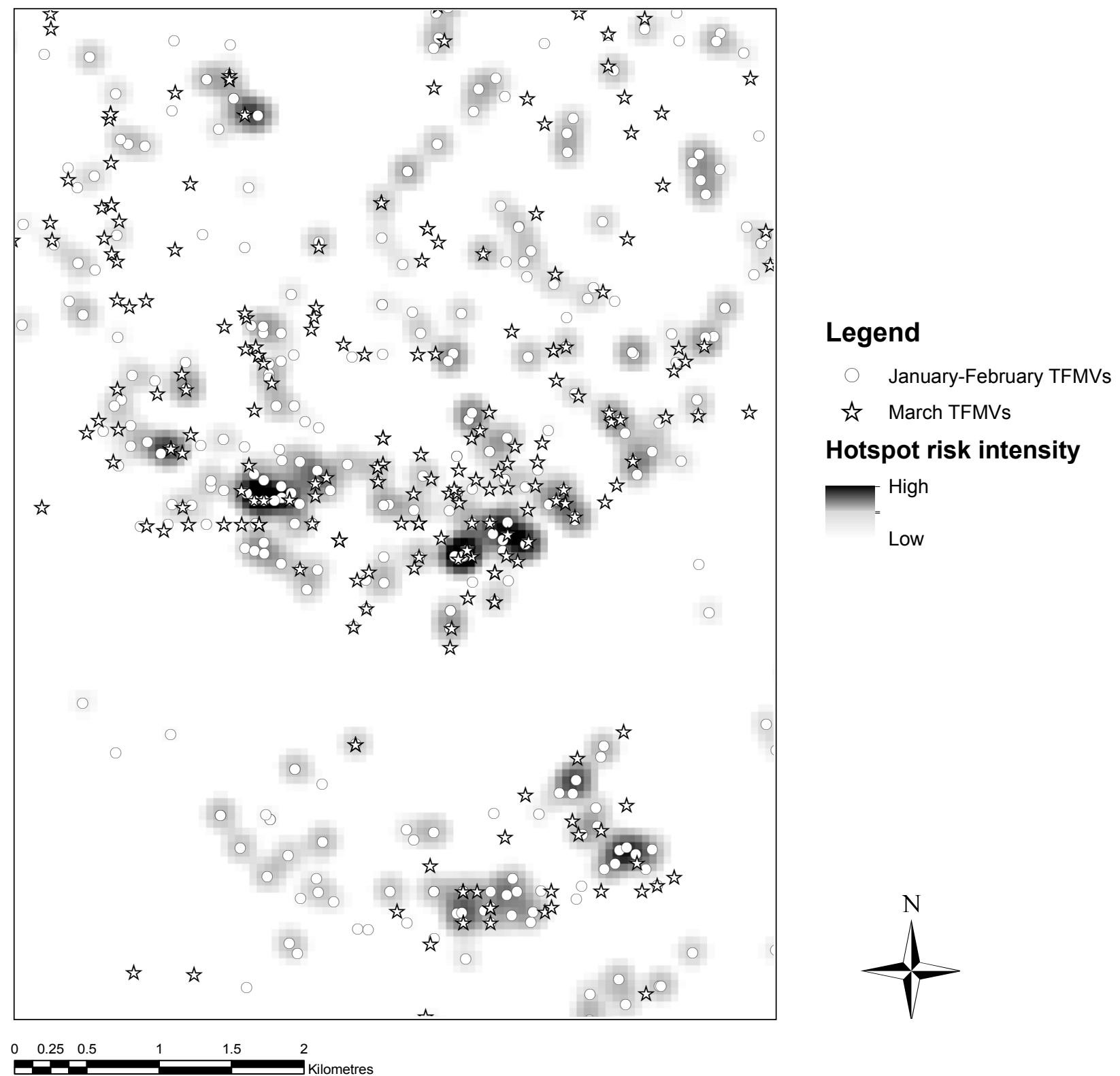

Figure C4. Phase 2: Prospective hot-spotting (2-month temporal bandwidth) map for Edmonton TFMV January-February. 


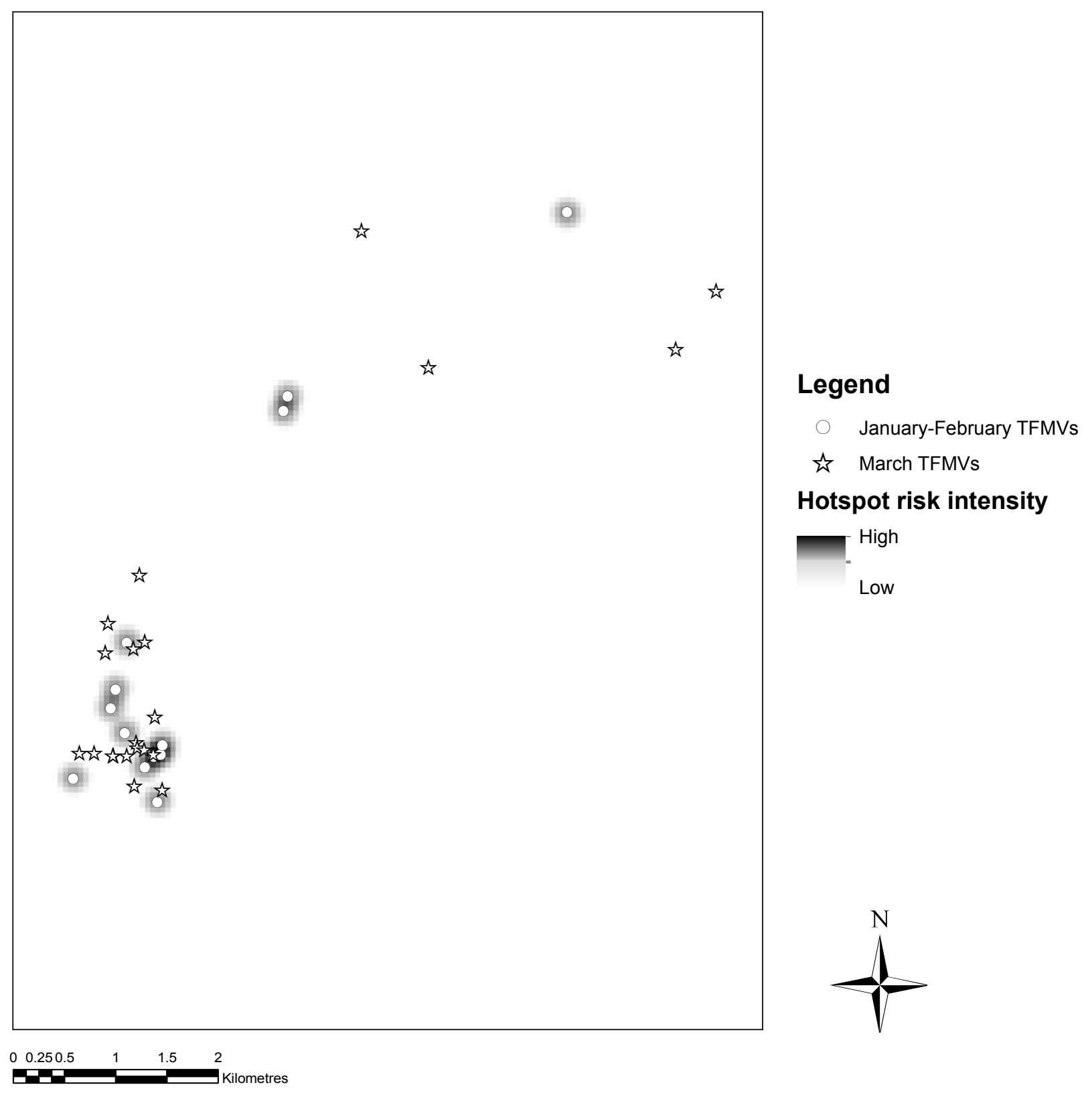

Figure C5. Phase 2: KDE map for Saint John TFMV January-February. 


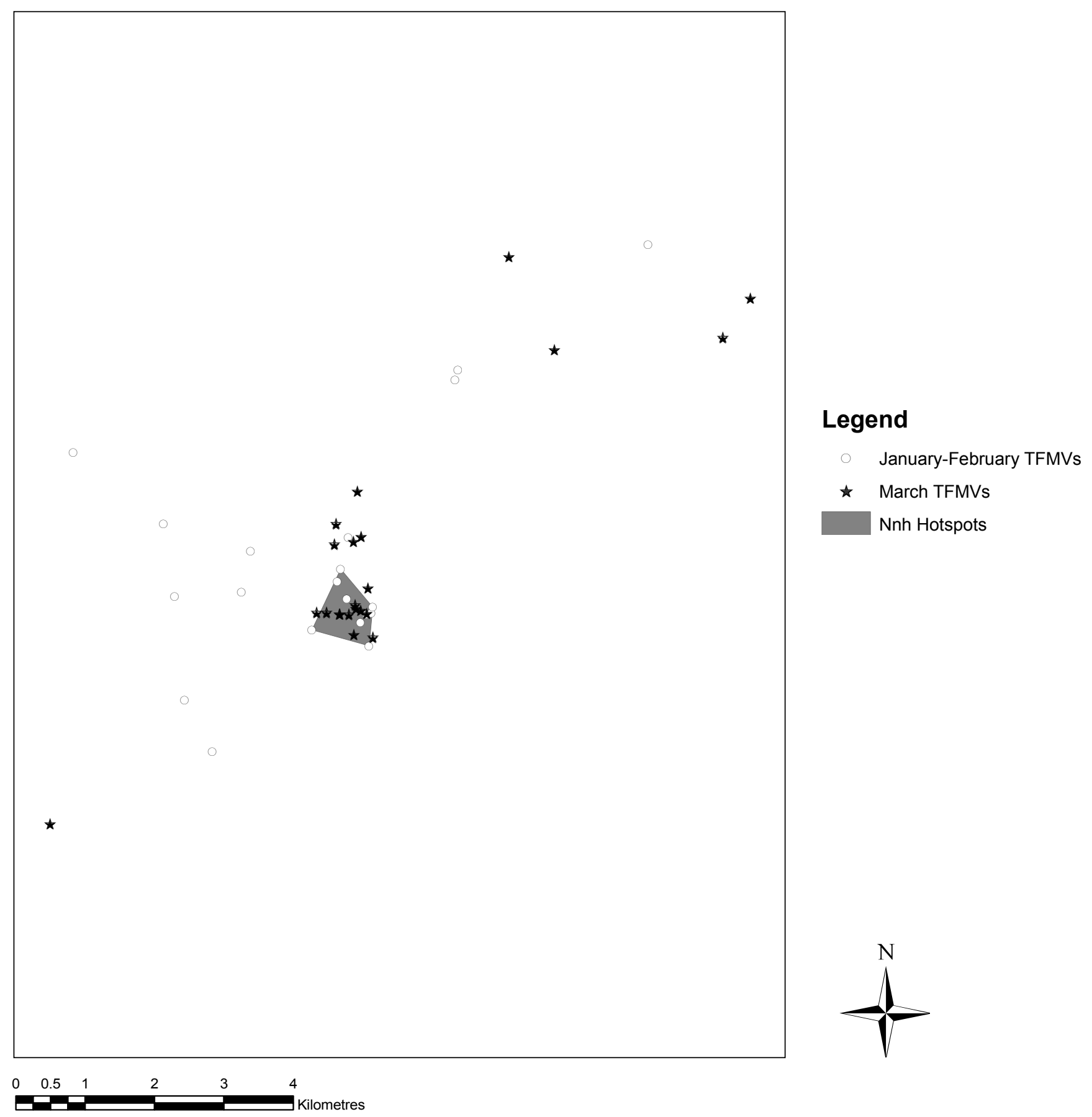

Figure C6. Phase 2: Nnh map for Saint John TFMV January-February. 


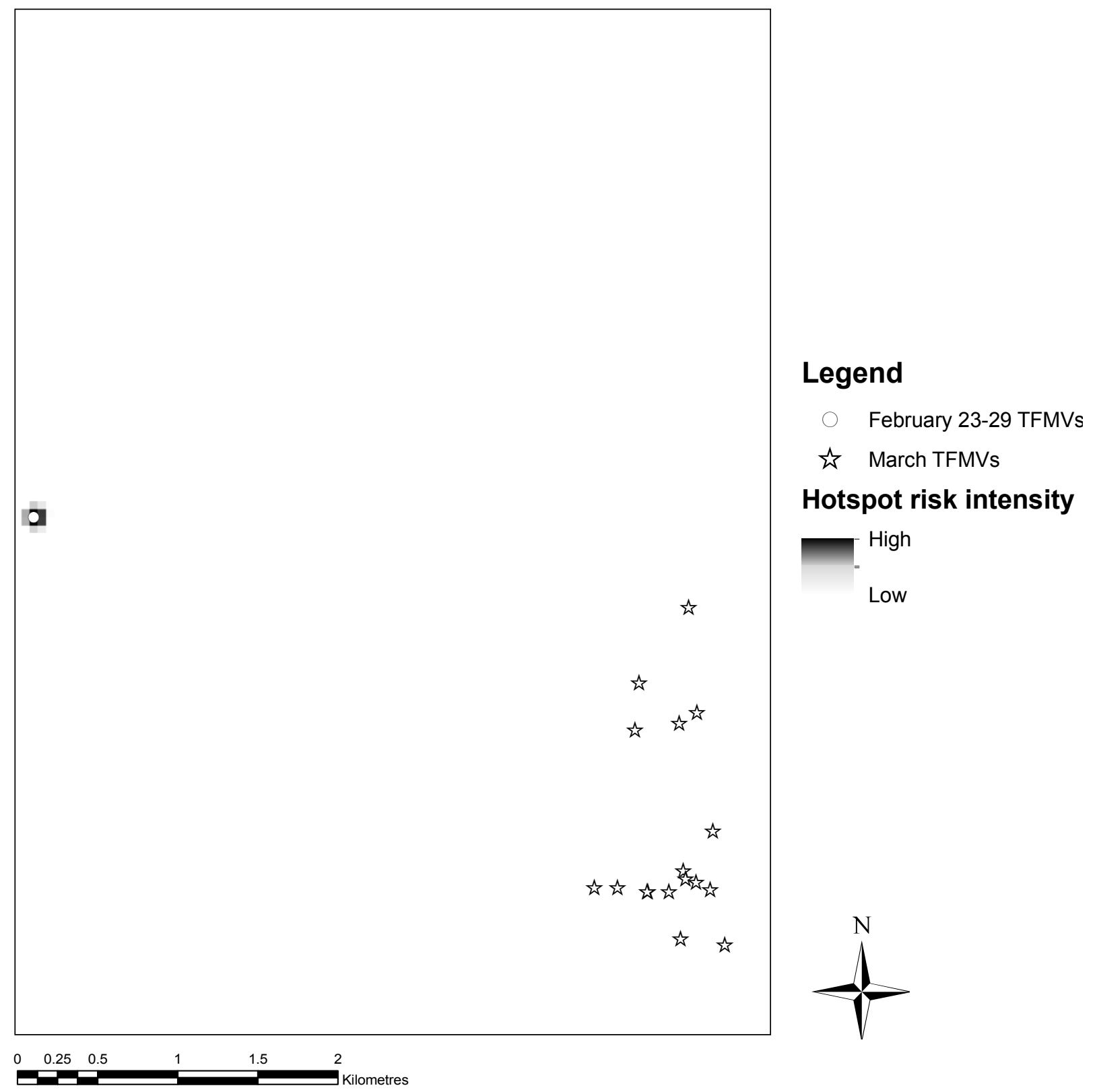

Figure C7. Phase 2: Prospective hot-spotting map (7-day temporal bandwidth) for Saint John TFMV February 23-29. 


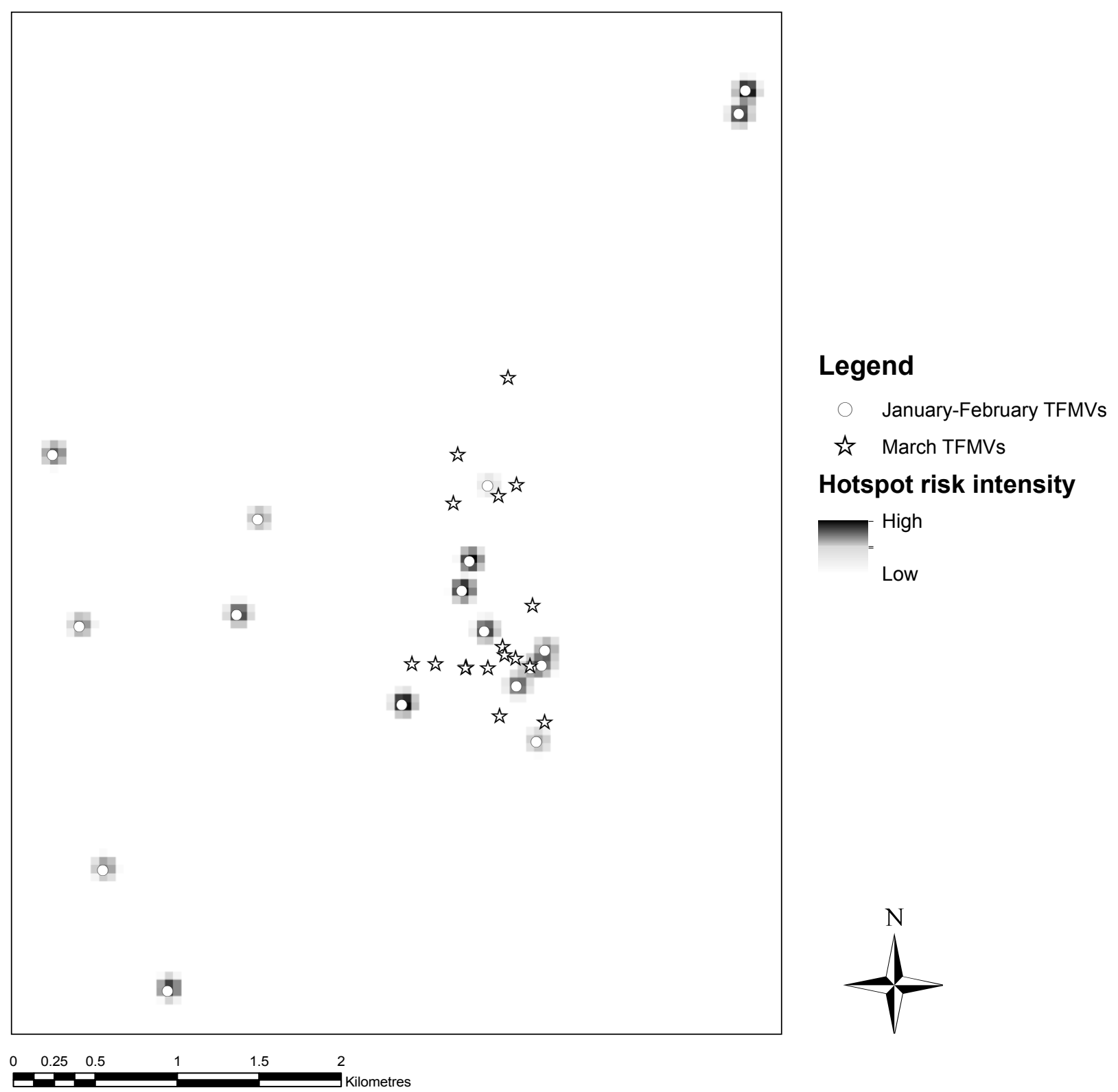

Figure C8. Phase 2: Prospective hot-spotting map (2-month temporal bandwidth) for Saint John TFMV January-February. 
Appendix C

Number of Burglary Pairs for Each Space-Time Interval Where One or More Offenders Were Involved in Both Offences (Number of

Crime Pairs where Same Offender Committed Both Crimes/Total Number of Crime Pairs)

\begin{tabular}{|c|c|c|c|c|c|c|c|c|c|}
\hline \multirow{2}{*}{$\begin{array}{l}\text { Distance } \\
\text { between } \\
\text { offences }\end{array}$} & \multicolumn{9}{|c|}{ Days between offences } \\
\hline & 14 & 28 & 42 & 56 & 70 & 84 & 98 & 112 & $112+$ \\
\hline Same & $6 / 8$ & $3 / 4$ & $0 / 2$ & $2 / 2$ & $0 / 1$ & $0 / 3$ & -- & -- & $2 / 25$ \\
\hline $1-100 \mathrm{~m}$ & $20 / 27$ & $1 / 4$ & $2 / 6$ & $0 / 8$ & $0 / 9$ & $0 / 2$ & $0 / 2$ & $0 / 3$ & $1 / 93$ \\
\hline $101-200 \mathrm{~m}$ & $13 / 22$ & $0 / 7$ & $0 / 10$ & $0 / 12$ & $1 / 13$ & $0 / 1$ & $0 / 6$ & $0 / 6$ & $1 / 136$ \\
\hline $201-300 \mathrm{~m}$ & $11 / 27$ & $0 / 13$ & $1 / 13$ & $0 / 12$ & $1 / 18$ & $0 / 13$ & $0 / 13$ & $0 / 11$ & $2 / 246$ \\
\hline $301-400 \mathrm{~m}$ & $17 / 47$ & $1 / 24$ & $2 / 22$ & $0 / 19$ & $0 / 14$ & $0 / 16$ & $0 / 16$ & $0 / 19$ & $0 / 312$ \\
\hline $401-500 \mathrm{~m}$ & $20 / 41$ & $1 / 17$ & $0 / 21$ & $0 / 13$ & $0 / 18$ & $0 / 17$ & $1 / 13$ & $0 / 15$ & $2 / 373$ \\
\hline $501-600 \mathrm{~m}$ & $16 / 44$ & $0 / 32$ & $0 / 16$ & $0 / 34$ & $0 / 22$ & $0 / 20$ & $2 / 18$ & $0 / 24$ & $1 / 553$ \\
\hline $601-700 \mathrm{~m}$ & $22 / 57$ & $1 / 36$ & $0 / 27$ & $1 / 26$ & $1 / 26$ & $0 / 29$ & $0 / 23$ & $0 / 25$ & $3 / 573$ \\
\hline $701-800 \mathrm{~m}$ & $22 / 52$ & $1 / 19$ & $0 / 30$ & $0 / 27$ & $1 / 29$ & $0 / 39$ & $0 / 25$ & $1 / 33$ & $1 / 626$ \\
\hline $801-900 \mathrm{~m}$ & $8 / 37$ & $2 / 37$ & $0 / 34$ & $1 / 28$ & $0 / 32$ & $0 / 24$ & $0 / 28$ & $0 / 29$ & $0 / 575$ \\
\hline $901 \mathrm{~m}-1 \mathrm{~km}$ & $16 / 51$ & $0 / 42$ & $0 / 27$ & $0 / 33$ & 0/33 & $0 / 25$ & 0/29 & $0 / 28$ & 0/676 \\
\hline $1 \mathrm{~km}+$ & $84 / 14315$ & $64 / 13358$ & $33 / 12799$ & $13 / 12228$ & $3 / 11752$ & $5 / 11407$ & $3 / 11377$ & $3 / 11432$ & $155 / 253585$ \\
\hline
\end{tabular}


Appendix D

Space-Time Pattern Results from Phase 4

Table D1. Observed over mean expected frequencies for Edmonton solved burglary data file.

\begin{tabular}{lccccccccccc}
\hline & \multicolumn{10}{c}{ Number of Days } \\
\hline $\begin{array}{l}\text { Distance } \\
\text { (in metres) }\end{array}$ & 0 to 7 & 8 to 14 & 15 to 21 & 22 to 28 & 29 to 35 & 36 to 42 & 43 to 49 & 50 to 56 & 57 to 63 & 64 to 70 & $\begin{array}{c}\text { More } \\
\text { than } 70\end{array}$ \\
\hline Same location & $7.5^{* *}$ & 2.97 & 5.211 & & & 2.063 & 1.338 & 1.394 & 1.021 \\
1 to 100 & $8.185^{* *}$ & 1.684 & 0.647 & 0.669 & 1.467 & 1.014 & 1.541 & 1.616 & 0.372 & $2.405^{* *}$ & 0.807 \\
101 to 200 & $4.593^{* *}$ & 0.697 & 0.495 & 1.266 & 1.707 & 1.238 & 1.888 & 0.863 & $2.628^{* *}$ & 1.478 & 0.856 \\
201 to 300 & $2.878^{* *}$ & 0.839 & 1.021 & 0.975 & 1.348 & 0.581 & 0.749 & 0.979 & $2.092^{*}$ & 1.195 & 0.943 \\
301 to 400 & $3.825^{* *}$ & 1.042 & 1.355 & 1.209 & 1.047 & 1.449 & 1.358 & 1.038 & 0.51 & 1.255 & 0.907 \\
401 to 500 & $3.389^{* *}$ & 0.751 & 1.12 & 0.602 & 1.106 & 0.744 & 1.183 & 0.786 & 1.026 & 0.947 & 0.964 \\
501 to 600 & $2.154^{* *}$ & 0.737 & 1.166 & 1.038 & 0.735 & 0.429 & 1.37 & 1.475 & 0.623 & 1.084 & 0.984 \\
601 to 700 & $2.248^{* *}$ & 1.248 & 1.343 & 1.034 & 0.872 & 1.009 & 0.691 & 1.026 & 1.06 & 0.927 & 0.966 \\
701 to 800 & $1.867 *$ & 1.107 & 0.686 & 0.552 & 0.795 & 0.884 & 1.129 & 0.645 & 1.092 & 0.957 & 1.006 \\
801 to 900 & 1.369 & 1.026 & 0.926 & 1.216 & 1.325 & 1.114 & 1.115 & 0.916 & 0.879 & 1.408 & 0.973 \\
901 to 1000 & 1.082 & $1.603 *$ & 1.111 & 1.266 & 0.788 & 0.727 & 0.692 & 1.29 & 1.179 & 0.964 & 0.984 \\
1001 to 1100 & 1.111 & 1.129 & 0.916 & 1.049 & 1.148 & 1.019 & 1.21 & $1.494 *$ & 1.004 & 0.712 & 0.983 \\
1101 to 1200 & 1.086 & $1.763 * *$ & 0.942 & 0.719 & 1.409 & 0.467 & 0.767 & 0.893 & 1.117 & 0.838 \\
1201 to 1300 & 0.895 & 1.163 & 1.038 & 1.208 & 0.792 & 0.939 & 1.04 & 1.094 & 1.352 & 1.068 & 0.987 \\
1301 to 1400 & 1.332 & 1.189 & 0.978 & 1.165 & 0.825 & 0.915 & 0.909 & 1.055 & 0.965 & 1.144 & 0.989 \\
More than 1400 & 0.975 & 0.994 & 0.999 & 1 & 1 & 1.004 & 0.999 & 0.998 & 0.998 & 0.999 & $1.001 * *$ \\
\hline
\end{tabular}

$* p<.05, * * p<.01$ 
Table D2. Statistical significance table for Edmonton solved burglary data file.

\begin{tabular}{|c|c|c|c|c|c|c|c|c|c|c|c|}
\hline \multirow[b]{2}{*}{$\begin{array}{l}\text { Distance } \\
\text { (in metres) }\end{array}$} & \multicolumn{11}{|c|}{ Number of Days } \\
\hline & 0 to 7 & 8 to 14 & 15 to 21 & 22 to 28 & 29 to 35 & 36 to 42 & 43 to 49 & 50 to 56 & 57 to 63 & 64 to 70 & $\begin{array}{l}\text { More } \\
\text { than } 70\end{array}$ \\
\hline Same location & 0.01 & 0.11 & 0.03 & 1 & 1 & 0.27 & 0.53 & 0.52 & 0.66 & 1 & 1 \\
\hline 1 to 100 & 0.01 & 0.15 & 0.81 & 0.8 & 0.31 & 0.6 & 0.27 & 0.25 & 0.88 & 0.01 & 1 \\
\hline 101 to 200 & 0.01 & 0.83 & 0.87 & 0.39 & 0.16 & 0.39 & 0.08 & 0.65 & 0.01 & 0.21 & 1 \\
\hline 201 to 300 & 0.01 & 0.77 & 0.55 & 0.57 & 0.22 & 0.86 & 0.81 & 0.55 & 0.02 & 0.38 & 0.99 \\
\hline 301 to 400 & 0.01 & 0.47 & 0.15 & 0.3 & 0.48 & 0.12 & 0.16 & 0.46 & 0.95 & 0.31 & 1 \\
\hline 401 to 500 & 0.01 & 0.85 & 0.4 & 0.94 & 0.44 & 0.87 & 0.35 & 0.86 & 0.55 & 0.58 & 0.99 \\
\hline 501 to 600 & 0.01 & 0.94 & 0.32 & 0.52 & 0.88 & 0.99 & 0.11 & 0.1 & 0.96 & 0.37 & 0.86 \\
\hline 601 to 700 & 0.01 & 0.24 & 0.14 & 0.49 & 0.75 & 0.52 & 0.92 & 0.51 & 0.47 & 0.67 & 0.98 \\
\hline 701 to 800 & 0.02 & 0.35 & 0.97 & 0.97 & 0.79 & 0.8 & 0.38 & 0.96 & 0.4 & 0.61 & 0.42 \\
\hline 801 to 900 & 0.09 & 0.46 & 0.67 & 0.25 & 0.09 & 0.36 & 0.37 & 0.62 & 0.74 & 0.12 & 0.96 \\
\hline 901 to 1000 & 0.41 & 0.04 & 0.36 & 0.12 & 0.83 & 0.93 & 0.95 & 0.16 & 0.24 & 0.63 & 0.9 \\
\hline 1001 to 1100 & 0.34 & 0.31 & 0.71 & 0.41 & 0.3 & 0.52 & 0.21 & 0.03 & 0.52 & 0.93 & 0.89 \\
\hline 1101 to 1200 & 0.42 & 0.01 & 0.65 & 0.93 & 0.09 & 1 & 0.88 & 0.71 & 0.35 & 0.74 & 0.59 \\
\hline 1201 to 1300 & 0.7 & 0.25 & 0.42 & 0.17 & 0.82 & 0.58 & 0.42 & 0.32 & 0.12 & 0.47 & 0.82 \\
\hline 1301 to 1400 & 0.07 & 0.25 & 0.59 & 0.26 & 0.85 & 0.65 & 0.67 & 0.45 & 0.66 & 0.35 & 0.79 \\
\hline More than 1400 & 1 & 1 & 0.65 & 0.63 & 0.59 & 0.05 & 0.64 & 0.87 & 0.85 & 0.74 & 0.01 \\
\hline
\end{tabular}

